\title{
Avoiding Regeneration with a Matrix Converter Drive
}

\author{
M Imayavaramban
}

Submitted to the University of Nottingham for the degree of Doctor of Philosophy, December 2008. 
dedicated to my mother, my brothers, my father and my teachers 


\section{Acknowledgements}

I would like to thank my supervisor, Prof. Patrick .W. Wheeler of the Power Electronics, Machines and Control (PEMC) Group at the University of Nottingham for his technical suggestions and invaluable support during the course of my research on Matrix Converters for aerospace applications. I would thank to my parents and my brothers. I could never reach this honour without their support and affection.

I would like to thank L.Empringham, James Campell, Liliana, Qao, Alan, Xulie, Lee, Maurice, Saul, Adam, Cook, Junaidi, Wei, Tianning, Omar, Milijana, Okaeme, Kamal, Jesus, Si, Piniwan, Pinit, Fan, Kostas, Kostas, Kongpan, Dinesh, Ed, Ruse, Almaleki, Lavopa, Yahan, Fabio, Andrew, Zhang, Jing, Fabio, Matteo and Mason for their support and encouragement.

I would like to thank all academics in the PEMC group and all technicians from ground floor, 9th floor and 11th floor for their help.

I would like to thank my primary school teachers, my earlier supervisors, my beloved family friends, my beloved people living in my country and my relations.

Once again, I would like to thank my supervisor Prof. Patrick. W. Wheeler for his financial help by providing a scholarship and paid part-time research work. I would like to thank the Royal Academy of Engineering, IEEE Power Engineering Society and IEEE Power Electronics Society for their Awards in 2006 and 2007. 


\begin{abstract}
Recently, the conventional Matrix Converter has been considered for aerospace applications because of its compactness in weight and size due to absence of a DC-Link capacitor. In addition the Matrix Converter is capable of producing a variable output voltage with unrestricted input and output frequency. This is useful in aerospace applications which require a wide range of input frequency, sometimes from $360 \mathrm{~Hz}$ to $900 \mathrm{~Hz}$. These key features are only obtained from the Matrix Converter without using any large passive components. The Matrix Converter has an inherent regeneration capability. However, the avoidance of the regeneration may be vital in many aerospace applications, such as aircraft surface actuation systems. According to current aircraft power quality specifications regeneration is not allowed and must be dissipated with in the Matrix Converter drive itself.
\end{abstract}

This thesis proposes two novel methods which allow regeneration from the Matrix Converter motor drive to be avoided. These are the Bi-Directional Switch (BDS) method and Input Power Clamp (IPC) method. In order to detect regeneration in the Matrix Converter motor drive two techniques are used. These are the Power Comparison (PC) technique and Input Voltage Reference (IVR) technique. Finally, to validate the proposed methods a Matrix Converter has been designed and built with a Regeneration Control Circuit (RCC). Indirect vector control is used to control $4.0 \mathrm{~kW}$ Induction Motor. Based on the simulation results and experimental results using the BDS method to avoid regeneration with a Matrix Converter is feasible. 


\section{Contents}

1 Introduction 1

1.1 Introduction . . . . . . . . . . . . . . 1

1.2 Matrix Converter Technology . . . . . . . . . . . . . . 4

1.3 Vector Control in $\mathrm{AC}$ drives . . . . . . . . . . . . . . 6

1.4 Regeneration in Power Electronics Converters . . . . . . . . . . . 7

1.5 Scope of this Research . . . . . . . . . . . . . . . 8

1.6 Overview of Thesis Structure . . . . . . . . . . . . . . . 10

2 Review of Matrix Converter Technology 11

2.1 Introduction . . . . . . . . . . . . . . . . . 11

2.2 Fundamentals of the Matrix Converter . . . . . . . . . . . . 13

2.2.1 Structure of the Matrix Converter . . . . . . . . . . . . . 13

2.2.2 Features of the Matrix Converter . . . . . . . . . . . 16 
2.3 Comparison with Conventional AC-AC drives . . . . . . . . . . . 17

2.3.1 DC-Link Converters . . . . . . . . . . . . . 17

2.3.2 Cycloconverters ......................... 18

2.4 Modulation strategies . . . . . . . . . . . . . . . 20

2.4.1 Venturini Algorithm ................. 20

2.4.2 Modified Venturini Algorithm . . . . . . . . . . . 26

2.4.3 Scalar Modulation Algorithm . . . . . . . . . . . . 27

2.4.4 Space Vector Modulation . . . . . . . . . . . . . . . 29

2.4.4.1 Space Phasors .............. . . . 29

2.4.4.2 Matrix Converter Output Space Phasors . . . . . . . 30

2.4.4.3 Selection of Switching States . . . . . . . . 30

2.5 Converter Construction . . . . . . . . . . . . . . . 35

2.5.1 Structure of Bi-Directional Switches . . . . . . . . . . . . 35

2.5.1.1 Diode Embedded Bi-Directional Switch . . . . . . . 35

2.5.1.2 Common Emitter Bi-Directional Switch . . . . . . 36

2.5.1.3 Common Collector Bi-Directional Switch . . . . . . . 37

2.5.1.4 Reverse Blocking IGBTs Bi-Directional Switch . . . 38

2.5.2 Commutation Techniques ................ 39 
2.5.2.1 Dead Time Commutation . . . . . . . . . . . 40

2.5.2.2 Multi-Step Current Commutation . . . . . . . . . . 40

2.6 Avoiding Regeneration in Traditional Power Converter Topologies . . 43

2.6.1 Dynamic Braking Method for Diode Bridge fed $V S I_{s} \ldots \ldots$

2.6.2 Dynamic Braking Method with a Back-to-Back VSI . . . . . . 44

2.7 Conclusions . . . . . . . . . . . . . . . . . . . 45

3 Induction Motor Control $\quad 47$

3.1 Introduction . . . . . . . . . . . . . . . . . . . 47

3.2 Open Loop Motor Control . . . . . . . . . . . . . . . . . . . . . 48

3.2.1 Volts/Hertz Control . . . . . . . . . . . . . . . . . . . . 48

3.3 Closed Loop Control : Application of Vector Control . . . . . . . . . 50

3.3.1 The Principle of Indirect Field Orientation . . . . . . . . . . . 50

3.3.2 Two Phase Transformation . . . . . . . . . . . . . . . . . 52

3.3.3 Stationary Frame to Rotating Reference Frame Transformation 53

3.3.4 The Rotor Flux Angle $(\lambda) \ldots . . . . . . . . . . .555$

3.3.4.1 Direct Measurement . . . . . . . . . . . 55

3.3.4.2 Indirect Measurement . . . . . . . . . . . . . 57

3.3.5 Vector Control . . . . . . . . . . . . . . . . 59 
3.3.5.1 Speed Control Design _. . . . . . . . . . . 63

3.3.5.2 Current Loop Control Design . . . . . . . . . . . 64

3.3.5.3 Voltage Compensation Terms . . . . . . . . . 65

3.3.6 Rotating Reference Frame to Stationary Frame Transformation 66

3.3.7 Stationary Frame to Three Phase Transformation . . . . . . 67

3.4 Conclusions . . . . . . . . . . . . . . . . . . . . . . . . 69

4 Novel Methods for Avoiding Regeneration $\quad 70$

4.1 Introduction . . . . . . . . . . . . . . 70

4.2 Regeneration in Matrix Converters _. . . . . . . . . . . 72

4.2.1 Operating Conditions which cause Regeneration in Motor Drives 73

4.2 .2 Braking Methods . . . . . . . . . . . . . . . . 74

4.2.2.1 Regenerative Braking . . . . . . . . . . . 74

$4.2 .2 .2 \quad$ Dynamic Braking . . . . . . . . . . . . . . 75

4.2.2.3 DC Injection Braking $\ldots \ldots \ldots \ldots \ldots$

4.2.2.4 Field Current or Flux Braking . . . . . . . . . . . 77

4.2.2.5 Counter Current Braking _. . . . . . . . . 78

4.3 Techniques to detect Regeneration in Matrix Converters _. . . . . 79

4.3.1 Power Comparison (PC) Technique . . . . . . . . . . . . 79 
4.3.2 Input Voltage Reference (IVR) Technique . . . . . . . . . . . 81

4.3.3 Comparison between PC Technique and IVR Technique . . . . 82

4.3.4 Summary of Proposed Methods (BDS, IPC) . . . . . . . . . 83

4.4 Avoiding Regeneration in Matrix Converters . . . . . . . . . . . . . . 84

4.4.1 Bi-Directional Switch (BDS) Method . . . . . . . . . . . 84

4.4.2 Input Power Clamp (IPC) Method . . . . . . . . . . . . . 86

4.4.3 Comparison between BDS Method and IPC Method . . . . . . 88

4.5 Description of the Techniques with both Dissipation Methods . . . . 89

4.5.1 Power Comparison (PC) Technique . . . . . . . . . . . . . . 89

4.5.2 Input Voltage Reference (IVR) Technique . . . . . . . . . . . 91

4.6 Conclusions . . . . . . . . . . . . . . . . . . . . . . . 93

5 Simulation Study $\quad 94$

5.1 Introduction . . . . . . . . . . . . . . . . . . . 94

5.2 Simulation Results for Basic Operation of MC . . . . . . . . . . . 95

5.2 .1 R-L Load . . . . . . . . . . . . . . . . . . 95

5.2 .2 Induction Motor Load . . . . . . . . . . . . . . . . . 101

5.2.3 Closed Loop Vector Control . . . . . . . . . . . . . . . . . . . 103

5.2.3.1 Regeneration ............... 107 
5.3 Bi-Directional Switch (BDS) Method . . . . . . . . . . . . . . 112

5.3.1 Power Comparison (PC) Technique . . . . . . . . . . . . . 112

5.3.2 Input Voltage Reference (IVR) Technique . . . . . . . . . 116

5.4 Input Power Clamp (IPC) Method . . . . . . . . . . . . . . 119

5.4.1 Power Comparison (PC) Technique . . . . . . . . . . . . . . 119

5.4.2 Input Voltage Reference (IVR) Technique . . . . . . . . . 122

5.5 Conclusions . . . . . . . . . . . . . . . . . . . . . . . 124

6 Experimental Implementation of the Matrix Converter $\quad 125$

6.1 Introduction . . . . . . . . . . . . . . . . . 125

6.2 Matrix Converter Design . . . . . . . . . . . . . . . . . 127

6.2.1 Gate Drive Circuit . . . . . . . . . . . . . . . . . 127

$6.2 .2 \quad$ Power Circuit . . . . . . . . . . . . . . . . . . . . . . . . . . 129

6.2 .3 Input Filter Circuit . . . . . . . . . . . . . . . 130

6.2.4 Output Current Polarity Detection Circuit . . . . . . . . . 130

6.2.5 Clamp Circuit . . . . . . . . . . . . . . . . . . . 132

6.3 Control and Interface Circuit Design _ . . . . . . . . 136

6.3.1 Control Circuits: DSP and FPGA . . . . . . . . . . . 137

$6.3 .2 \quad \mathrm{DSP} /$ Host PC Interface $\ldots \ldots \ldots \ldots$ 
6.3.3 Encoder Interface Board . . . . . . . . . . . . . . . . . . . . 142

6.4 Regeneration Control Circuit (RCC) Design . . . . . . . . . . . . 143

6.4.1 Power Circuit for RCC . . . . . . . . . . . . . . . . . . 143

6.4.2 DSP/FPGA Control for RCC . . . . . . . . . . . . . 147

6.5 Conclusions . . . . . . . . . . . . . . . . . . . . . . . 149

7 Testing and Experimental Results $\quad 150$

7.1 Introduction . . . . . . . . . . . . . . . . . 150

7.2 Test Procedures . . . . . . . . . . . . . . . . . . . 151

7.2.1 Finding the DC offset and the Gain for the Transducers . . . . 151

7.2.2 Protection Trips Setting . . . . . . . . . . . . . . 154

7.2.3 Test for the Four Step Commutation . . . . . . . . . . . . 156

7.2.4 Fixed Duty Cycle PWM Test . . . . . . . . . . . . . . . . 158

7.3 Experimental Results . . . . . . . . . . . . . . . . . . 159

$7.3 .1 \quad$ R-L load . . . . . . . . . . . . . . . . . . . . . 159

7.3.2 Voltz/Hertz Motor Control . . . . . . . . . . . . . . 160

7.3.3 Vector Control and Regeneration . . . . . . . . . . . . . 161

7.3.4 Avoiding Regeneration using BDS Method . . . . . . . . . . 168

7.4 Conclusions . . . . . . . . . . . . . . . . . . 172 
8.1 Further Work . . . . . . . . . . . . . . . . . . . 175

$\begin{array}{lr}\text { A Parameters used } & 176\end{array}$

B Circuit Diagrams 184

$\begin{array}{lr}\text { C Published Papers } & 186\end{array}$

$\begin{array}{ll}\text { D List of Symbols } & 187\end{array}$ 


\section{List of Figures}

1.1 Host Drum Drive System of Tanker Aircraft . . . . . . . . . . . 2

1.2 Host Drum Drive System (HDDS) of Tanker Aircraft (TA) . . . . . 3

1.3 AC-AC Power Converter Topologies . . . . . . . . . . . . . 4

2.1 The General Structure of the Conventional Matrix Converter . . . . . 14

2.2 Uncontrolled 6-Pulse Rectifier with PWM Voltage Source Inverter . . 17

2.3 Back-to-Back Voltage Source Inverter _ . . . . . . . . . . . 18

2.4 Three Phase to Three Phase Cycloconverter . . . . . . . . . . . 19

2.5 Theoretical Waveforms Illustrating the 50 \% Voltage Transfer Limit 23

2.6 Example of Typical Matrix Converter Waveforms . . . . . . . . . 24

2.7 General Form of Switching Pattern _ . . . . . . . . . . 25

2.8 Theoretical Waveforms Illustrating 87 \% Voltage Transfer Limit . . . 26

2.9 Output voltage space vectors $\ldots \ldots \ldots \ldots \ldots$

2.10 Synthesis of output voltage space phasor $\ldots \ldots \ldots \ldots \ldots$ 
2.11 Possible way of allocating states within the switching sequence . . . . 34

2.12 Diode Embedded Bi-Directional Switch . . . . . . . . . . . . . 35

2.13 Common Emitter Bi-Directional Switch . . . . . . . . . . . . 36

2.14 Common Collector Bi-Directional Switch . . . . . . . . . . . . 37

2.15 Reverse blocking IGBT Bi-Directional Switch . . . . . . . . . . 38

2.16 Baisc rules for safe operation of the Matrix Converter . . . . . . . . 39

2.17 2-phase to 1-phase Matrix Converter . . . . . . . . . . . . . 41

2.18 Timing diagram for four-step current commutation between two switches 41

2.19 Dynamic Braking Circuit for a Diode Bridge fed VSI . . . . . . . . . 43

2.20 Overview of a Dynamic Braking Circuit for a Back-to-Back VSI . . . 44

3.1 Conventional Volts/Hertz Control . . . . . . . . . . . . . . . . . . . 49

3.2 DC motor with inherent vector control . . . . . . . . . . . . 50

3.3 Vector Control Analogy with DC Motor . . . . . . . . . . . . . 51

3.4 Three Phase into Stationary Frame Transformation . . . . . . . . . . 52

3.5 The Stationary Frame to Rotating Reference Frame Transformation . 54

3.6 Graph for Time Domain Analysis for Two Phase Transformation . . . 54

3.7 Calculation of rotor flux angle in direct vector Control . . . . . . . 56

3.8 Calculation of rotor flux angle in direct vector Control . . . . . . . 57 
3.9 Field Orientation: $\Psi_{r}$ is aligned with d-axis $\ldots \ldots \ldots \ldots$

3.10 Per Phase Equivalent Circuit of an Induction Motor . . . . . . . . 60

3.11 Closed Loop Indirect Field Oriented Vector Control Scheme . . . . . 62

3.12 Speed Controller Design Scheme . . . . . . . . . . . . . . . 63

3.13 Current Controller Design Scheme . . . . . . . . . . . . . . . . 64

3.14 Rotating Reference Frame to Stationary Frame Transformation . . . . 66

$3.152 / 3$ Transformation . . . . . . . . . . . . . . 67

4.1 Inherent Bi-Directional Power Flow in a Matrix Converter Motor Drive 72

4.2 System for Avoiding Regeneration in a Matrix Converter Motor Drive 72

4.3 Overview of a Dynamic Braking Circuit for a DC-Link Converter . . 75

4.4 Overview of a Dynamic Braking Method for a Matrix Converter . . . 76

4.5 The DC Injection Braking Method _. . . . . . . . . . 77

4.6 Block Diagram of the Power Comparison (PC) Technique for both dissipation Methods . . . . . . . . . . . . . . . 80

4.7 Block Diagram for the Input Voltage Reference (IVR) Technique for both dissipation Methods . . . . . . . . . . . . . . . . . 81

4.8 Summary of the Proposed Methods (BDS, IPC) with Proposed Techniques $(\mathrm{PC}, \mathrm{IVR}) \ldots \ldots \ldots \ldots \ldots \ldots \ldots \ldots$

4.9 Avoiding Regeneration with a Matrix Converter Motor Drive using the Bi-Directional Switch (BDS) Method . . . . . . . . . . . . . . 84 
4.10 The Bi-Directional Switch (BDS) Method Regeneration Control Cir-

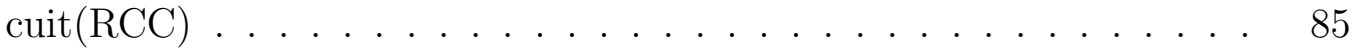

4.11 Regeneration Control Circuit for a Matrix Converter using the Input Power Clamp (IPC) dissipation Method . . . . . . . . . . . . . 86

4.12 Regeneration Control Circuit (RCC) for the Input Power Clamp (IPC) Method . . . . . . . . . . . . . . . . . 87

4.13 Block Diagram of the Power Comparison (PC) Technique for the BiDirectional Switch (BDS) dissipation Method . . . . . . . . . . . 89

4.14 Block Diagram of the Power Comparison (PC) Technique for the IPC dissipation Method . . . . . . . . . . . . . . 90

4.15 Block Diagram for the Input Voltage Reference (IVR) Technique with the Bi-Directional Switch (BDS) dissipation Method . . . . . . . . . 91

4.16 Block Diagram for the IVR Technique with the IPC dissipation Method 92

5.1 Circuit Diagram for a Matrix Converter with an R-L Load . . . . . 96

5.2 Unfiltered Output Voltages for a Matrix Converter with an R-L Load. $V_{\text {in }}=240 \mathrm{~V}$ at $60 \mathrm{~Hz}, \mathrm{q}=0.75, f_{\text {out }}=60 \mathrm{~Hz} \ldots \ldots 96$

5.3 The Unfiltered Output Line Voltage and Spectrum for a Matrix Converter with an R-L load. $V_{\text {in }}=240 \mathrm{~V}$ at $60 \mathrm{~Hz}, \mathrm{q}=0.75, f_{\text {out }}=60$ $\mathrm{Hz} \ldots \ldots \ldots \ldots \ldots \ldots$

5.4 The Unfiltered Input Current and Spectrum for a Matrix Converter with an R-L load. $V_{\text {in }}=240 \mathrm{~V}$ at $60 \mathrm{~Hz}, \mathrm{q}=0.75, f_{\text {out }}=60 \mathrm{~Hz}$. .

5.5 Output Currents for a Matrix Converter with an R-L Load. $V_{i n}=240$ $\mathrm{V}$ at $60 \mathrm{~Hz}, \mathrm{q}=0.75, f_{\text {out }}=60 \mathrm{~Hz} \ldots \ldots \ldots \ldots$ 
5.6 Filtered Input Currents for a Matrix Converter with an R-L load. $V_{\text {in }}$ $=240 \mathrm{~V}$ at $60 \mathrm{~Hz}, \mathrm{q}=0.75, f_{\text {out }}=60 \mathrm{~Hz} \ldots \ldots . \ldots 98$

5.7 Output Currents for a Matrix Converter with an R-L Load. $V_{\text {in }}=240$ $\mathrm{V}$ at $60 \mathrm{~Hz}, \mathrm{q}=0.75, f_{\text {out }}=50 \mathrm{~Hz} \ldots \ldots . \ldots$

5.8 Output Currents for a Matrix Converter with an R-L Load. $V_{\text {in }}=240$ $\mathrm{V}$ at $60 \mathrm{~Hz}, \mathrm{q}=0.75, f_{\text {out }}=75 \mathrm{~Hz} \ldots \ldots \ldots$

5.9 Circuit diagram for a Matrix Converter fed Induction Motor . . . . . 101

5.10 Speed, Input Currents and Output Currents of the Matrix Converter fed Induction Motor. $V_{i n}=240 \mathrm{~V}$ at $60 \mathrm{~Hz}, f_{s}=10 \mathrm{kHz}$ and $\mathrm{q}=0.75$

5.11 Overview of the Simulation of the Matrix Converter Vector Controlled Induction Motor Drive . . . . . . . . . . . . . . . . . . . . . 104

5.12 Speed of the Induction Motor, The Matrix Converter Input Currents, Output Currents and the Reference Voltages. $V_{i n}=240 \mathrm{~V}$ at $60 \mathrm{~Hz}, \mathrm{q}$ $=0.75$ and $f_{s}=10 \mathrm{kHz} \ldots \ldots \ldots \ldots$

5.13 Speed and Torque of the Induction Motor, Field Producing Current $\left(i_{d}\right)$ and Torque Producing Current $\left(i_{q}\right) . V_{i n}=240 \mathrm{~V}$ at $60 \mathrm{~Hz}, \mathrm{q}=$ 0.75 and $f_{s}=10 \mathrm{kHz} \ldots \ldots \ldots \ldots 6$

5.14 Overview of the Simulation Diagram for Obtaining Regeneration in the Matrix Converter Vector Controlled Induction Motor . . . . . . . . . 108

5.15 Speed and Torque of the Vector Controlled Induction Motor and Output Currents of the Matrix Converter in Regeneration. $V_{\text {in }}=240 \mathrm{~V}$ at $60 \mathrm{~Hz}, \mathrm{q}=0.75$ and $f_{s}=10 \mathrm{kHz} \ldots \ldots . \ldots . \ldots 109$

5.16 Field Producing Currents and Torque Producing Currents in Regeneration. $V_{\text {in }}=240 \mathrm{~V}$ at $60 \mathrm{~Hz}, \mathrm{q}=0.75$ and $f_{s}=10 \mathrm{kHz} \ldots \ldots$ 
5.17 Input Phase Currents for a Matrix Converter in Regeneration. $V_{i n}=$ $240 \mathrm{~V}$ at $60 \mathrm{~Hz}, \mathrm{q}=0.75$ and $f_{s}=10 \mathrm{kHz} \ldots \ldots . . . . . . .110$

5.18 Instantaneous Input Phase Powers for a Matrix Converter in Regeneration. $V_{i n}=240 \mathrm{~V}$ at $60 \mathrm{~Hz}, \mathrm{q}=0.75$ and $f_{s}=10 \mathrm{kHz} \ldots \ldots 111$

5.19 Phase Opposition between Input Phase Voltages and Input Phase Currents of the Matrix Converter during the Regeneration. $V_{i n}=240 \mathrm{~V}$ at $60 \mathrm{~Hz}, \mathrm{q}=0.75, f_{\text {out }}=60 \mathrm{~Hz}$ and $f_{\text {s }}=10 \mathrm{kHz} \ldots \ldots 111$

5.20 Circuit Diagram for a BDS Method with PC and IVR Technique . . . 112

5.21 Generation of the 6-Pulses, Duty Cycle Variation and Output Power for Regeneration Control Circuit for the BDS Method with the PC Technique. $V_{\text {in }}=240 \mathrm{~V}$ at $60 \mathrm{~Hz}, \mathrm{q}=0.75, f_{\text {out }}=60 \mathrm{~Hz}$ and $f_{s}=10$

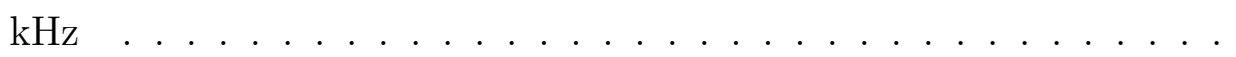

5.22 Input Phase Currents and Input Phase Powers for the BDS Method with the PC Technique. $V_{\text {in }}=240 \mathrm{~V}$ at $60 \mathrm{~Hz}, \mathrm{q}=0.75, f_{\text {out }}=60 \mathrm{~Hz}$ and $f_{s}=10 \mathrm{kHz} \ldots \ldots \ldots \ldots$

5.23 Phase Relationship between Input Phase Voltage and Input Phase Current in the BDS Method with the PC Technique. $V_{i n}=240 \mathrm{~V}$ at 60 $\mathrm{Hz}, \mathrm{q}=0.75, f_{\text {out }}=60 \mathrm{~Hz}$ and $f_{s}=10 \mathrm{kHz} \ldots \ldots$

5.24 Generation of 6-Pulses for RCC, Duty Cycle Variation and Output Power for the BDS Method with IVR Technique. $V_{i n}=240 \mathrm{~V}$ at 60 $\mathrm{Hz}, \mathrm{q}=0.75, f_{\text {out }}=60 \mathrm{~Hz}$ and $f_{s}=10 \mathrm{kHz} \ldots \ldots . . . . . .117$

5.25 Input Phase Currents and Input Phase Powers for the BDS Method with IVR Technique. $V_{\text {in }}=240 \mathrm{~V}$ at $60 \mathrm{~Hz}, \mathrm{q}=0.75, f_{\text {out }}=60 \mathrm{~Hz}$ and $f_{s}=10 \mathrm{kHz} \ldots \ldots \ldots \ldots \ldots$

5.26 Simulation Diagram for a IPC Method with PC and IVR Technique . 119 
5.27 Pulse for RCC, Duty Cycle Variation and Output Power for the IPC Method with the PC Technique. $V_{\text {in }}=240 \mathrm{~V}$ at $60 \mathrm{~Hz}, \mathrm{q}=0.75, f_{\text {out }}$ $=60 \mathrm{~Hz}$ and $f_{s}=10 \mathrm{kHz} \ldots \ldots \ldots \ldots$

5.28 Input Clamp Voltage, Voltage and Current of the RCC Resistor for the IPC Method with the PC Technique. $V_{\text {in }}=240 \mathrm{~V}$ at $60 \mathrm{~Hz}, \mathrm{q}=$ $0.75, f_{\text {out }}=60 \mathrm{~Hz}$ and $f_{\text {s }}=10 \mathrm{kHz} \ldots \ldots \ldots$

5.29 Input Phase Currents and Input Phase Powers for the IPC Method with the PC Technique. $V_{\text {in }}=240 \mathrm{~V}$ at $60 \mathrm{~Hz}, \mathrm{q}=0.75, f_{\text {out }}=60 \mathrm{~Hz}$ and $f_{s}=10 \mathrm{kHz} \ldots \ldots \ldots \ldots \ldots \ldots$

5.30 Pulse for RCC, Duty Cycle Variation and Output Power for the IPC Method with the IVR Technique. $V_{\text {in }}=240 \mathrm{~V}$ at $60 \mathrm{~Hz}, \mathrm{q}=0.75, f_{\text {out }}$ $=60 \mathrm{~Hz}$ and $f_{s}=10 \mathrm{kHz} \ldots \ldots \ldots \ldots$

5.31 Input Phase Currents and Input Phase Powers for the IPC Method with the IVR Technique. $V_{\text {in }}=240 \mathrm{~V}$ at $60 \mathrm{~Hz}, \mathrm{q}=0.75, f_{\text {out }}=60$ $\mathrm{Hz}$ and $f_{s}=10 \mathrm{kHz} \ldots \ldots \ldots \ldots . \ldots . \ldots . \ldots . \ldots 123$

6.1 Overview of the Experimental Implementation of the Novel Concept for Avoiding Regeneration in a Matrix Converter Motor Drive . . . . 126

6.2 Overview of the Matrix Converter Gate Drive Circuit . . . . . . . . 127

6.3 IGBT Switch Module SK60GM123 used in the Power Circuit . . . . . 129

6.4 Internal Circuit Layout of IGBT Module SK60GM123 . . . . . . . . . 130

6.5 A Small Input Filter for the Matrix Converter . . . . . . . . . . . . . 131

6.6 The Matrix Converter Output Current Direction Detection Circuit for One Output Phase .................... 132 
6.7 Matrix Converter Clamp Circuit . . . . . . . . . . . . . . . . . . . 133

6.8 Layout of Control and Interface Circuit . . . . . . . . . . . 136

6.9 Photograph of the FPGA card . . . . . . . . . . . . . . . 138

6.10 Block diagram of the FPGA card . . . . . . . . . . . . . 139

6.11 Diagram to show PWM interrupt DSP usage . . . . . . . . . . 140

6.12 Photograph of the DSK6713 HPI Daughtercard . . . . . . . . . 141

6.13 The Layout of Encoder Interface Circuit . . . . . . . . . . . . . 142

6.14 Photograph of the Encoder Interface Board . . . . . . . . . . . 143

6.15 Overview of the Regeneration Control Circuit used to avoid Regeneration in the Matrix Converter . . . . . . . . . . . . . . . . . . . . 144

6.16 Photograph of the RCC for Bi-Directional Switch (BDS) Method . . 145

6.17 Photograph of the Regeneration Control Circuit (RCC) for BiDirectional Switch (BDS) Method . . . . . . . . . . . . . . . 146

6.18 Overview of VHDL Blocks used in the FPGA Control Design for Regeneration Control Circuit . . . . . . . . . . . . . . . . . . 148

6.19 The Photograph of the Complete Experimental Converter . . . . . . 149

7.1 The Block Diagram of A/D Test for the Voltage Transducers . . . . 151

7.2 The Block diagram of A/D Test Circuit for the Current Transducers . 153

7.3 The Block diagram for Clamp Trip Setting . . . . . . . . . . . . . 154 
7.4 Test Setup for the Four Step Commutation _ . . . . . . . . . . . 156

7.5 Four Step Commutation: Positive Output Current Direction . . . . . 157

7.6 Four Step Commutation: Negative Output Current Direction . . . . . 157

7.7 The Switching Pattern of the Fixed Duty Cycle PWM Test . . . . . . 158

7.8 Output Line Voltage, Output Current and Input Current for a Matrix Converter with an R-L Load. $V_{\text {in }}=100 \mathrm{~V}$ at $50 \mathrm{~Hz}, \mathrm{q}=0.75, f_{\text {out }}=$ $50 \mathrm{~Hz} \ldots \ldots \ldots \ldots \ldots$

7.9 Voltz/Hertz Motor Control for MC. $V_{i n}=100$ Volts, $f_{o}=50 \mathrm{~Hz} \ldots . .160$

7.10 Output Currents for Voltz/Hertz Motor Control $V_{i n}=100$ Volts, $f_{o}=$ $50 \mathrm{~Hz} \ldots \ldots \ldots \ldots \ldots 16 \ldots \ldots \ldots \ldots$

7.11 Digital angle, Motor speed and dq-voltages for the Vector Controlled Matrix Converter $\left[V_{\text {in }}=200\right.$ Volts, $f_{\text {in }}=50 \mathrm{~Hz}, f_{s}=12.5 \mathrm{kHz}$ and $\mathrm{q}$ $=0.75] \ldots \ldots \ldots \ldots \ldots \ldots \ldots \ldots \ldots \ldots \ldots \ldots \ldots \ldots \ldots$

7.12 Output Currents and dq-Currents for Vector Controlled Matrix Converter $\left[V_{\text {in }}=200\right.$ Volts, $f_{\text {in }}=50 \mathrm{~Hz}, f_{s}=12.5 \mathrm{kHz}$ and $\left.\mathrm{q}=0.75\right] . .162$

7.13 Speed and Output Power of the Motor in Regeneration at speed reversal from $+157 \mathrm{rad} / \mathrm{s}$ to $-157 \mathrm{rad} / \mathrm{s}\left[V_{\text {in }}=200\right.$ Volts, $f_{s}=12.5 \mathrm{kHz}$ and $\mathrm{q}=0.75]$.

7.14 Rotor position (rotor angle) and Rotor flux angle $(\lambda)$ in Regeneration during a speed reversal from $+157 \mathrm{rad} / \mathrm{s}$ to $-157 \mathrm{rad} / \mathrm{s}\left[V_{i n}=200\right.$ Volts, $f_{s}=12.5 \mathrm{kHz}$ and $\left.\mathrm{q}=0.75\right] \ldots \ldots \ldots$. . . . . . . . . . . . . . 
7.15 Torque and dq-Currents of the Motor during Regeneration during a speed reversal from $+157 \mathrm{rad} / \mathrm{s}$ to $-157 \mathrm{rad} / \mathrm{s}\left[V_{i n}=200\right.$ Volts, $f_{s}=$ $12.5 \mathrm{kHz}$ and $\mathrm{q}=0.75] \ldots \ldots \ldots \ldots 5$

7.16 Stator Currents of the Motor during Regeneration during a speed reversal from $+157 \mathrm{rad} / \mathrm{s}$ to $-157 \mathrm{rad} / \mathrm{s}\left[V_{i n}=200\right.$ Volts, $f_{i n}=50 \mathrm{~Hz}, f_{s}$ $=12.5 \mathrm{kHz}$ and $\mathrm{q}=0.75] \ldots \ldots \ldots$. . . . . . . . . . . . . .

7.17 Input Phase Voltages $\left(V_{A}, V_{B}\right)$, Input Phase Currents $\left(i_{A}, i_{B}\right)$ and Three Phase Input Power (using two-wattmeter method) during Regeneration during a speed reversal from $+157 \mathrm{rad} / \mathrm{s}$ to $-157 \mathrm{rad} / \mathrm{s}\left[V_{i n}\right.$ $=200$ Volts, $f_{\text {in }}=50 \mathrm{~Hz} f_{s}=12.5 \mathrm{kHz}$ and $\left.\mathrm{q}=0.75\right] \ldots 166$

7.18 The Output Power of the Motor and Duty Cycle Variation of the BiDirectional Switches in the RCC during a speed reversal from +157 $\mathrm{rad} / \mathrm{s}$ to $-157 \mathrm{rad} / \mathrm{s}\left[V_{\text {in }}=200\right.$ Volts, $f_{\text {in }}=50 \mathrm{~Hz} f_{s}=12.5 \mathrm{kHz}$ and $\mathrm{q}$ $=0.75] \ldots \ldots \ldots \ldots \ldots$. . . . . . . . . . . . . . . . . . .

7.19 Duty Cycle Variation, Voltage $\left(V_{A B}\right)$ across the $R_{A B}$ in RCC, Current $\left(i_{A B}\right)$ through $R_{A B}$ and Input Power Dissipation for One Phase through the $\mathrm{RCC}$ during a speed reversal from $+157 \mathrm{rad} / \mathrm{s}$ to $-157 \mathrm{rad} / \mathrm{s}\left[V_{i n}\right.$ $=200$ Volts, $f_{\text {in }}=50 \mathrm{~Hz} f_{s}=12.5 \mathrm{kHz}$ and $\left.\mathrm{q}=0.75\right] \ldots$. . .

7.20 Input Phase Currents $\left(i_{A}, i_{B}\right)$ and Three Phase Input Power during a speed reversal from $+157 \mathrm{rad} / \mathrm{s}$ to $-157 \mathrm{rad} / \mathrm{s}\left[V_{\text {in }}=200\right.$ Volts, $f_{\text {in }}=$

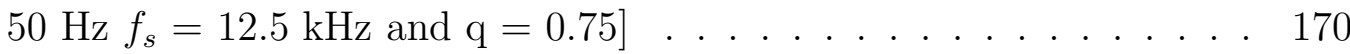

A.1 FPGA Test Bench to generate the PWM Signals for the Gate Drives of the Regeneration Control Circuit (RCC) . . . . . . . . . . . . 181

A.2 FPGA Simulation Results for PWM generation for RCC . . . . . . . 182

B.1 Schematic of Power Circuit PCB for Avoiding Regeneration . . . . . 184 
B.2 Schematic of Gate Drive PCB for Avoiding Regeneration . . . . . . . 185 


\section{List of Tables}

2.1 Switching states for a 3-phase to 3-phase matrix converter . . . . . . 31

2.2 Summary of Comparison between the Matrix Converter and other topologies ............................. 45

4.1 Summary of difference between PC and IVR techniques . . . . . . . . 82

4.2 Comparison between the Bi-Directional Switch (BDS) Method and the Input Power Clamp (IPC) Method Circuits . . . . . . . . . . . . . 88

6.1 Required data Information for Sizing the Clamp Capacitors . . . . . . 135

6.2 Hardware and Software Trips Used in this Application . . . . . . . . 140

6.3 Specifications of the Encoder . . . . . . . . . . . . . . . . . . 142

6.4 Specification of the RCC resistors . . . . . . . . . . . . . . . 145

6.5 Specification of the varistors . . . . . . . . . . . . . 146

7.1 Test Data's used in this Application . . . . . . . . . . . . . . . 150

7.2 Test Data for the Clamp Circuit Trip Voltage Transducer . . . . . . . 155 
7.3 Four Steps for Current Commutation . . . . . . . . . . . . . . 157

8.1 Suitability of the Matrix Converter for aerospace applications . . . . 174

A.1 Input Signals with Datas of the Test Bench to generate PWM signals 181 


\section{Chapter 1}

\section{Introduction}

\section{$1.1 \quad$ Introduction}

In $21^{\text {st }}$ century, power electronics is playing a major role in global industrialization and energy conservation. The impact of power electronics has been seen in almost several fields of engineering, such as mechanical, aeronautics, textiles, robotics, mining and marine [1]. The need for power electronics has increased over the years due to the advantages of controlling electrical energy.

One application of power electronics is efficient power conversion. In addition control of electric power leads to the rapid developments in the power generation, distribution and utility systems [2].

This research in this thesis is related to the application of power electronics in the control of motor drives for aerospace applications. In the first stage of the work a Matrix Converter is used to control an induction motor. In second stage, using a proposed additional power electronic circuit, regeneration is avoided in the Matrix Converter motor drive. 
This research is focussed on aerospace applications, such as aircraft surface actuation control systems and Air to Air (in-flight) Refueling systems (AAR), where regeneration into the main supply is not allowed. The avoidance of regeneration is very important in aerospace applications. For example, When Air-Air Refuelling (AAR) the Tanker Aircraft (TA) hose trails and winds, the regeneration takes place in the Host Drum Drive Motor (HDDM). The air refuelling system in the Tanker Aircraft as depicted in the figure 1.1 .

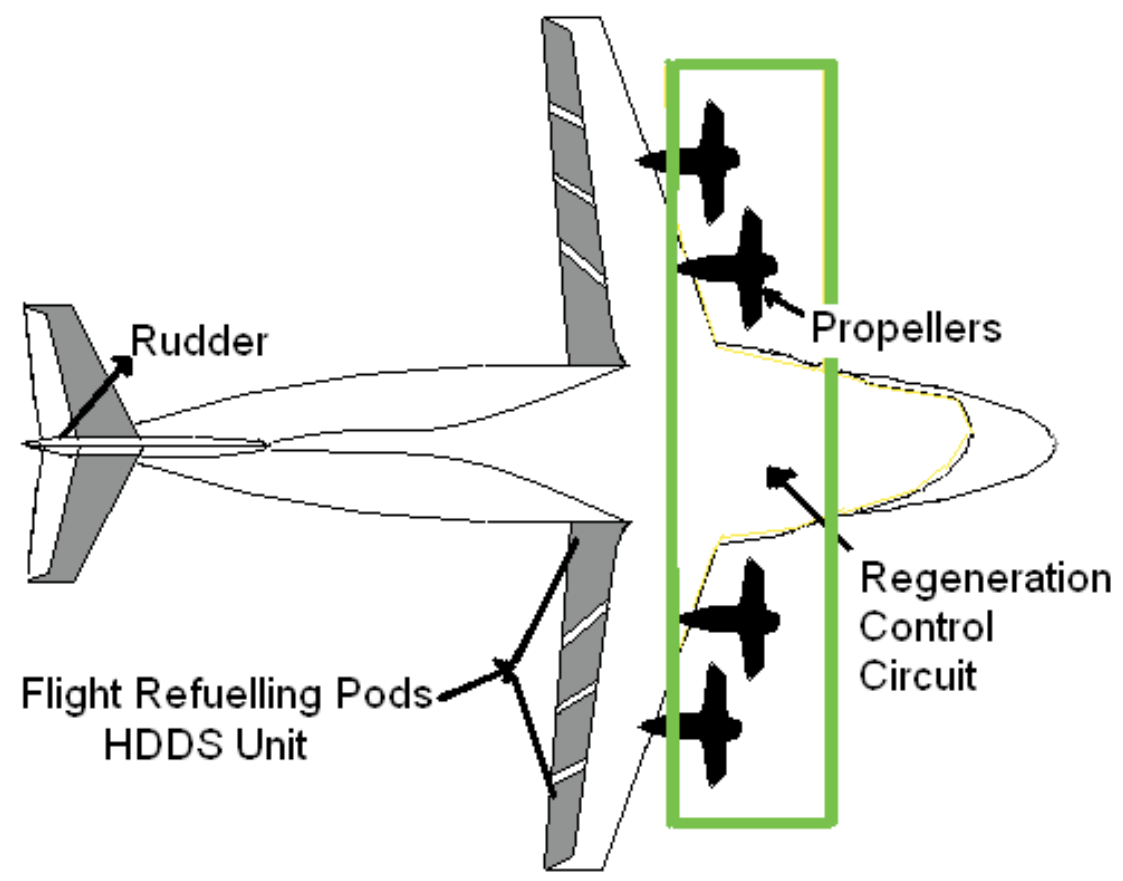

Figure 1.1: Host Drum Drive System of Tanker Aircraft

Air to air refuelling means the receiver aircraft receives the fuel from the Tanker Aircraft. It includes the refuelling hose which is controlled by the Host Drum Drive System (HDDS). This system is commanded by Refuelling Control Unit (RCU) by sending Aeronautical Radio Incorporated commands (ARINC). HDDS has three main components such as Motor Control Unit (MCU), Dump Resistor Pack (DRP) and two motors as shown in the figure 1.2. The MCU controls the motors based on RCU commands. 
For refuelling purpose the Tanker Aircraft refuelling hose trails and winds by Hose Drive Drum Motor. At the moment, the tension and retrieval of refuelling hose is controlled by MCU by changing the direction of motors speed. So that regeneration occurs in the motors. HDDS should able to dissipate the regenerated power otherwise it can cause two major problems:

1. Regeneration can increase the input supply to HDDS

2. Deactivate the control system of HDDS and the whole system become unstable.

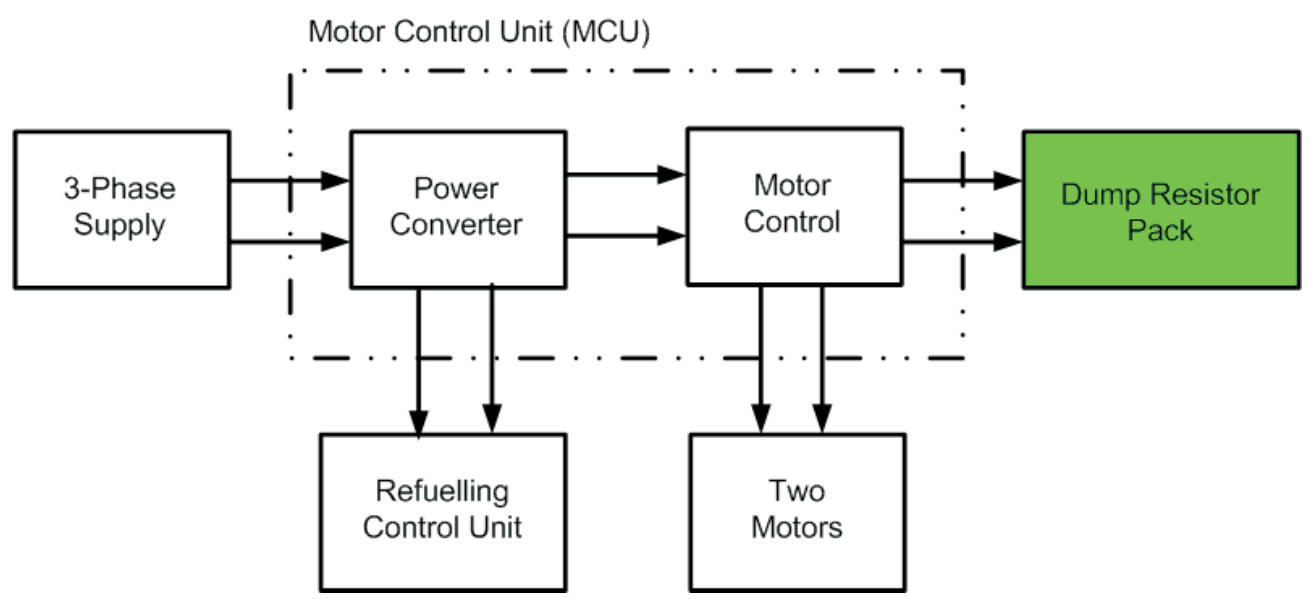

Figure 1.2: Host Drum Drive System (HDDS) of Tanker Aircraft (TA)

Currently, two-stage DC-Link converters are used in the MCU of HDDS. DC-Link converters are more weight and bulk. HDDS should be as light as possible. Because of above reasons Matrix Converter is recommended. However, inherent regeneration unique feature of Matrix Converter because of its bidirectional switches the regenerated energy is directly fed back to the supply without requiring any additional power electronics components. Regeneration should be avoided the Matrix Converter drive. 


\subsection{Matrix Converter Technology}

Improvements in power semi-conductor switches over the last two decades have resulted in the development of many structures of AC-AC converters. AC-AC converters transform a constant frequency AC supply into variable voltage, variable frequency output required, for example, in adjustable speed drives.

As shown in the figure 1.3, there are two kind of AC-AC converter topologies [3]:

- DC-Link converters (AC-DC-AC)

- Direct AC-AC converters

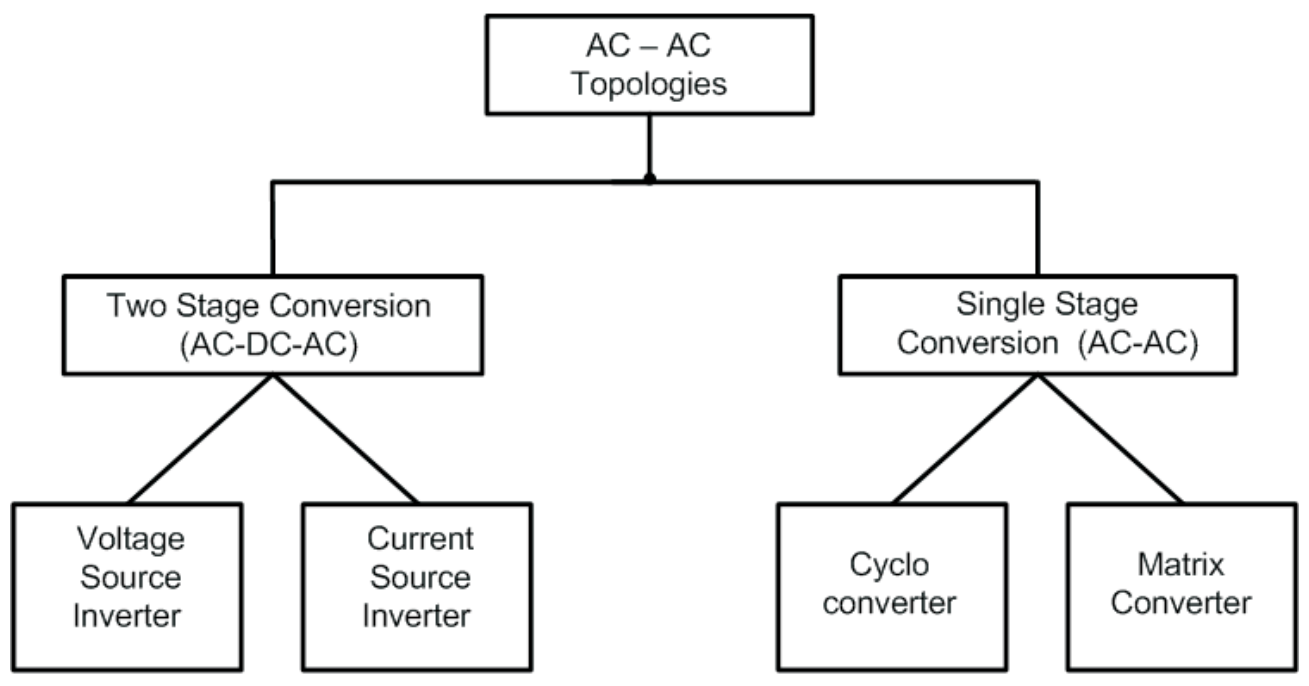

Figure 1.3: AC-AC Power Converter Topologies

DC-Link converter or AC-DC-AC converter has many advantages so that they are commercially used in the industries. For example, Voltage Source Inverter (VSI) has two significant advantages:

1. Voltage supply to the Voltage Source Inverter can be easily controlled

2. As the voltage is to be controlled, the Voltage Source Inverter output wave shape and its harmonic content are not significantly changed. 
AC-DC-AC converter with DC-Link have the disadvantage of large capacitor or large inductor in the circuit [4]. Some of the disadvantages of the DC-Link converters are overcome by direct AC-AC converters such as cycloconverters and Matrix Converters $[4,5]$. In this research the Matrix Converter $[6,7]$ is considered instead of cycloconverter to avoid some limitations in the cycloconverter [8] such as limitations of its output frequency. 


\subsection{Vector Control in AC drives}

DC motors were traditionally used for variable speed drives applications even though the induction machine has some superior characteristics such as simple construction, reliability, ruggedness, high efficiency and low cost [9] because of the excellent torque and speed control of the DC motors. In case of a separately excited DC motor, the commutator makes the armature flux perpendicular (or orthogonal) to the field flux regardless of the speed of rotation, so the flux and torque can be controlled independently by the field and armature current respectively. Hence, the electromagnetic torque of the DC motor is directly proportional to the armature current and field flux, as shown in equation 1.1.

$$
T=k \phi I_{a}
$$

where $T$ is the electromagnetic torque, $\phi$ is the magnetic flux in the DC motor and $I_{a}$ is armature current, $k$ is machine constant. However, DC motors have some disadvantages such as requirement of periodic maintenance of the commutator and brushes. Furthermore they have limited speed as the armature reaction will become noticeable at high speeds.

The above problems can be overcome by using $\mathrm{AC}$ machines. However, the induction motor has poor torque and speed response. To overcome this problem in the induction motors, a new technique called vector control was invented by Blaschke [10] and later developed by Leonhard [11].

The aim of vector control is to decouple the vectors of armature flux and field current so that both the field current and the torque are independently controlled and a torque response can be obtained, in a similar way to the separately excited DC motor. With the advantages of rapid developments in power electronics, $\mathrm{AC}$ drives employing vector control with induction motors can be seen as economical alternatives to the adjustable speed DC drives. 


\subsection{Regeneration in Power Electronics Converters}

Regeneration in drives occurs when mechanical energy (from a motor) is transferred into electrical energy and fed back to the supply. Under this condition the motor act as a generator. This section briefly explains how regeneration occurs in the power electronic converters such as the diode bridge fed Voltage Source Inverter (VSI), the Back-to-Back VSI, the cycloconverter and the Matrix Converter.

When using a diode bridge fed VSI, regenerative energy is not put back onto the supply since the diode bridge is a uni-directional circuit $[12,13]$ and hence bi-directional power flow is not possible. The conventional dynamic braking method is used to avoid regeneration in this kind of DC-Link converter as shown in figure 2.2.

When using a back-to-back VSI the regeneration capability is obtained by using a controlled PWM rectifier instead of a diode bridge rectifier [14]. In this system the power factor is improved in addition to the advantage bi-directional power flow [15] as shown in figure 2.3. Whenever regeneration occurs, the energy is fed back to the supply. With regard to avoiding regeneration, a dynamic braking method can be used.

The cycloconverter allows power flow in both directions [16] as shown in figure 2.4. Hence, regeneration of energy back to the supply is the advantage of the cycloconverter. However, the cycloconverter is obsolete in many industries due to its limitations such as its output frequency limit [17].

In the Matrix Converter the regenerative energy is fed back to the supply without requiring any additional power electronics components $[18,19]$. With regard to avoiding regeneration in the Matrix Converter, two novel methods are proposed in this thesis. 


\subsection{Scope of this Research}

The target of this research work is to investigate the techniques for avoiding regeneration from the Matrix Converter (MC) onto the supply. The avoidance of regeneration is vital in many aerospace applications such as aircraft surface actuation systems. In order to avoid regeneration in the Matrix Converter two novel methods are proposed:

- Bi-Directional Switch (BDS) method.

- Input Power Clamp (IPC) method.

The Regeneration Control Circuit (RCC) for the BDS method consists three bidirectional switches in series with three resistors which are connected across the input filter capacitors of each phase. The IPC requires one conventional uncontrolled 6pulse rectifier and a Uni-Directional Switch (UDS) in series with a resistor. In order to detect regeneration in the Matrix Converter two techniques are proposed:

- Power Comparison (PC) technique.

- Input Voltage Reference (IVR) technique.

The simulation results of the both proposed methods show that the Matrix Converter is a feasible alternative to other topologies for aerospace applications. With regard to the experimental results the BDS method is used to verify the proposed concept from the in-built lap prototype Matrix Converter used as a $4 \mathrm{~kW}$ induction motor drive. 
The IPC method is not implemented experimentally because the IPC method is not suitable for aerospace applications because of the following significant disadvantages when compared to the Bi-Directional Switch (BDS) method:

- IPC method requires the electrolytic capacitor in the output side of the three uncontrolled diode bridge. Hence, the weight and size of the Regeneration Control Circuit (RCC) for the IPC method is increased.

- Due to absence of the DC-Link, the Matrix Converter can be easily disturbed by the input voltage fluctuations or abnormal conditions.

- With regard to PCB design, the power circuit of the IPC method is not possible to include in the same power plane of the Matrix Converter's PCB. So IPC method requires additional space when compared to the BDS method. 


\subsection{Overview of Thesis Structure}

In Chapter 2, a review of Matrix Converter technology is presented. This chapter includes a section describing the comparison between the Matrix Converter and other conventional AC-AC topologies. The second section of this chapter describes the modulation strategies such as the Venturini algorithm, the scalar control algorithm and Space Vector Modulation (SVM). The final section of this chapter describes the Matrix Converter construction, which includes the structure of bi-directional switches and commutation techniques.

In Chapter 3, the open loop operation of the Matrix Converter motor drive is described. The concept of indirect filed oriented vector control is introduced in this chapter. The implementation of vector control to improve the torque response of the induction motor is also explained.

The proposed methods to avoid the regeneration from a Matrix Converter motor drive for aerospace applications are discussed in Chapter 4. The second section of this chapter describes how regeneration occurs in the Matrix Converter and braking methods for conventional AC-AC converters. Finally, the techniques to detect regeneration in the Matrix Converter and the proposed methods for avoiding regeneration in a Matrix Converter motor drive are investigated.

The simulation analysis of the proposed methods are described in Chapter 5. Simulation results of the two different proposed methods are presented. The comparison between two methods is depicted in the simulation results.

Chapter 6 presents the design and construction of a prototype Matrix Converter. The design of control circuit and interface circuit for the Matrix Converter motor drive is discussed in this chapter.

Testing procedures and the experimental results for the BDS method are presented in Chapter 7. 


\section{Chapter 2}

\section{Review of Matrix Converter Technology}

\section{$2.1 \quad$ Introduction}

In 1976, the basic principles of Matrix Converter technology were proposed in [5]. This work proposed a direct AC-AC converter with unrestricted output frequency. Other early papers $[6,7]$ reported that the converter topology had a maximum voltage transfer ratio of 0.5 with sinusoidal input and output waveforms. In 1986 [7], this ratio was improved with the introduction of techniques to give a maximum voltage transfer ratio of 0.866. A lot of papers discussed different schemes for the modulation of the Matrix Converters $[6,7,20]$. Only a few papers described the potential problems of the Matrix Converter, such as current commutation between the Bi-Directional Switches or protection of the Converter under fault conditions. In 1992 semi-soft commutation $[21,22]$ for Matrix Converters was proposed using four step commutation strategy. In 2001 Yaskawa Electric in Japan made Matrix Converters at low power ratings of $5.5 \mathrm{~kW}$ and $11 \mathrm{~kW}$. Currently, Yaskawa are developing higher power rated Matrix Converters at $22 \mathrm{~kW}$ and $45 \mathrm{~kW}$ [23]. The $22 \mathrm{~kW}$ unit is a commercial product sold for lift applications. 
Recently, the Matrix Converter has been considered for many commercial, industrial [24] and aerospace applications, due to the potential advantages.

The first section of this chapter describes the fundamentals of the Matrix Converter. This section outlines the structure of the Matrix Converter, as well as the special features of the Converter. The second section of this chapter compares the Matrix Converter to conventional converters, such as DC-Link converters and other topologies.

The third section of this chapter describes a range of modulation strategies for the Matrix Converter, such as the Venturini algorithm, the scalar control algorithm and Space Vector Modulation (SVM). The final section discusses the construction of the Matrix Converter. This section outlines the different types of bi-directional switches and current commutation techniques. 


\subsection{Fundamentals of the Matrix Converter}

This section describes the main components and the significant features of the Matrix Converter.

\subsubsection{Structure of the Matrix Converter}

A practical Matrix Converter has three main components:

- Power circuit.

- Input filter.

- Clamp circuit.

\section{Power Circuit :}

The Matrix Converter is a single stage, direct AC - AC power converter which is capable of converting an input voltage waveform into a variable output voltage with unrestricted output frequency, within the limits imposed by the switching frequency. For three phase systems the Matrix Converter comprises nine bi-directional switches arranged in $3 \times 3$ matrix as shown in figure 2.1. The arrangement of bi-directional switches is such that any of the input phases $(\mathrm{A}, \mathrm{B}, \mathrm{C})$ can be connected to any of the output phases $(\mathrm{a}, \mathrm{b}, \mathrm{c})$ for any switching period of time. The switches are controlled in such a way that the average output voltage is a sinusoidal waveform of the desired frequency and amplitude.

Basic Rules :

The Matrix Converter consists of nine bi-directional switches with $2^{9}$ (512) possible switching states. However, only twenty seven switching states can be used because two basic rules have to be followed [19]. 


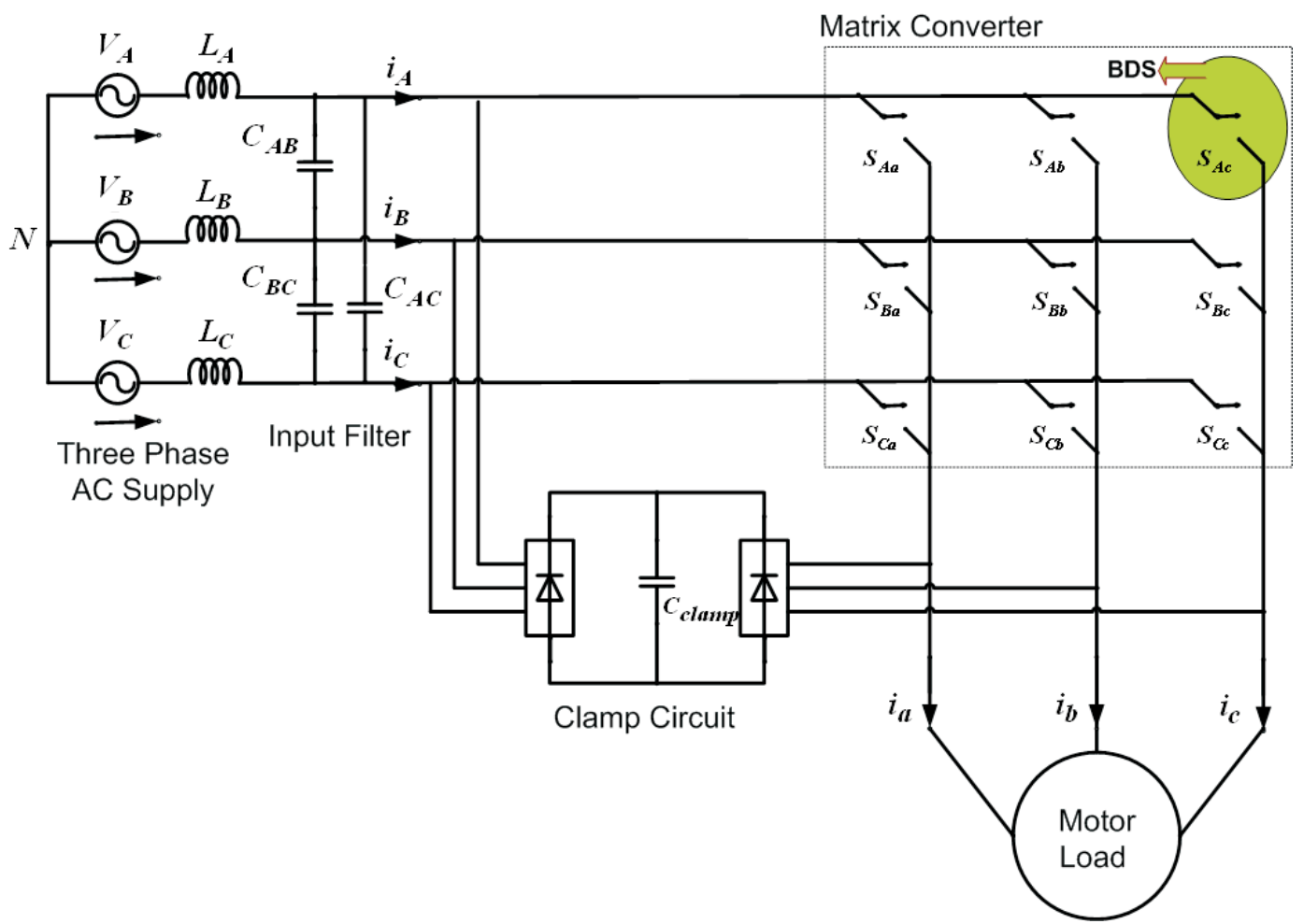

Figure 2.1: The General Structure of the Conventional Matrix Converter

- Two input phases must never be short circuited.

- Due to inductive nature of the load, output phases never be open circuit.

Therefore, each output line must always be connected to an input line. Under these basic rules, the maximum number of permitted switching states of the Matrix Converter is 27 . 


\section{Input Filter :}

Even though the Matrix Converter is sometimes referred to as an all silicon solution for AC - AC power conversion, a small input filter is necessary to reduce the switching harmonics in the input current [19]. The input filter consists of source inductances $\left(L_{A}, L_{B}, L_{C}\right)$ and line capacitors $\left(C_{A B}, C_{B C}, C_{A C}\right)$, as shown in figure 2.1.

\section{Clamp Circuit :}

The clamp circuit allows safe operation of the Matrix Converter during abnormal operating conditions. The clamp circuit connects the input side and output side to a clamp capacitor through diode bridges, as shown in figure 2.1. The Matrix Converter connects the load directly to the source $\left(V_{A}, V_{B}, V_{C}\right)$ without using any energy storage elements. There is no natural free wheeling paths in the Matrix Converter. Therefore a clamp circuit is required to store the inductive energy which may be transferred from the load in the event of turning off the converter.

When the switches are all turned off, the current in the load can suddenly be interrupted. The energy stored in the motor inductance has to be discharged without creating any dangerous over voltages. The clamp circuit is the most common solution to avoid these over voltages [25]. The capacitor, $C_{\text {clamp }}$, is used to store the energy during these abnormal operating conditions. 


\subsubsection{Features of the Matrix Converter}

Compared to the other AC - AC converter topologies, the Matrix Converter has the following significant features [19]:

- Sinusoidal input and output waveforms.

- Unity input Displacement Factor.

- Bi-directional power flow, natural four quadrant operation.

- Potential for compact design due to the lack of dc-link capacitors.

In aerospace applications regeneration onto the power system is not allowed under current power quality specifications. Therefore this thesis considers techniques for removing this inherent feature of the converter. 


\subsection{Comparison with Conventional AC-AC drives}

\subsubsection{DC-Link Converters}

DC-Link converters are commercially used in industrial applications for adjustable speed motor drive systems. DC-Link converters are two-stage converters because they convert the AC supply into a DC voltage, the rectification stage, and then this DC voltage is converted into variable voltage with variable frequency, the inversion stage.

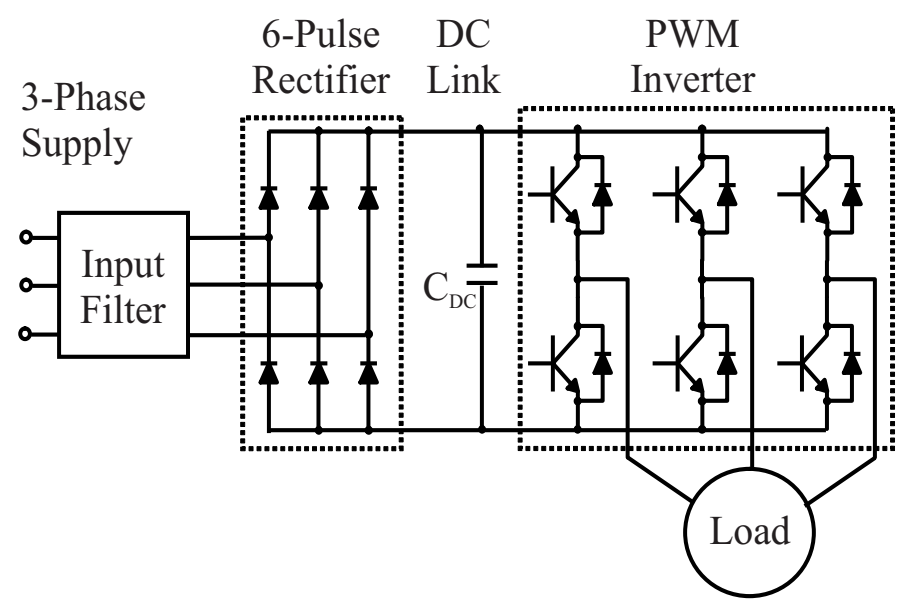

Figure 2.2: Uncontrolled 6-Pulse Rectifier with PWM Voltage Source Inverter

The regeneration is not possible $[12,26]$ when the VSI is fed from a uncontrolled rectifier, as shown in figure 2.2. In order to overcome this limitation the uncontrolled rectifier can be replaced by a controlled PWM rectifier, as shown in figure 2.3. This configuration is sometimes called a Back-to-Back VSI and is commercially available [3].

High switching operation, low dv/dt for power devices and zero voltage switching with reduced switching losses are the significant advantages of the DC-Link converters. The large DC-Link capacitors can be a problem in these converters in applications where volume and weight are important factors [27, 28]. 


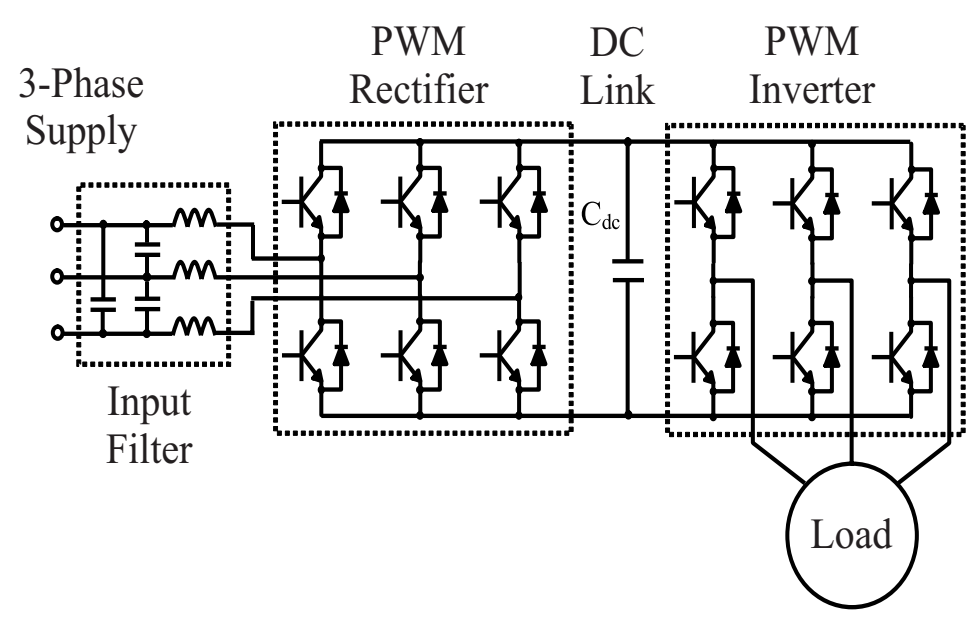

Figure 2.3: Back-to-Back Voltage Source Inverter

\subsubsection{Cycloconverters}

A cycloconverter is a direct AC - AC power converter which converts an input voltage waveform into a variable output voltage with variable frequency [17]. The circuit diagram for three phase to three phase cycloconverter is shown in figure 2.4. The cycloconverters are controlled by phase control principle $[29,30]$ so that forced commutation is not necessary. Producing wide range of output frequencies and natural commutation are the significant advantages of the cycloconverters [31, 32]. In addition, the cycloconverters can capable to supply lagging, leading and unity power factor [33]. This characteristic is similar to synchronous machine characteristic so that it is suitable to drive synchronous machines which can draw any power factor current [34].

The disadvantages of cycloconverters are :

- The output frequency of the cycloconverter is limited to $1 / 3$ of the input frequency. If the output frequency is less than $1 / 3$ of the input frequency, the output voltage is rich in harmonics [35] which leads to low input power factor, discontinuous current operation and higher switching losses. 


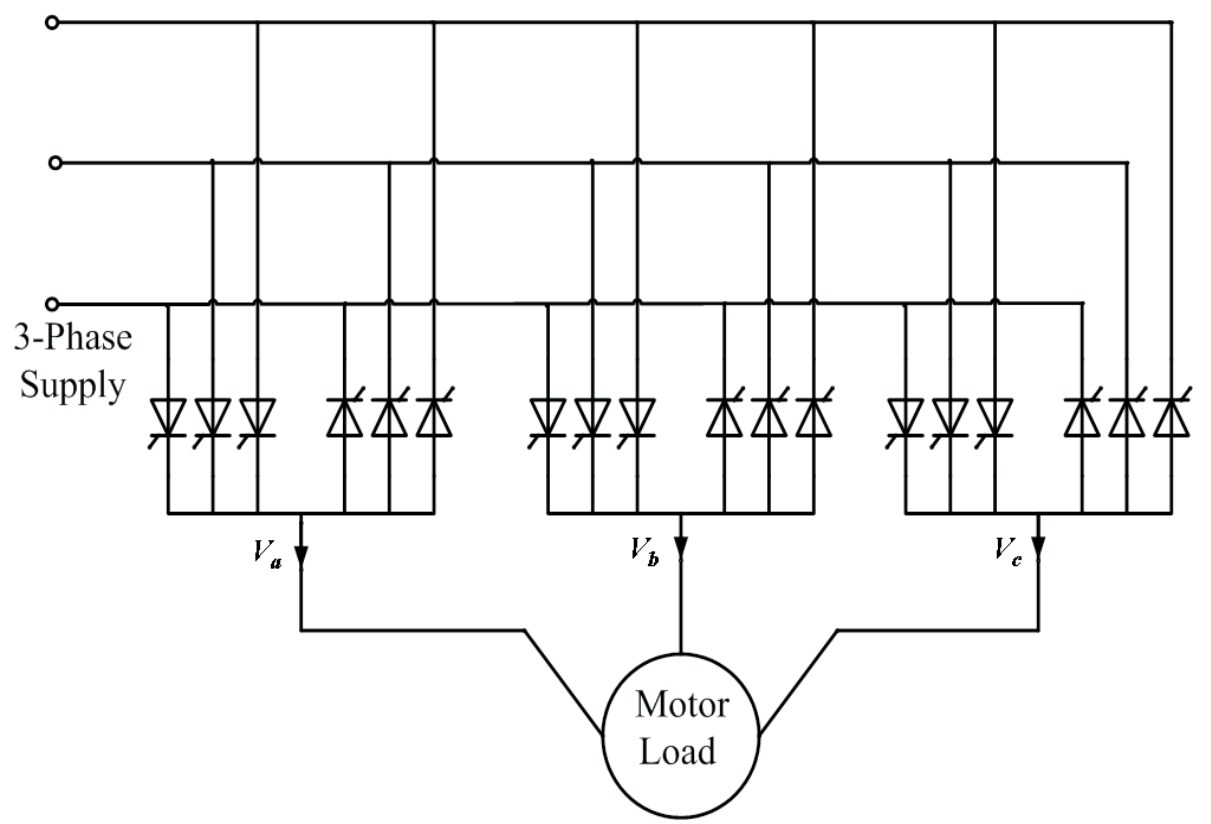

Figure 2.4: Three Phase to Three Phase Cycloconverter

- In order to avoid the circulating current in cycloconverter, a large Inter Group Reactor (IGR) is required, increasing the volume or size of the converter.

- The higher number of switching devices, especially in a three phase cycloconverter. Three phase cycloconverter requires 36 thyristors [36, 34].

Because of the above reasons, cycloconverters are not attractive in the industry except in high power applications. The above mentioned disadvantages are overcome by the conventional Matrix Converter, as discussed in section 2.2. 


\subsection{Modulation strategies}

This section describes the different modulation strategies for the Matrix Converter. These are the Venturini algorithm, the modified Venturini algorithm, the scalar control algorithm and the Space Vector Modulation (SVM) strategy.

\subsubsection{Venturini Algorithm}

The bi-directional switches of a Matrix Converter are connected so that any of the input phases (A, B, C) can be connected to any of the output phases (a, b, c). The output voltages of the Matrix Converter are therefore derived directly from the input voltages. To obtain the switching algorithm of the Matrix Converter, it can be assumed that the three input phase voltages of the Matrix Converter are balanced and symmetrical as given in equation 2.1

$$
\left[\begin{array}{c}
V_{A} \\
V_{B} \\
V_{C}
\end{array}\right]=\left[\begin{array}{c}
V_{i m} \cos \left(\omega_{i} t\right) \\
V_{i m} \cos \left(\omega_{i} t+\frac{2 \pi}{3}\right) \\
V_{i m} \cos \left(\omega_{i} t+\frac{4 \pi}{3}\right)
\end{array}\right]
$$

The target output voltages of the Matrix Converter are given in equation 2.2 for a load requiring sinusoidal waveforms.

$$
\left[\begin{array}{c}
V_{a} \\
V_{b} \\
V_{c}
\end{array}\right]=\left[\begin{array}{c}
V_{o m} \cos \left(\omega_{o} t\right) \\
V_{o m} \cos \left(\omega_{o} t+\frac{2 \pi}{3}\right) \\
V_{o m} \cos \left(\omega_{o} t+\frac{4 \pi}{3}\right)
\end{array}\right]
$$

where $\omega_{i}$ and $\omega_{o}$ are the angular frequencies of input and output voltages of the Matrix Converter respectively. The relationship between the output voltage $\left(V_{o}\right)$ and the input voltage $\left(V_{i}\right)$ can be written, as shown in equation 2.3

$$
V_{o}(t)=M(t) \cdot V_{i}(t)
$$


where $\mathrm{M}(\mathrm{t})$ is the transfer matrix given in equation 2.4

$$
M(t)=\left[\begin{array}{ccc}
M_{A a} & M_{B a} & M_{C a} \\
M_{A b} & M_{B b} & M_{C b} \\
M_{A c} & M_{B c} & M_{C c}
\end{array}\right]
$$

$M_{A a}\left(=\frac{t_{A a}}{T_{s}}\right)$, is the duty cycle of switch $S_{A a} . T_{s}$ is the sampling period. The instantaneous relationship between the input currents and output currents can be given in equation 2.5 and 2.6

$$
\begin{gathered}
{\left[\begin{array}{c}
i_{A}(t) \\
i_{B}(t) \\
i_{C}(t)
\end{array}\right]=\left[\begin{array}{ccc}
M_{A a}(t) & M_{A b}(t) & M_{A c}(t) \\
M_{B a}(t) & M_{B b}(t) & M_{B c}(t) \\
M_{C a}(t) & M_{C b}(t) & M_{C c}(t)
\end{array}\right]\left[\begin{array}{c}
i_{a}(t) \\
i_{b}(t) \\
i_{c}(t)
\end{array}\right]} \\
I_{\text {in }}=M^{T} I_{o}
\end{gathered}
$$

Where $M^{T}$ is the transpose of the matrix $\mathrm{M}(\mathrm{t})$. The duty cycles must satisfy the following conditions in order to avoid short circuits on the input side of the converter or open circuit on the output side:

$$
\begin{aligned}
M_{A a}+M_{B a}+M_{C a} & =1 \\
M_{A b}+M_{B b}+M_{C b} & =1 \\
M_{A c}+M_{B c}+M_{C c} & =1
\end{aligned}
$$

The Venturini algorithm [37] modulates the switches according to the desired output voltage and output frequency. The equations to calculate the duty cycles for the nine switches are :

$$
\begin{aligned}
M_{A a} & =\frac{1}{3}\left(1+2 q \cos \left(\omega_{m} t+\theta\right)\right) \\
M_{B a} & =\frac{1}{3}\left(1+2 q \cos \left(\omega_{m} t+\theta-\frac{2 \pi}{3}\right)\right) \\
M_{C a} & =\frac{1}{3}\left(1+2 q \cos \left(\omega_{m} t+\theta-\frac{4 \pi}{3}\right)\right)
\end{aligned}
$$




$$
\begin{aligned}
& M_{A b}=\frac{1}{3}\left(1+2 q \cos \left(\omega_{m} t+\theta-\frac{4 \pi}{3}\right)\right) \\
& M_{B b}=\frac{1}{3}\left(1+2 q \cos \left(\omega_{m} t+\theta\right)\right) \\
& M_{C b}=\frac{1}{3}\left(1+2 q \cos \left(\omega_{m} t+\theta-\frac{2 \pi}{3}\right)\right) \\
& M_{A c}=\frac{1}{3}\left(1+2 q \cos \left(\omega_{m} t+\theta-\frac{2 \pi}{3}\right)\right) \\
& M_{B c}=\frac{1}{3}\left(1+2 q \cos \left(\omega_{m} t+\theta-\frac{4 \pi}{3}\right)\right) \\
& M_{C c}=\frac{1}{3}\left(1+2 q \cos \left(\omega_{m} t+\theta\right)\right)
\end{aligned}
$$

where $\omega_{m}=\omega_{o}-\omega_{i}$, is the modulation frequency, $\theta$ is the relative phase of the output and $q$ is the voltage transfer ratio. The output voltages of Matrix Converter can then be written as :

$$
\begin{aligned}
V_{a}(t) & =M_{A a} V_{A}(t)+M_{B a} V_{B}(t)+M_{C a} V_{C}(t) \\
V_{b}(t) & =M_{A b} V_{A}(t)+M_{B b} V_{B}(t)+M_{C b} V_{C}(t) \\
V_{c}(t) & =M_{A c} V_{A}(t)+M_{B c} V_{B}(t)+M_{C c} V_{C}(t)
\end{aligned}
$$

The switching arrangement which were derived by Venturini [6]:

$$
[M 1(t)]=\frac{1}{3}\left[\begin{array}{ccc}
1+2 q \cos \left(\omega_{m} t\right) & 1+2 q \cos \left(\omega_{m} t-\frac{2 \pi}{3}\right) & 1+2 q \cos \left(\omega_{m} t-\frac{4 \pi}{3}\right) \\
1+2 q \cos \left(\omega_{m} t-\frac{4 \pi}{3}\right) & 1+2 q \cos \left(\omega_{m} t\right) & 1+2 q \cos \left(\omega_{m} t-\frac{2 \pi}{3}\right) \\
1+2 q \cos \left(\omega_{m} t-\frac{2 \pi}{3}\right) & 1+2 q \cos \left(\omega_{m} t-\frac{4 \pi}{3}\right) & 1+2 q \cos \left(\omega_{m} t\right)
\end{array}\right]
$$

with $\omega_{m}=\left(\omega_{o}-\omega_{i}\right)$

$$
[M 2(t)]=\frac{1}{3}\left[\begin{array}{ccc}
1+2 q \cos \left(\omega_{m} t\right) & 1+2 q \cos \left(\omega_{m} t-\frac{2 \pi}{3}\right) & 1+2 q \cos \left(\omega_{m} t-\frac{4 \pi}{3}\right) \\
1+2 q \cos \left(\omega_{m} t-\frac{2 \pi}{3}\right) & 1+2 q \cos \left(\omega_{m} t-\frac{4 \pi}{3}\right) & 1+2 q \cos \left(\omega_{m} t\right) \\
1+2 q \cos \left(\omega_{m} t-\frac{4 \pi}{3}\right) & 1+2 q \cos \left(\omega_{m} t\right) & 1+2 q \cos \left(\omega_{m} t-\frac{2 \pi}{3}\right)
\end{array}\right]
$$

with $\omega_{m}=\left(\omega_{o}+\omega_{i}\right)$.

Where $q$ is the voltage transfer ratio, $\omega_{i}$ and $\omega_{o}$ are the input and output frequencies and $\phi_{i}$ and $\phi_{o}$ are the input and output phase displacement angles respectively. 
The solution in (2.7) yields $\phi_{i}=\phi_{o}$ giving the same phase displacement at the input and output of the converter whereas the solution in (2.8) yields $\phi_{i}=-\phi_{o}$ giving reversed phase displacement at the input. Combining the two switching arrangement provides the means for input displacement factor control.

$$
[M(t)]=\alpha_{1}[M 1(t)]+\alpha_{2}[M 2(t)] \quad \text { where } \alpha_{1}+\alpha_{2}=1
$$

Setting $\alpha_{1}=\alpha_{2}$ gives unity input displacement factor regardless of the load displacement factor. Other possibilities exist, through the choice of $\alpha_{1}$ and $\alpha_{2}$, to have a leading or lagging displacement factor at the input with a inductive load at the output.

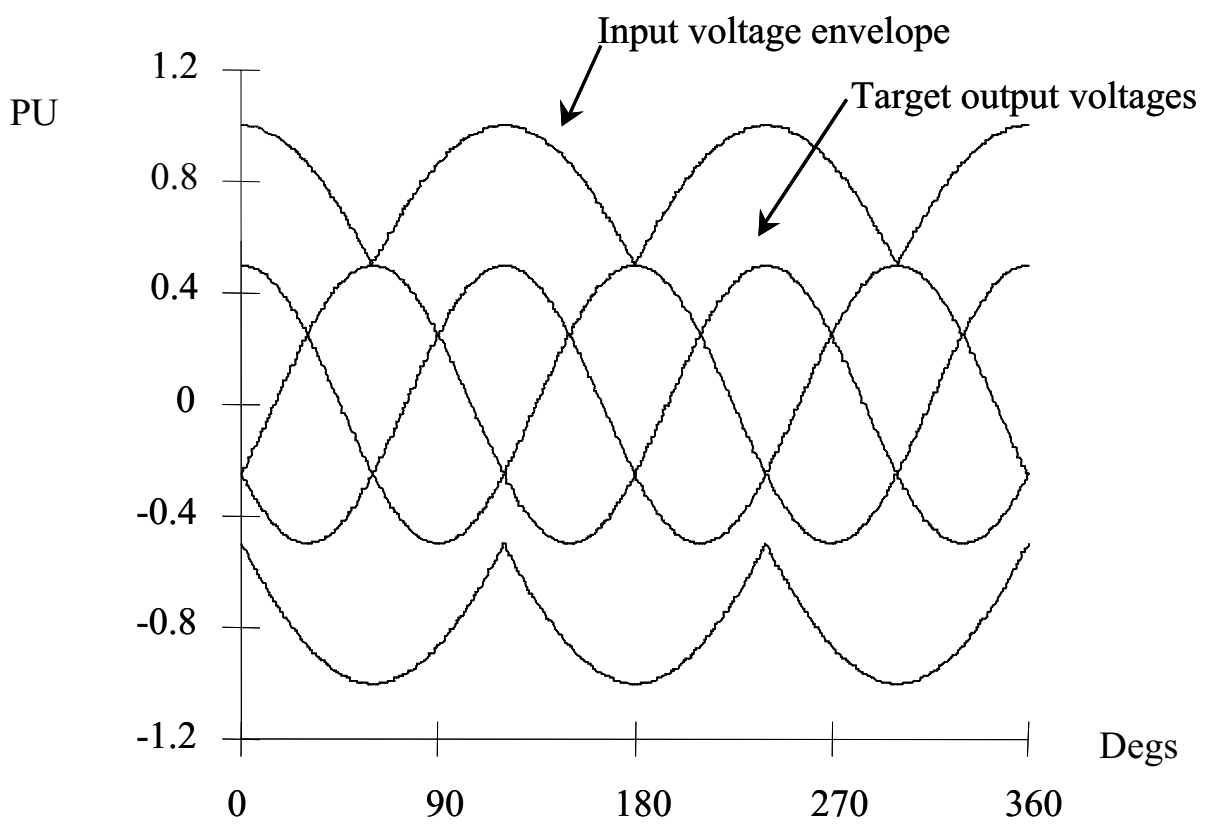

Figure 2.5: Theoretical Waveforms Illustrating the 50 \% Voltage Transfer Limit

For $\alpha_{1}=\alpha_{2}$ the modulation functions can be expressed in a compact form :

$$
M_{\beta \alpha}=\frac{T_{\beta \alpha}}{T_{s e q}}=\frac{1}{3}\left(1+\frac{2 V_{o \alpha} V_{i \beta}}{V_{i m}^{2}}\right) \quad \text { for } \beta=A, B, C \text { and } \alpha=a, b, c
$$

The modulation algorithm defined by (2.10) operates such that, during each switching sequence, the average output voltages (taken over the switching sequence) equal the 
target output voltages $\left[v_{o}(t)\right]$. For this to be possible the target output voltages must fit within the input voltage envelope for all operating conditions. Using this solution the maximum value of input to output voltage ratio $(q)$ that the converter can achieve is 50\%, as shown in Figure 2.5. The algorithm (2.10) is ideally suited for real time implementation of this basic method but is of little practical use because of the $50 \%$ voltage transfer ratio limitation.
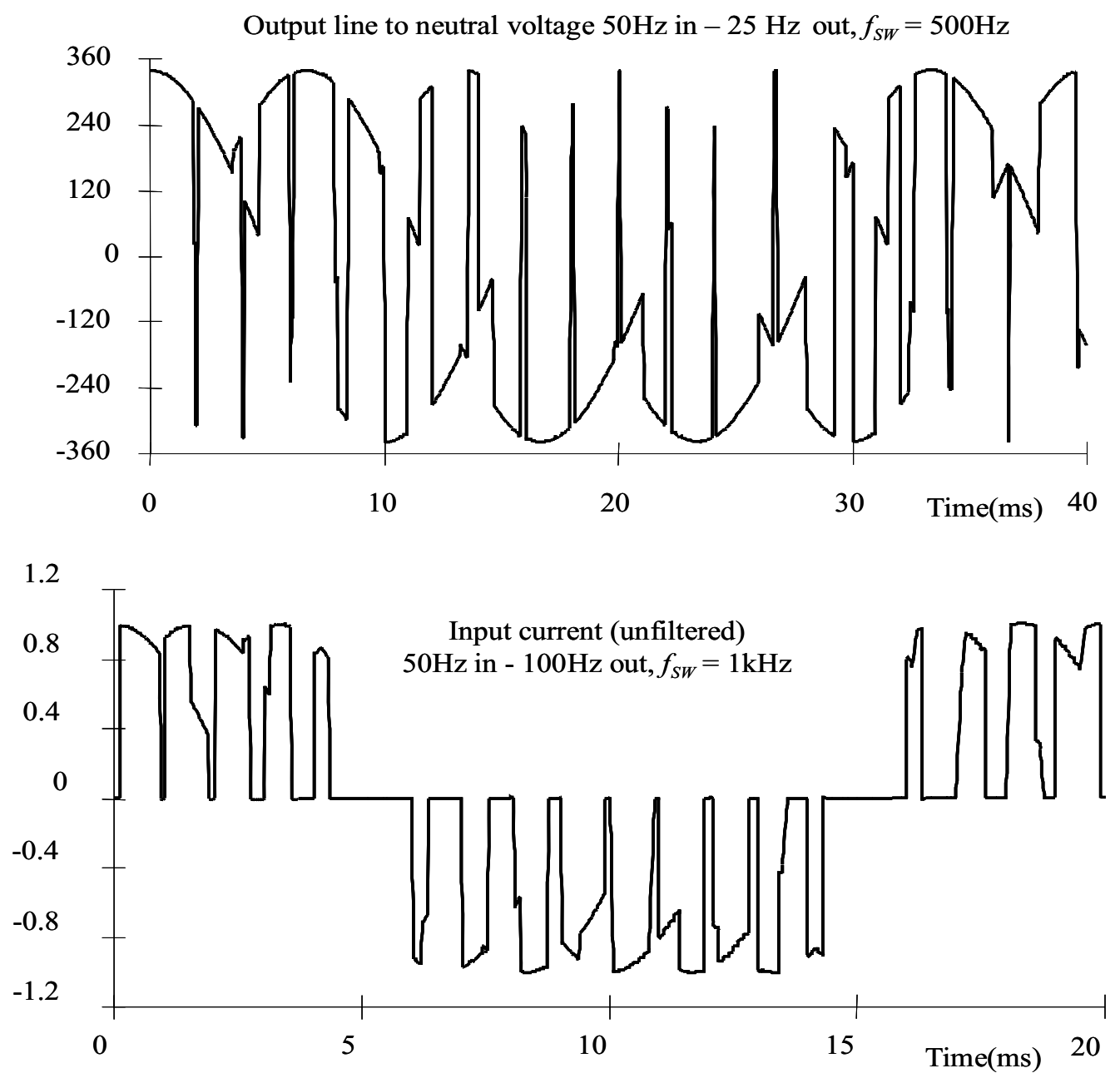

Figure 2.6: Example of Typical Matrix Converter Waveforms

The output waveforms of the matrix converter are formed by selecting each of the input phases in sequence for defined periods of time. Typical waveforms for a relatively low switching frequency are shown in Figure 2.6. 


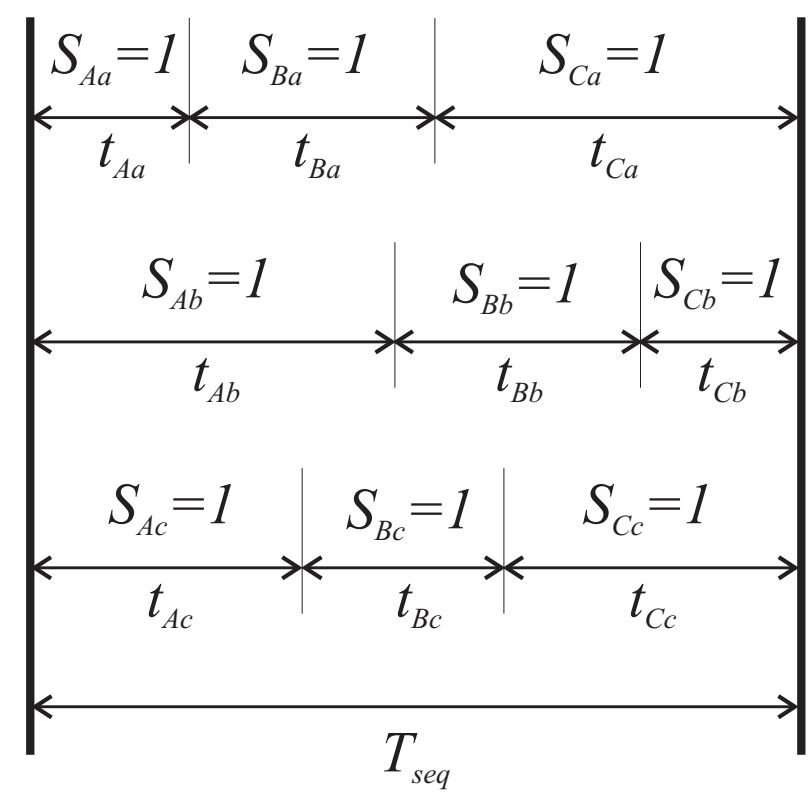

Figure 2.7: General Form of Switching Pattern

The output voltage consists of segments made up from the three input voltages. The input current consists of segments of the three output currents plus blank periods during which the output current freewheels through the switch matrix. There is normally a fixed repeat period for the switch sequence, $T_{\text {seq }}$ which is analogous to the carrier period in conventional PWM. The switching pattern normally follows something similar to that shown in Figure 2.7. To determine the average behaviour of the converter at output frequencies well below the switching frequency a modulation duty cycle can be defined for each switch (eg. $M_{A a}(t)=\frac{t_{A a}}{T_{s e q}}$ where $t_{A a}$ refers to the time for which $S_{A a}$ is ON and $T_{s e q}$ is the sequence time of the PWM pattern). These continuous time functions can then be used to define and compare the modulation strategies, as set out in equation 2.5.

The maximum peak-to-peak output voltage should be contained within the continuous envelope of input voltages, as shown in figure 2.5. This condition restricts the maximum voltage transfer ratio of the Matrix Converter to 0.5 [6]. To overcome this limitation the modified Venturini algorithm was proposed by Alesina and Venturini $[7]$. 


\subsubsection{Modified Venturini Algorithm}

The maximum possible voltage transfer ratio of the Matrix Converter, 0.866, can be achieved by injecting the third harmonics of the input and output frequencies onto the target output waveforms [7]. Hence the output target voltages can be allowed to use the maximum of input voltage envelope, as shown in the figure 2.8.

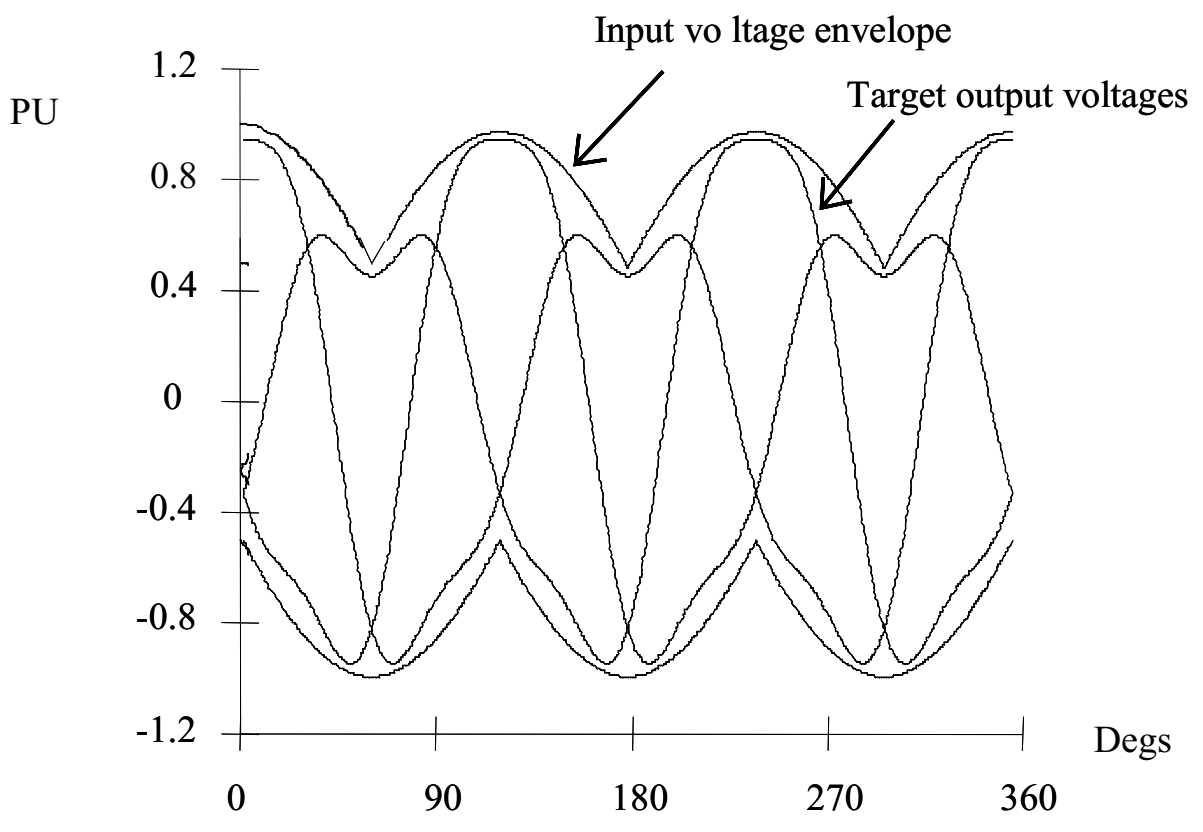

Figure 2.8: Theoretical Waveforms Illustrating 87 \% Voltage Transfer Limit

The injection of the third harmonic does not affect the operation of the load since there is no neutral connection between the supply and the load.

The target output phase voltages $\left(V_{o \alpha}\right)$ become :

$$
V_{o \alpha}=q V_{i m} \cos \left(\omega_{o} t+\psi_{\alpha}\right)-\frac{q}{6} V_{i m} \cos \left(3 \omega_{o} t\right)+\frac{q}{4 q_{m}} V_{i m} \cos \left(3 \omega_{i} t\right)
$$

where $\psi_{\alpha}=0,2 \pi / 3,4 \pi / 3$; corresponding to output phases (a, b, c) respectively. 
The switching times $\left(T_{\beta \alpha}\right)$ for voltage transfer ratio of 0.866 is given in equation 2.12,

$$
T_{\beta \alpha}=\frac{T_{s}}{3}\left[1+\frac{2 V_{o \alpha} V_{i \beta}}{V_{i m}^{2}}+\frac{2 q}{3 q_{m}} \sin \left(\omega_{i} t+\psi_{\beta}\right) \sin \left(3 \omega_{i} t\right)\right]
$$

where $\psi_{\beta}: 0,2 \pi / 3,4 \pi / 3$ corresponding to input phases $(\mathrm{A}, \mathrm{B}, \mathrm{C})$ respectively, $q_{m}$ is the maximum voltage ratio (0.866), q is the required voltage transfer ratio, $V_{i m}$ is the input voltage vector magnitude and $T_{s}$ is the sampling period.

\subsubsection{Scalar Modulation Algorithm}

The scalar modulation algorithm is based on the instantaneous ratio of measured input phase voltages to calculate the duty cycles of the bi-directional switches in the Matrix Converter as proposed in [38] and [39].

According to this algorithm, two basic rules must be followed :

- Subscript Z is assigned to the input phase which has a different polarity to the other input phases.

- Subscripts X and Y are assigned to the same polarity input phases. The absolute value of $\mathrm{Y}$ is greater than $\mathrm{X}$.

Equation 2.13 gives the average value of output phase voltage,

$$
V_{o \alpha}=V_{o m} \cos \left(\omega_{o} t\right)
$$

where $\alpha=0,2 \pi / 3,4 \pi / 3$, corresponding to the output phases (a, b, c) respectively.

In each sampling period, the target output voltage should satisfy the condition given equation in 2.14

$$
V_{o \alpha}=\frac{1}{T_{s}}\left[M_{X} V_{X}+M_{Y} V_{Y}+M_{Z} V_{Z}\right]=V_{o m} \cos \left(\omega_{o} t\right)
$$


where $T_{s}=M_{X}+M_{Y}+M_{Z}$

The duty cycles can then be calculated using below equations 2.15 :

$$
\begin{aligned}
M_{Y} & =\frac{\left(V_{o \alpha}-V_{Z}\right) V_{Y}}{1.5 V_{i} m^{2}} \\
M_{X} & =\frac{\left(V_{o \alpha}-V_{Z}\right) V_{X}}{1.5 V_{i} m^{2}} \\
M_{Z} & =T_{s}-\left(M_{Y}+M_{X}\right)
\end{aligned}
$$

As shown in equation 2.15, the scalar modulation algorithm depends on the scalar value of the instantaneous input phase voltages. The scalar algorithm is capable of operating the Matrix Converter with the maximum voltage transfer ratio of 0.866 .

Again, common-mode addition is used with the target output voltages $V_{o \alpha}$ to achieve $87 \%$ voltage ratio capability. Despite the apparent differences, this method yields virtually identical switch timings to the optimum Venturini method. Expressed in the form of 2.12, the modulation duty cycles for the scalar method are given in 2.16.

$$
\begin{gathered}
T_{\beta \alpha}=\frac{1}{3}\left(1+\frac{2 V_{o \alpha} V_{i \beta}}{V_{i m}^{2}}+\frac{2}{3} \sin \left(\omega_{i} t+\psi_{\beta}\right) \sin \left(3 \omega_{i} t\right)\right) \quad \text { for } \beta=A, B, C \text { and } \alpha=a, b, c \\
\psi_{\beta}=0, \frac{2 \pi}{3}, \frac{4 \pi}{3} \text { for } \beta=A, B, C \text { respectively }
\end{gathered}
$$

At maximum output voltage $\left(q=\frac{\sqrt{3}}{2}\right), 2.12$ and 2.16 are identical. The only difference between the methods is that the right most term is used in conjunction with $q$ in the Venturini method and is fixed at its maximum value in the scalar method. In practice the effect on output voltage is negligible. 


\subsubsection{Space Vector Modulation}

The space vector modulation method (SVM) is well known in conventional PWM inverters and has its roots in the space phasor method of representing and analysing 3 -phase machines. This method of analysis is particularly popular with researchers in the area of field orientated (or vector) control since it allows visualization of the spatial and time relationships between the resultant current and flux vectors (or space phasors) in various reference frames. SVM was first used with matrix converters in [40] where this new PWM control technique for Matrix Converters was introduced based on the space vector representation of the voltages.

\subsubsection{Space Phasors}

The voltage space phasor of the target output voltages is defined, in terms of the line to line voltages, by 2.17 .

$$
\overrightarrow{\mathbf{V}}_{o}(t)=\frac{2}{3}\left(v_{a b}+a v_{b c}+a^{2} v_{c a}\right) \quad \text { where } a=e^{j 2 \pi / 3}
$$

On an Argand diagram, multiplication by $a$ corresponds to ' $a$ ' rotation of $120^{\circ}$ and ' $a$ ', by $240^{\circ}$. On the same diagram, $\overrightarrow{\mathbf{V}}_{o}(t)$ is a vector of constant length $\left(q V_{i m} \sqrt{3}\right)$ rotating at frequency $\omega_{o}$. The basis of the space vector modulation is that the possible output voltages for the converter (for each permissible switching state) are expressed in the same form as 2.17. At each sampling instant, the position of $\overrightarrow{\mathbf{V}}_{o}(t)$ is compared with the possible vectors and the desired output voltage is synthesised by time averaging (within the switching interval) between adjacent vectors to give the correct mean voltage. This is a relatively simple process for a conventional DC link inverter since there are only eight possible switching states. Two of these give zero volts (termed zero vectors) and the others are at the vertices of a regular hexagon. The locations and length of the possible output space vectors are fixed in the case of a DC link inverter. The situation with a Matrix Converter is more complex since there are twenty seven possible switching states and the input voltages are time varying. 


\subsubsection{Matrix Converter Output Space Phasors}

The 27 possible switching states for a 3-phase to 3-phase Matrix Converter together with the resulting output voltages are tabulated in Table 2.1.

From this table, the output voltage states may be split into three groups:

Group I Each output line is connected to a different input line

- constant amplitude, rotating (in either direction) at the supply angular frequency

Group II Two output lines are connected to a common input line, the remaining output line is connected to one of the other two input lines - varying amplitude, fixed position occupying one of 6 positions regularly spaced $60^{\circ}$ apart.

Group III All output lines are connected to the same input line

- zero amplitude at the origin

\subsubsection{Selection of Switching States}

The method used to select the vectors to produce the desired output voltage at each sampling instant is not unique. A simple method is described here. Other more complex methods, giving better performance are possible [41] but the underlying concept is the same.

The rotating vectors of Group I are not used. Group II vectors are split into three sub-groups as shown in Table 2.1. The six states in each sub-group produce a space phasor along a defined direction. For the three sub-groups the directions are mutually displaced by $120^{\circ}$. The amplitude and polarity of the space phasor along the defined direction depends on which of the line to line voltages is used. This yields the hexagon of possible vectors, as shown in figure 2.9. For example, subgroup IIa can produce 


\begin{tabular}{|c|c|c|c|c|c|c|}
\hline \multirow[t]{2}{*}{ Group } & \multicolumn{3}{|c|}{$\begin{array}{c}\text { Output phase } \\
\text { voltages }\end{array}$} & \multicolumn{3}{|c|}{$\begin{array}{l}\text { Output line to } \\
\text { line voltages }\end{array}$} \\
\hline & $v_{a}$ & $v_{b}$ & $v_{c}$ & $v_{a b}$ & $v_{b c}$ & $v_{c a}$ \\
\hline \multirow{6}{*}{ I } & $v_{A}$ & $v_{B}$ & $v_{C}$ & $v_{A B}$ & $v_{B C}$ & $v_{C A}$ \\
\hline & $v_{A}$ & $v_{C}$ & $v_{B}$ & $-v_{C A}$ & $-v_{B C}$ & $-v_{A B}$ \\
\hline & $v_{B}$ & $v_{A}$ & $v_{C}$ & $-v_{A B}$ & $-v_{C A}$ & $-v_{B C}$ \\
\hline & $v_{B}$ & $v_{C}$ & $v_{A}$ & $v_{B C}$ & $-v_{C A}$ & $v_{A B}$ \\
\hline & $v_{C}$ & $v_{A}$ & $v_{B}$ & $v_{C A}$ & $v_{A B}$ & $v_{B C}$ \\
\hline & $v_{C}$ & $v_{B}$ & $v_{A}$ & $-v_{B C}$ & $-v_{A B}$ & $-v_{C A}$ \\
\hline \multirow{6}{*}{ IIa } & $v_{A}$ & $v_{A}$ & $v_{B}$ & 0 & $v_{A B}$ & $-v_{A B}$ \\
\hline & $v_{A}$ & $v_{A}$ & $v_{C}$ & 0 & $-v_{C A}$ & $v_{C A}$ \\
\hline & $v_{B}$ & $v_{B}$ & $v_{A}$ & 0 & $-v_{A B}$ & $v_{A B}$ \\
\hline & $v_{B}$ & $v_{B}$ & $v_{C}$ & 0 & $v_{B C}$ & $-v_{B C}$ \\
\hline & $v_{C}$ & $v_{C}$ & $v_{A}$ & 0 & $v_{C A}$ & $-v_{C A}$ \\
\hline & $v_{C}$ & $v_{C}$ & $v_{B}$ & 0 & $-v_{B C}$ & $v_{B C}$ \\
\hline \multirow{6}{*}{ IIb } & $v_{B}$ & $v_{A}$ & $v_{A}$ & $-v_{A B}$ & 0 & $v_{A B}$ \\
\hline & $v_{C}$ & $v_{A}$ & $v_{A}$ & $v_{C A}$ & 0 & $-v_{C A}$ \\
\hline & $v_{A}$ & $v_{B}$ & $v_{B}$ & $v_{A B}$ & 0 & $-v_{A B}$ \\
\hline & $v_{C}$ & $v_{B}$ & $v_{B}$ & $-v_{B C}$ & 0 & $v_{B C}$ \\
\hline & $v_{A}$ & $v_{C}$ & $v_{C}$ & $-v_{C A}$ & 0 & $v_{C A}$ \\
\hline & $v_{B}$ & $v_{C}$ & $v_{C}$ & $v_{B C}$ & 0 & $-v_{B C}$ \\
\hline \multirow{6}{*}{ IIc } & $v_{A}$ & $v_{B}$ & $v_{A}$ & $v_{A B}$ & $-v_{A B}$ & 0 \\
\hline & $v_{A}$ & $v_{C}$ & $v_{A}$ & $-v_{C A}$ & $v_{C A}$ & 0 \\
\hline & $v_{B}$ & $v_{A}$ & $v_{B}$ & $-v_{A B}$ & $v_{A B}$ & 0 \\
\hline & $v_{B}$ & $v_{C}$ & $v_{B}$ & $v_{B C}$ & $-v_{B C}$ & 0 \\
\hline & $v_{C}$ & $v_{A}$ & $v_{C}$ & $v_{C A}$ & $-v_{C A}$ & 0 \\
\hline & $v_{C}$ & $v_{B}$ & $v_{C}$ & $-v_{B C}$ & $v_{B C}$ & 0 \\
\hline \multirow{3}{*}{ III } & $v_{A}$ & $v_{A}$ & $v_{A}$ & 0 & 0 & 0 \\
\hline & $v_{B}$ & $v_{B}$ & $v_{B}$ & 0 & 0 & 0 \\
\hline & $v_{C}$ & $v_{C}$ & $v_{C}$ & 0 & 0 & 0 \\
\hline
\end{tabular}

Table 2.1: Switching states for a 3-phase to 3-phase matrix converter 


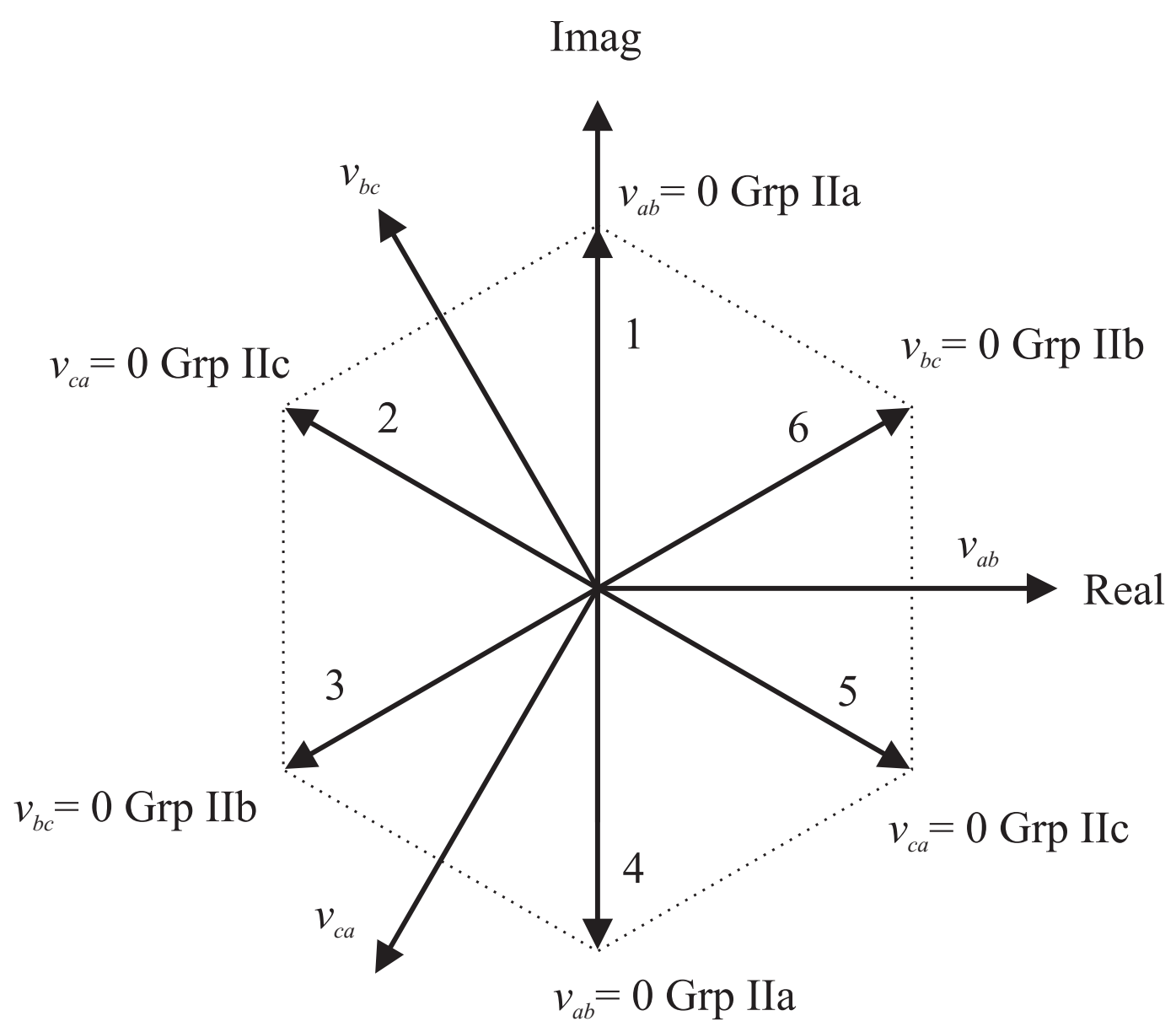

Figure 2.9: Output voltage space vectors 
vector 1 or 4 . A number of switching states will produce each of these vectors but at any instant in time only one choice of switching state (for each vector) will maximize the length of the vector. This occurs when the input line to line voltage that is selected is the one with the maximum amplitude and the output therefore follows the rectified envelope of the input voltages, as shown in figure 2.8.

For example, consider a time when $v_{a b}$ is the most positive line to line voltage. Selecting the first state in subgroup IIa will produce a maximum length vector in direction 1 - selecting the third state in subgroup IIa will produce a vector in direction 4 . Similarly, selecting the first state in subgroup IIb will produce a maximum length vector in direction 3 and so on. Only the maximum length vectors in each of the directions 1 to 6 are used in this simple example. The length of these vectors is $\frac{2}{\sqrt{3}} V_{\text {env }}$ where $V_{e n v}$ is the instantaneous value of the rectified envelope.

To determine the modulation times, the position and length of the desired output voltage vector, $\overrightarrow{\mathbf{V}}_{o}(t)$, is determined at the start of the sampling interval $\left(T_{s e q}\right)$. The correct output voltage is then synthesised by switching between the two adjacent maximum length vectors from group II and one or more of the zero vectors from group III. For example, consider a time when $\overrightarrow{\mathbf{V}}_{o}(t)$ lies in the sextant between vector 1 and vector 6 as shown, in figure 2.10. $\overrightarrow{\mathbf{V}}_{o}(t)$ is generated from a weighted sum of the 1 and 6 vectors. The weighting is achieved through time averaging by choosing the time spent in vector $1\left(t_{1}\right)$ and vector $6\left(t_{6}\right)$ during the switching sequence. From figure 2.10 (applying the sine rule) the relationship in (2.18) is found.

$$
\frac{2}{\sqrt{3}} \frac{t_{1}}{T_{\text {seq }}} \frac{V_{\text {env }}}{\sin (\theta)}=\frac{2}{\sqrt{3}} \frac{t_{6}}{T_{\text {seq }}} \frac{V_{\text {env }}}{\sin \left(\frac{\pi}{3}-\theta\right)}=\frac{\overrightarrow{\mathbf{V}}_{o}}{\sin \left(\frac{2 \pi}{3}-\theta\right)}
$$

which yields:

$$
\left.t_{1}=\frac{\overrightarrow{\mathbf{V}}_{o}}{V_{\text {env }}} T_{\text {seq }} \sin (\theta) \quad \text { and } \quad t_{6}=\frac{\overrightarrow{\mathbf{V}}_{o}}{V_{\text {env }}} T_{\text {seq }} \sin \left(\frac{\pi}{3}-\theta\right)\right)
$$

then:

$$
t_{0}=T_{s e q}-\left(t_{1}+t_{6}\right)
$$

where $t_{0}$ is the time spent in the zero vector. 


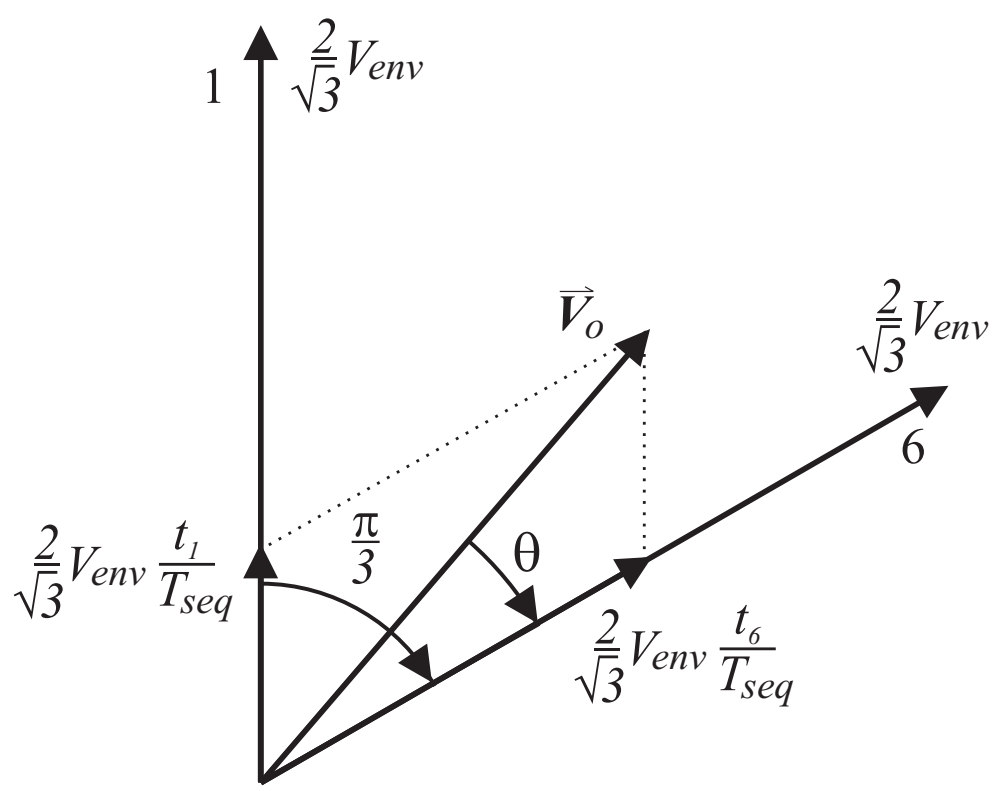

Figure 2.10: Synthesis of output voltage space phasor

There is no unique way in which the times $\left(t_{1}, t_{6}, t_{0}\right)$ have to be distributed within the switching sequence. A method suggested by some authors is to arrange them symmetrically with the zero state in the middle, as shown in figure 2.11. However,

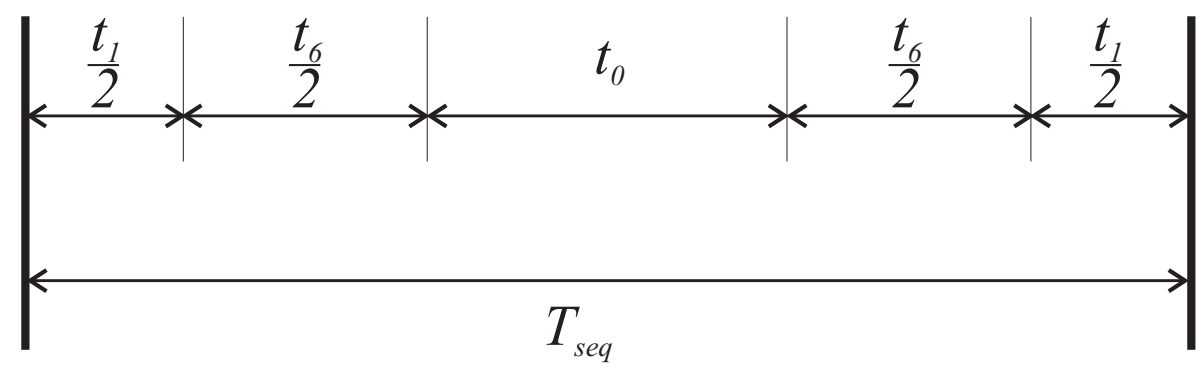

Figure 2.11: Possible way of allocating states within the switching sequence

several variations of the space vector modulation method have been proposed. These more sophisticated methods take into account the desired input current direction making it possible to draw sinusoidal input currents with controllable displacement factor. 


\subsection{Converter Construction}

This section describes the different configurations which can be used for the bidirectional switches needed in a Matrix Converter.

\subsubsection{Structure of Bi-Directional Switches}

As mentioned in section 2.2, the realization of the Matrix Converter requires a bidirectional switch which is capable of blocking voltage and conducting current in both directions. Since no such device is available the switch has to be constructed using discrete semiconductor switching devices [42].

\subsubsection{Diode Embedded Bi-Directional Switch}

The diode embedded bi-directional switch consists of a single IGBT switch and a diode bridge, as shown in figure 2.12 [19]. The main advantage of this bi-directional switch

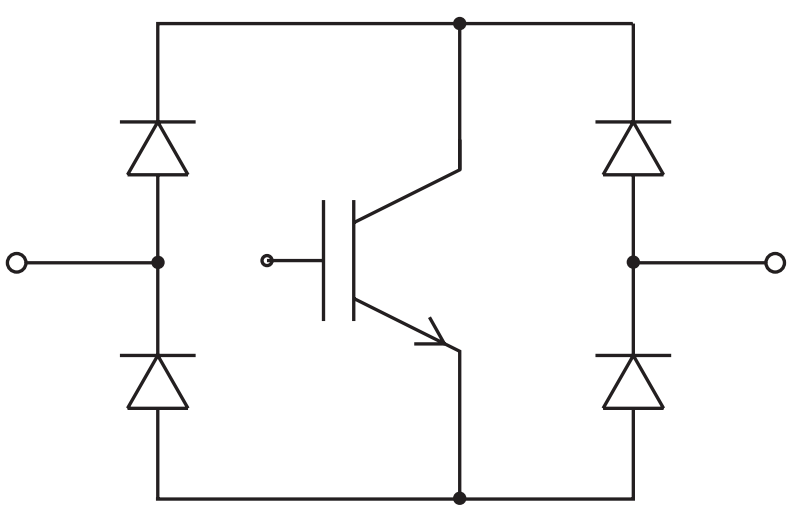

Figure 2.12: Diode Embedded Bi-Directional Switch

is the simple configuration when compared to other bi-directional switch structures and requires only one active (uni-directional) controlled switching device. 
The main disadvantage of the configuration is the high conduction loss due to the conduction of three devices in the current conduction path through the switch.

\subsubsection{Common Emitter Bi-Directional Switch}

The common emitter bi-directional switch configuration is formed from two IGBTs connected in back to back in such a way that they form a common emitter mode and two anti parallel diodes which have inherent reverse blocking capability, as shown in figure 2.13 .

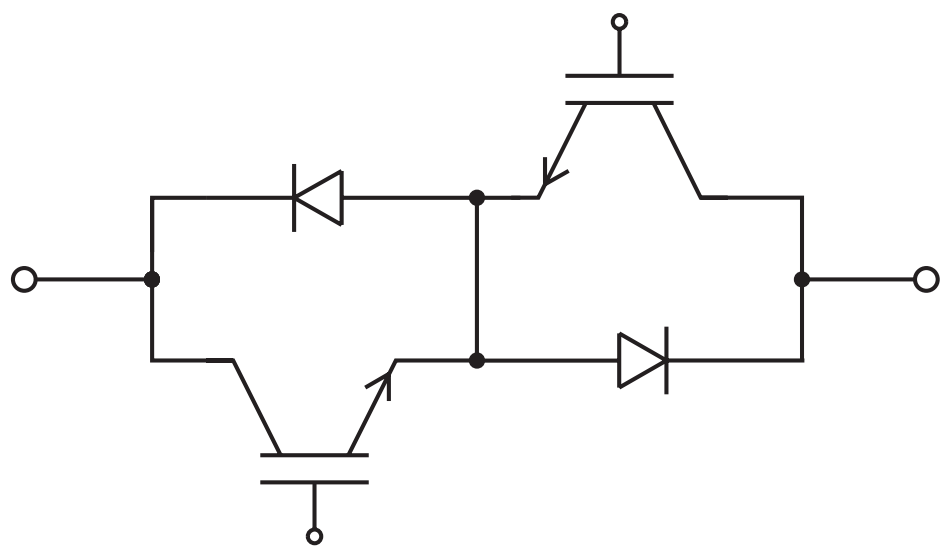

Figure 2.13: Common Emitter Bi-Directional Switch

The advantages of this configuration are :

- The direction of current through the switch is controllable.

- Lower conduction losses when compared to the diode embedded bi-directional switch because only two devices are conducing at any given time.

The disadvantage of this configuration is that more gate drive power supplies are required when compared to common collector bi-directional switch. Each common 
emitter bi-directional switch requires individual isolated power supply for their gate drives.

\subsubsection{Common Collector Bi-Directional Switch}

The common collector bi-directional switch configuration is similar to common emitter configuration. The common collector configuration is obtained by using two IGBTs with two anti parallel diodes, as shown in figure 2.14.

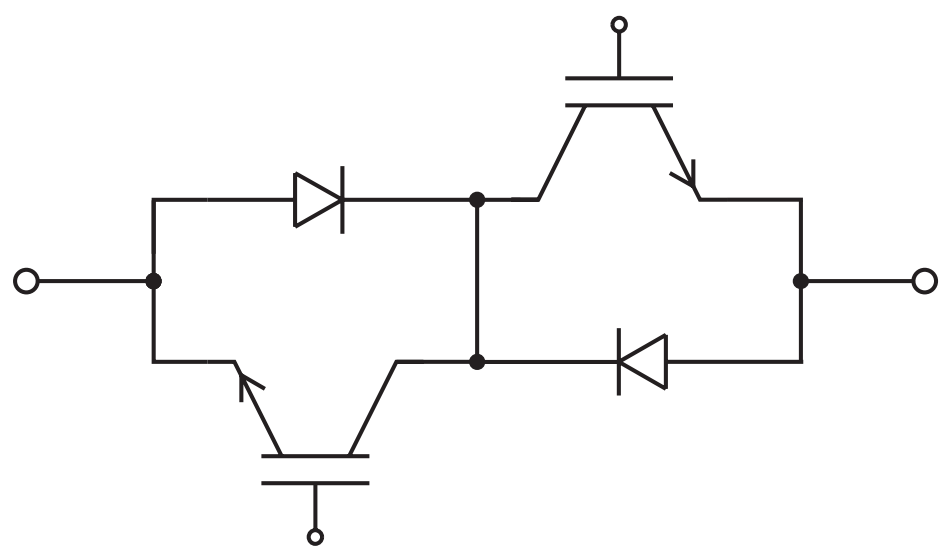

Figure 2.14: Common Collector Bi-Directional Switch

The advantages of this configuration are :

- The direction of current through the active switching devices can be controlled.

- The conduction losses are the same as common emitter bi-directional switch.

The significant advantage of the common collector configuration is that only six isolated power supplies are needed to supply the gate drive signals. This is possible if the inductance between the devices sharing the same isolated power supply is low which is the case for matrix converter modules where all the bi-directional switches 
are integrated in one package [43]. Therefore at higher power converters it is desirable to package the IGBTs into individual bi-directional switches or complete output legs. Hence the common emitter configuration is usually preferred for higher power levels $[42]$.

\subsubsection{Reverse Blocking IGBTs Bi-Directional Switch}

The two anti-parallel diodes are not necessary, as in the case of common emitter or common collector configurations, if the switching devices have a inherent reverse voltage blocking capability. It is possible to build the bi-directional switches by simply placing two reverse blocking, switching devices in anti-parallel, as shown in figure 2.15 .

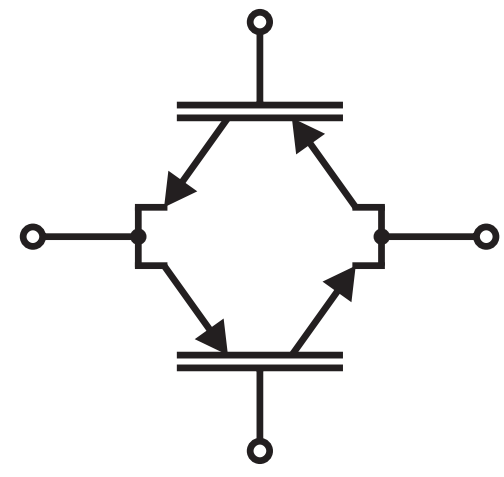

Figure 2.15: Reverse blocking IGBT Bi-Directional Switch

The advantage of this configuration is that the conduction loss is lower when compared to other bi-directional switch configurations. The disadvantage of this configuration is that in practical, the IGBT has poor reverse recovery characteristics which increases the switching losses, hence the overall system efficiency is decreased. 


\subsubsection{Commutation Techniques}

Achieving proper commutation between the switches in the Matrix Converter is not straight forward when compared to conventional converters such as Voltage Source Inverter (VSI) and Current Source Inverter (CSI) because the absence of inherent freewheeling paths in the Matrix Converter. The commutation is restricted to two basic rules [19]. This can be visualized by considering just two switches on one output line of the Matrix Converter. It is important that no two bi-directional switches are turn-on at any one time, as shown in figure 2.16(a). This would result in line-to-

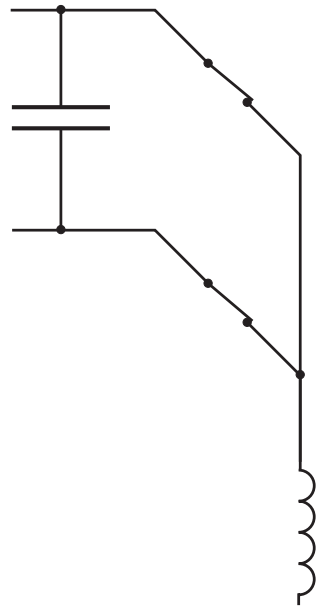

(a) Short circuit of capacitive input

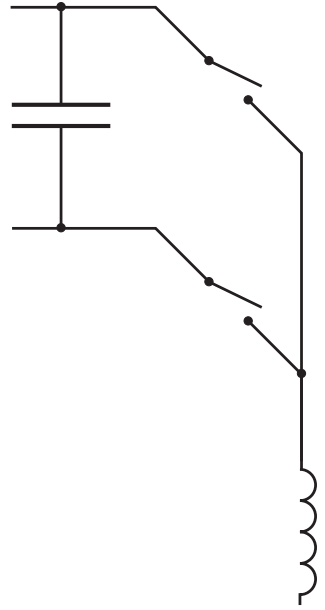

(b) Open circuit of inductive load

Figure 2.16: Baisc rules for safe operation of the Matrix Converter

line short circuits and the destruction of the Matrix Converter due to over current. The bi-directional switches for each output phase should not all be turned off at any point in time, as shown in figure 2.16(b). This would result in the absence of a path for the inductive load current, causing large over-voltages. These two considerations cause a conflict since semiconductor devices cannot be switched instantaneously due to propagation delays and finite switching times. 


\subsubsection{Dead Time Commutation}

In conventional converters such as VSI and CSI, a dead time commutation method is commonly used. Due to the presence of freewheeling paths provided by anti-parallel diodes, the load current freewheels through the anti-parallel diodes during the dead time period. Since there is no freewheeling paths in the Matrix Converter the load is open circuited during the dead time period. This would cause large over voltage spikes across the switches leading to distraction of the converter. In order to avoid this distraction snubbers are used to provide a path for the load current during the dead time period $[44,45]$.

The disadvantages of dead time commutation is that the snubbers are very difficult to design and increase the size of power circuit of the Matrix Converter.

\subsubsection{Multi-Step Current Commutation}

To create a reliable method of the current commutation, which obeys the basic rules, the fact that direction of current flow through the bi-directional switches can be controlled is used. To implement these strategies the bi-directional switches must be designed in such a way as to allow this direction of current flow to be controlled.

A schematic of a two phase to single phase Matrix Converter is shown in figure 2.17 to explain the multi-step commutation strategy. The following explanation assumes that the load current is in the direction shown and that the upper bi-directional switch $\left(S_{A}\right)$ is closed. When a commutation to $S_{B}$ is required, the current direction is used to determine which device in the active switch is not conducting. This device is then turned off, Q2 in this example. The device that will conduct the current in the incoming switch is then gated, Q3 in this example. The load current transfers to the incoming device either at this point or when the outgoing device, Q1, is turned off depending on the polarity of the line to line input voltage. The remaining device in the incoming switch, Q4, is turned on to allow for current reversals. This process 


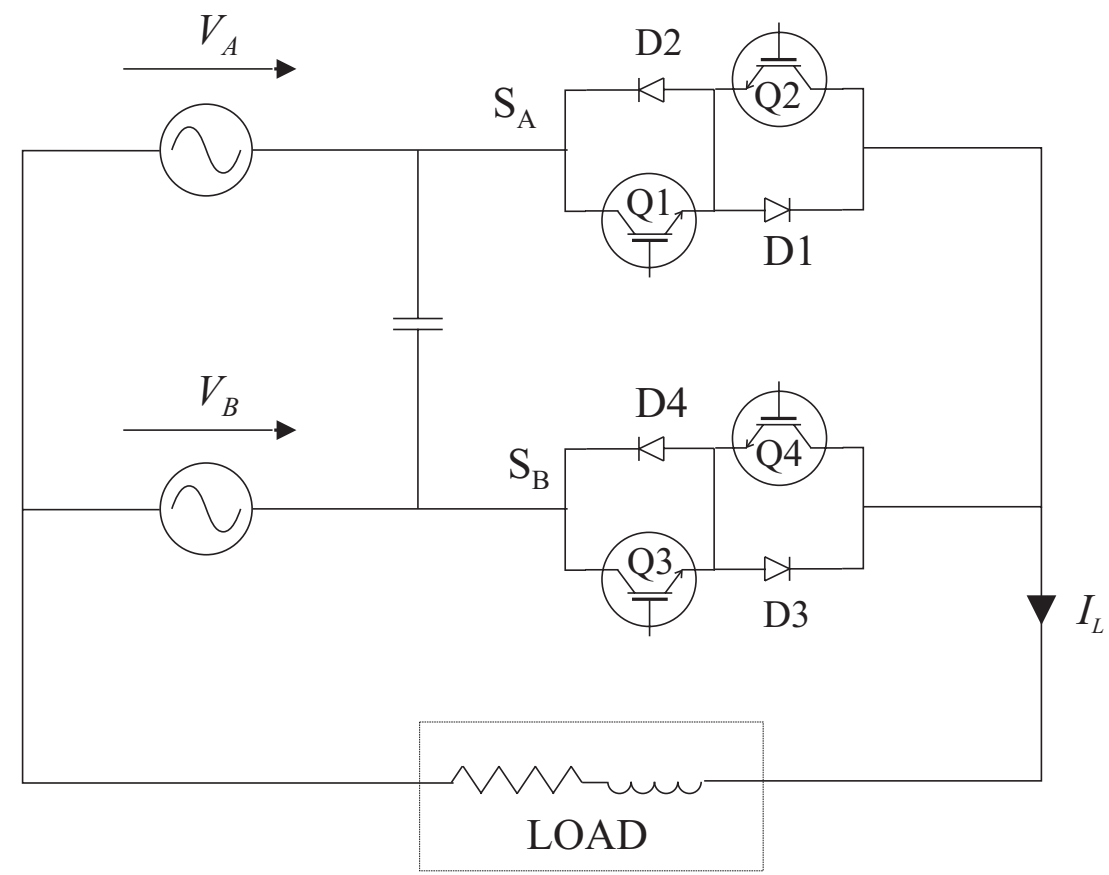

Figure 2.17: 2-phase to 1-phase Matrix Converter

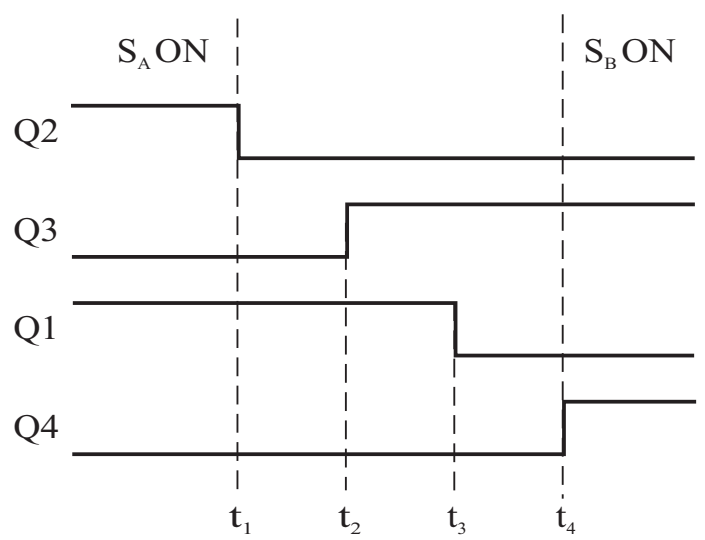

Figure 2.18: Timing diagram for four-step current commutation between two switches 
is shown as a timing diagram in figure 2.18, the delay added between each switching event is determined by the device and gate drive characteristics.

This current commutation technique relies on a knowledge of the output current direction. This current direction can be difficult to reliably determine, especially at low current levels in high power drives. To avoid this problem a technique for using the voltage across the bi-directional switch to determine the current direction has been developed [46]. This technique provides reliable current commutation using an intelligent gate drive circuit which controls the firing of the IGBTs and detects the direction of current flow within the bidirectional switch cell. The current direction information calculated by the active gate drive is passed to all of the other gate drivers on the same output leg. In this way all the gate drivers contribute to operate a safe commutation. 


\subsection{Avoiding Regeneration in Traditional Power Converter Topologies}

This section briefly explains the conventional method for avoiding regeneration in the traditional (DC-Link) power converters such as uncontrolled front-end diode bridge fed Voltage Source Inverter (VSI) and Back-to-Back VSI. The conventional method $[47,48]$ is the Dynamic Braking method

\subsubsection{Dynamic Braking Method for Diode Bridge fed $V S I_{s}$}

In this system, the regenerative energy is not put back onto the main bus since the diode bridge is a uni-directional circuit $[12,13]$ and hence bi-directional power flow is not possible. The main disadvantage of this kind of DC-Link converter are the harmonics in the input current [49]. The conventional dynamic braking method is used to avoid regeneration in this kind of traditional DC-Link converter, as shown in the figure 2.19 .

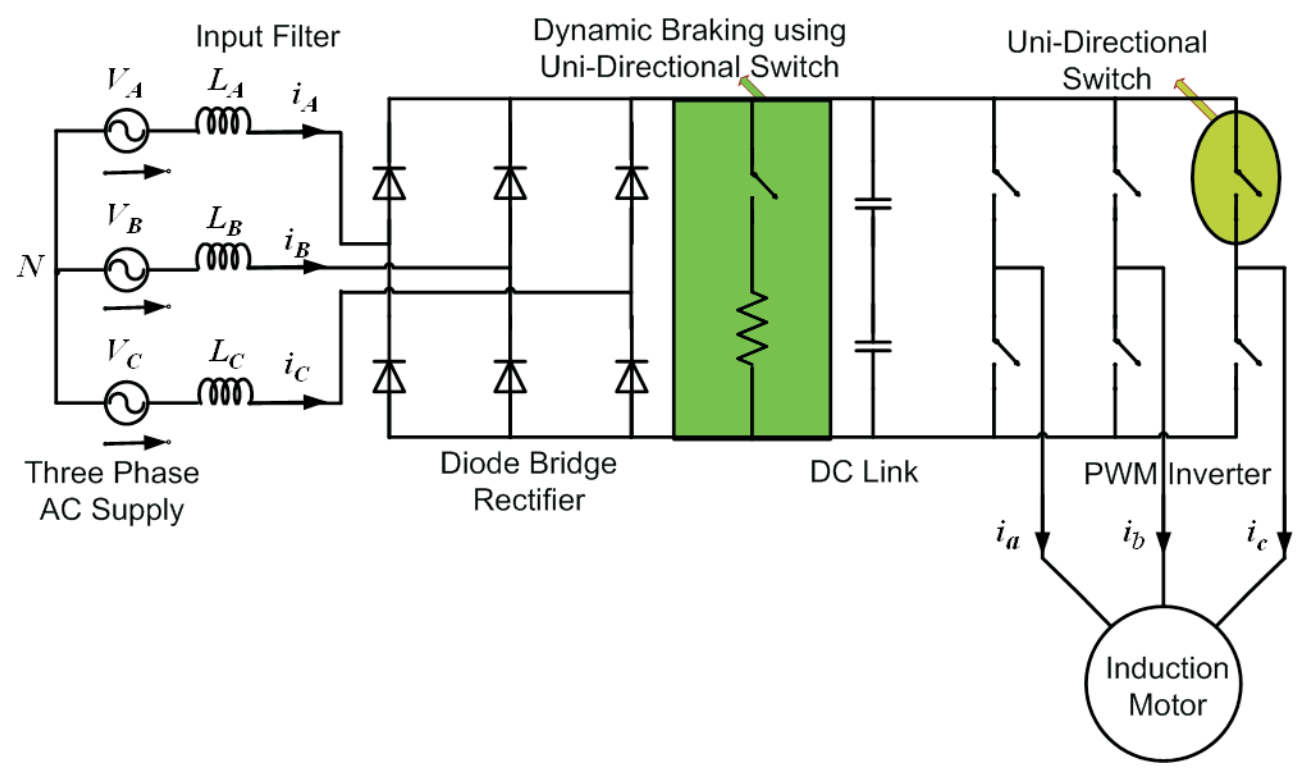

Figure 2.19: Dynamic Braking Circuit for a Diode Bridge fed VSI 
In the dynamic braking method, the voltage across the DC-Link capacitor is monitored. If this voltage rises above a set value, the switch can be turned ON and connects the resistor across DC-Link, dissipating the regenerative energy. The significant advantage of this method is the low requirement for additional hardware.

\subsubsection{Dynamic Braking Method with a Back-to-Back VSI}

The procedure for dynamic braking in Back-to-Back VSI is similar to dynamic braking in uncontrolled front-end diode bridge fed VSI. A controlled Uni-Directional Switch (UDS) with a series resistor can be used to absorb energy during the regeneration and dissipate this energy in the form of heat, as shown in the figure 2.20. To obtain the dynamic braking detecting the regeneration in the system is important. The sign of output power and the magnitude of the input line voltage of the Matrix Converter is used to detect the regeneration.

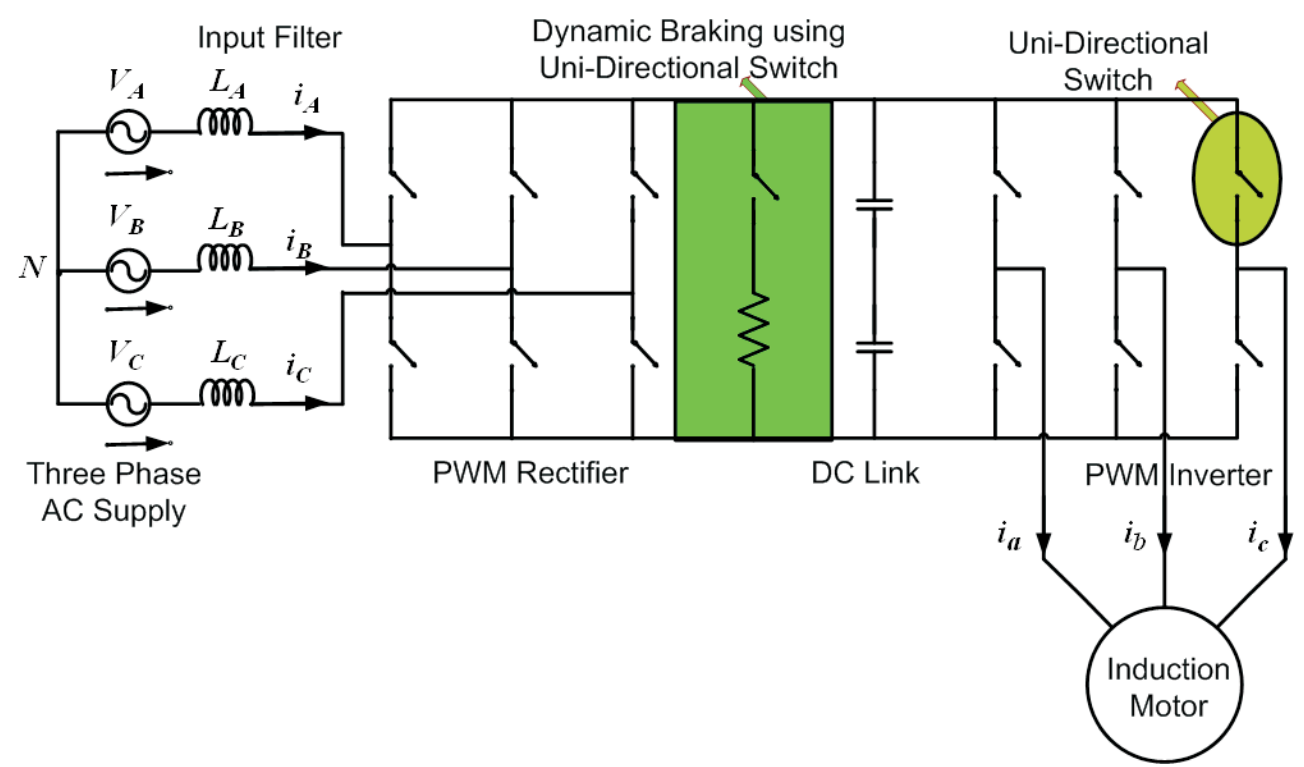

Figure 2.20: Overview of a Dynamic Braking Circuit for a Back-to-Back VSI 


\subsection{Conclusions}

An overview of Matrix Converter technology has been presented. Even though the Matrix Converter has been described as a all silicon solution, it requires an input filter to reduce the switching frequency harmonics. The size of the Matrix Converter can be increased if this input filter is not properly designed. Some special features of the Matrix Converter have been discussed :

- Inherent regenerative capability.

- Compact size due to absence of DC-Link energy storage components.

Based on the above features, it is concluded that the Matrix Converter is an good alternative to the conventional AC-DC-AC topologies. The maximum voltage transfer ratio of the Matrix Converter is limited to 0.866 ( $86.6 \%$ ) therefore the circuit has not been considered for standard industrial applications. If the Matrix Converter is used with a non-standard machines (the rating of machine is designed according to maximum voltage transfer ratio of the Matrix Converter) then the limitation in the voltage transfer ratio of the Matrix Converter is not considered as disadvantage. The comparison between the Matrix Converter and the conventional AC-DC-AC topologies has been discussed, as summarised on Table 2.2.

\begin{tabular}{||c||c||c||c||c||}
\hline \hline $\begin{array}{c}\text { AC-AC } \\
\text { Topologies }\end{array}$ & $\begin{array}{c}\text { No. of } \\
\text { switching } \\
\text { devices }\end{array}$ & $\begin{array}{c}\text { DC-Link } \\
\text { energy } \\
\text { storage }\end{array}$ & $\begin{array}{c}\text { 4-Quadrant } \\
\text { operation }\end{array}$ & $\begin{array}{c}\text { Input } \\
\text { current }\end{array}$ \\
\hline \hline Diode Bridge VSI & 6 & Yes & No & Poor-Sine \\
Back to Back VSI & 12 & Yes & Yes & Good-Sine \\
Cycloconverter & 36 & No & Yes & Non-Sine \\
Matrix Converter & 18 & No & Yes & Good-Sine \\
\hline \hline
\end{tabular}

Table 2.2: Summary of Comparison between the Matrix Converter and other topologies

Techniques for the construction of the Matrix Converter, such as the bi-directional switch configurations and the commutation techniques, have been explained in the 
section 2.5. The common emitter bi-directional switches is preferred to the other bi-directional switch configurations because it is suitable for high power applications. With regard to current commutation technique, the 4-step commutation is used in this application [50].

The current direction based, four step commutation technique has the advantage that it is easier to handle the commutation failures than in a voltage direction based strategies. The reason is that failure to correctly commutate in a current direction based technique can cause an open circuit of the load and not a short circuit of the input. 


\section{Chapter 3}

\section{Induction Motor Control}

\subsection{Introduction}

In this chapter the open loop conventional Volts/Hertz control and closed loop indirect vector control of induction motors is discussed. Volts/Hertz controlled induction motor drives are commonly used in many applications because motor speed control can be easily achieved. However, constant Volts/Hertz control is still challenging to implement in low speed range because of the stator resistance voltage drop. Even though many compensation methods have been proposed [51, 52, 53], stator resistance drop in low speed range is a disadvantage of conventional Volts/Hertz control. In addition, the accuracy of speed response is a significant problem under transient load. For simple applications such as pumps and fans where the load is predictable and high dynamic performance is not required, Volts/Hertz control can be used [54]. Volts/Hertz control is not suitable for applications which require high dynamic performance.

In order to achieve high dynamic performance in an induction motor drive application vector control is often applied [10]. Vector control makes the AC drive behave in an equivalent way to DC drives by independently controlling flux and torque in the 
motor. This section includes the theoretical design of speed and current controllers as well as the mathematical calculation of rotor time constant for the application of a Matrix Converter drives.

\subsection{Open Loop Motor Control}

This section describes the concept of constant Volts/Hertz motor speed control and considers the advantages and disadvantages of this form of control.

\subsubsection{Volts/Hertz Control}

The synchronous speed and rotor speed of an induction motor can be found by using equations 3.1 and 3.2 respectively. From 3.1 and 3.2, there are two possible ways to change the speed of induction motor:

1. changing the motor slip

2. changing the supply frequency

$$
\begin{gathered}
n_{s}=\frac{120 * f_{m}}{P} \\
n_{r}=n_{s}(1-\text { slip })
\end{gathered}
$$

Where, $n_{s}$ is the Synchronous speed of the induction motor, $f_{m}$ is the supply fre-

quency, $P$ is number of poles. $n_{r}$ is the rotor speed of the induction motor. slip is defined as the difference between the synchronous speed $\left(n_{s}\right)$ and the rotor speed $\left(n_{r}\right)$. 
Volts/Hertz motor control is a type of motor control that has a goal of keeping the air-gap flux $(\phi)$ constant by controlling stator voltage (V) and stator frequency (f) so that the ratio between them is constant. In the low speed range the frequency and the stator voltage approach zero. This low voltage will be seen across the stator resistance so the air-gap flux $(\phi)$ will not be maintained at the required level, consequently the maximum available torque will decrease.

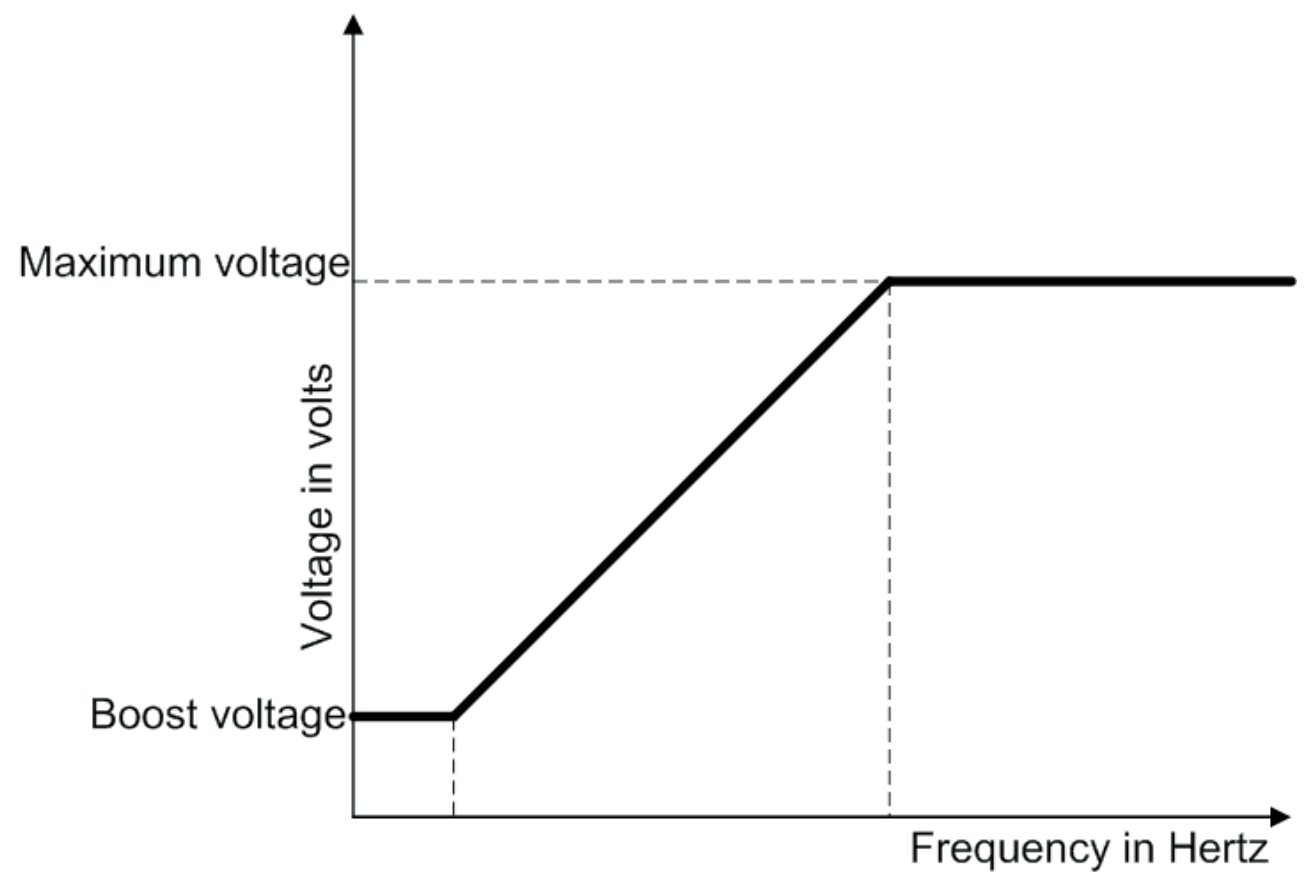

Figure 3.1: Conventional Volts/Hertz Control

In order to compensate for the stator resistance voltage drop it is necessary to boost the stator voltage, as shown in figure 3.1. In the low speed range this compensation of voltage drop is necessary to prevent a decrease in the maximum available motor torque [52]. Simple design and low cost are the advantages of constant Volts/Hertz control. Poor dynamic response is the significant disadvantage of Volts/Hertz control. Therefore, Volts/Hertz control is not used in applications where high dynamic performance of a motor drive is required. 


\subsection{Closed Loop Control : Application of Vector Control}

The principal aim of vector control is to independently control the flux and torque in the induction motor, in a similar way to the control of a separately excited DC machine. To achieve independent control of the flux and torque, the direct axis ( $d$ axis) is aligned to a rotor flux vector $\left(\Psi_{r}\right)$, as discussed in section 3.3.1.

\subsubsection{The Principle of Indirect Field Orientation}

In $\mathrm{AC}$ induction motors, the three phase currents that electrically displaced by 120 - are applied to the three stationary stator coils of the motor. The resulting flux in the stator coils induces alternating currents in the conductors of the rotor to create a magnetic field. Due to inherent coupling effect between the filed and armature current, the sluggish control response is obtained $[55,56,57]$.

Unlike the separately excited DC motor the rotor currents in an induction motor are not controlled from the external source. The rotor currents are derived from the stator flux interaction with the rotor.
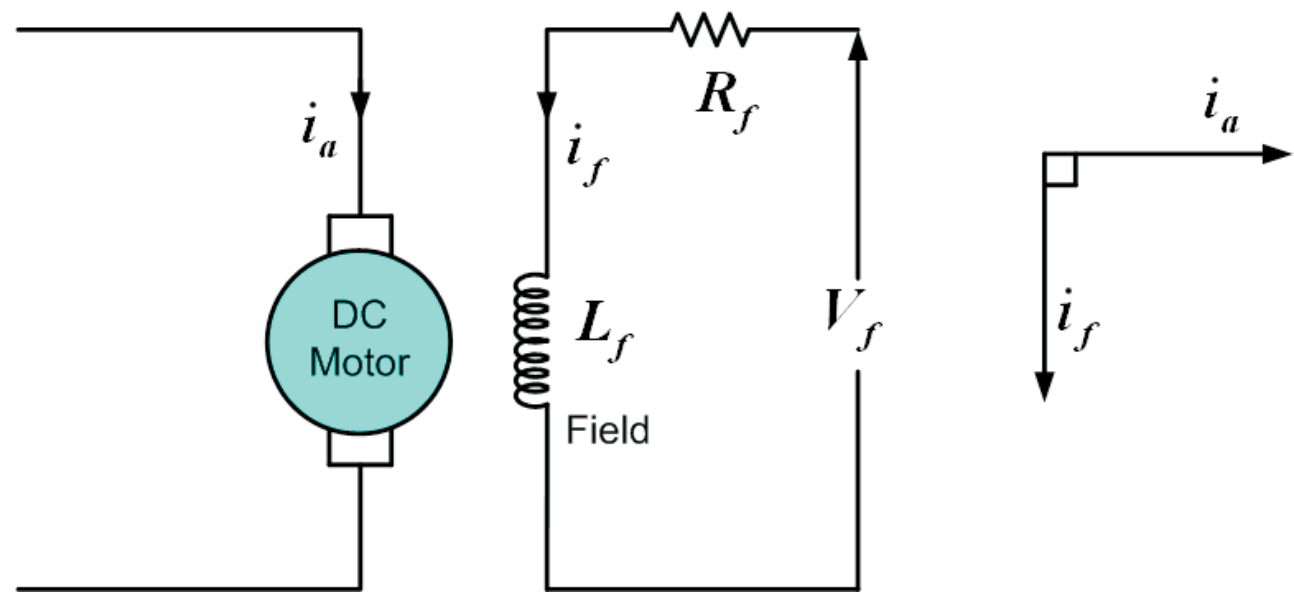

Figure 3.2: DC motor with inherent vector control 
Vector control of an induction motor is equivalent to the control of the separately excited DC motor as shown in the figure 3.2. Figure 3.2 shows that the field flux produced by the field current $\left(i_{f}\right)$ is perpendicular to the armature flux produced by the armature current $\left(i_{a}\right)$. The dynamic equation for the field circuit of the separately excited motor are given in the equation 3.3 and the equation for defining the developed torque in the DC motor is given in equation 3.4

$$
\begin{gathered}
\frac{L_{f} d}{R_{f} d t} i_{f}+i_{f}=\frac{V_{f}}{R_{f}} \\
T_{e} \propto i_{a} i_{f}
\end{gathered}
$$

Where, $T_{e}$ is electrical torque developed by the DC motor. The $i_{a}$ and $i_{f}$ fields are inherently decoupled (or independent), so it is possible to control the torque by controlling the armature current and keeping the field constant. Similarly, in order to get fast torque response in the induction motor, vector control is used to decouple the armature current (or torque producing current) and field current (or flux producing current).

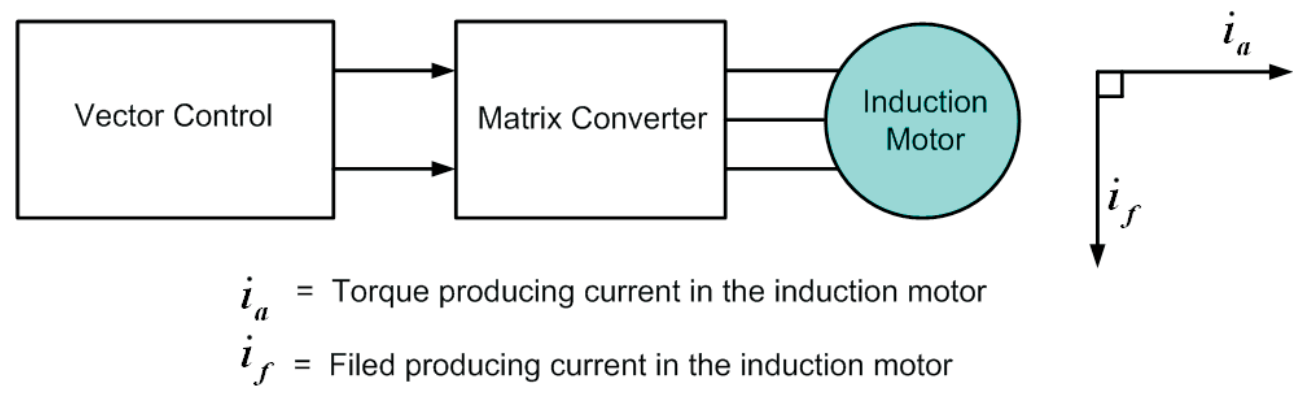

Figure 3.3: Vector Control Analogy with DC Motor

Induction motor synchronous frame currents are orthogonal and analogous to the DC motor currents $\left(i_{a}\right.$ and $\left.i_{f}\right)$. The vector control analogy with DC motor is depicted in the figure 3.3. To obtain the decoupling between induction motor currents some waveform transformations to the stationary and rotating reference frames are required. 


\subsubsection{Two Phase Transformation}

This section describes a transformation that can be used to convert three phase quantities into a stationary frame. In order to get the two phase transformation, consider the general case of a three phase set of sinusoidal quantities $x_{a}, x_{b}$ and $x_{c}$. Assume these three phase sinusoidal quantities are balanced so that the vector sum of the quantities is zero. Figure 3.4 shows the two phase transformation using a phasor vector diagram. The complex vector form of three phase quantities is given in the equation 3.5

$$
\overrightarrow{\mathbf{x}}=x_{a}+a x_{b}+a^{2} x_{c} \quad \text { where } a=e^{j 2 \pi / 3}
$$
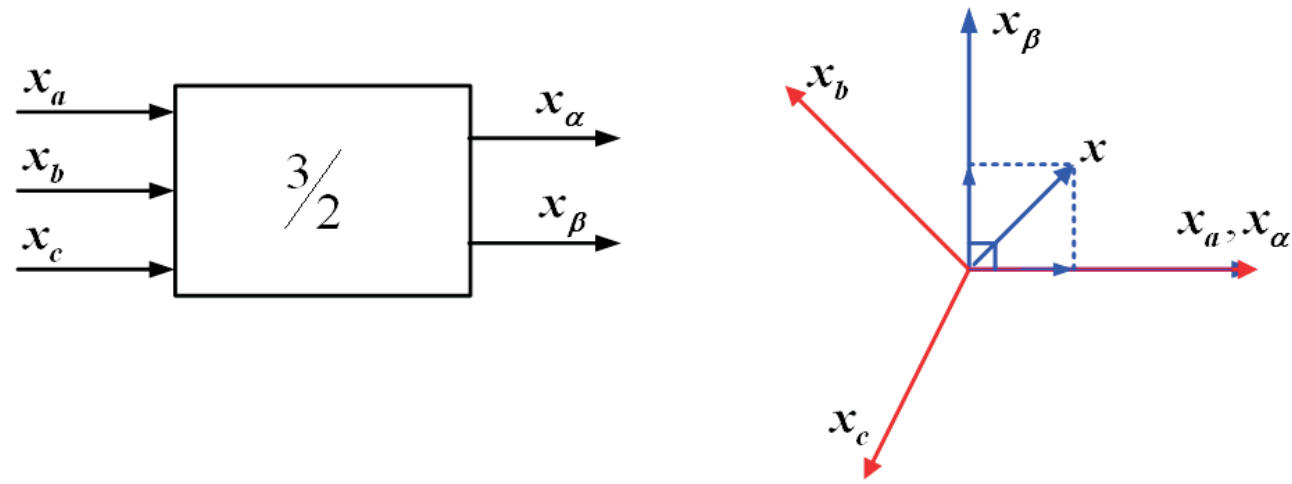

Figure 3.4: Three Phase into Stationary Frame Transformation

The vector sum of three phase quantities is zero in a balanced three phase system as defined in the equation 3.6

$$
x_{a}+x_{b}+x_{c}=0
$$

However, space vectors are not restricted to sinusoidal variation in time at constant frequency. The instantaneous values of three phase quantities are transformed into stationary frame $x_{\alpha}(t)$ and $x_{\beta}(t)$ as in equations 3.7 and 3.8 ,

$$
\begin{gathered}
x_{\alpha}(t)=\frac{3}{2} x_{a}(t) \\
x_{\beta}(t)=\frac{\sqrt{3}}{2} x_{b}(t)-\frac{\sqrt{3}}{2} x_{c}(t)
\end{gathered}
$$

$x_{\alpha}(t), x_{\beta}(t)$ are time varying quadrature values as viewed from the reference of the three phase quantities. Using this technique the three phase stator currents of an 
induction motor $\left(i_{a}, i_{b}, i_{c}\right)$ can be transformed into stationary frame $\left(i_{s \alpha}(t)\right.$ and $i_{s \beta}(t)$ ). This transformation of the currents can be realized by substituting the $x=i_{s}$ in the above equations. The equivalent complex stator current vector $\left(\overrightarrow{\mathbf{i}}_{s}\right)$ becomes, as represented in the equation 3.9

$$
\overrightarrow{\mathbf{i}}_{s}=i_{a s}+a i_{b s}+a^{2} i_{c s} \quad \text { where } a=e^{j 2 \pi / 3}
$$

For a balanced system, the vector sum of three phase currents is zero as shown in the equation 3.10

$$
i_{a s}+i_{b s}+i_{c s}=0
$$

The instantaneous values of three phase stator currents are transformed into stationary frame $i_{s \alpha}(t)$ and $i_{s \beta}(t)$ as in equations 3.11 and 3.12 ,

$$
\begin{gathered}
i_{s \alpha}(t)=\frac{3}{2} i_{a s}(t) \\
i_{s \beta}(t)=\frac{\sqrt{3}}{2} i_{b s}(t)-\frac{\sqrt{3}}{2} i_{c s}(t)
\end{gathered}
$$

From the two phase transformation, the rotating reference frame transformation is derived using rotor flux angle $(\lambda)$. The rotating reference frame transformation and calculation of rotor flux angle is explained in the section 3.3.3 and 3.3.4 respectively.

\subsubsection{Stationary Frame to Rotating Reference Frame Trans- formation}

This section explains how to derive the rotating reference frame from the stationary frame. As shown in the figure 3.5, the factor 'y' represents the angle between the stationary frame and rotating reference frame. The factor ' $y$ ' is used to obtain the rotating reference frame $\left(x_{d}(t)\right.$ and $\left.x_{q}(t)\right)$ from the stationary frame can be represented in the equations 3.13 and 3.14 ,

$$
x_{d}(t)=x_{\alpha}(t) \cos y+x_{\beta}(t) \sin y
$$



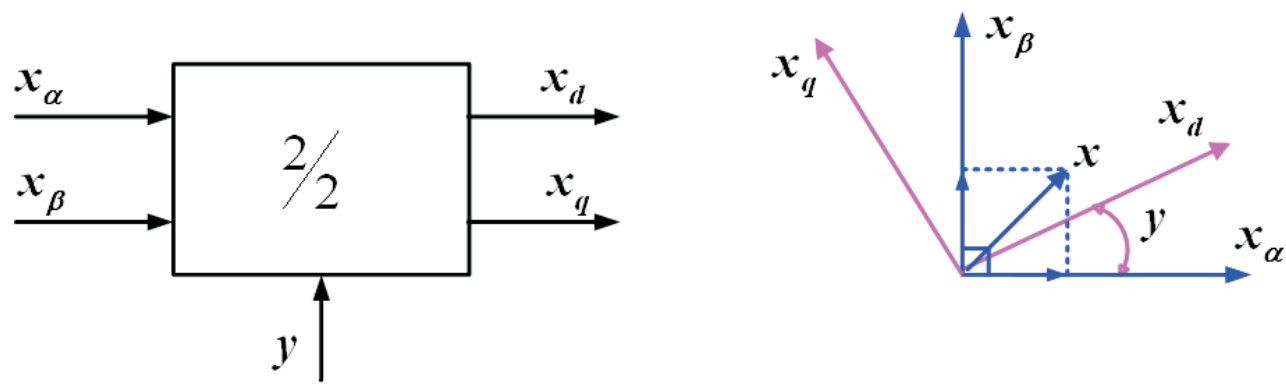

Figure 3.5: The Stationary Frame to Rotating Reference Frame Transformation

$$
x_{q}(t)=-x_{\alpha}(t) \sin y+x_{\beta}(t) \cos y
$$

$x_{d}(t)$ and $x_{q}(t)$ are the quadrature quantities transformed into the rotating reference frame. Both are considered as 'dc' quantities under steady state conditions.

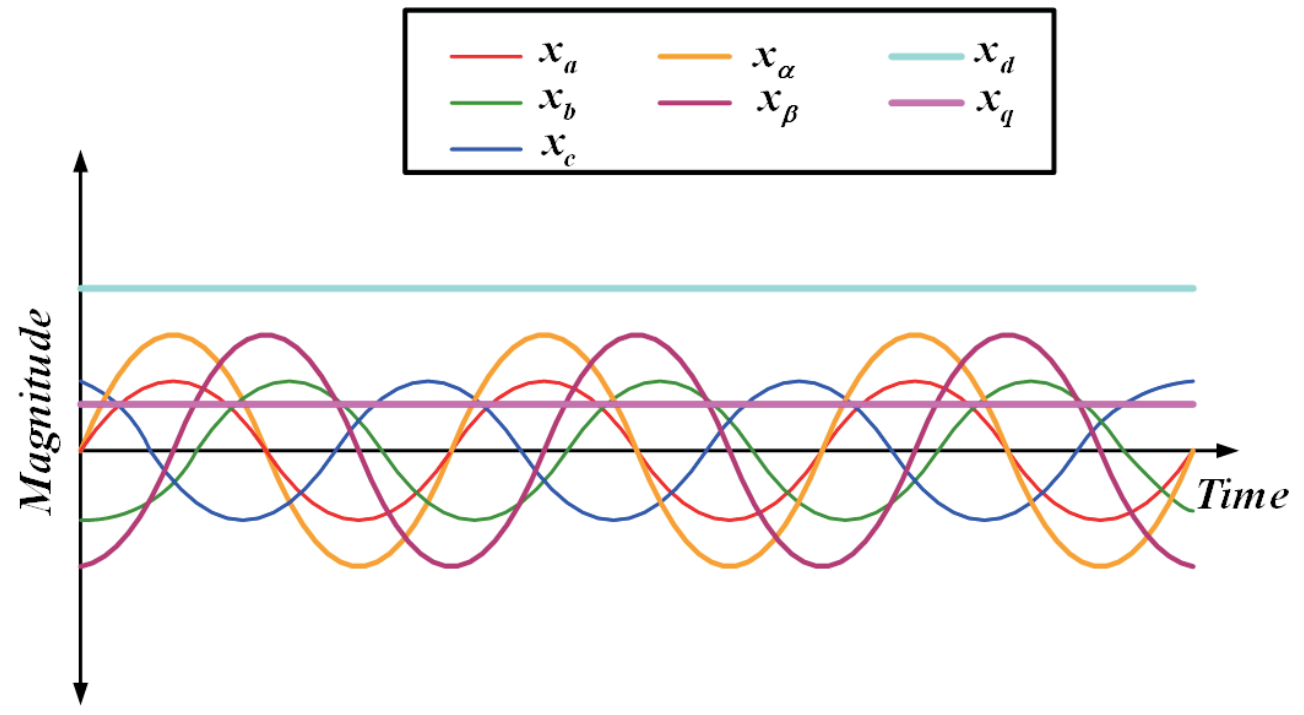

Figure 3.6: Graph for Time Domain Analysis for Two Phase Transformation

$$
\begin{gathered}
i_{s d}(t)=i_{s \alpha}(t) \cos \lambda+i_{s \beta}(t) \sin \lambda \\
i_{s q}(t)=-i_{s \alpha}(t) \sin \lambda+i_{s \beta}(t) \cos \lambda
\end{gathered}
$$

The stationary frame of stator currents of an induction motor are transformed into rotating frame transformation by substituting $x=i_{s}$ and $y=\lambda$ in the above equations 
3.15 and 3.16. For example, in general case, if ' $y$ ' $=30^{\circ}$, the resulting waveforms for $x_{\alpha}(t), x_{\beta}(t), x_{d}(t)$ and $x_{q}(t)$ are graphically shown in the figure 3.6.

In this application, ' $y$ ' is analogous to the $\lambda$ (rotor flux angle). The resulting rotating reference frame $i_{s d}(t)$ and $i_{s q}(t)$ can be represented in the equations 3.15 and 3.16.

\subsubsection{The Rotor Flux Angle $(\lambda)$}

There are two methods for finding rotor flux angle $(\lambda)$, required by the transforms described above. These two methods lead to two vector control schemes:

- Direct Vector Control [58]

- Indirect Vector Control [59]

\subsubsection{Direct Measurement}

This section describes the principle of the direct vector control with respect to finding the rotor flux angle $(\lambda)$. In direct vector control the rotor flux angle $(\lambda)$ is obtained by directly measuring the air-gap flux for example by mounting hall effect sensors with in the air-gap of the machine. The air-gap flux linkages $\left(\Psi_{o \alpha}, \Psi_{o \beta}\right)$ can then be obtained from these hall effect sensors, which are arranged in electrical quadrature, as shown in figure 3.7 .

From these measurements the rotor flux linkages $\left(\Psi_{r \alpha}, \Psi_{r \beta}\right)$ can be calculated, as shown in equations 3.17 and 3.18 respectively. Rotor flux linkages are referred to the stator stationary frame $\left(i_{s \alpha}, i_{s \beta}\right)$, as explained in section 3.3.2.

$$
\begin{aligned}
& \Psi_{r \alpha}=\left(1+\sigma_{r}\right) \Psi_{o \alpha}-L_{o} i_{s \alpha} \\
& \Psi_{r \beta}=\left(1+\sigma_{r}\right) \Psi_{o \beta}-L_{o} i_{s \beta}
\end{aligned}
$$




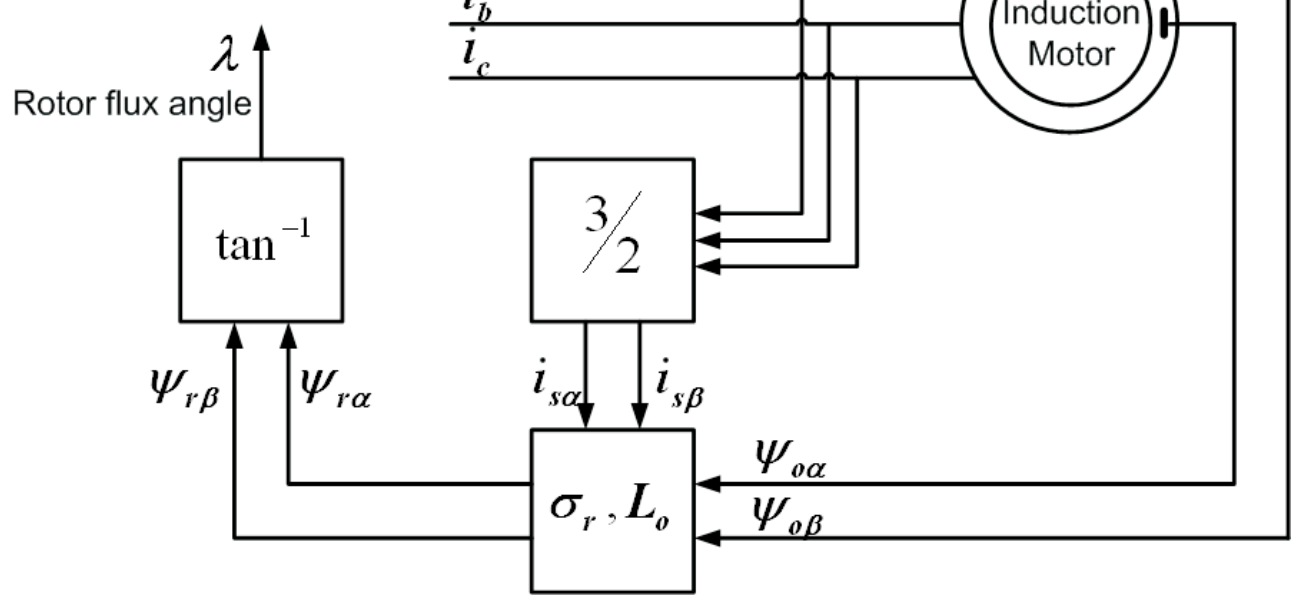

Figure 3.7: Calculation of rotor flux angle in direct vector Control

where, $\sigma_{r}=\frac{L_{r}-L_{o}}{L_{o}}, \sigma_{r}$ is Leakage co-efficient, $L_{r}$ is rotor inductance and $L_{o}$ is Mutual inductance.

The rotor flux angle $(\lambda)$ is given by,

$$
\lambda=\arctan \left(\frac{\Psi_{r \beta}}{\Psi_{r \alpha}}\right)
$$

The advantage of direct vector control is that the implementation is not dependent on a knowledge of the machine parameters [59,60]. It might be possible to use direct vector control for high performance drives, but:

- At low speeds direct vector control is susceptible to noise.

- The need for hall sensors or search coils increases the difficulty of hardware implementation and installation cost. These sensors can be affected by mechanical vibrations and the temperature of the operating environment [59].

Therefore, direct vector control is not commonly used in motor drives for industrial applications. 


\subsubsection{Indirect Measurement}

The concept of indirect vector control is that rotor flux position is estimated instead of directly measured. This form of vector control has also been called slip frequency control because the instantaneous rotor flux angle $(\lambda)$ depends on the slip frequency $\left(\omega_{s l}\right)$ and the measured shaft speed $\left(\omega_{r e}\right)$ as shown in figure 3.8. This form of vector control is the most popular and is widely accepted in industrial applications because of the absence of instantaneous rotor flux position sensors [9].

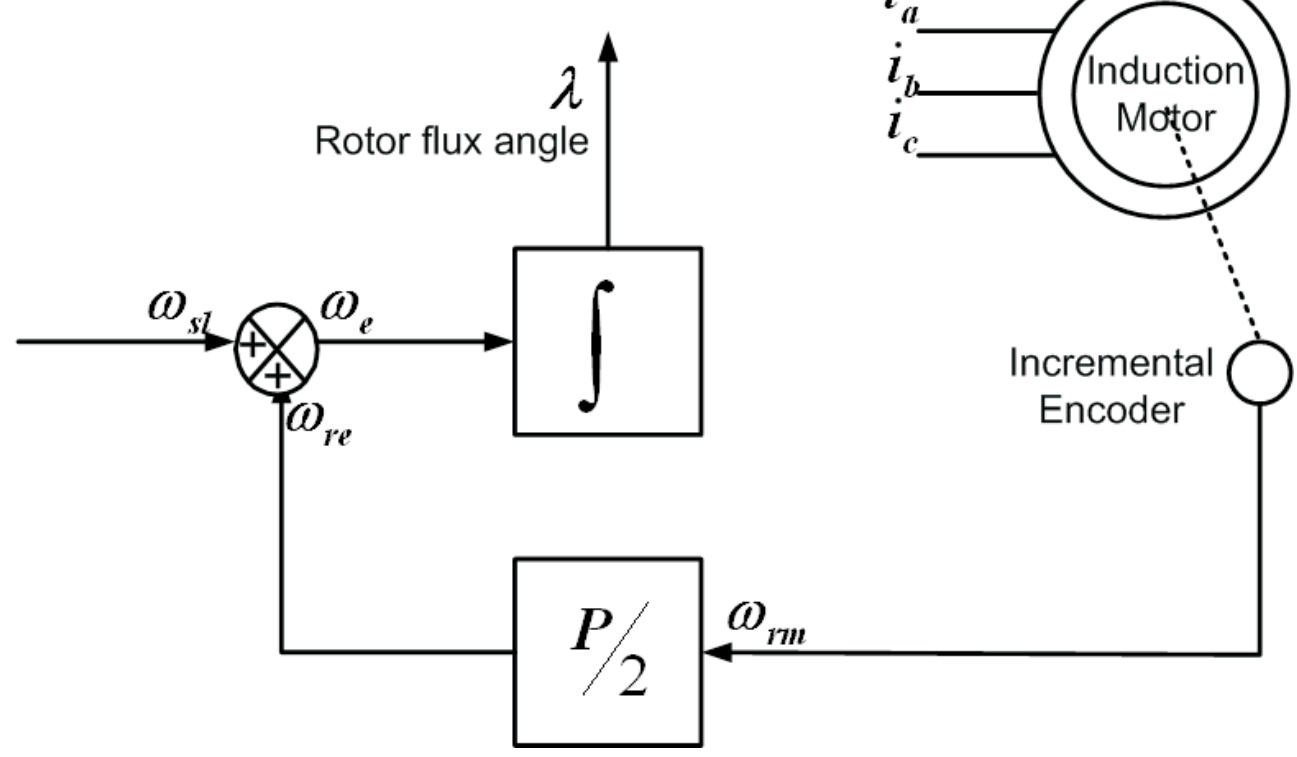

Figure 3.8: Calculation of rotor flux angle in direct vector Control

Equation 3.20 shows the derivation of the slip frequency $\left(\omega_{s l}\right)$ from the reference dq-axis currents $\left(i_{s d}^{*}, i_{s q}^{*}\right)$ and rotor time constant $\left(\tau_{r}\right)$.

$$
\omega_{s l}=\frac{i_{s q}^{*}}{\tau_{r} i_{s d}^{*}}
$$

As shown in equation 3.21, the electrical frequency $\left(\omega_{e}\right)$ is obtained by adding slip frequency with the measured shaft speed $\left(\omega_{r e}\right)$ in electrical rad/sec. $\omega_{r e}$ is derived from mechanical speed $\left(\omega_{r m}\right)$ of the motor and number of poles $(\mathrm{P})$ in the motor, as shown in figure 3.8 .

$$
\omega_{e}=\omega_{r e}+\omega_{s l}
$$




$$
\lambda=\int \omega_{e} d t
$$

The rotor flux angle $(\lambda)$ is obtained by integration of electrical frequency $\left(\omega_{e}\right)$, as shown in equation 3.22. Indirect field orientation is maintained regardless of the rotational speed of the motor. Therefore it is possible to use indirect vector control when the motor is at stand still.

The advantages of Indirect Vector Control are that :

1. Even in low speed operation the excellent dynamic response can be obtained.

2. The method is suitable for high performance applications, where good speed and torque response are required [61].

The disadvantages of Indirect Vector Control are that:

1. The performance of indirect vector control is dependent on the correct identification of the motor parameters [58].

2. The reliance of an accurate measurement of the rotor position [62]. 


\subsubsection{Vector Control}

The concept of the indirect field oriented vector control is depicted in the figure 3.9. The rotating reference frame is rotating at synchronous angular velocity $\left(\omega_{e}\right)$. This reference frame allows the 3-phase currents to be viewed as two 'dc' quantities under steady state conditions. The direct axis or real axis component is responsible for the field producing current $\left(i_{s d}\right)$ and is ideally maintained constant up to the motor synchronous speed. If d-axis is aligned with rotor flux vector $\left(\Psi_{r}\right)$ and the system is said to be field oriented. The q-axis component is responsible for torque producing current $\left(i_{s q}\right)$. These two vectors are orthogonal to each other so that the field current and torque current can be controlled independently.

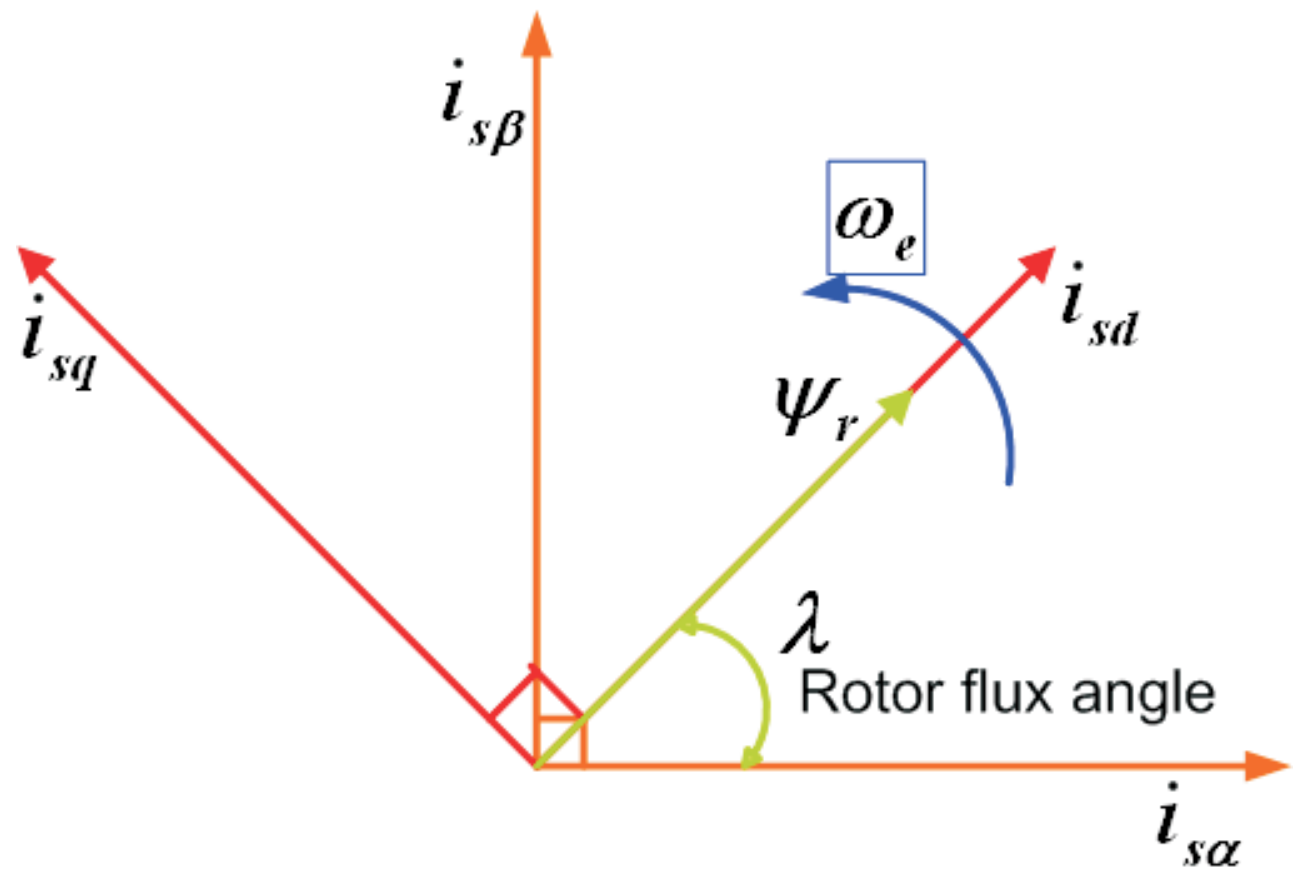

Figure 3.9: Field Orientation: $\Psi_{r}$ is aligned with d-axis

The dq-model of induction motor dynamic equations is used to drive the field oriented vector control algorithm. The dynamic equation terms such as $R_{s}, L_{s}, R_{r}$ and $L_{r}$ are described using per phase equivalent circuit of an induction motor as shown in the figure 3.10. Equations 3.23 and 3.24 are called stator equations. 


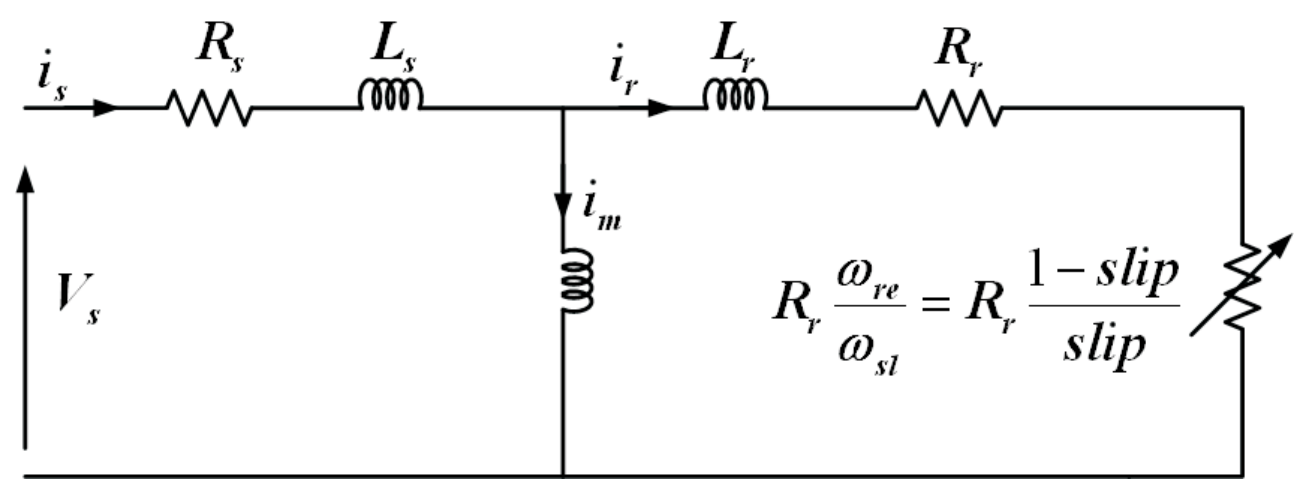

Figure 3.10: Per Phase Equivalent Circuit of an Induction Motor

$$
\begin{aligned}
& V_{s d}=R_{s} i_{s d}+\sigma L_{s} \frac{d}{d t} i_{s d}-\omega_{e} \sigma L_{s} i_{s q}+\frac{L_{o}}{L_{r}} \frac{d}{d t} \psi_{r d}-\omega_{e} \frac{L_{o}}{L_{r}} \psi_{r q} \\
& V_{s q}=R_{s} i_{s q}+\sigma L_{s} \frac{d}{d t} i_{s q}-\omega_{e} \sigma L_{s} i_{s d}+\frac{L_{o}}{L_{r}} \frac{d}{d t} \psi_{r q}-\omega_{e} \frac{L_{o}}{L_{r}} \psi_{r d}
\end{aligned}
$$

These equations are derived from the rotating reference frame of the induction motor model. With regard to indirect rotor field orientation, the stator equations are not useful. The rotor equations 3.25 and 3.26 are used to derive the field oriented equations.

$$
\begin{aligned}
& 0=\frac{R_{r}}{L_{r}} \psi_{r d}+\frac{d}{d t} \psi_{r d}-\frac{L_{o}}{L_{r}} R_{r} i_{s d}-\omega_{s l} \psi_{r q} \\
& 0=\frac{R_{r}}{L_{r}} \psi_{r q}+\frac{d}{d t} \psi_{r q}-\frac{L_{o}}{L_{r}} R_{r} i_{s q}-\omega_{s l} \psi_{r d}
\end{aligned}
$$

In order to obtain the field orientation, d-axis is made aligned with the rotor flux vector $\left(\psi_{r}\right)$ by substituting $\psi_{r q}=0$ in above rotor equations so that $\psi_{r d}=\psi_{r}$ as shown in the figure 3.9. The simplified equations 3.27 and 3.28 can be framed, these are called field oriented equations:

$$
\begin{gathered}
0=\frac{R_{r}}{L_{r}} \psi_{r d}+\frac{d}{d t} \psi_{r d}-\frac{L_{o}}{L_{r}} R_{r} i_{s d} \\
0=-\frac{L_{o}}{L_{r}} R_{r} i_{s q}-\omega_{s l} \psi_{r d}
\end{gathered}
$$

Vector control theory is derived from equations 3.27 and 3.28 by substituting $\psi_{r d}=$ $L_{o} i_{m r d}$. Here, $i_{m r d}$ is called the equivalent magnetising current. Further, it can always 
be assumed that $i_{m r d}=i_{s d}=i_{s d}^{*}$ because field weakening mode is not considered in this application. Therefore equation 3.27 becomes equation 3.29 where $i_{s d}$ is the field current.

$$
\frac{L_{r} d}{R_{r} d t} i_{m r d}+i_{m r d}=i_{s d}
$$

Equation 3.28 becomes equation 3.30 and is called as vector control constraint equation. This equation shows that the motor slip is directly proportional to the torque producing current and inversely proportional to the rotor time constant $\left(\tau_{r}\right)$.

$$
\omega_{s l}=\frac{R_{r}}{L_{r} i_{m r d}} i_{s q}
$$

since $i_{m r d}=i_{s d}=i_{s d}^{*}$, the equation 3.30 becomes,

$$
\omega_{s l}=\frac{i_{s q}^{*}}{\tau_{r} i_{s d}^{*}}
$$

where,

$$
\tau_{r}=\frac{L_{r}}{R_{r}}
$$

The rotor flux angle $(\lambda)$ depends up on slip gain constant $\left(\tau_{r}\right)$, which is defined as the ratio between the rotor inductance $\left(L_{r}\right)$ and the rotor resistance $\left(R_{r}\right)$ as shown in equation 3.32. In order to obtain good performance indirect field oriented vector control the value of $\tau_{r}$ must be accurate.

Equations 3.29 and 3.30 are common to both direct vector control and indirect vector control. The difference is the way of measuring flux as explained in the section 3.3.4. Equation 3.33 shows the calculation of the electromagnetic torque $\left(T_{e}\right)$ developed by induction motor

$$
T_{e}=\frac{2}{3} \frac{P}{2} \frac{L_{o}^{2}}{L_{r}} i_{s d} i_{s q}
$$

If we define $k=\frac{2}{3} \frac{P}{2} \frac{L_{o}}{L_{r}}$ then equation 3.33 becomes equation 3.34. This equation shows that under a constant field current $\left(i_{s d}\right)$, the electromagnetic torque is directly proportional to the torque current $\left(i_{s q}\right)$.

$$
T_{e}=k L_{o} i_{s d} i_{s q}
$$




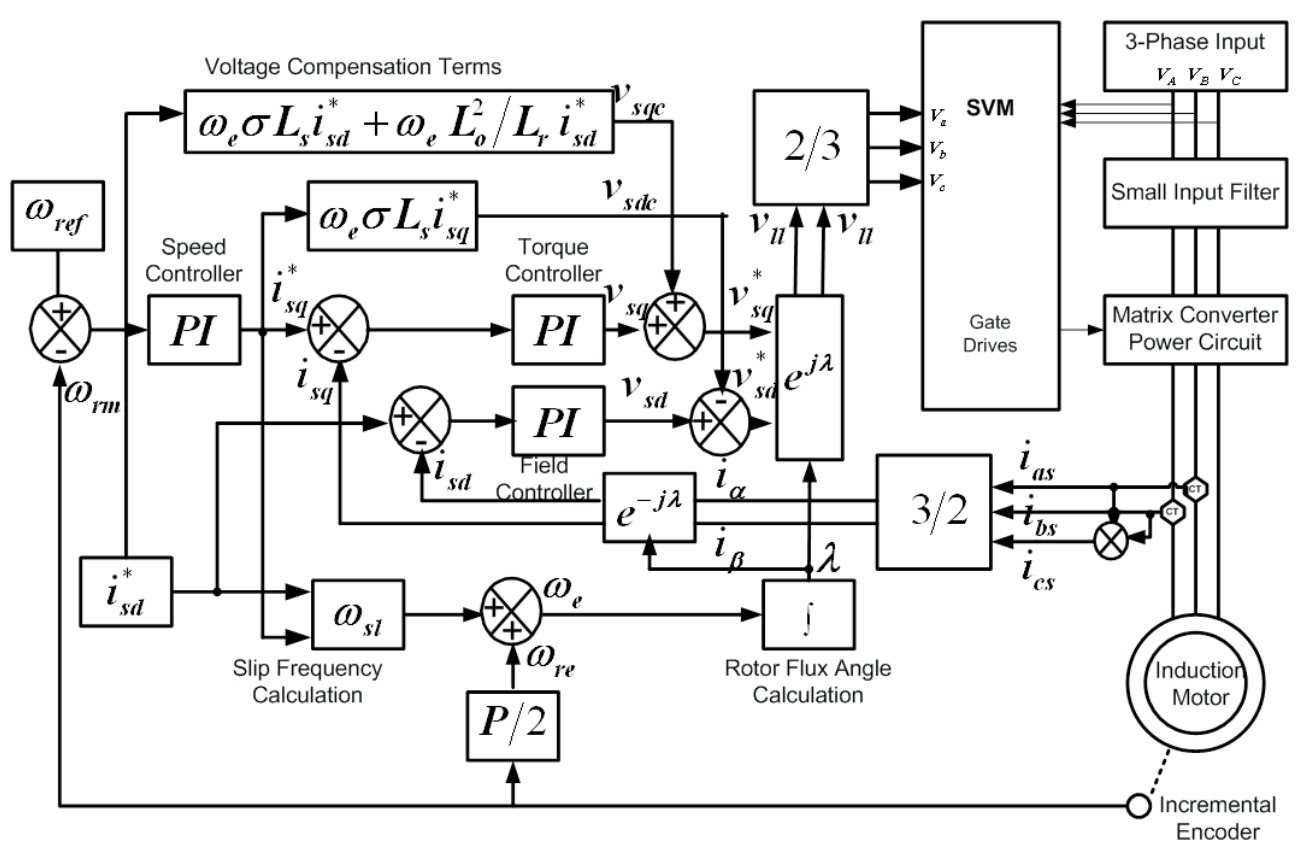

Figure 3.11: Closed Loop Indirect Field Oriented Vector Control Scheme

To obtain the stable operation, the reference voltages for space vector modulation are derived from output of speed and current control loops. The output of the speed controller $\left(i_{s q}^{*}\right)$ is considered as reference for $i_{s q}$ because this value defines the torque produced by the motor. In case of current loop, a calculated constant value ( $60 \%$ of the no load current) is used as a reference for the field producing current $\left(i_{s d}^{*}\right)$. Design of speed controller and current controllers will be discussed in the section 3.3.5.1 and 3.3.5.2 respectively. The outputs of the faster current controllers are summed with voltage compensation terms which are derived from the stator equations 3.23 and 3.24. Finally, the stator reference quantities are obtained from $2 / 3$ transformation as shown in the figure 3.11 . 


\subsubsection{Speed Control Design}

The block diagram of the speed controller is shown in the figure 3.12. The slower outer speed loop includes a PI controller, torque producing current $\left(i_{s q}^{*}\right)$ limiter, torque constant $\left(k_{t}\right)$ and mechanical parameters of the machine. The motor time constant $\left(\tau_{m}\right)$ is defined as ratio between moment of Inertia $(\mathrm{J})$ and Friction co-efficient $(\mathrm{B})$. The PI controller generates $i_{s q}^{*}$ from the speed error. The speed error is the difference between the actual speed and reference speed as shown in figure 3.12. In this project $i_{s q}^{*}$ is limited to 5.0 Amps for running the induction motor in safe mode. For this application, a prototype is operated at half of the rated speed so that the $i_{s q}^{*}$ is limited to $60 \%$ (5.0 Amps) of the rated value of $i_{s q}^{*}$.

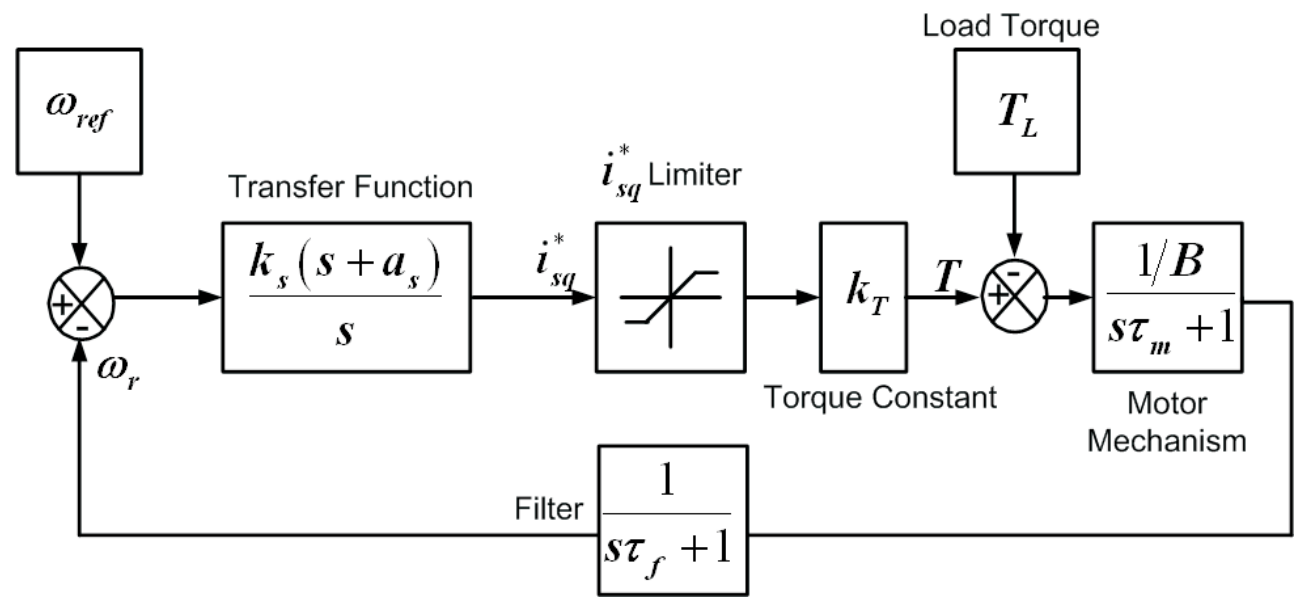

Figure 3.12: Speed Controller Design Scheme

$$
k_{t}=\frac{2}{3} \frac{P}{2} \frac{L_{o}^{2}}{L_{r}} i_{s d}
$$

The unknown torque constant $\left(k_{t}\right)$ is calculated using equation 3.35 , where it is relating $i_{s q}^{*}$ to electrical torque developed by the motor. The bandwidth of the speed controller is normally in the range from $2 \mathrm{~Hz}$ to $20 \mathrm{~Hz}$. In this project, PI values of $k_{s}=0.1, a_{s}=9.0$, are used, giving a bandwidth of $2 \mathrm{~Hz}$ because the calculated slip of the induction motor is $4 \%(0.04 * 50 \mathrm{~Hz}=2 \mathrm{~Hz})$. For this application damping ratio $(\zeta)$ of 0.707 is used. The PI controller values are designed by using the second order 
equation $\left(s^{2}+2 \zeta \omega_{n}^{2} s+\omega_{n}^{2}\right)$ and the closed loop transfer function of the system. In order to avoid noise in the speed measurement signals from incremental encoder as shown in figure 3.11 , a small digital filter is used.

\subsubsection{Current Loop Control Design}

The inner, faster current controllers have a much higher bandwidth than outer speed controller. In this application bandwidth of $100 \mathrm{~Hz}$ and a damping ratio $(\zeta)$ of 0.707 . The bandwidth of the current controller must be at least much faster than the speed controller to ensure that the current control tracks the output of the speed loop. An identical controller is used to maintain the field producing current $\left(i_{s d}\right)$. The

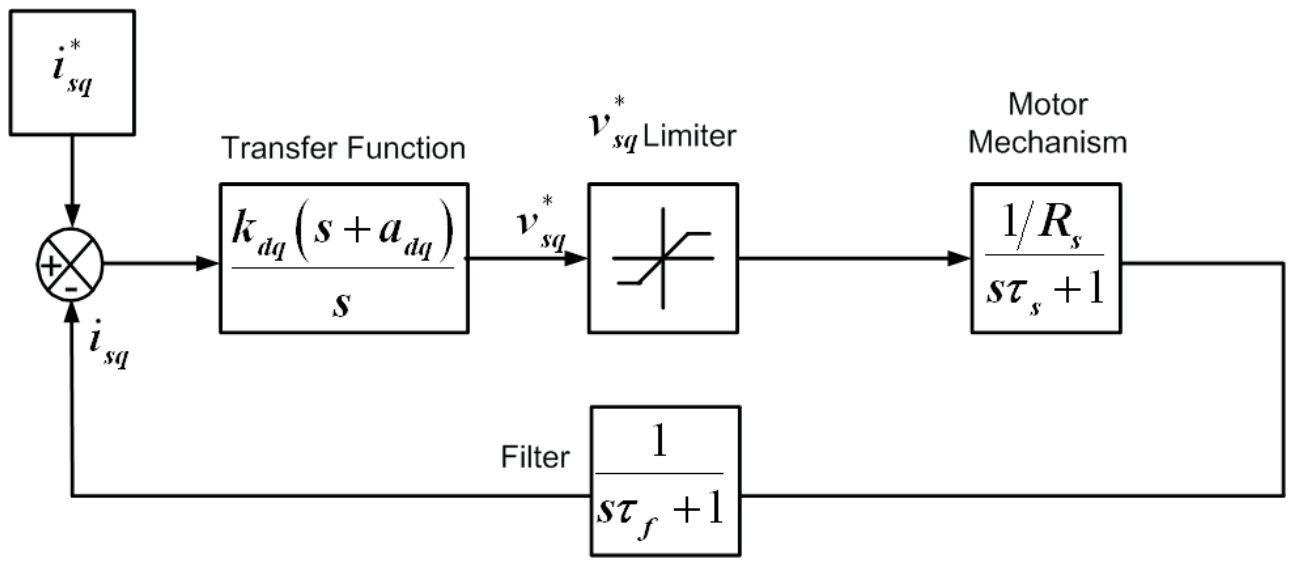

Figure 3.13: Current Controller Design Scheme

schematic of dq-controllers design is shown in figure 3.13. The faster inner current loop includes a PI controller, $v_{s q}^{*}$ limiter and electrical parameters of the machine. The armature time constant $\tau_{s}$ is defined as the ratio between the motor leakage co-efficient $\left(\sigma L_{s}\right)$ and the rotor resistance $\left(R_{s}\right)$.

The motor leakage co-efficient $\left(\sigma L_{s}\right)$ can be calculated from self inductance of stator $\left(L_{s}\right)$, self inductance of rotor $\left(L_{r}\right)$ and Mutual inductance $\left(L_{o}\right)$ as depicted in equation. 3.36

$$
\sigma L_{s}=\frac{L_{r} L_{s}-L_{o}^{2}}{L_{r}}
$$


The calculation of $\sigma L_{s}$ is depends on the assumption of variation in the motor inductive parameters and the rotor resistance. In order to avoid noise in current measurement first order filter is used. This filter is called as Anti-Aliasing filter. The purpose of Anti-Aliasing filter is to avoid the over lap of the measured signals. In this application, the cut-off frequency of the filter is equivalent to half of the sampling frequency of the Matrix Converter.

The outputs of the current controllers are used as a reference for the converter output voltages $\left(v_{s d}\right.$ and $\left.v_{s q}\right)$ which are limited to the maximum line to line output voltage of the Matrix Converter. In this application, PI values of $k_{d q}=35.0$ and $a_{d q}=600.0$ are used for the current controllers.

\subsubsection{Voltage Compensation Terms}

In order to compensate the resistive voltage drop, the value of compensation voltages are added with the output of the current controllers. This voltage compensation can improve the performance of the current control loops. The compensations terms are derived from the stator equations 3.23 and 3.24 .

$$
\begin{gathered}
v_{s d c}=-\omega_{e} \sigma L_{s} i_{s q}^{*} \\
v_{s q c}=\omega_{e} \sigma L_{s} i_{s d}^{*}+\omega_{e} \frac{L_{o}^{2}}{L_{r}} i_{s d}^{*}
\end{gathered}
$$

The compensation voltage terms are described in equations 3.37 and 3.38. The summation of both controller output and compensation terms generates the reference voltages $v_{s d}^{*}$ and $v_{s q}^{*}$ for the Matrix Converter. For experimental analysis $250 \mathrm{~V}$ is used as a limit for dq-reference voltages both $v_{s d}^{*}$ and $v_{s q}^{*}$. The dq-reference voltages are transformed to the stationary reference frame in two steps, as explained in the next section. 


\subsubsection{Rotating Reference Frame to Stationary Frame Trans- formation}

This section describes the general transformation to obtain stationary reference frame variables from rotating reference frame variables. By using this general transformation the real stationary quadrature voltages with reference to the stator angle can be obtained.

The rotating reference frame quantities $x_{d}(t)$ and $x_{q}(t)$ are transformed into stationary frame quantities $x_{\alpha}(t)$ and $x_{\beta}(t)$. The transformation is carried out by using the factor ' $y$ ' as shown in figure 3.14. The factor ' $y$ ' represents the angle between the stationary frame and the rotating reference frame.
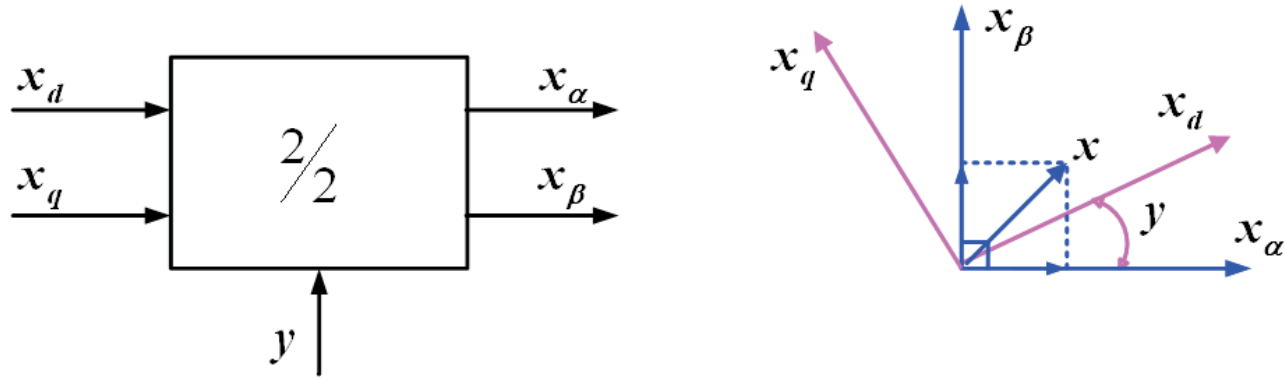

Figure 3.14: Rotating Reference Frame to Stationary Frame Transformation

$$
\begin{aligned}
& x_{\alpha}(t)=x_{d}(t) \cos y-x_{q}(t) \sin y \\
& x_{\beta}(t)=x_{d}(t) \sin y+x_{q}(t) \cos y
\end{aligned}
$$

The stationary frame quantities are given in the equations 3.39 and 3.40. This transformation is equivalent to the $e^{j \lambda}$ in the figure 3.11 .

$$
\begin{aligned}
& v_{s \alpha}=v_{s d}^{*} \cos \lambda-v_{s q}^{*} \sin \lambda \\
& v_{s \beta}=v_{s d}^{*} \sin \lambda+v_{s q}^{*} \cos \lambda
\end{aligned}
$$

Similarly, the stationary frame voltages $\left(v_{s \alpha}\right.$ and $\left.v_{s \beta}\right)$ for Matrix Converter modulation 
is obtained from the rotating reference frame voltages $\left(v_{s d}^{*}\right.$ and $\left.v_{s q}^{*}\right)$ as described in the equations 3.41 and 3.42 .

\subsubsection{Stationary Frame to Three Phase Transformation}

Deriving the three phase quantities from the stationary frame is explained in this section. Figure 3.15 depicts the transformation between the stationary frame quantities $\left(x_{\alpha}(t)\right.$ and $\left.x_{\beta}(\mathrm{t})\right)$ to reference quantities $x_{a}, x_{b}$ and $x_{c}$.
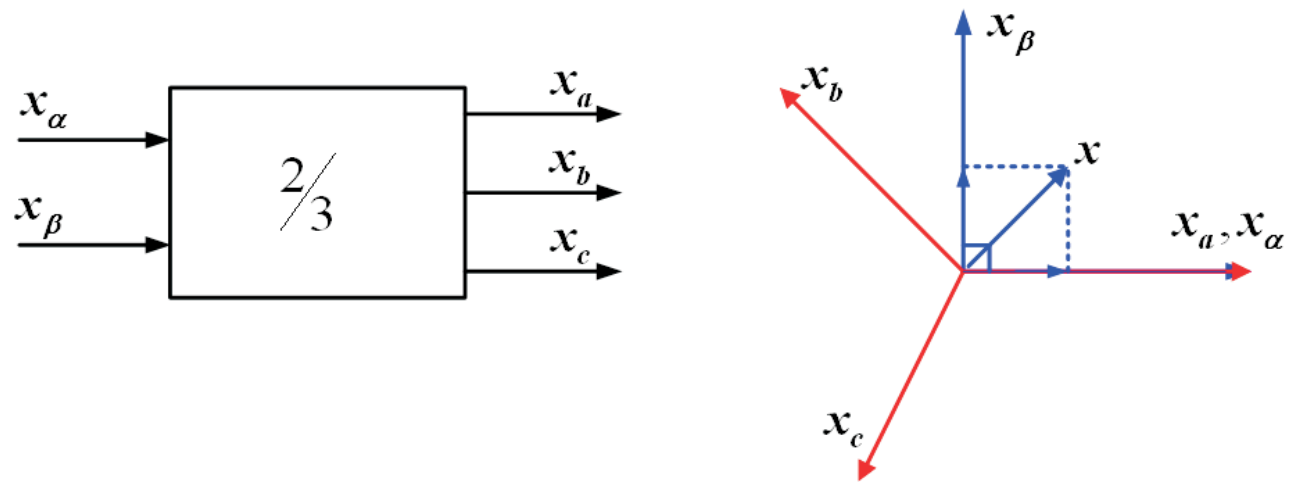

Figure 3.15: 2/3 Transformation

For this transformation $3 / 2$ peak conversion method is used as shown in the equations $3.43,3.44$ and 3.45 .

$$
\begin{gathered}
x_{a}=\frac{2}{3} x_{\alpha}(t) \\
x_{b}=-\frac{1}{3} x_{\alpha}(t)+\frac{1}{\sqrt{3}} x_{\beta}(t) \\
x_{c}=-\frac{1}{3} x_{\alpha}(t)-\frac{1}{\sqrt{3}} x_{\beta}(t)
\end{gathered}
$$

Similarly, the stationary frame voltages $v_{\alpha}$ and $v_{\beta}$ can be transformed into three phase reference voltages $V_{a}^{*}, V_{b}^{*}$ and $V_{c}^{*}$.

$$
\begin{gathered}
V_{a}^{*}=\frac{2}{3} v_{s \alpha} \\
V_{b}^{*}=-\frac{1}{3} v_{s \alpha}+\frac{1}{\sqrt{3}} v_{s \beta}
\end{gathered}
$$




$$
V_{c}^{*}=-\frac{1}{3} v_{s \alpha}-\frac{1}{\sqrt{3}} v_{s \beta}
$$

The reference voltages are described in the equations 3.46, 3.47 and 3.48 and used as input signals for Space Vector Modulation (SVM) to generate pulses for the Matrix Converter. 


\subsection{Conclusions}

The control methods for open loop and closed loop operation of high performance induction motor drives has been described. Even though open loop Volts/Hertz motor control is simple, it is not suitable for low speed operation due to stator voltage drop as explained in section 3.2.1. To overcome this problem, vector control is considered. Mathematically decoupling the flux and torque producing current is analogous to that of separately excited DC motor. The direct and indirect measurement for finding the rotor flux angle has been explained. For this application, indirect measurement is used to avoid the changes in the standard machine model. Even though indirect vector control is sensitive in machine parameters such as rotor time constant $\left(\tau_{r}\right)$ and actual speed measurement signal $\left(\omega_{r e}\right)$, it is capable of producing the fast torque response. Finally, design of the speed and current controllers has been described. 


\section{Chapter 4}

\section{Novel Methods for Avoiding Regeneration}

\subsection{Introduction}

Regeneration into the $\mathrm{AC}$ mains supply is an attractive feature for $\mathrm{AC}$ drives in applications such as hoists, conveyor belts, cranes and elevators. All these applications require four quadrant operation. For example, in an electric vehicle the regenerative energy can be used to recharge the battery and to brake (or stop) the electric vehicle. Even though regeneration leads to energy savings, it can cause many problems to the power electronic converters and power systems [63].

Most industrial drives utilize an electrical braking system which contains a power transistor switch in series with a large braking resistor to dissipate the excessive regenerative power. In aerospace applications, in order to avoid power quality problems, regeneration onto the supply is not allowed. The purpose of this research is to investigate methods of avoiding regeneration from Matrix Converter drive. This research is focussed on aerospace applications, such as aircraft surface actuation control systems and in-flight refueling systems, where regeneration into the main supply is not 
allowed. This chapter investigates ways to avoid regeneration in a Matrix Converter based motor drive. The first section of this chapter describes the principles of regeneration and conventional braking methods, such as regenerative braking, dynamic braking, D.C injection braking, field current braking and counter current braking.

The second section of this chapter proposes two novel techniques to detect regeneration in the Matrix Converters. These are the Power Comparison technique (PC) and Input Voltage Reference technique (IVR). In PC technique, output power is used as a reference and in case of IVR technique input voltage across the input filter inductor is used as reference for detecting the regeneration.

The final section of this chapter explains two novel methods of dissipating the regenerative power from a Matrix Converter. These are the Bi-Directional Switch (BDS) method and Input Power Clamp method (IPC). 


\subsection{Regeneration in Matrix Converters}

As mentioned in section 1.4, a feature of a Matrix Converter is the inherent bidirectional power flow or four quadrant operation capability, as shown in figure 4.1.

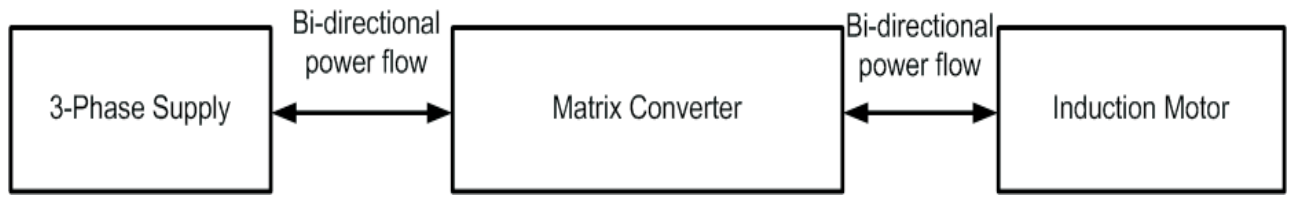

Figure 4.1: Inherent Bi-Directional Power Flow in a Matrix Converter Motor Drive

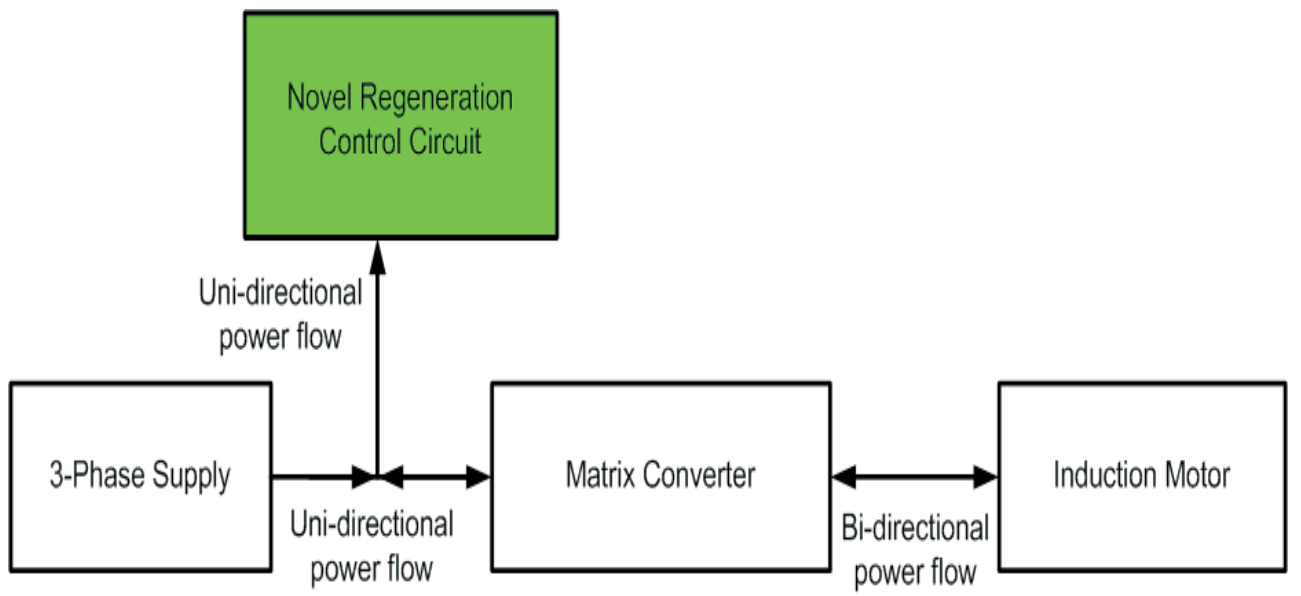

Figure 4.2: System for Avoiding Regeneration in a Matrix Converter Motor Drive

However, the aim of this research is to eliminate this prominent property of the Matrix Converter using a Regeneration Control Circuit (RCC). 


\subsubsection{Operating Conditions which cause Regeneration in Motor Drives}

There are many operating conditions which can cause regeneration from a power converter [47, 48], for example:

- when a motor load is rapidly decelerated.

- when a load is being controlled whilst aided by gravity, for example in hoists and cranes applications.

In the above conditions, the motor slip frequency is less than zero, so regeneration occurs. Negative slip occurs when the load causes the rotor of an induction motor run faster than the stator field. Therefore, whenever an induction motor runs faster than the rotating field, regeneration occurs and the Kinetic Energy of the rotating parts can be returned to the supply if a return path is provided. With a Matrix Converter there is no need to provide a return path because the Matrix Converter has inherent bi-directional power flow. 


\subsubsection{Braking Methods}

When electrical braking of a motor is used, the regenerative energy can be fed back to the mains supply or dissipated as heat in a resistor or load. Some common braking methods that are used to convert the kinetic energy into heat [47] are:

1. Regenerative Braking

2. Dynamic Braking

3. DC Injection Braking

4. Field Current or Flux Braking

5. Counter Current Braking

All the methods are used to dissipate regenerative energy. In this research the dynamic braking method is adopted. The significant advantage of this method is the use of relatively simple hardware, for example a controlled switch in series with a braking resistor.

\subsubsection{Regenerative Braking}

DC-Link converter: In order for a DC-Link converter to allow the regenerated energy back onto the main bus, a separate active controlled rectifier is connected in a back-to-back configuration, as shown in the figure 2.3. This method is useful for continuous braking applications and the braking energy is not wasted. The higher cost of the hardware is the potential draw back of this system, so it is only used in specific drives which have high loads of regenerative energy.

Matrix Converter: Matrix Converters have inherent regenerative braking. No additional hardware is required to feed back regenerative energy. 


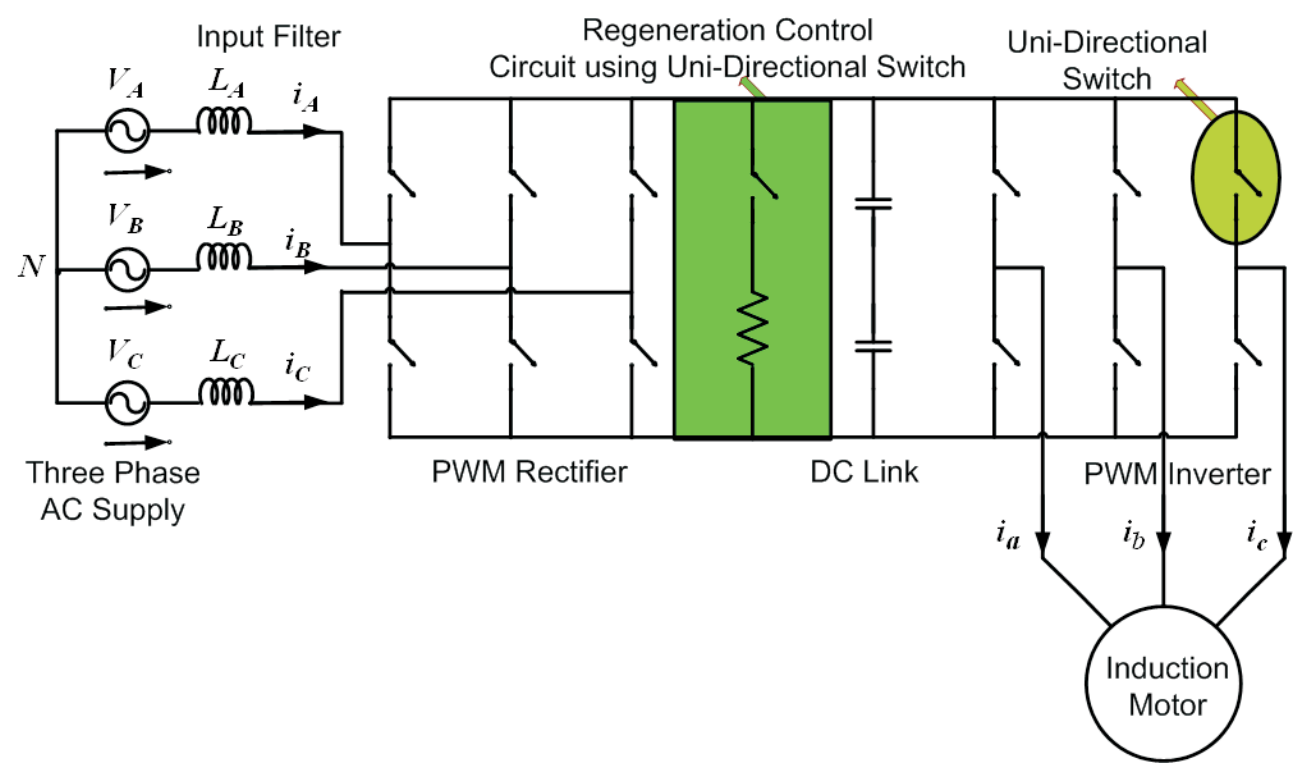

Figure 4.3: Overview of a Dynamic Braking Circuit for a DC-Link Converter

\subsubsection{Dynamic Braking}

DC-Link converter: A controlled Uni-Directional Switch (UDS) with a series resistor can be used to absorb energy during the regeneration and dissipate this energy in the form of heat, as shown in the figure 4.3. In DC-Link converters the voltage across the DC-Link capacitor can be continuously monitored. If this voltage rises above a set value, the switch can be turned ON to connect the resistor across DC-Link, dissipating the regenerative energy. The significant advantage of this method is small requirement for additional hardware circuit and the fact that a diode bridge rectifier may be used.

Matrix Converter: A similar principle can be used to dissipate the regenerative energy, but the Matrix Converter requires Bi-Directional Switches instead of UniDirectional Switches, as shown in the figure 4.4. 


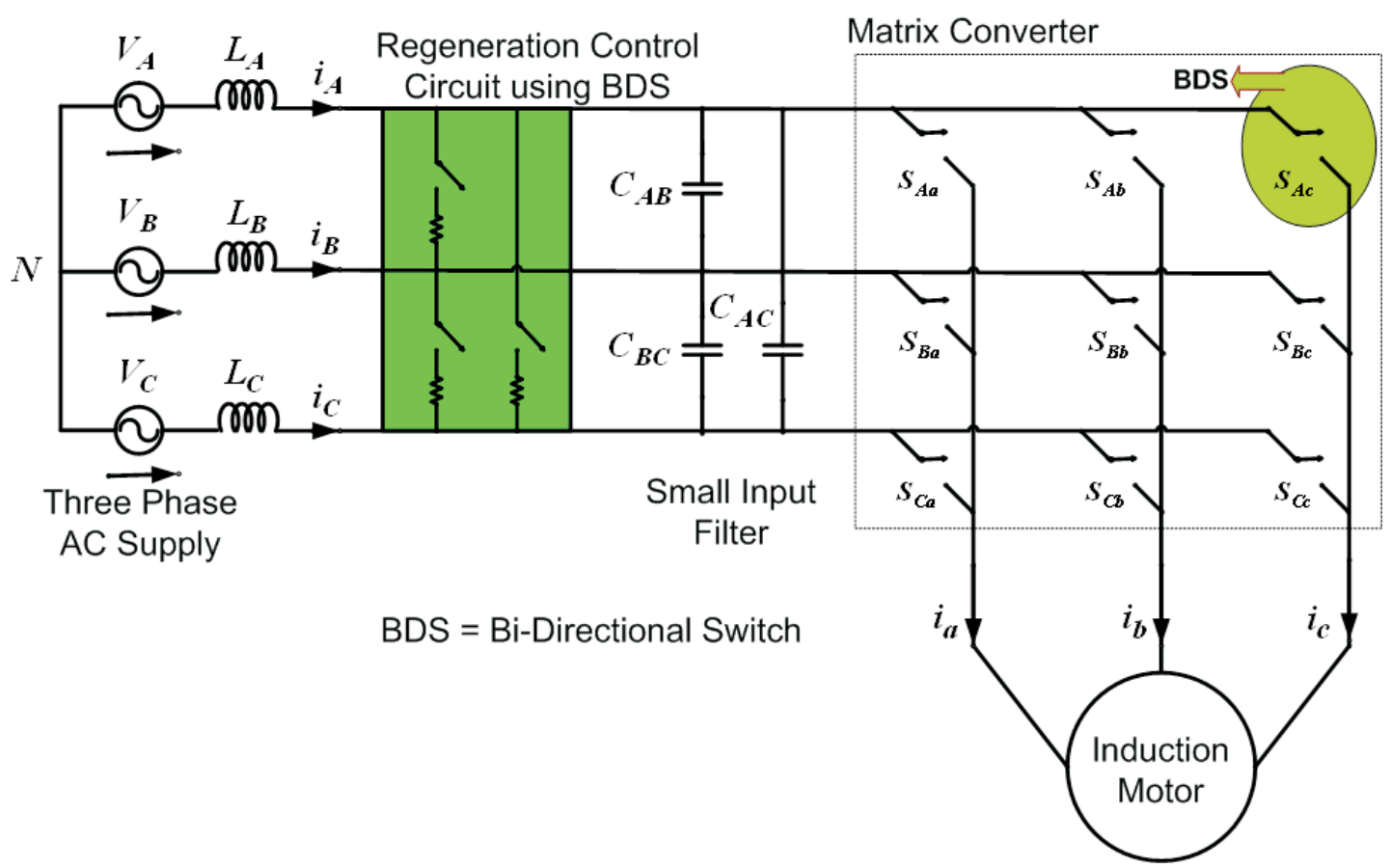

Figure 4.4: Overview of a Dynamic Braking Method for a Matrix Converter

\subsubsection{DC Injection Braking}

This method of braking can be applied to brake non reversible AC motors [47]. In order to brake the stator of the machine is excited using a DC supply instead of an AC supply. The DC supply can be obtained from AC supply using step down transformer and uncontrolled full wave rectifier, as shown in the figure 4.5.

When the stator is excited from a DC supply a stationary magnetic field is set-up in the stator. This field induces the rotor currents which produce a torque to bring the rotor to a rest position quickly. The braking torque and deceleration during electrical braking depends upon the amount of DC power injected into the motor and rotor resistance. DC Magneto Motive Force (MMF) is influenced by the stator connections and the number of turns on the motor. The DC current injected into the stator circuit can me controlled by adjusting the stator resistance $\left(R_{s}\right)$, as shown in figure 4.5.

The DC supply is permanently connected to the stator of the induction motor. This arrangement is purposely made to avoid a considerable delay in creating a stationary 


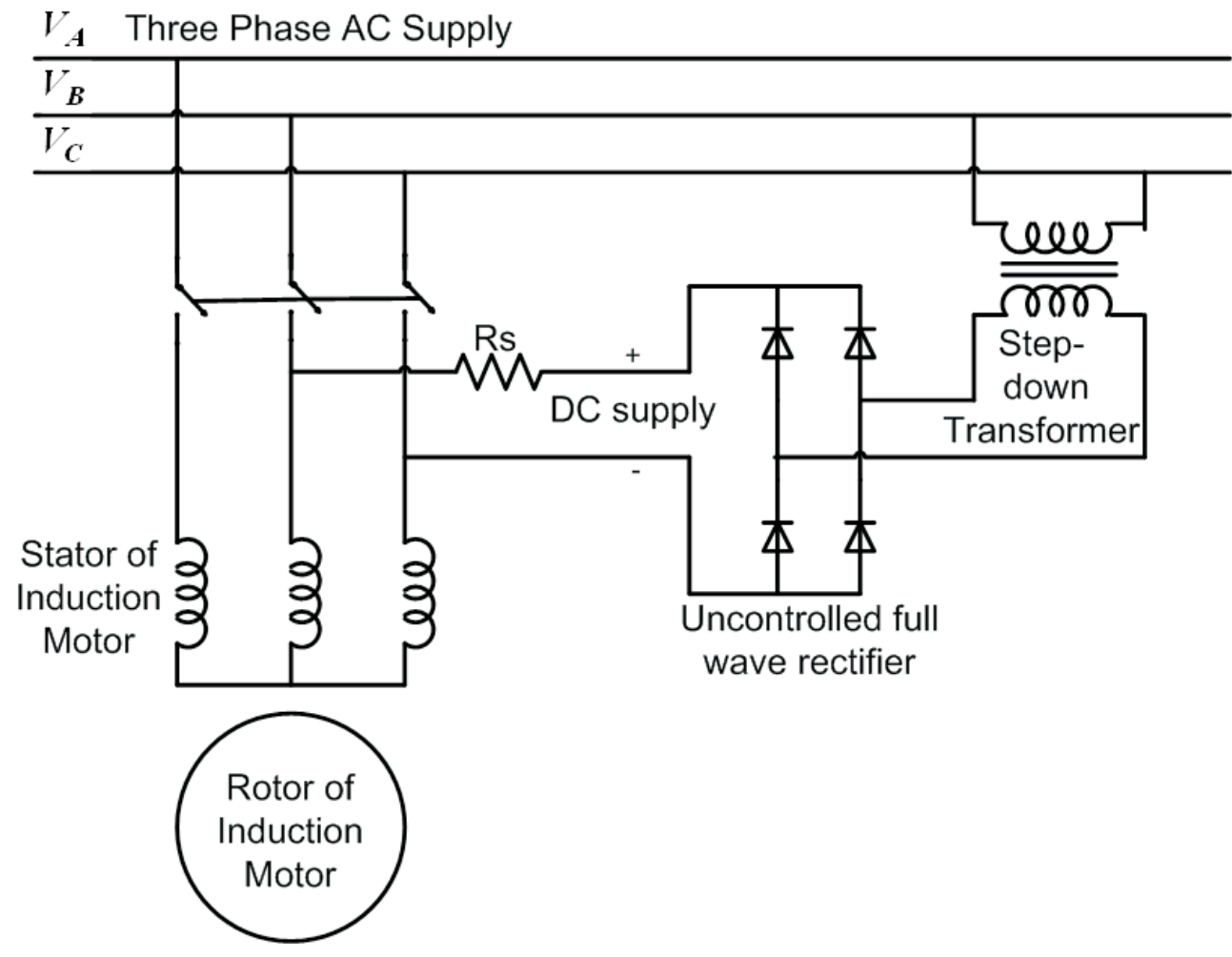

Figure 4.5: The DC Injection Braking Method

magnetic field. During the normal motoring mode there is no power flow back to the AC supply through this set-up because the diodes are reverse biased.

\subsubsection{Field Current or Flux Braking}

The Field Current method is suitable for the field oriented vector controlled AC drives [48]. In principle, the field producing current $\left(i_{s d}\right)$ of the motor increases which causes higher motor losses. This method therefore converts the regenerative energy into heat in the motor. This method is not commonly applied because of the possibility of overheating the motor windings [47]. 


\subsubsection{Counter Current Braking}

The direction of the stator field can be reversed by interchanging the phase sequence of AC supply to the induction motor [47]. Hence braking torque is developed and motor can be stopped quickly.

When the main supply to the induction motor is reversed, the induced EMF is added to the AC supply voltage. This cumulative voltage causes very high currents during braking and effectively increase the braking torque. Counter current braking can be applied where the developed braking torque is required to stop the rotor quickly. 


\subsection{Techniques to detect Regeneration in Matrix Converters}

Two techniques for detecting regeneration in Matrix Converter motor drives are presented in this section. The first technique is the Power Comparison technique (PC) where the motor output power is used as a reference for the Regeneration Control Circuit (RCC). The second technique is the Input Voltage Reference (IVR) technique, which is similar to dynamic braking techniques used in DC-Link converters.

\subsubsection{Power Comparison (PC) Technique}

With regard to Power Comparison (PC) technique, the output power calculation is important. The absolute value of the calculated output power can be used as reference for both power dissipation methods (BDS and IPC).

The output power $\left(P_{o}\right)$ of the converter is calculated from the torque producing current $\left(i_{s q}^{*}\right)$ and measured rotor speed $\left(\omega_{r e}\right)$. Generation of gate drive signals is required for the switches in the Regeneration Control Circuit (RCC) for both dissipation methods, as shown in figure 4.6. Power dissipation through the resistors in the Regeneration Control Circuit (RCC) is directly proportional to the duty cycle of switches, as shown in equation 4.1,

$$
P_{d i s} \propto D
$$

where, $\mathrm{D}=$ Duty cycle of the bi-directional switches and $P_{d i s}=$ Power dissipation of the resistors.

The duty cycle calculation requires the maximum electrical braking power $\left(P_{m b}\right)$ to be calculated. The duty cycle of the switches is then less than or equal to unity under all operating conditions.

$$
P_{m b}=T_{m e} \omega_{m r e}
$$




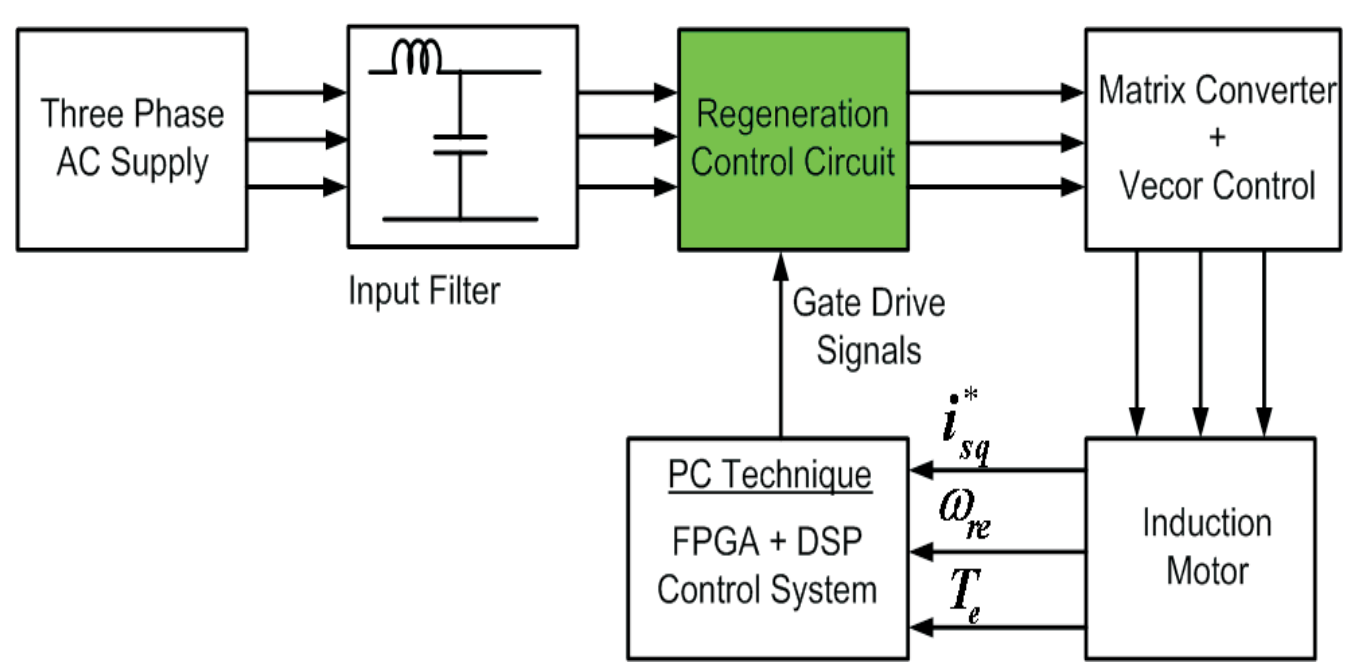

Figure 4.6: Block Diagram of the Power Comparison (PC) Technique for both dissipation Methods

where, $T_{m e}=$ the maximum electromagnetic torque and $\omega_{m r e}=$ the maximum motor speed.

The duty cycles are reduced linearly with the required dissipation. The Digital Signal Processor (DSP) calculates the dissipated regenerative power during every PWM interrupt cycle. The induction motor will not feed back the whole of the regenerated power because of the losses such as friction, windage and iron losses in the motor as well as switching and conduction losses in the Matrix Converter. Therefore, the resistor dissipates slightly less power than the actual motor regenerative power.

The design of braking resistor $\left(R_{b}\right)$ depends upon the maximum power under the regeneration, as shown in equation 4.3 ,

$$
\begin{gathered}
P_{\text {in }, \max }=\frac{V_{i n}^{2}}{R_{b}} \\
I_{b}=\frac{V_{i n}}{R_{b}}
\end{gathered}
$$

Where the braking current $\left(I_{b}\right)$ and input power $\left(P_{i n}\right)$ are directly proportional to the input voltage. The braking resistor design also depends on the braking time, the 
thermal capacity of the resistor and heatsink. The value of braking current must also be less than the current rating of switches in the Regeneration Control Circuit $(\mathrm{RCC})$.

\subsubsection{Input Voltage Reference (IVR) Technique}

In the Input Voltage Reference (IVR) technique, the voltage across the input filter capacitor is measured and compared to the supply voltage. The IVR technique can be used to detect the regeneration in the Matrix Converter for both dissipation methods (BDS and IPC).

Generation of control signals are required for the switches in the Regeneration Control Circuit (RCC), as shown in figure 4.7.

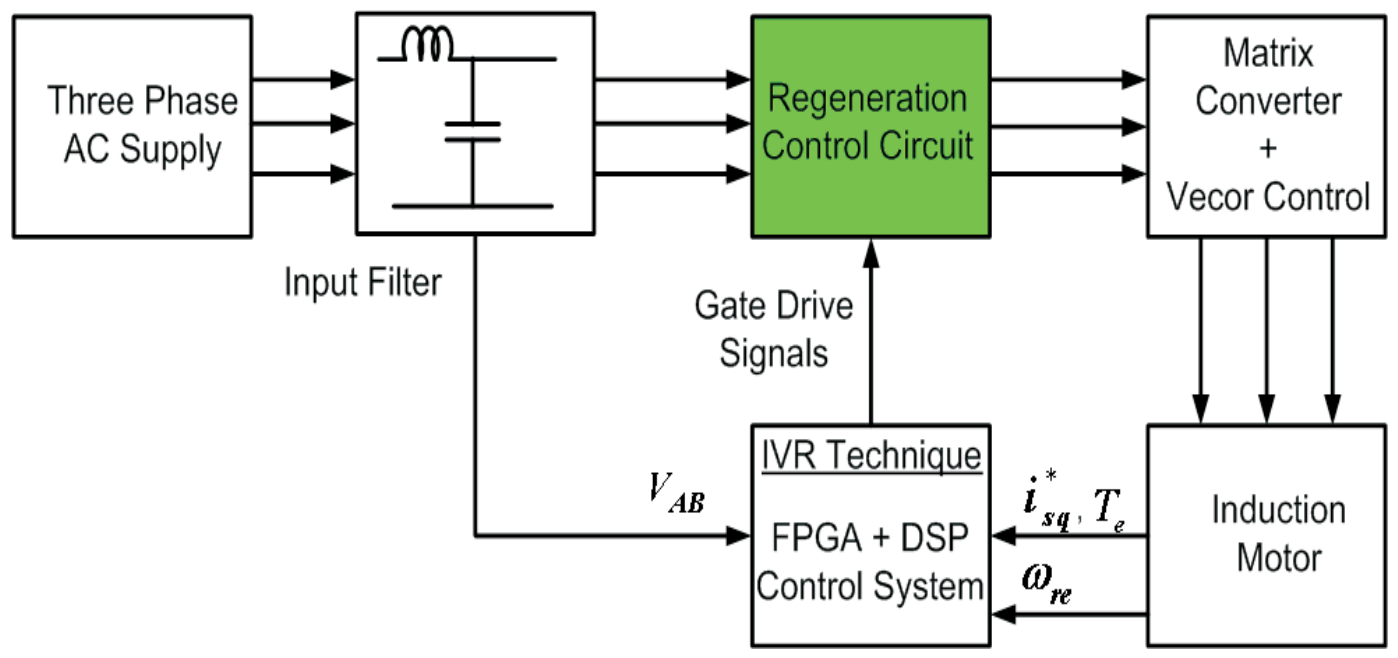

Figure 4.7: Block Diagram for the Input Voltage Reference (IVR) Technique for both dissipation Methods

The duty cycle variation is directly proportional to the increase in the line to line voltage across the input filter capacitor of the Matrix Converter under regeneration with respect to the output power $\left(P_{o}\right)$, as shown in the equation 4.5.

$$
V_{A B} \propto P_{o} \propto D
$$


here $V_{A B}$ is line to line voltage across the input filter capacitor. The regeneration is determined by considering the difference between the supply voltage and Matrix Converter voltage (the voltage across the input filter inductor of the Matrix Converter) during each sampling period. The voltage difference is monitored by the DSP. If the voltage exceeds a specified limit, the DSP control system turns on the switches in the Regeneration Control Circuit (RCC) with a duty cycle proportional to the voltage level. The regenerative energy is dissipated as heat through the RCC resistors. This power dissipation happens only when the drive is operating under regenerative conditions. If the capacitor voltage is equal to the supply voltage then the duty cycle is set to zero.

\subsubsection{Comparison between PC Technique and IVR Tech- nique}

The differences between the two techniques are briefly described in the Table 4.1.

\begin{tabular}{|c|c|c|}
\hline \hline Factors & PC Technique & IVR Technique \\
\hline \hline $\begin{array}{c}\text { Required inputs } \\
\text { to control platform }\end{array}$ & Analogue inputs & 4 \\
\hline Measured variables & Output power: Torque, & Anplogue inputs \\
& $\begin{array}{c}\text { Torque producing current } \\
\text { of the motor drive } \\
\end{array}$ & $\begin{array}{c}\text { across the input } \\
\text { filter capacitors } \\
\end{array}$ \\
& Speed and Input power & Output power and Speed \\
\hline \hline
\end{tabular}

Table 4.1: Summary of difference between PC and IVR techniques

With regard to the implementation, the PC technique is less complicated than the IVR technique. The reason for this is that the number of measurements required for $\mathrm{PC}$ technique is lower than for the IVR technique. 


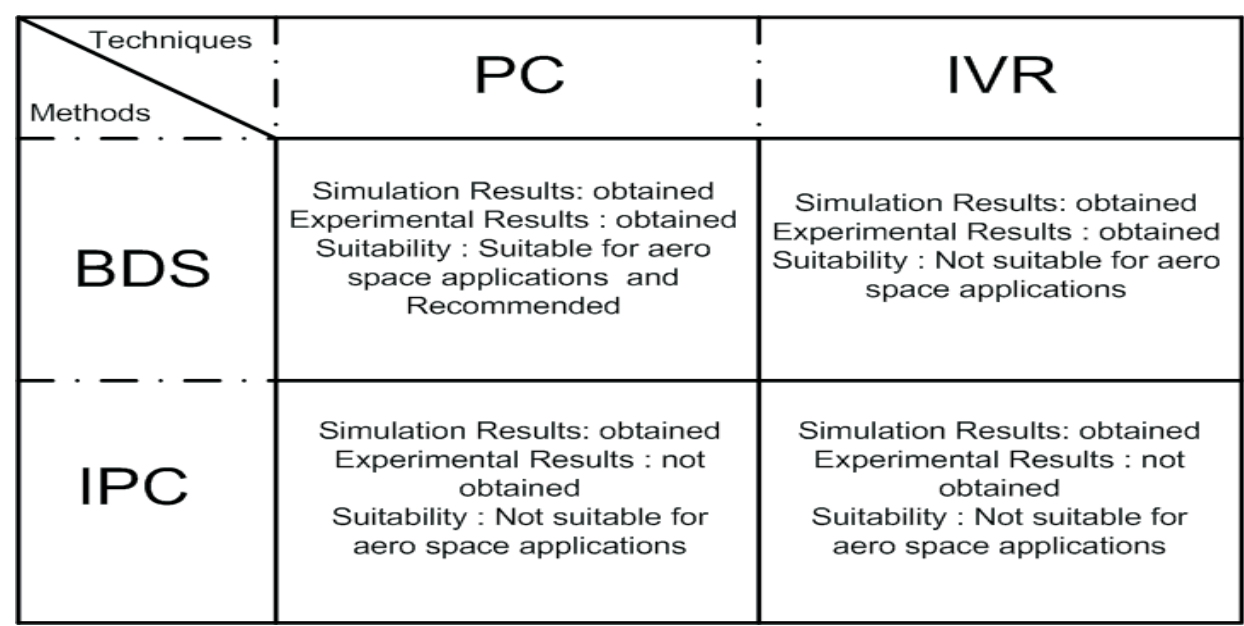

Figure 4.8: Summary of the Proposed Methods (BDS, IPC) with Proposed Techniques $(\mathrm{PC}, \mathrm{IVR})$

\subsubsection{Summary of Proposed Methods (BDS, IPC)}

The summary of the proposed methods (BDS, IPC) with proposed regeneration detection techniques is shown in the figure 4.8. Even though there are more combinations to avoid regeneration in the Matrix Converter, the Bi-Directional Switch (BDS) with Power Comparison (PC) technique is recommended for aerospace applications because it is easy to implement with less hardware requirements.

BDS with IVR : This combination is not suitable for aerospace applications because it has a issue of noise problem when the voltage as a reference for detecting regeneration in the Matrix Converter drive. Even though duty cycle for Regeneration Control Circuit (RCC) is made linear, the power dissipation is not linear because of noise in the input line voltage.

IPC with PC : This combinations is not experimentally implemented because it requires electrolytic capacitor in the output side of the diode bridge. Some additional informations are already discussed in the section 1.5.

IPC with IVR : This combination is not suitable for aerospace applications because of noise problems and the requirements of more hardware for RCC. 


\subsection{Avoiding Regeneration in Matrix Converters}

To do avoiding regeneration in Matrix Converters two novel circuit topologies are investigated. These are:

1. Bi-Directional Switch (BDS) method

2. Input Power Clamp (IPC) method

The power circuits for both methods will be explained in sections 4.4.1 and 4.4.2.

\subsubsection{Bi-Directional Switch (BDS) Method}

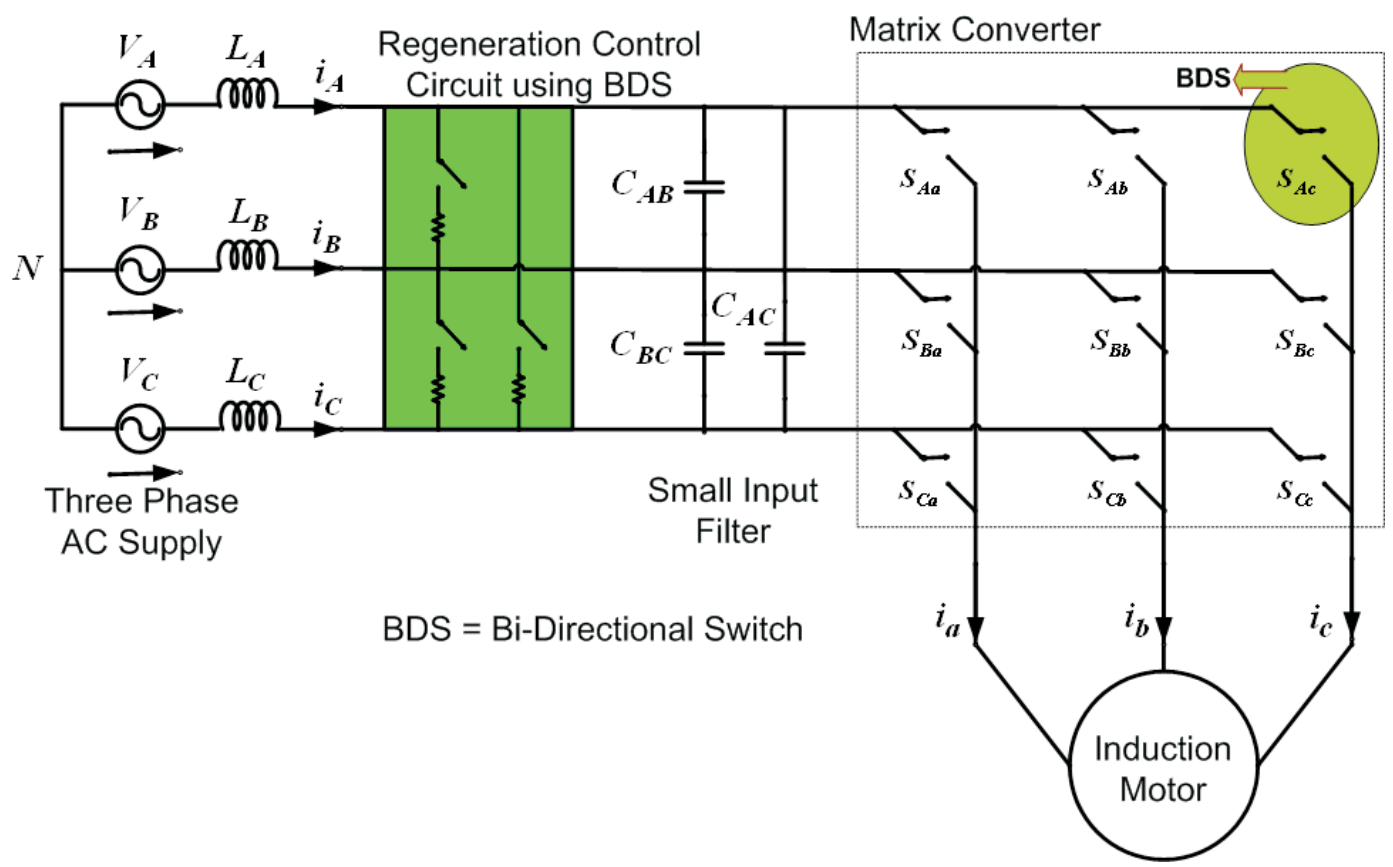

Figure 4.9: Avoiding Regeneration with a Matrix Converter Motor Drive using the Bi-Directional Switch (BDS) Method

The power circuit for the BDS method Regeneration Control Circuit (RCC) is shown in figure 4.9. The Regeneration Control Circuit (RCC) is introduced across the input filter capacitors $\left(C_{A B}, C_{B C}\right.$ and $\left.C_{A C}\right)$. 


\section{The BDS Method Regeneration Control Circuit (RCC):}

The Regeneration Control Circuit (RCC) is responsible for power dissipation when regeneration takes place in the Matrix Converter motor drive. The RCC consists of three bi-directional switches $\left(B D S_{A B}, B D S_{B C}\right.$ and $\left.B D S_{A C}\right)$ in series with three resistors $\left(R_{A B}, R_{B C}\right.$ and $\left.R_{A C}\right)$ connected across the input lines, in parallel with the input filter capacitor. The schematic of the RCC is depicted in the figure 4.10.

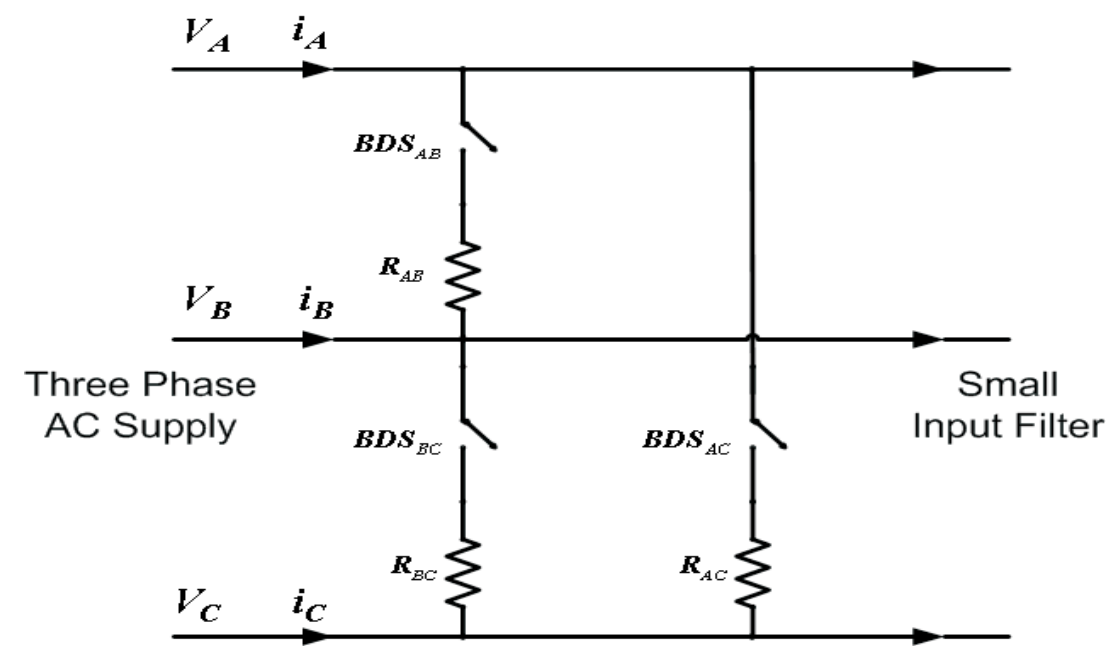

Figure 4.10: The Bi-Directional Switch (BDS) Method Regeneration Control Circuit(RCC) 


\subsubsection{Input Power Clamp (IPC) Method}

The second method, the Input Power Clamp (IPC) method, has also been proposed to avoid regeneration in a Matrix Converter motor drive. The IPC method requires only one breaking resistor and switch, compared to three switches in series with three resistors for the BDS method

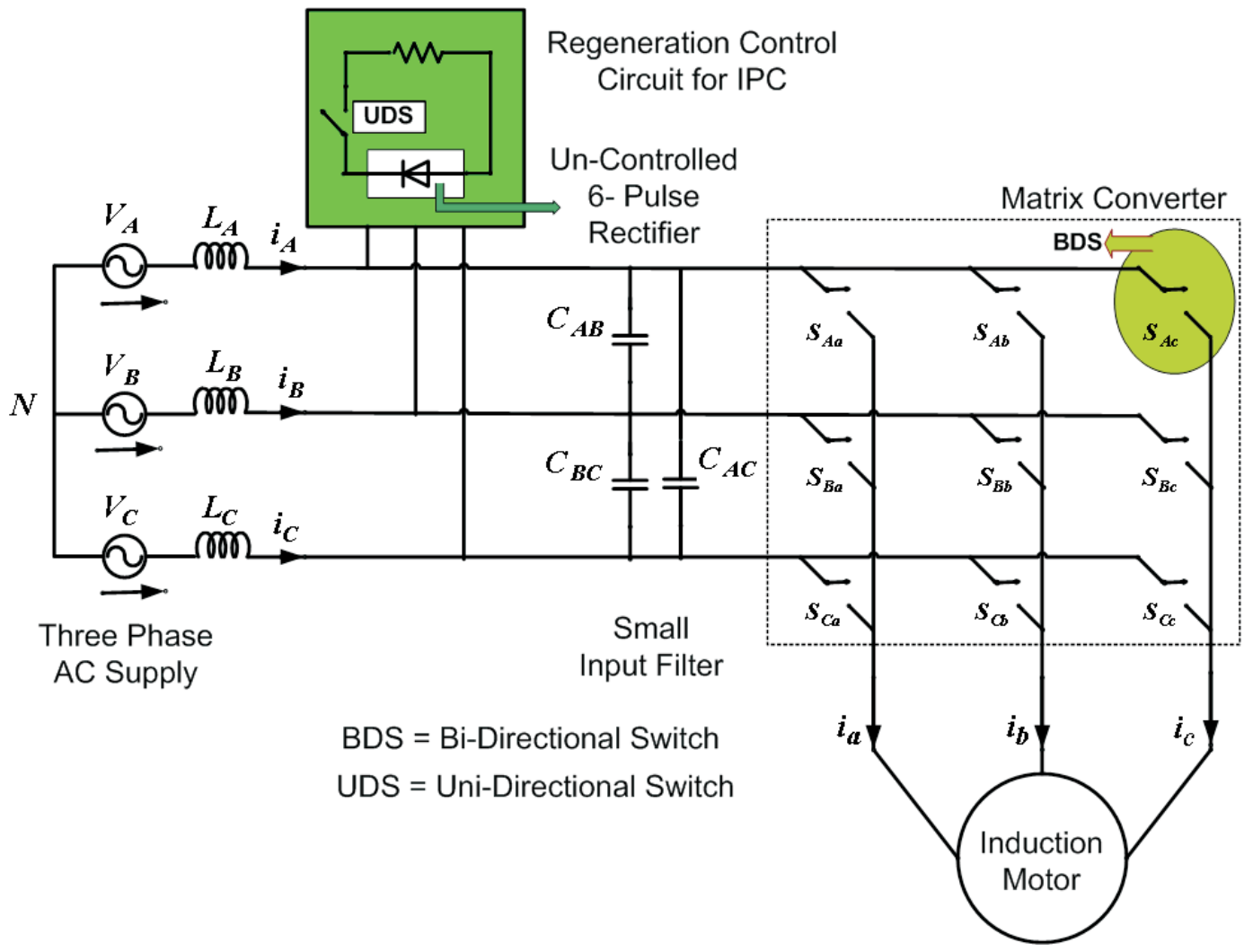

Figure 4.11: Regeneration Control Circuit for a Matrix Converter using the Input Power Clamp (IPC) dissipation Method

The Regeneration Control Circuit (RCC) for the Input Power Clamp (IPC) method is located across the input filter capacitors $\left(C_{A B}, C_{B C}\right.$ and $\left.C_{A C}\right)$. The schematic for the Input Power Clamp (IPC) method circuit is shown in figure 4.11. To control the switch in the Regeneration Control Circuit (RCC), a reference signal is generated using either the Power Comparison (PC) technique or the Input Voltage Reference (IVR) technique. 


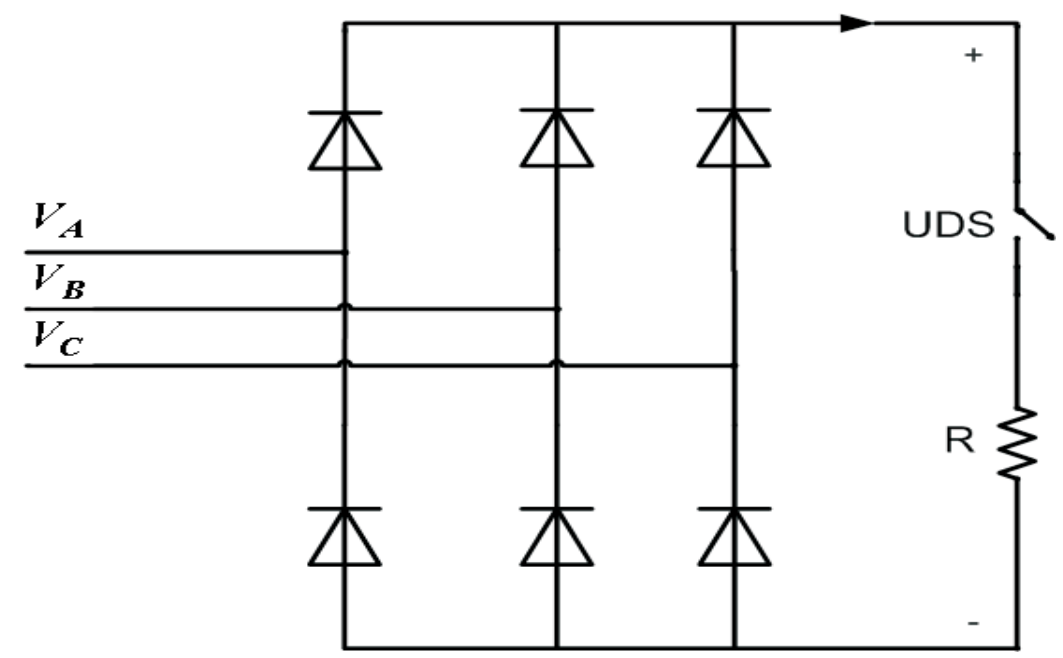

Figure 4.12: Regeneration Control Circuit (RCC) for the Input Power Clamp (IPC) Method

\section{Regeneration Control Circuit for IPC Method:}

The Input Power Clamp (IPC) method Regeneration Control Circuit (RCC) consists of a conventional, un-controlled 6-pulse rectifier and a Uni-directional Switch (UDS) in series with a braking resistor $(\mathrm{R})$, as shown in figure 4.12. When compared to Bi-Directional Switch (BDS) method, the IPC method requires fewer power semiconductor switching components. With regard to practical implementation, IPC method is not suitable for aerospace applications because it requires electrolytic capacitor in the output side.

According to aerospace power quality specifications, the standard clamp in the Matrix Converter is not allowed to use for avoiding regeneration in the Matrix Converter. The reason is, the standard clamp is considered as a safety device to protect the Matrix Converter under abnormal conditions such as over voltage in the input side or output side. 


\subsubsection{Comparison between BDS Method and IPC Method}

The Input Power Clamp (IPC) method has some advantages over the Bi-Directional Switch (BDS) method with respect to the number of required switches and resistors. The major differences between BDS and IPC methods are given in the Table 4.2.

\begin{tabular}{|c|c|c|}
\hline \hline Factors & BDS Method & IPC Method \\
\hline \hline Switches & $\begin{array}{c}\text { 3 Bi-Directional } \\
\text { Switch (BDS) }\end{array}$ & $\begin{array}{c}\text { 1 Uni-Directional } \\
\text { Switch (UDS) }\end{array}$ \\
\hline Resistors & 3 & 1 \\
\hline Implementation & easy & complicated \\
\hline \hline
\end{tabular}

Table 4.2: Comparison between the Bi-Directional Switch (BDS) Method and the Input Power Clamp (IPC) Method Circuits 


\subsection{Description of the Techniques with both Dis- sipation Methods}

The description of two techniques (PC and IVR) with two dissipation methods (BDS and IPC) for avoiding regeneration from the Matrix Converter motor drives are presented in this section.

\subsubsection{Power Comparison (PC) Technique}

The Power Comparison technique for both the Bi-Directional Switch (BDS) and Input Power Clamp (IPC) dissipation methods is described in this section.

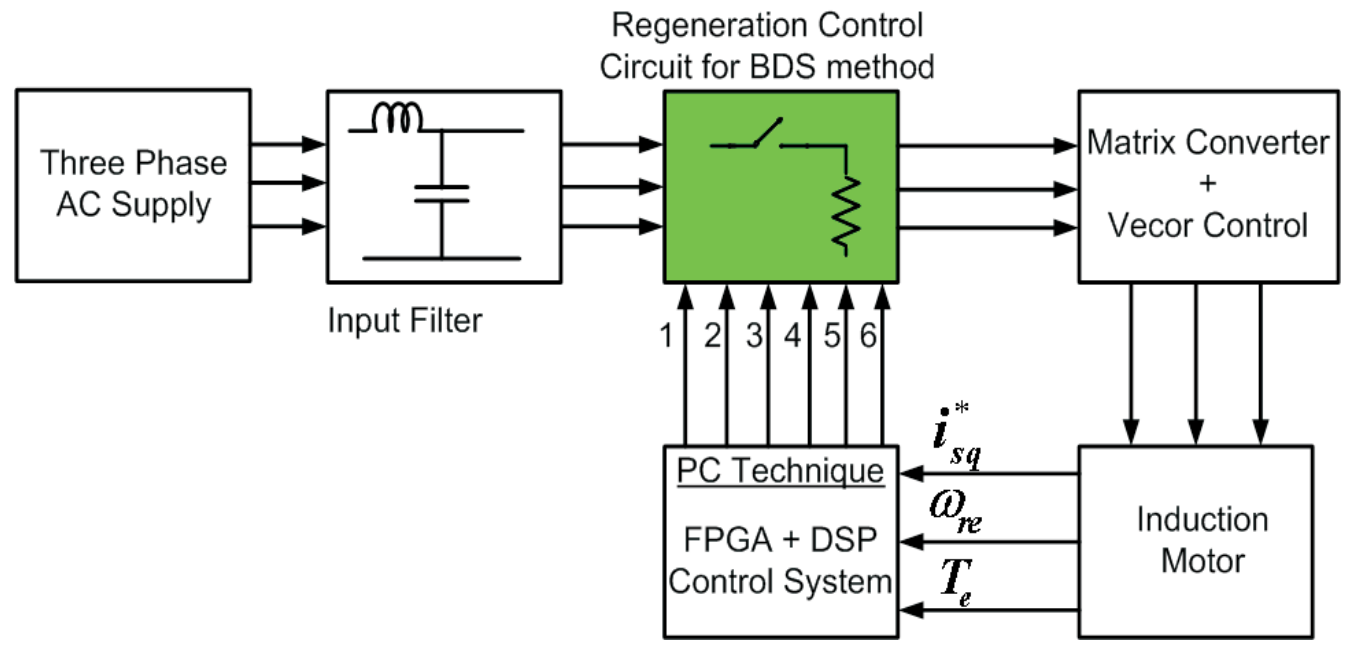

Figure 4.13: Block Diagram of the Power Comparison (PC) Technique for the BiDirectional Switch (BDS) dissipation Method

\section{Bi-Directional Switch (BDS) Method:}

Power Comparison technique for the Bi-Directional Switch method (BDS) is shown in figure 4.13. Generation of six gate drive signals is required for the three bi-directional switches in the Regeneration Control Circuit (RCC). Power dissipation through three resistors in the RCC is directly proportional to the duty cycle of the bi-directional switches, as described in section 4.3.1. 


\section{Input Power Clamp (IPC) Method:}

The duty cycle calculation for avoiding regeneration in the Matrix Converter motor drive using IPC dissipation method is similar to the Bi-Directional Switch (BDS) method. Power dissipation through a resistor is directly proportional to the duty cycle of the Uni-Directional Switch (UDS) in the Regeneration Control Circuit (RCC). Only one control signal is required for this method, as shown in the figure 4.14. The design of braking resistor for this method is same as the BDS method.

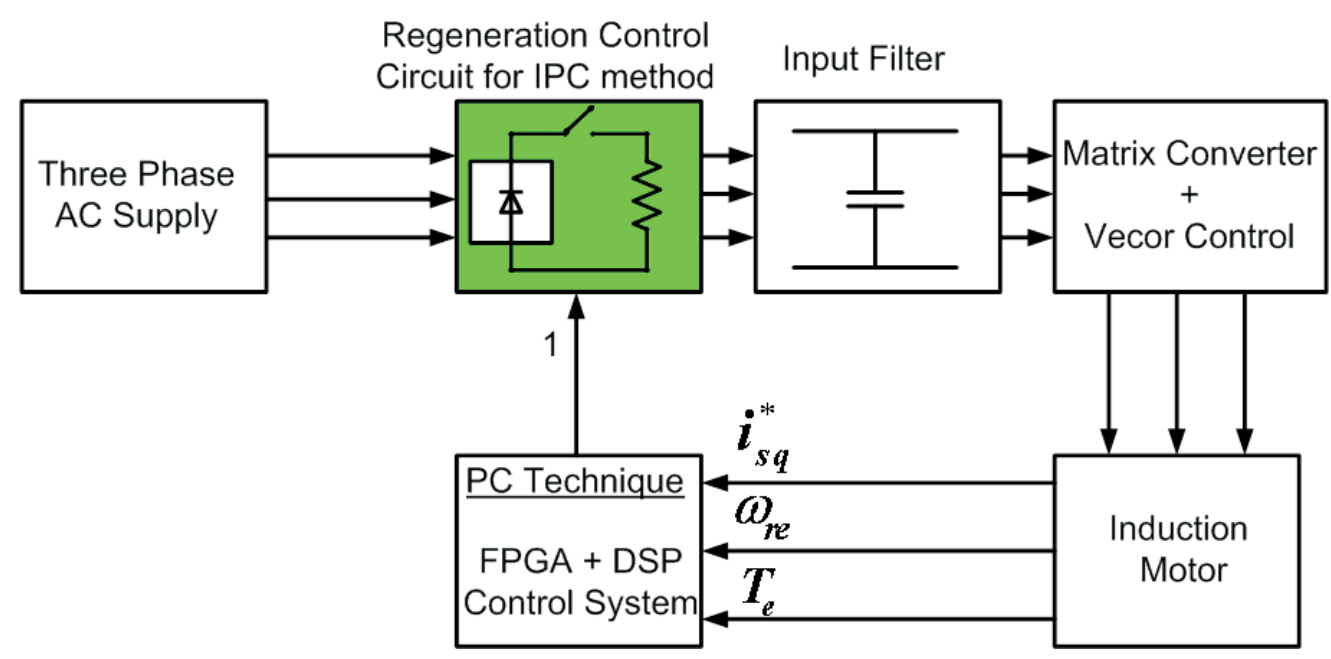

Figure 4.14: Block Diagram of the Power Comparison (PC) Technique for the IPC dissipation Method 


\subsubsection{Input Voltage Reference (IVR) Technique}

Input Voltage Reference (IVR) technique for both the Bi-Directional Switch (BDS) and Input Power Clamp (IPC) dissipation methods is described in this section.

\section{Bi-Directional Switch (BDS) Method:}

Input Voltage Reference (IVR) technique for the Bi-Directional Switch (BDS) method is shown in figure 4.15. Generation of six control signals required for the three bidirectional switches in the Regeneration Control Circuit (RCC) of the BDS method. The duty cycle variation of the bi-directional switches in the Regeneration Control Circuit (RCC) is linear.

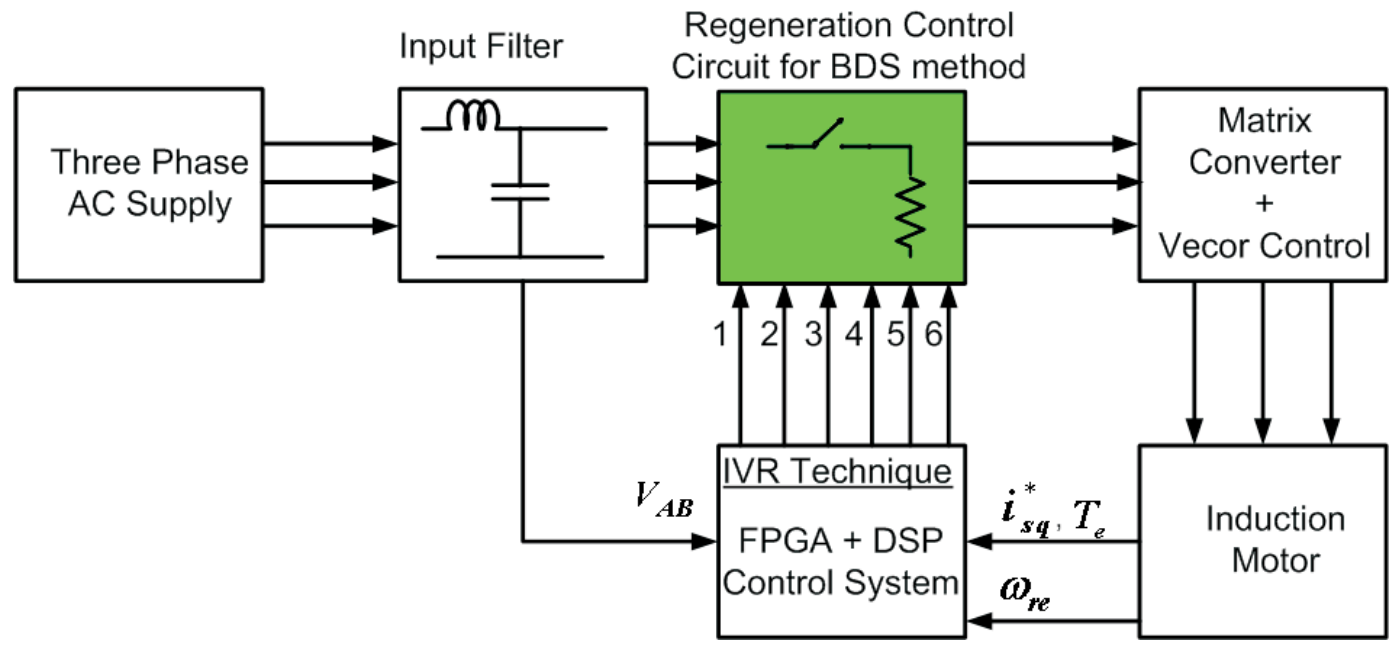

Figure 4.15: Block Diagram for the Input Voltage Reference (IVR) Technique with the Bi-Directional Switch (BDS) dissipation Method

The duty cycle variation is directly proportional to the increase in the line to line voltage across the input filter capacitor of the Matrix Converter under regeneration with respect to the output power $\left(P_{o}\right)$, as described in section 4.3.2. 


\section{Input Power Clamp (IPC) Method:}

The duty cycle calculation for the IVR technique using the IPC dissipation method is similar to the Bi-Directional Switch (BDS) method. The power dissipation through the resistor is directly proportional to the duty cycle of the Uni-Directional Switch (UDS) in the Regeneration Control Circuit (RCC). Only one control signal is required for this method to activate a switch in the RCC, as shown in the figure 4.16.

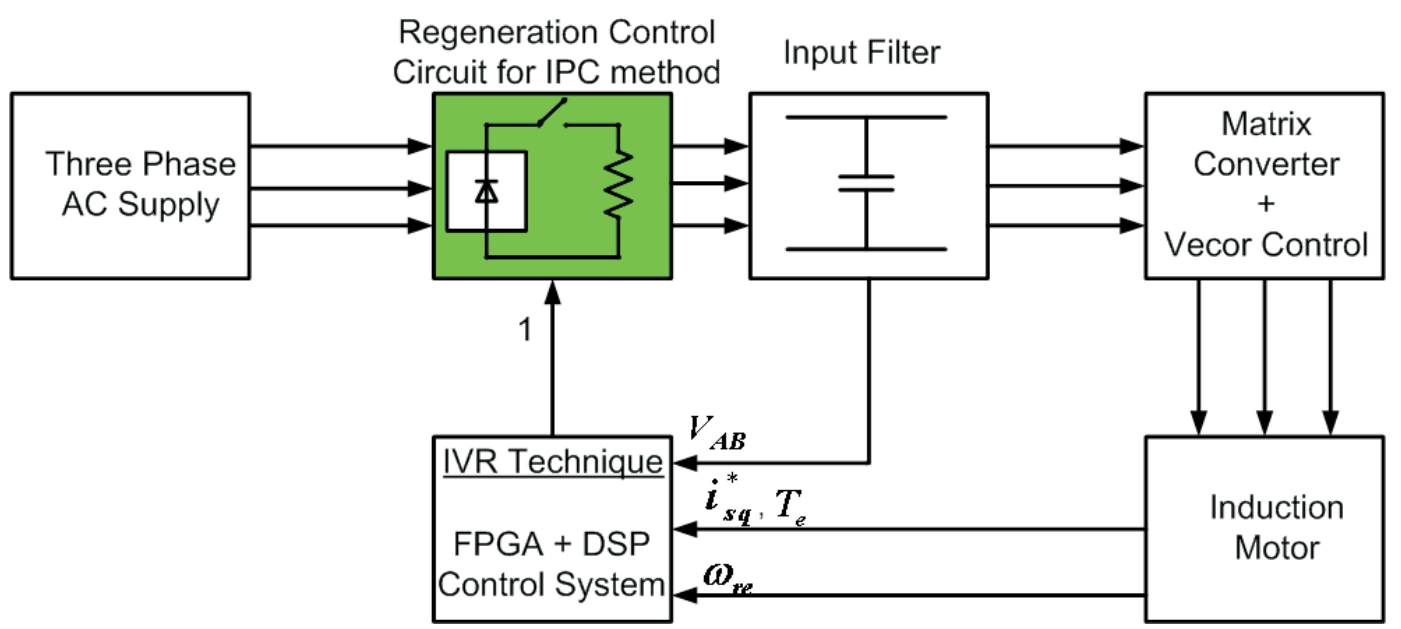

Figure 4.16: Block Diagram for the IVR Technique with the IPC dissipation Method 


\subsection{Conclusions}

The operating conditions which can cause regeneration in the motor drives have been discussed. The different braking methods to dissipate regenerative power have been analysed. Even though some methods are used to reduce the kinetic energy, a dynamic braking circuit is more successful because of simple hardware. This is the reason that the dynamic braking circuit is used in this application [47].

Two techniques for detecting regeneration in the Matrix Converter motor drive, the Power Comparison (PC) technique and the Input Voltage Reference (IVR) technique have been discussed. The use of these techniques to generate the reference for the Regeneration Control Circuit (RCC) for both the Bi-Directional Switch (BDS) and Input Power Clamp (IPC) dissipation methods has been introduced. It is concluded that avoiding regeneration in the Matrix Converter motor drive is potentially feasible. 


\section{Chapter 5}

\section{Simulation Study}

\section{$5.1 \quad$ Introduction}

To predict and verify the performance of the proposed methods for avoiding regeneration in a Matrix Converter, a simulation study is carried out using SABER software package [64]. The first section of this chapter describes the simulation results for open loop control of the Matrix Converter with both a R-L load and an induction motor load.

The second section of this chapter describes the simulation results of the first method of avoiding regeneration, the Bi-Directional Switch (BDS) method, with both techniques for detecting regeneration, the Power Comparison (PC) technique and Input Voltage Reference (IVR) technique. In the BDS method 6-pulses are required to trigger the Regeneration Control Circuit (RCC) switches irrespective of the technique adopted for detecting the regeneration in the Matrix Converter motor drive.

The final section of this chapter outlines the simulation results of the second method of avoiding regeneration, the Input Power Clamp (IPC) method. The IPC method requires only one pulse to trigger the Uni-Directional Switch in the Regeneration 
Control Circuit (RCC) irrespective of the technique used to detect the regeneration in the Matrix Converter motor drive.

\subsection{Simulation Results for Basic Operation of MC}

When the Matrix Converters is used with an inductive load, it is necessary to avoid the open circuits on the output side of the Matrix Converter [19]. As mentioned in section 5.1, two load cases are simulated to verify the basic operation of the Matrix Converter. These are:

1. An R-L load

2. An induction motor load

\subsubsection{R-L Load}

In order to validate the modulation of the Matrix Converter, the circuit is simulated with a passive R-L load. The circuit diagram for Matrix Converter with an R-L load is shown in the figure 5.1. The Matrix Converter model is represented using the ideal bi-directional switches $\left(S_{A a}, S_{B a}, S_{C a}, S_{A b}, S_{B b}, S_{C b}, S_{A c}, S_{B c}, S_{C c}\right)$. The load in the model is a series connection of a $5 \Omega$ resistor $\left(R_{a}, R_{b}, R_{c}\right)$ and a $5 \mathrm{mH}$ inductor $\left(L_{a}, L_{b}, L_{c}\right)$.

The switches are controlled using a Space Vector Modulation (SVM) strategy. The Matrix Converter is supplied by a balanced three phase supply $\left(V_{A}, V_{B}, V_{C}\right)$. To reduce the switching harmonics a small input filter is implemented between the Matrix Converter and the three phase supply. The input filter consists of source inductors $\left(L_{A}, L_{B}, L_{C}\right)$ and line capacitors $\left(C_{A B}, C_{B C}, C_{A C}\right)$. By using this formula, $f_{c}=2 \pi \frac{\sqrt{L}}{\sqrt{C}}$, $2 \mu \mathrm{F}$ of capacitance is calculated for the input filter capacitors. 


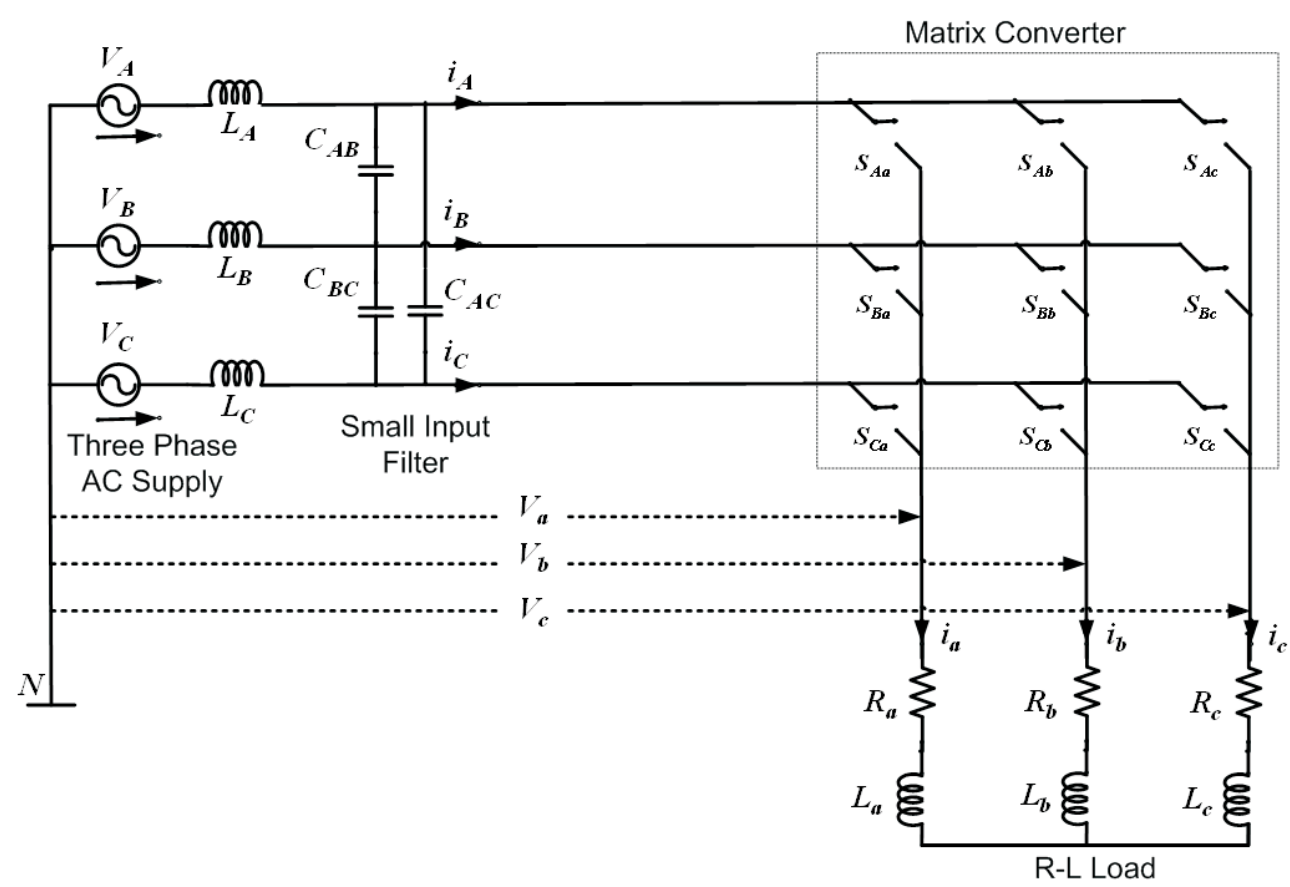

Figure 5.1: Circuit Diagram for a Matrix Converter with an R-L Load
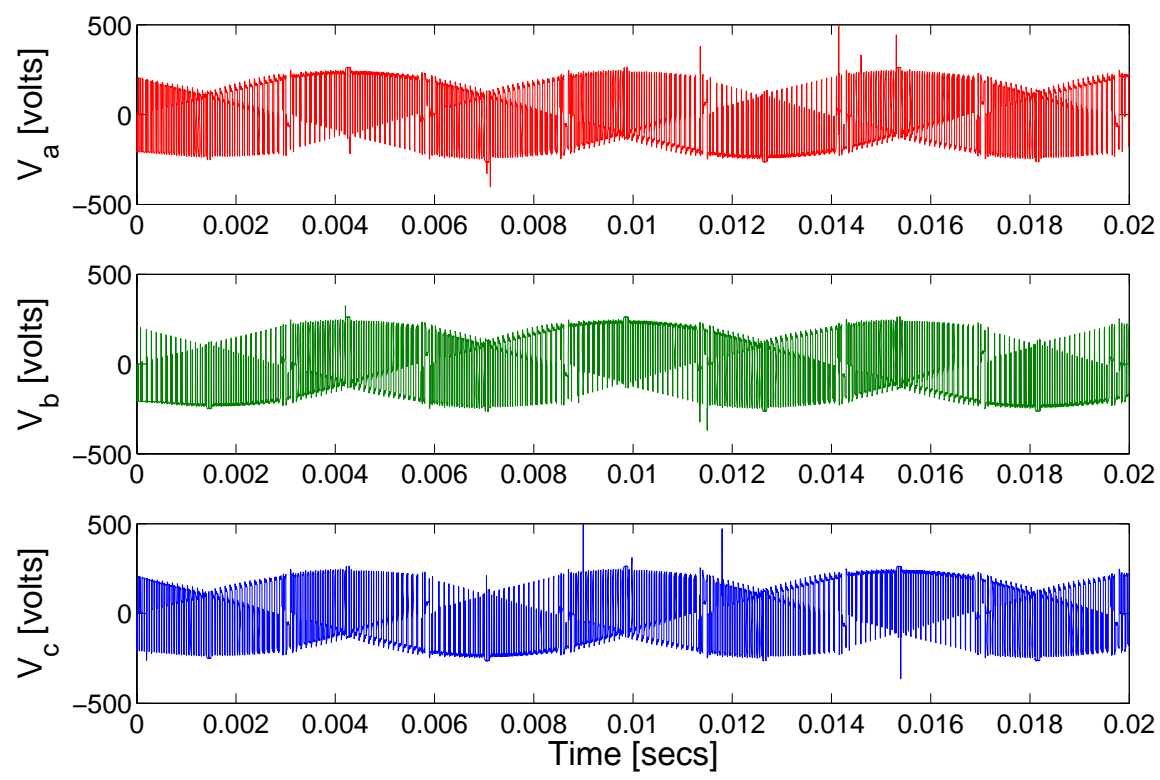

Figure 5.2: Unfiltered Output Voltages for a Matrix Converter with an R-L Load. $V_{\text {in }}=240 \mathrm{~V}$ at $60 \mathrm{~Hz}, \mathrm{q}=0.75, f_{\text {out }}=60 \mathrm{~Hz}$ 

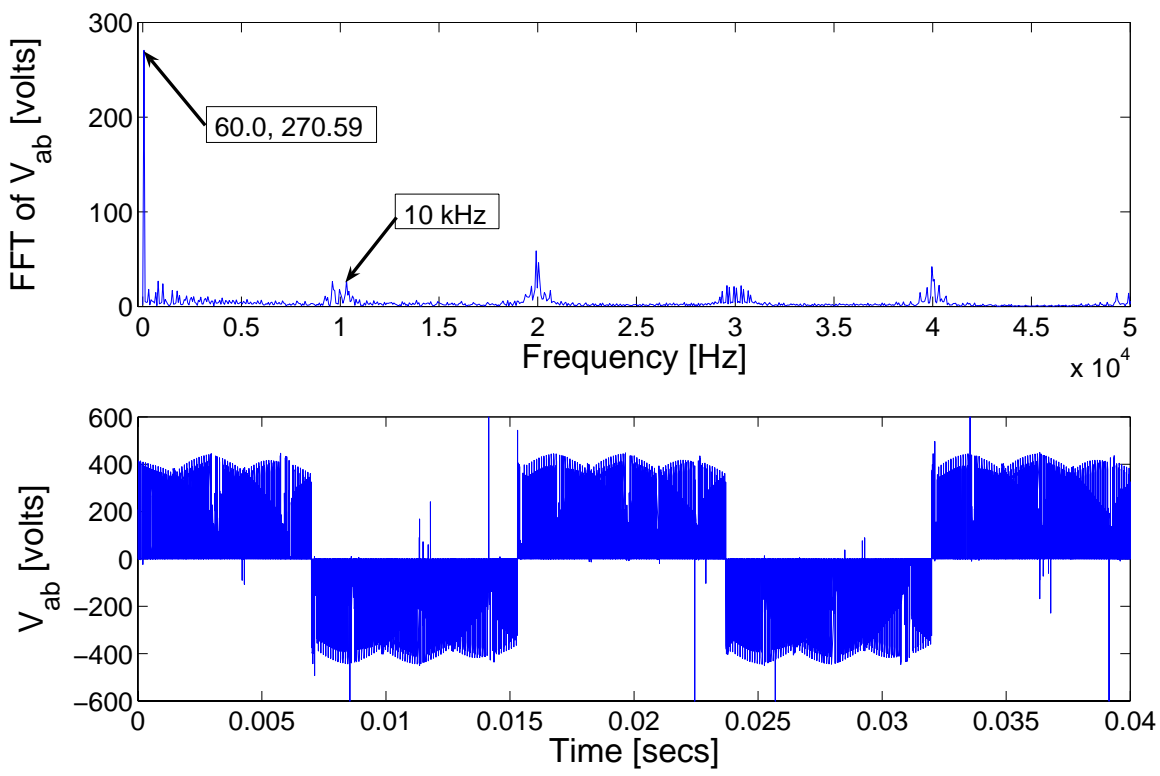

Figure 5.3: The Unfiltered Output Line Voltage and Spectrum for a Matrix Converter with an R-L load. $V_{\text {in }}=240 \mathrm{~V}$ at $60 \mathrm{~Hz}, \mathrm{q}=0.75, f_{\text {out }}=60 \mathrm{~Hz}$
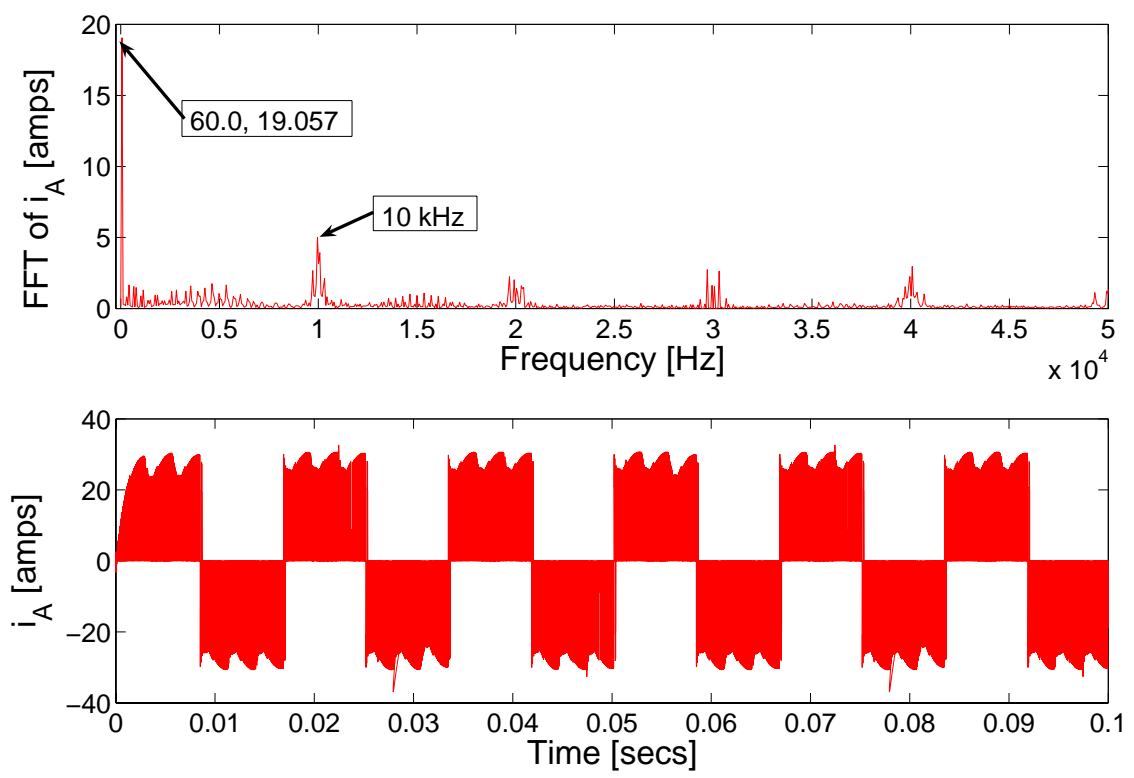

Figure 5.4: The Unfiltered Input Current and Spectrum for a Matrix Converter with an R-L load. $V_{\text {in }}=240 \mathrm{~V}$ at $60 \mathrm{~Hz}, \mathrm{q}=0.75, f_{\text {out }}=60 \mathrm{~Hz}$ 

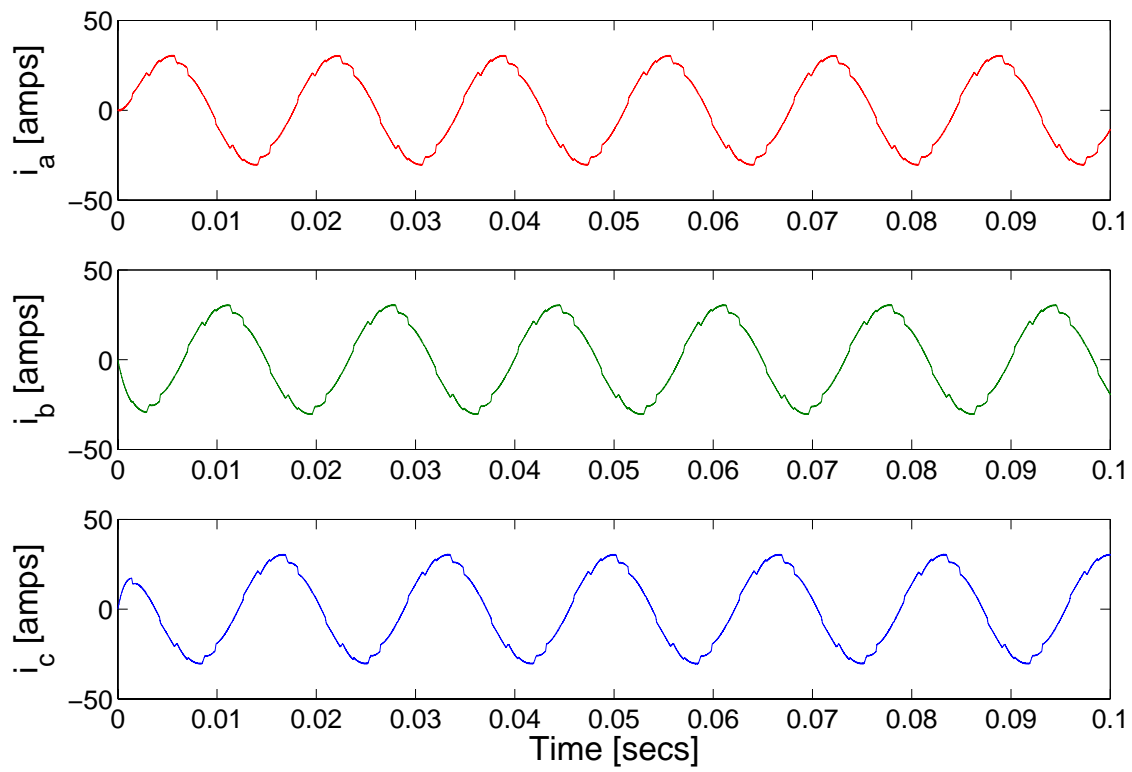

Figure 5.5: Output Currents for a Matrix Converter with an R-L Load. $V_{\text {in }}=240 \mathrm{~V}$ at $60 \mathrm{~Hz}, \mathrm{q}=0.75, f_{\text {out }}=60 \mathrm{~Hz}$
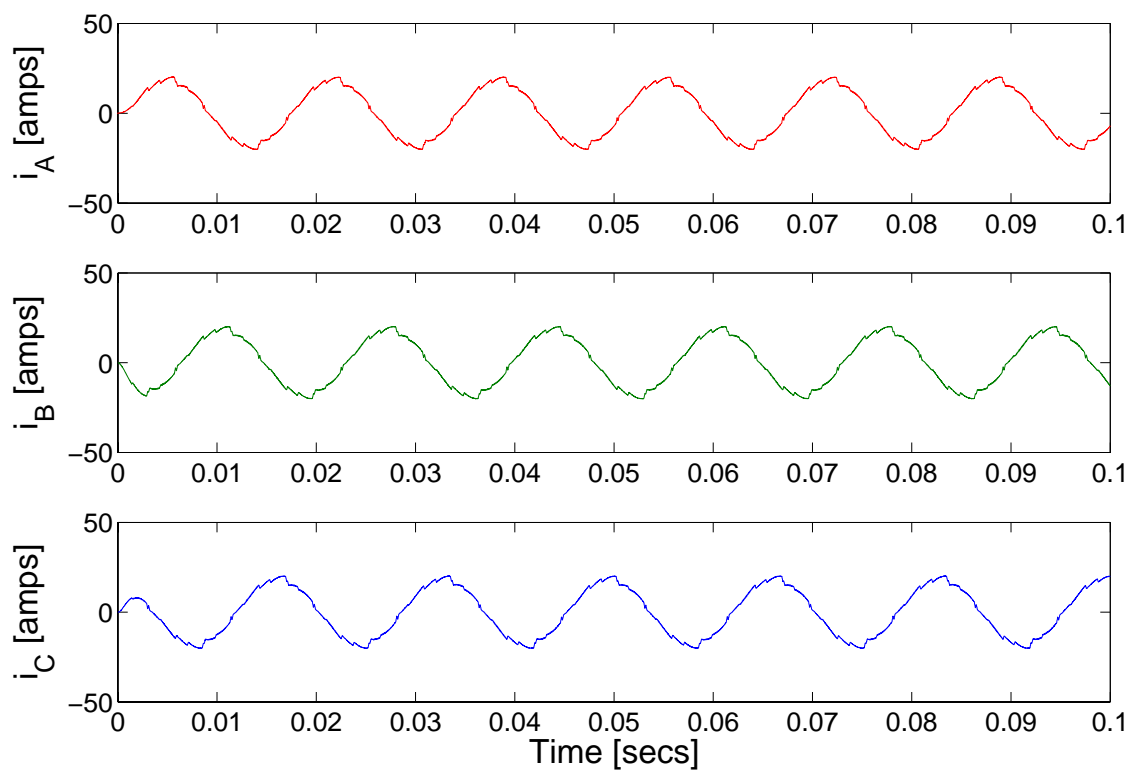

Figure 5.6: Filtered Input Currents for a Matrix Converter with an R-L load. $V_{i n}=$ $240 \mathrm{~V}$ at $60 \mathrm{~Hz}, \mathrm{q}=0.75, f_{\text {out }}=60 \mathrm{~Hz}$ 

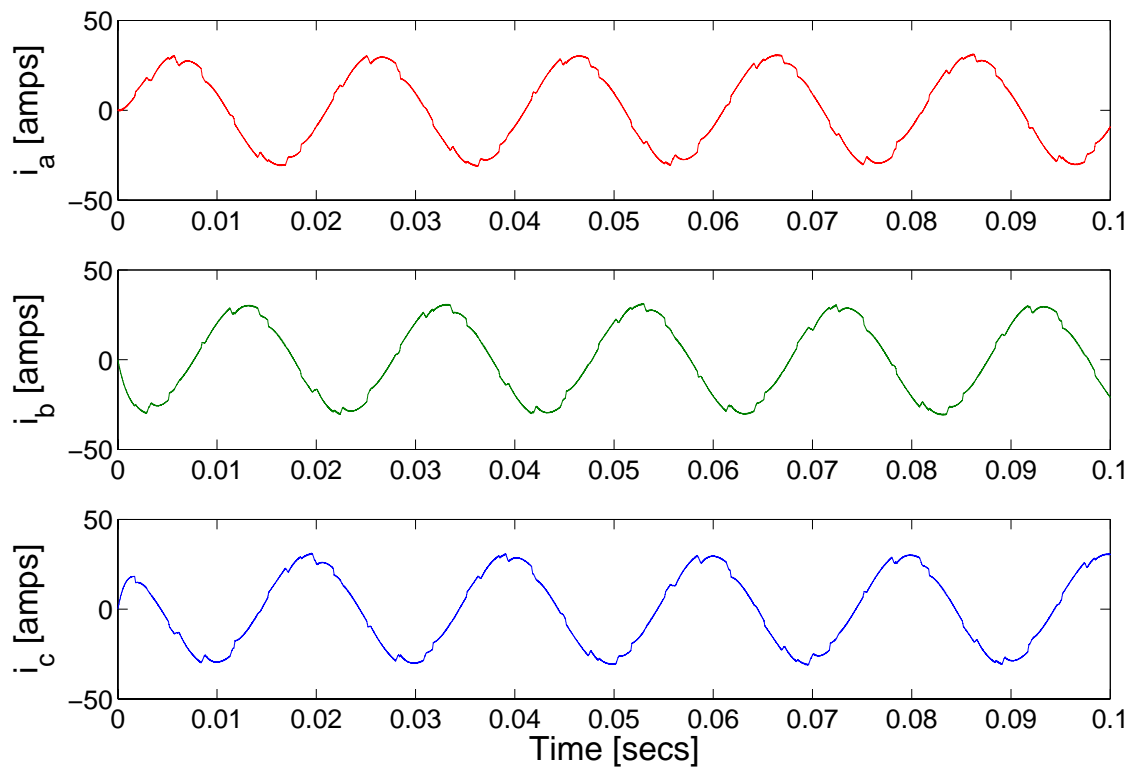

Figure 5.7: Output Currents for a Matrix Converter with an R-L Load. $V_{\text {in }}=240 \mathrm{~V}$ at $60 \mathrm{~Hz}, \mathrm{q}=0.75, f_{\text {out }}=50 \mathrm{~Hz}$
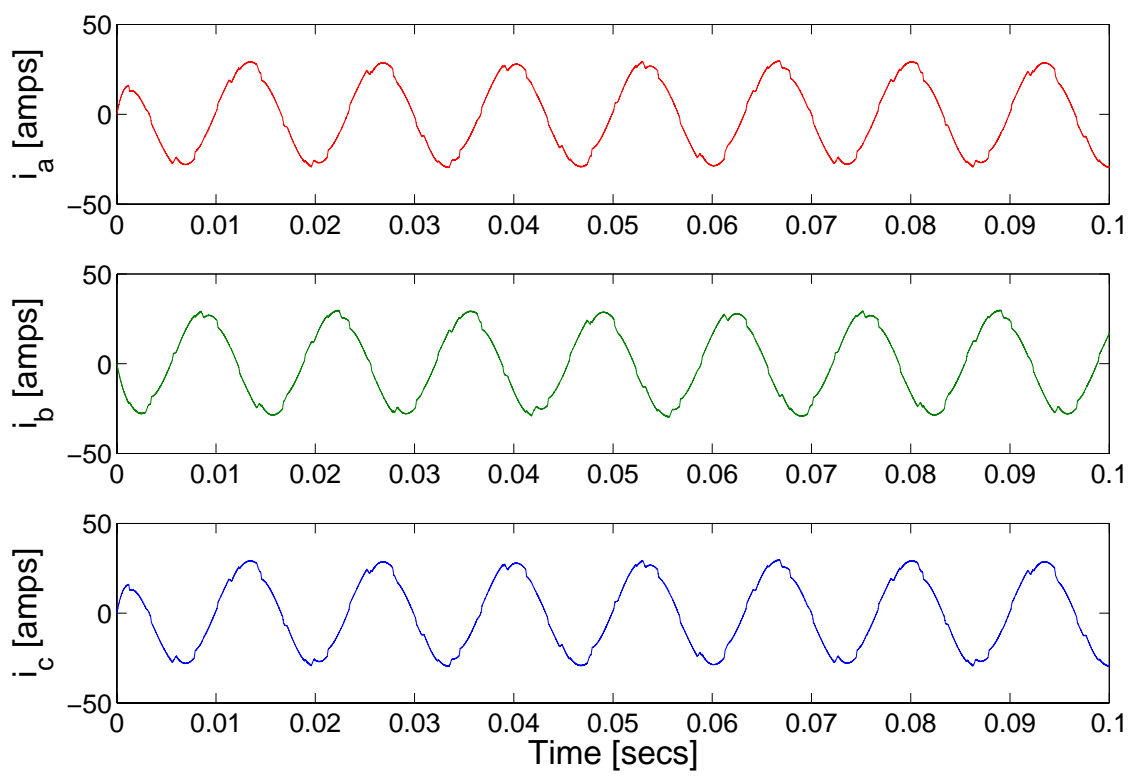

Figure 5.8: Output Currents for a Matrix Converter with an R-L Load. $V_{\text {in }}=240 \mathrm{~V}$ at $60 \mathrm{~Hz}, \mathrm{q}=0.75, f_{\text {out }}=75 \mathrm{~Hz}$ 
Figure 5.2 shows the three phase output voltages $\left(V_{a}, V_{b}, V_{c}\right)$ of the Matrix Converter for the input supply of $240 V_{\max }$ at $60 \mathrm{~Hz}$. The voltage transfer ratio (q) is taken as 0.75 . The switching frequency is taken as $10 \mathrm{kHz}$. The spectrum of unfiltered output voltage harmonics of switching frequency $(10 \mathrm{kHz})$ is shown in the figure 5.3. The unfiltered input current and its spectrum is shown in the figure 5.4. The corresponding output currents $\left(i_{a}, i_{b}, i_{c}\right)$ and input currents $\left(i_{A}, i_{B}, i_{C}\right)$ are shown in the figures 5.5 and 5.6 respectively. From these figures, it is clearly proved that the Matrix Converter has a good sinusoidal input and output current waveforms when compared to the conventional converters.

The simulation results for output frequencies of $50 \mathrm{~Hz}$ and $75 \mathrm{~Hz}$ are shown in the figures 5.7 and 5.8 respectively. The special feature of the Matrix Converter, producing unrestricted output frequency, is demonstrated in these figures. The maximum feasible limit of the output frequency of the Matrix Converter is imposed by the switching frequency of the Matrix Converter. The limit is approximately 1/10 of the switching frequency. 


\subsubsection{Induction Motor Load}

This section describes the simulation results for a Matrix Converter with an induction motor load. A $2.2 \mathrm{~kW}$ three phase induction motor is directly connected to the Matrix Converter, as shown in the figure 5.9. The SABER model induction motor called ind3psc [64] is used in the simulation. The parameters of the induction motor used in the simulation are given in the Appendix A. The Matrix Converter supplies to the induction motor with a balanced input line voltage $240 V_{\max }$ at $60 \mathrm{~Hz}$. The Space Vector Modulation (SVM) strategy is used to modulate the bi-directional switches in the Matrix Converter as described in the section 2.4.4. The Volts/Hertz control is applied to confirm the operation of the Matrix Converter fed induction motor

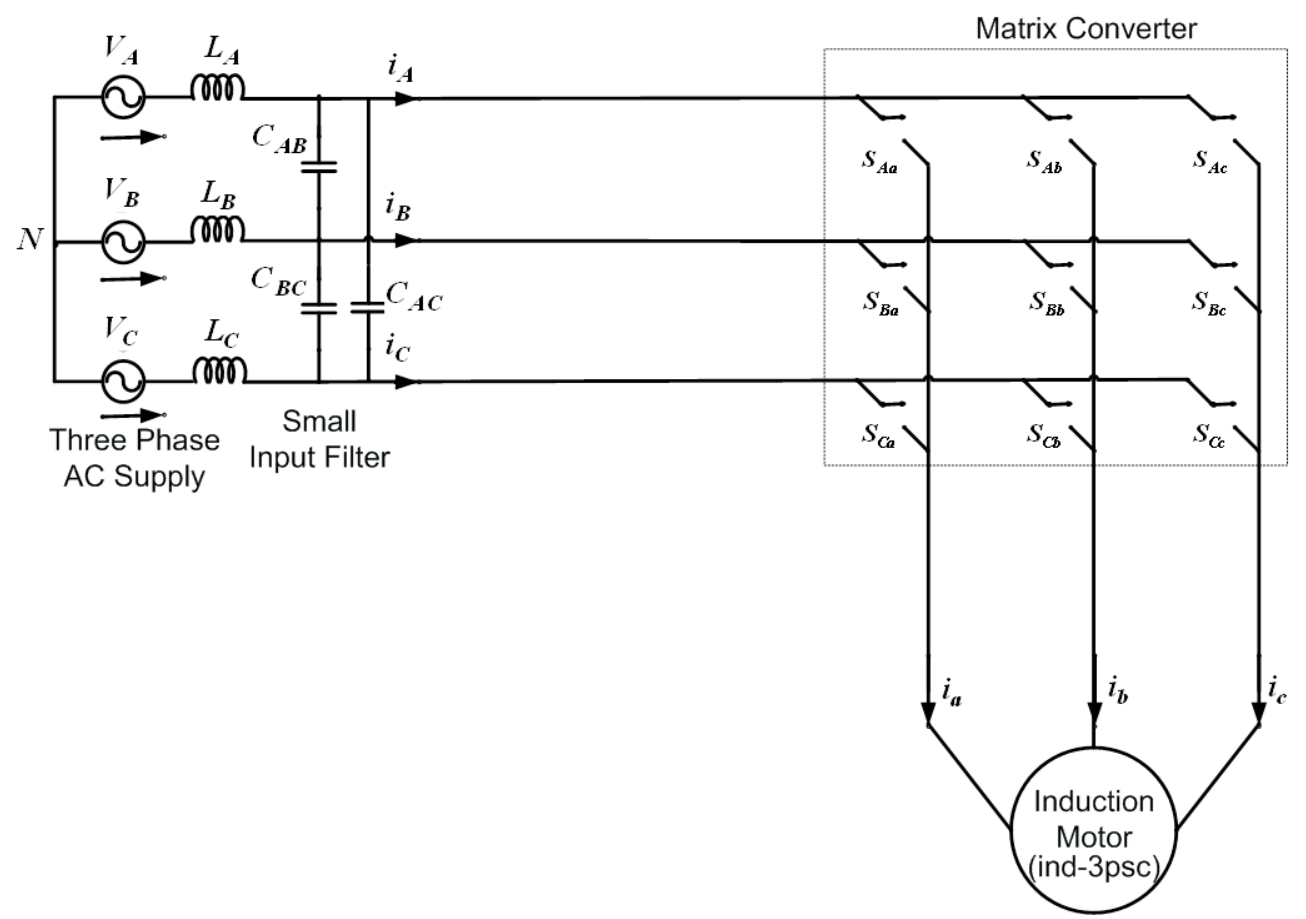

Figure 5.9: Circuit diagram for a Matrix Converter fed Induction Motor

drive. The Figure 5.10 shows the speed, input currents and output currents or stator currents of the induction motor. From the figure 5.10, it is shown that if the input frequency to the induction motor is changed, the speed of the induction motor changes accordingly. 

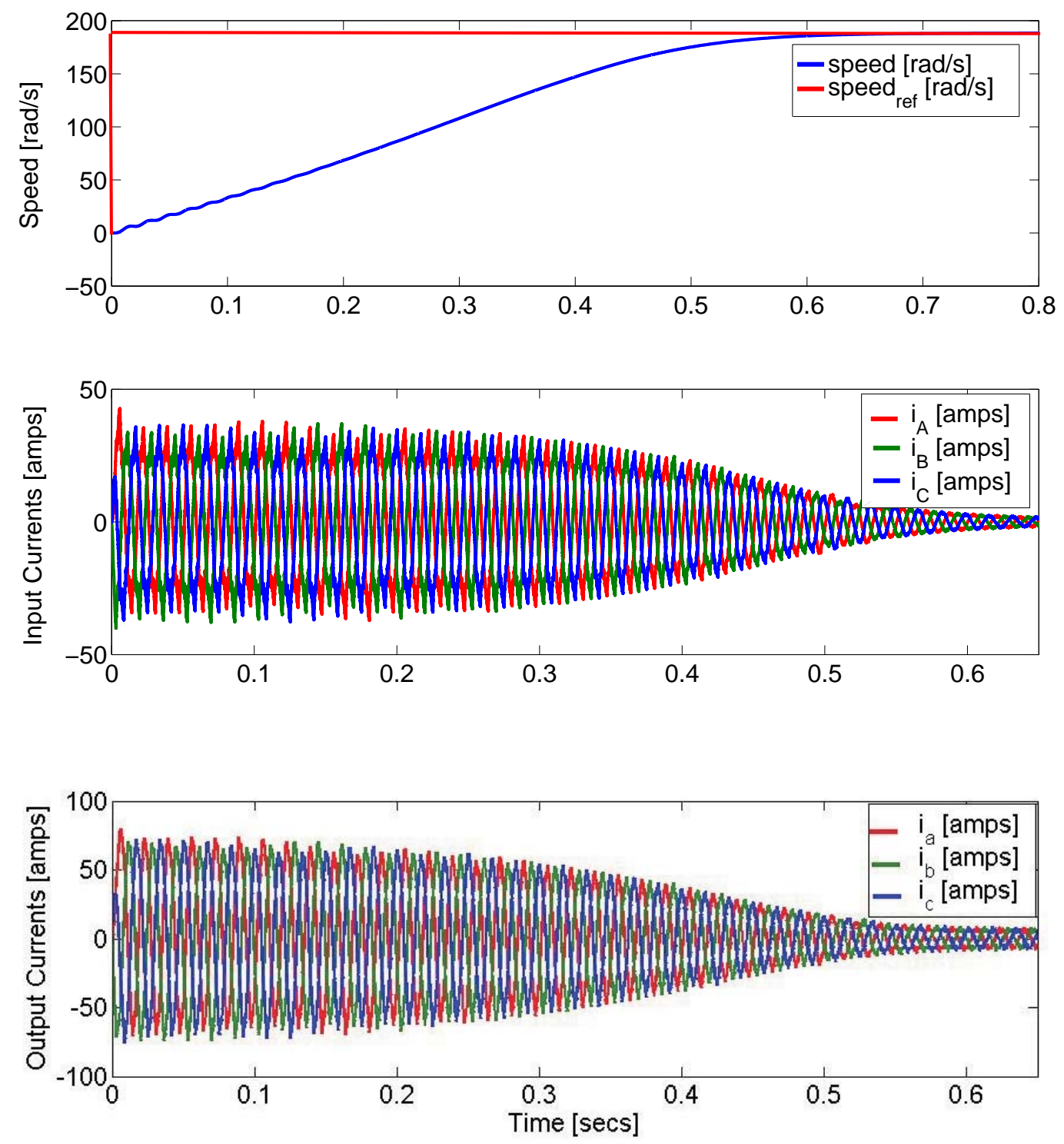

Figure 5.10: Speed, Input Currents and Output Currents of the Matrix Converter fed Induction Motor. $V_{\text {in }}=240 \mathrm{~V}$ at $60 \mathrm{~Hz}, f_{s}=10 \mathrm{kHz}$ and $\mathrm{q}=0.75$ 


\subsubsection{Closed Loop Vector Control}

In order to analyse the closed loop vector control performance, a simulation study into the performance of a Matrix Converter with the control is performed. An overview of the simulated control system is shown in figure 5.11. The output currents $\left(i_{a}, i_{b}\right.$, $i_{c}$ ) of the Matrix Converter are used to calculate the dq-currents $\left(i d, i d_{r e f}, i q, i q_{r e f}\right)$ using a SABER MAST program. The reference voltages $\left(V_{a r}, V_{b r}, V_{c r}\right)$ for the Space Vector Modulation (SVM) strategy [41] is calculated from the dq-currents using a SABER MAST program as shown in the figure 5.11.

Figure 5.12 shows the speed ramp transient from $0 \mathrm{rad} / \mathrm{s}$ to $188.5 \mathrm{rad} / \mathrm{s}$ under closed loop vector control. It is known that the Matrix Converter has an inherent regeneration capability, this feature allows to control the speed reversal quickly with large inertial load without a breaking resistor. The steady state input currents $\left(i_{A}, i_{B}, i_{C}\right)$ and output currents $\left(i_{a}, i_{b}, i_{c}\right)$ of the Matrix Converter with a large inertial load are shown in figure 5.12. The figure 5.12 also shows the three reference output voltages for the Space Vector Modulation strategy $\left(V_{a r}, V_{b r}, V_{c r}\right)$.

Figure 5.13 shows the motor speed and the developed torque in the induction motor under closed loop vector control. Under no load condition, the developed torque in the induction motor is zero. As explained in the section 3.3.5, the field producing current $(i d)$ is maintained a constant level, as shown in figure 5.13. For this simulation, the reference of field producing current $\left(i d_{r e f}\right) 10$ Amps is maintained and the torque producing current $\left(i q_{r e f}\right)$ is limited to 35 Amps as shown in figure 5.13.

From figure 5.13, it is noted that the values of both $i d$ and $i q$ follow the reference values. In indirect vector control the developed torque of the induction motor is directly proportional to the torque producing current $(i q)$. From these simulation results, it is concluded that indirect vector control works well in this application 


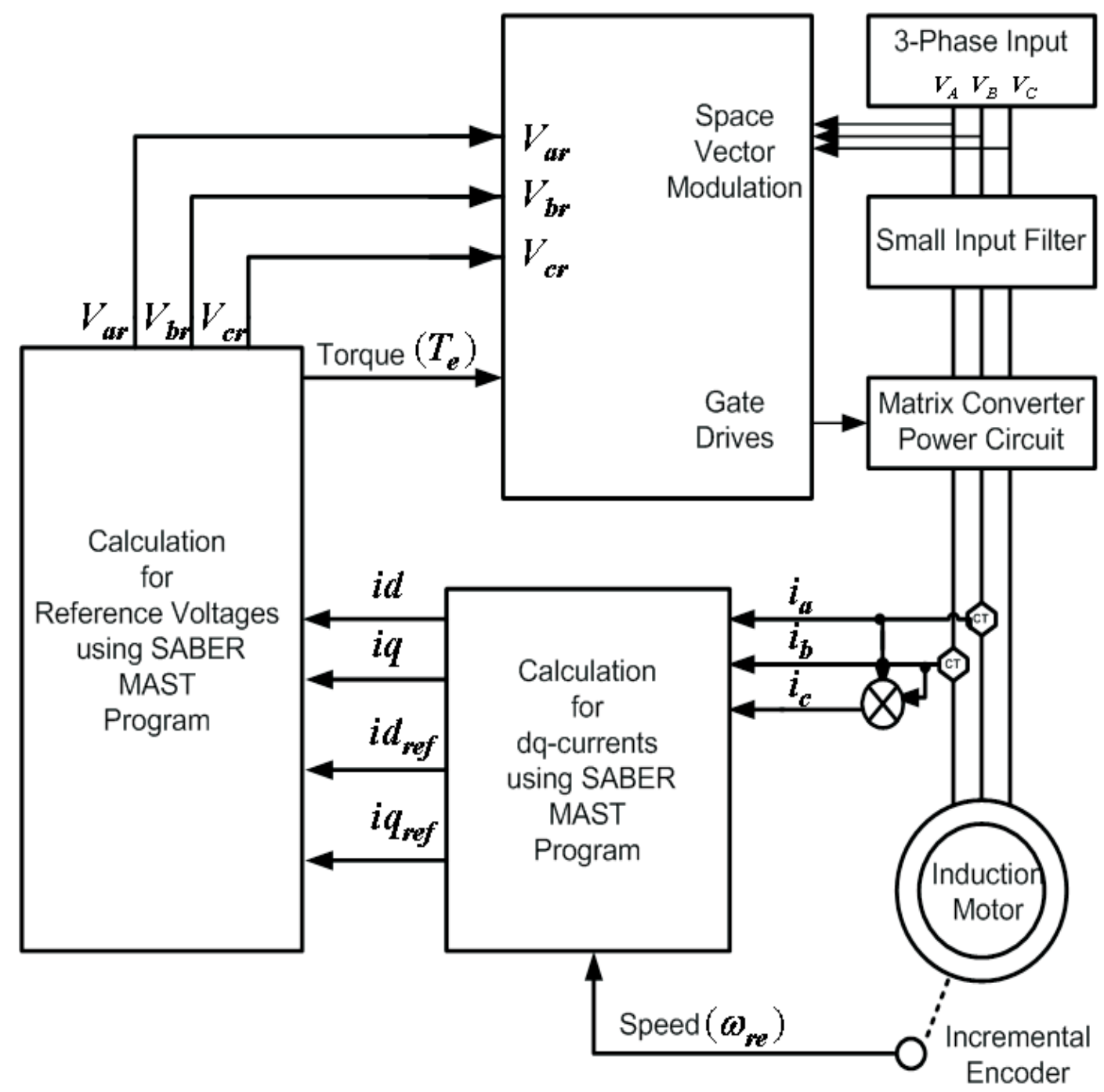

Figure 5.11: Overview of the Simulation of the Matrix Converter Vector Controlled Induction Motor Drive 

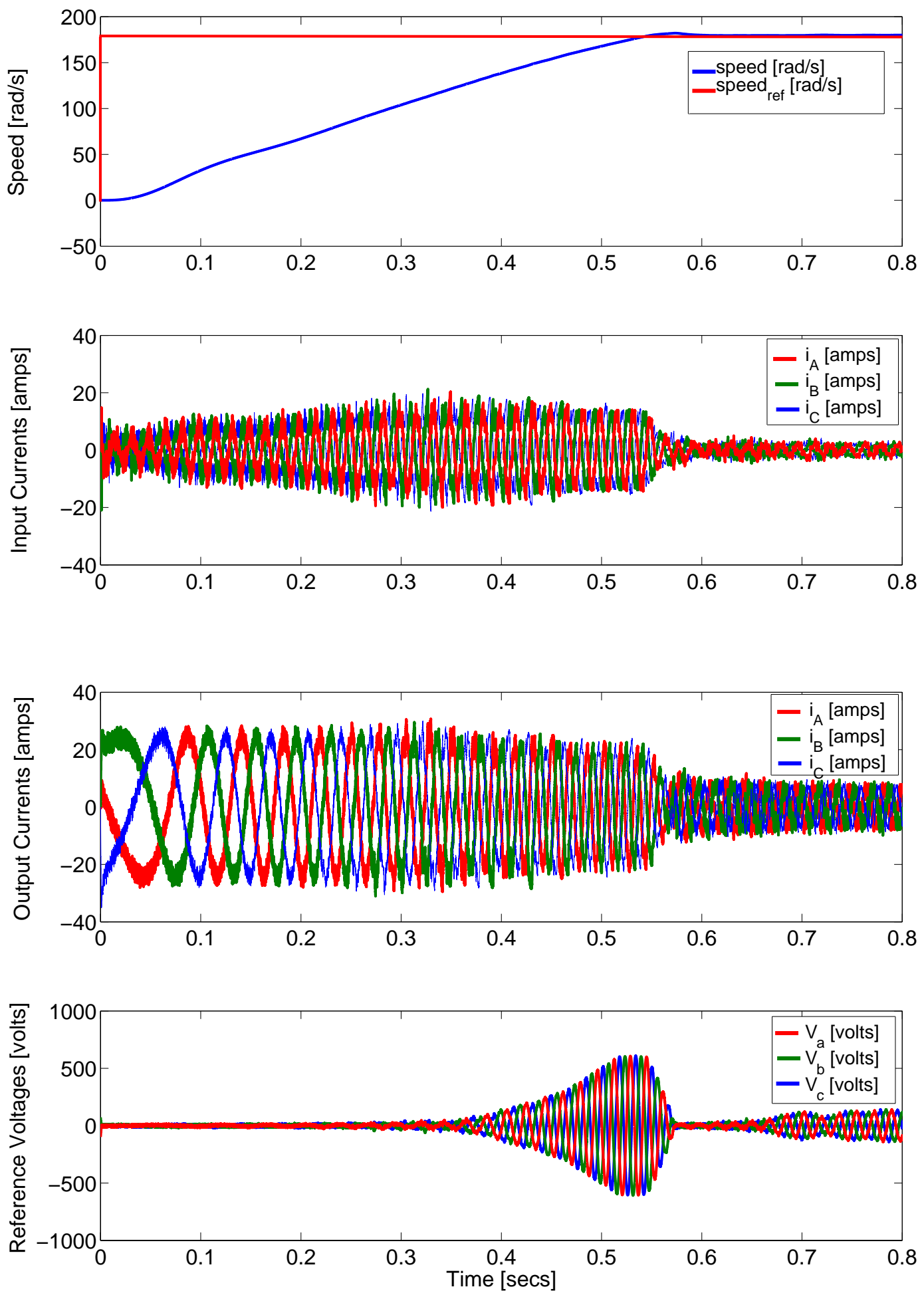

Figure 5.12: Speed of the Induction Motor, The Matrix Converter Input Currents, Output Currents and the Reference Voltages. $V_{i n}=240 \mathrm{~V}$ at $60 \mathrm{~Hz}, \mathrm{q}=0.75$ and $f_{s}$ $=10 \mathrm{kHz}$ 

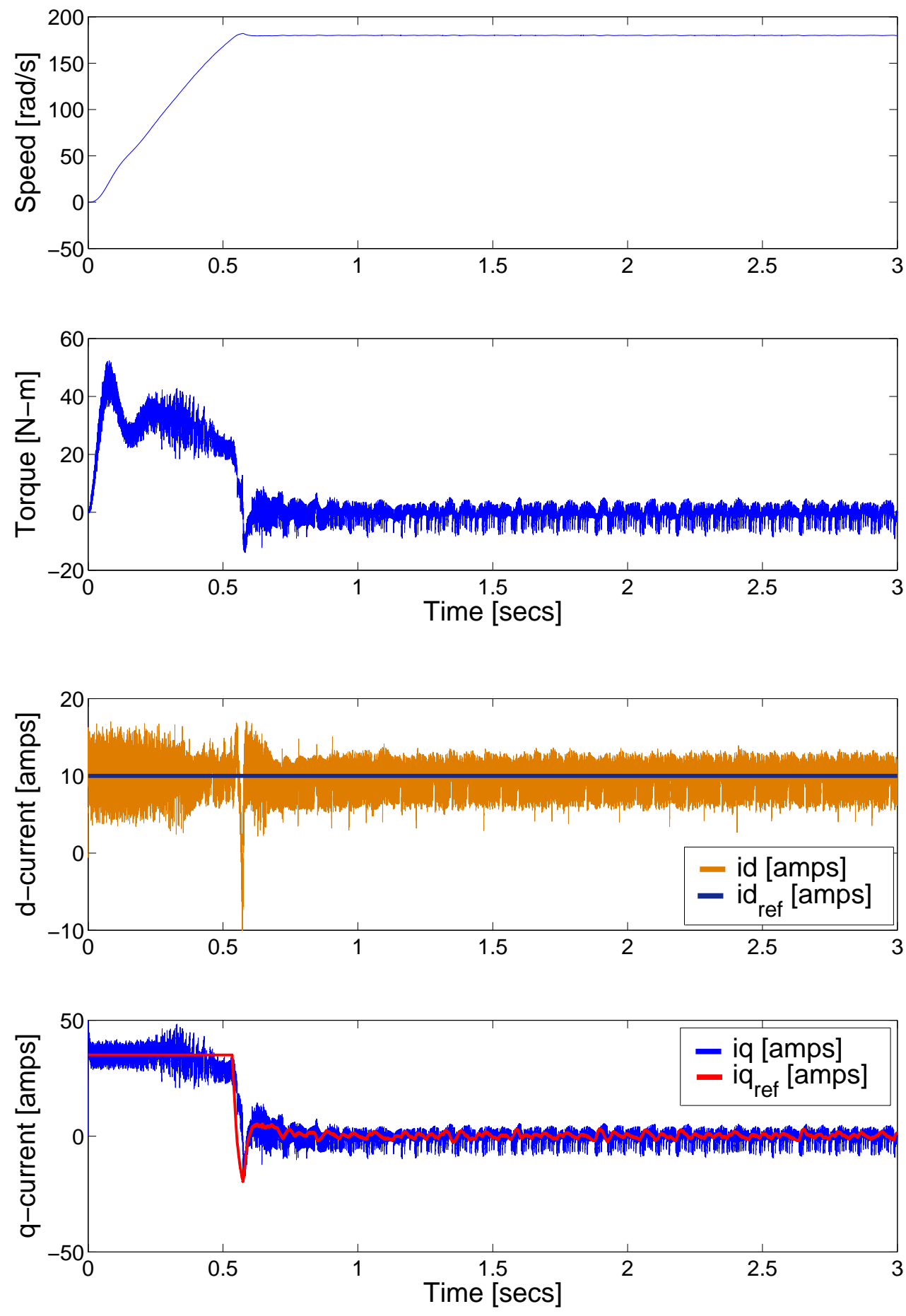

Figure 5.13: Speed and Torque of the Induction Motor, Field Producing Current $\left(i_{d}\right)$ and Torque Producing Current $\left(i_{q}\right) . V_{i n}=240 \mathrm{~V}$ at $60 \mathrm{~Hz}, \mathrm{q}=0.75$ and $f_{s}=10 \mathrm{kHz}$ 


\subsubsection{Regeneration}

As explained in the section 4.2.1, the regeneration can be demonstrated by reversing the speed using the step response (speed reversal command) as shown in the figure 5.14. In this application a step is applied at 1.2 (secs) as shown in the figure 5.15. Figure 5.15 shows the speed transient and the developed torque in the induction motor for a no load speed reversal (from $+188.5 \mathrm{rad} / \mathrm{s}$ to $-188.5 \mathrm{rad} / \mathrm{s}$ ) using vector control. During the acceleration the speed increases rapidly and the regenerative energy is rapidly transferred from the induction motor to the three phase mains and viceversa. The speed reversal of the induction motor is obtained with a large inertial load $\left(\mathrm{j}=0.089 \mathrm{~kg} \cdot \mathrm{m}^{2}\right)$ for the induction motor. From simulation results, it is concluded that the Matrix Converter has inherent capability the four quadrant operation.

The output current waveforms of the Matrix Converter in the figure 5.15 indicate that the speed reversal change from motoring mode to regenerating mode is smoothly achieved. During the step transient (the acceleration and deceleration of the speed), the torque producing current $(i q)$ of the induction motor reaches the maximum limit 35 Amps as shown in the figure 5.16. The control of dq-currents $(i d, i q)$ with no coupling effects is demonstrated.

Figure 5.17 shows the input phase currents $\left(i_{A}, i_{B}, i_{C}\right)$ of the Matrix Converter during the four quadrant operation. The input regenerative powers $\left(P_{A}, P_{B}, P_{C}\right)$ to be dissipated using the Regeneration Control Circuit (RCC) are shown in the figure 5.18. During regeneration the phase opposition $\left(180^{\circ}\right.$ phase displacement) between the input phase voltages $\left(V_{A}, V_{B}, V_{C}\right)$ and input phase currents $\left(i_{A}, i_{B}, i_{C}\right)$ can be seen, as shown in the figure 5.19. 


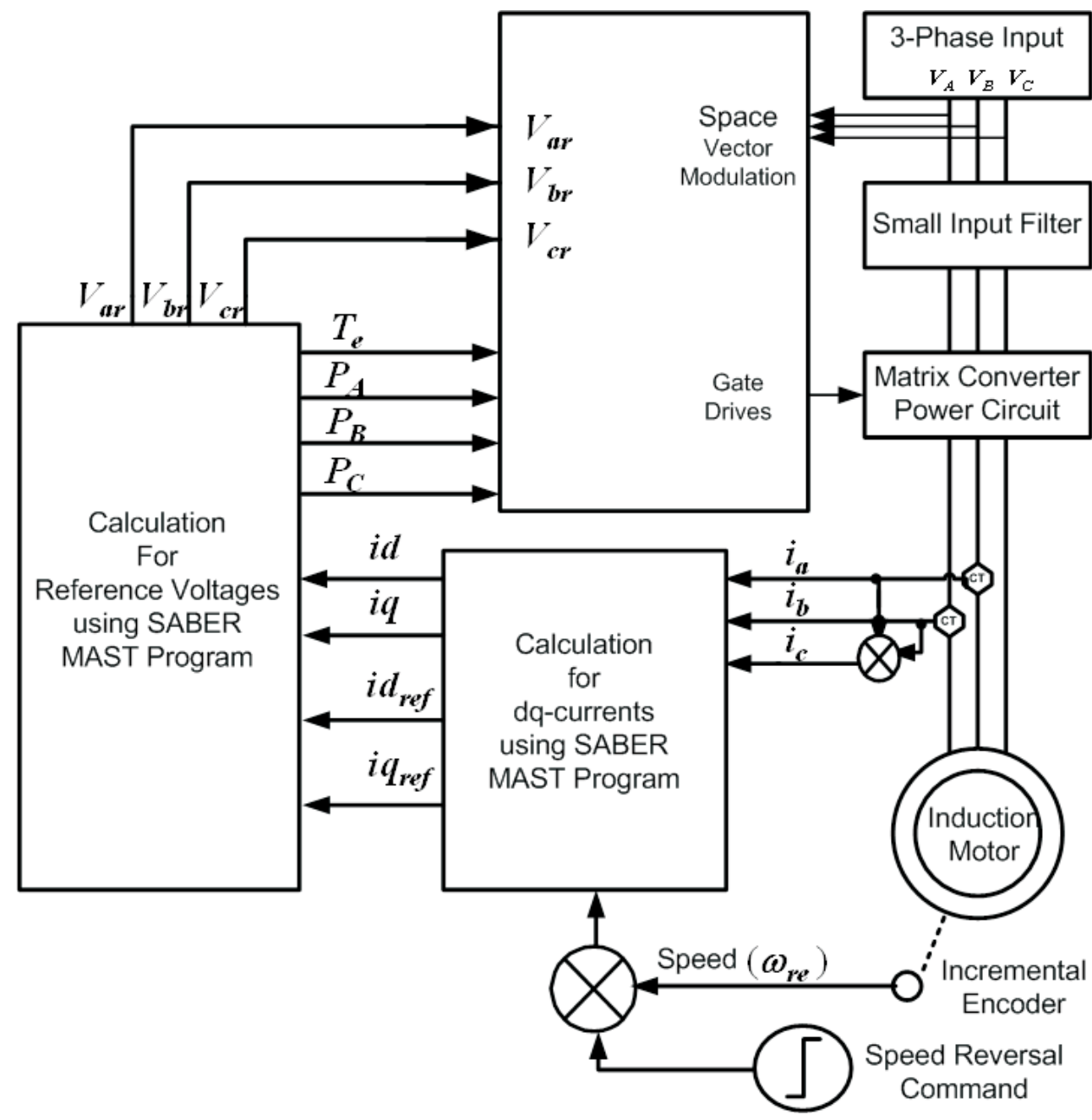

Figure 5.14: Overview of the Simulation Diagram for Obtaining Regeneration in the Matrix Converter Vector Controlled Induction Motor 

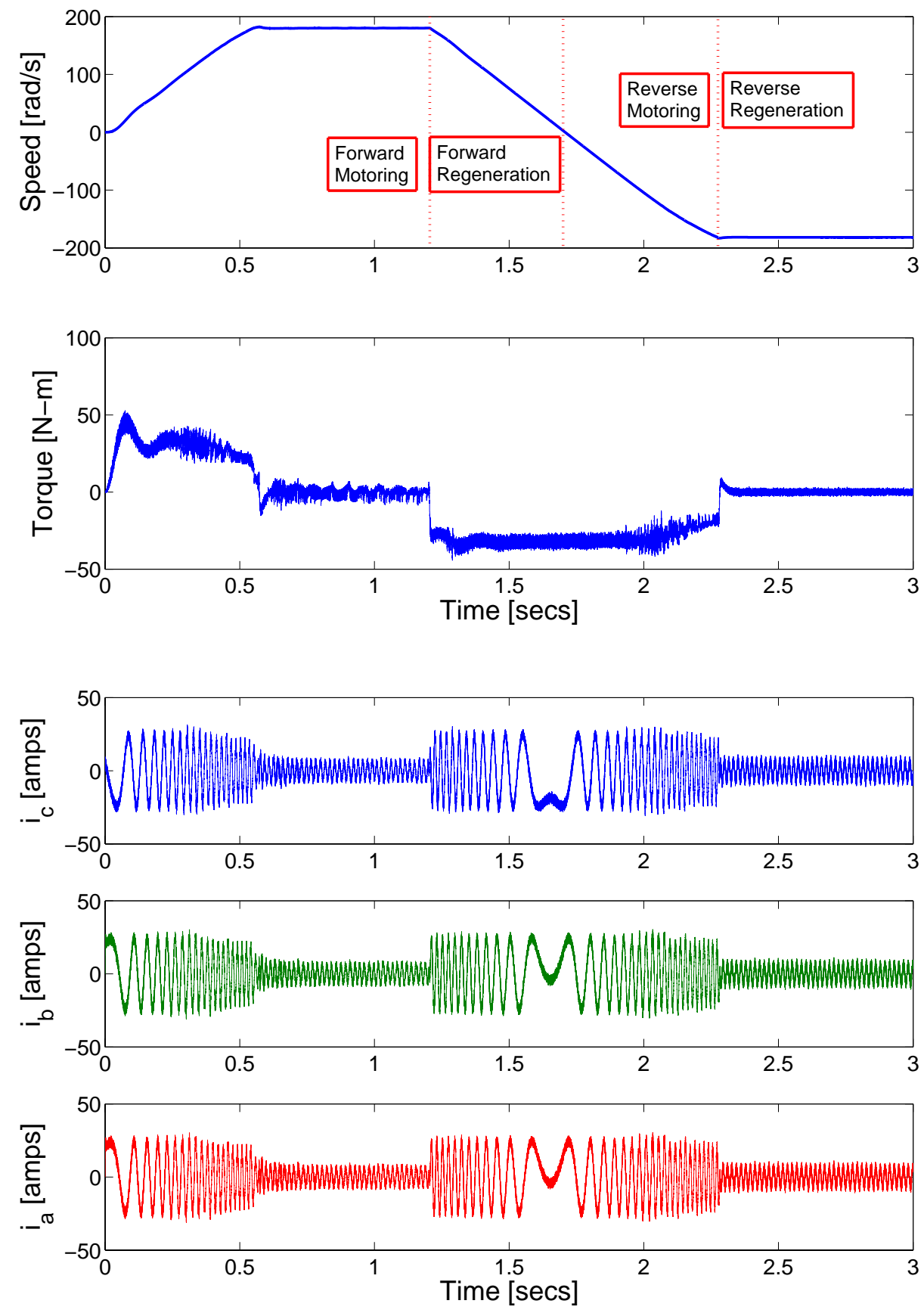

Figure 5.15: Speed and Torque of the Vector Controlled Induction Motor and Output Currents of the Matrix Converter in Regeneration. $V_{\text {in }}=240 \mathrm{~V}$ at $60 \mathrm{~Hz}, \mathrm{q}=0.75$ and $f_{s}=10 \mathrm{kHz}$ 

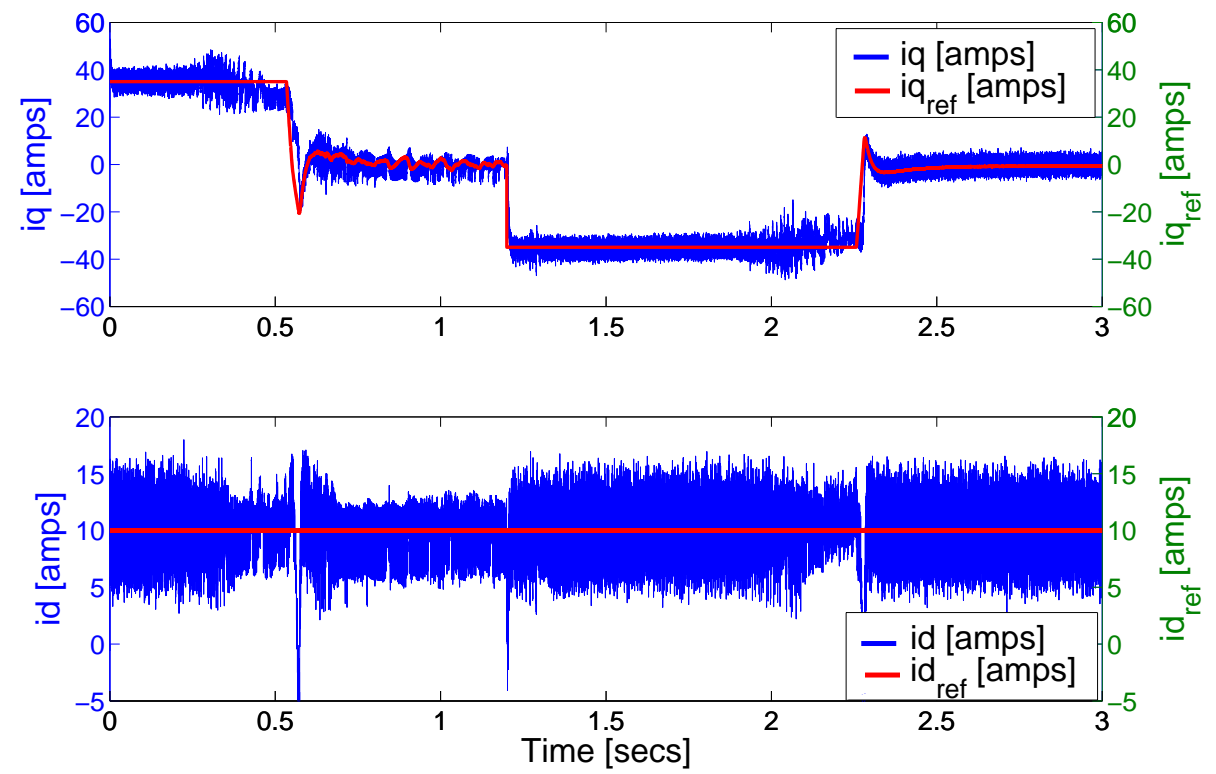

Figure 5.16: Field Producing Currents and Torque Producing Currents in Regeneration. $V_{\text {in }}=240 \mathrm{~V}$ at $60 \mathrm{~Hz}, \mathrm{q}=0.75$ and $f_{s}=10 \mathrm{kHz}$
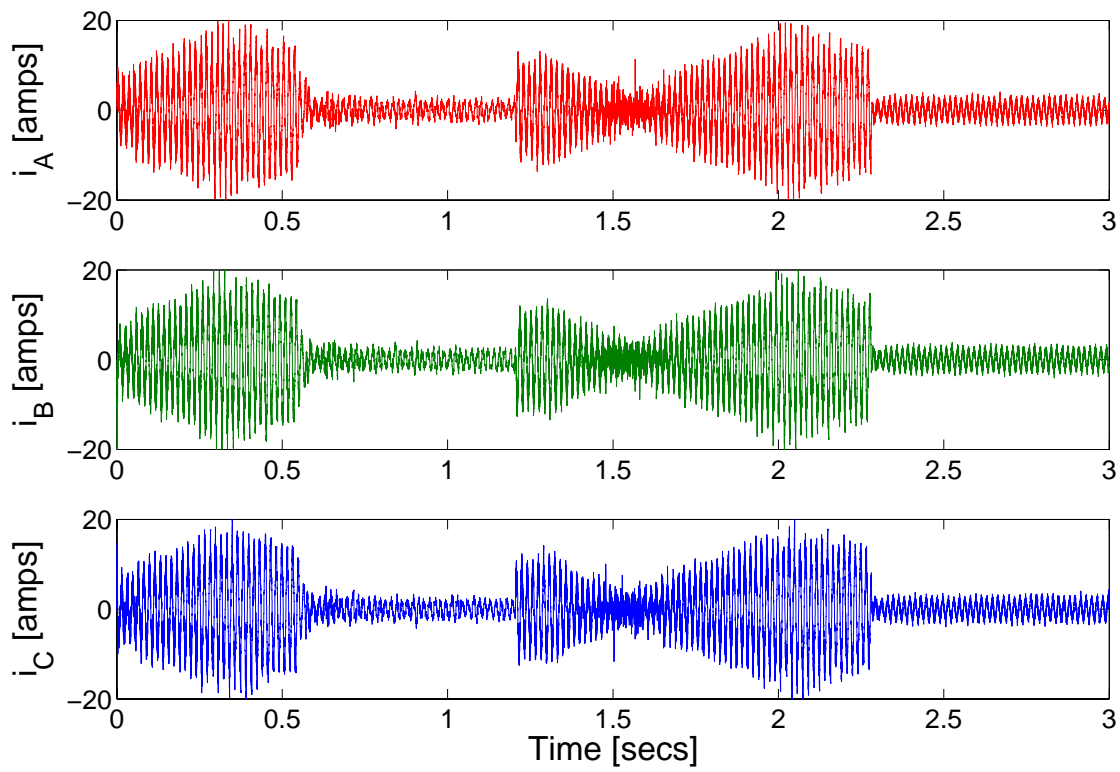

Figure 5.17: Input Phase Currents for a Matrix Converter in Regeneration. $V_{\text {in }}=$ $240 \mathrm{~V}$ at $60 \mathrm{~Hz}, \mathrm{q}=0.75$ and $f_{s}=10 \mathrm{kHz}$ 

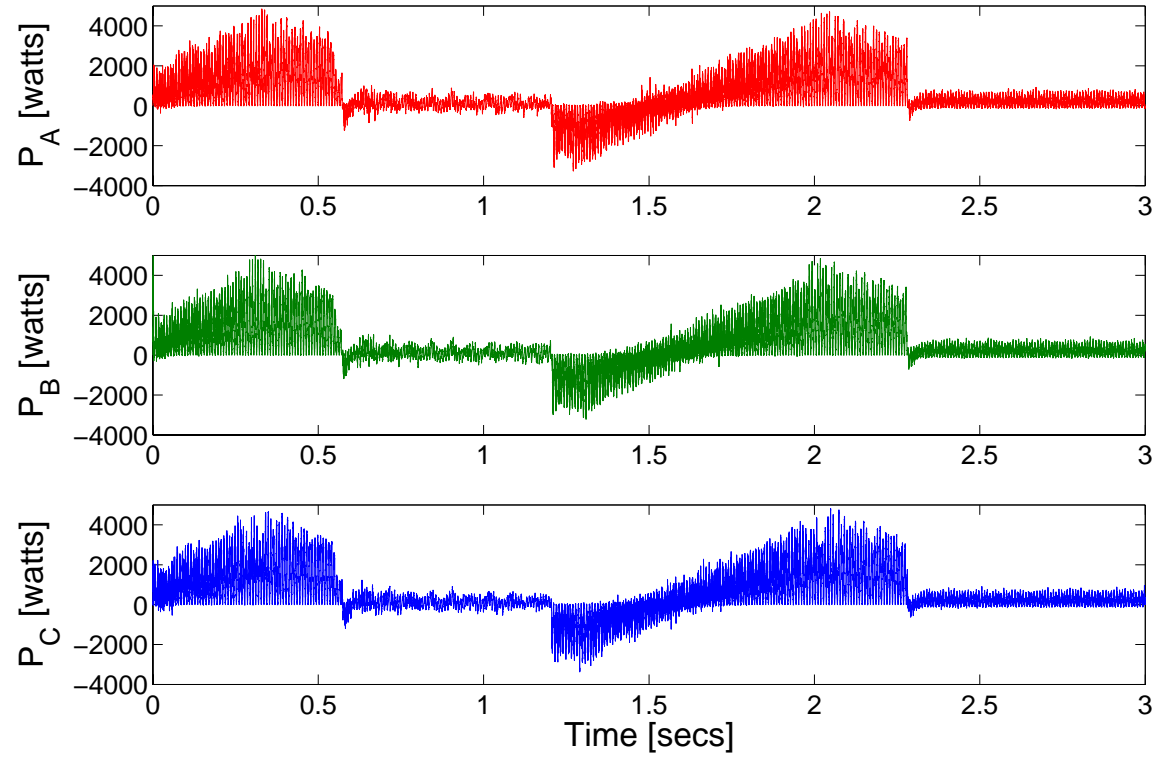

Figure 5.18: Instantaneous Input Phase Powers for a Matrix Converter in Regeneration. $V_{\text {in }}=240 \mathrm{~V}$ at $60 \mathrm{~Hz}, \mathrm{q}=0.75$ and $f_{s}=10 \mathrm{kHz}$
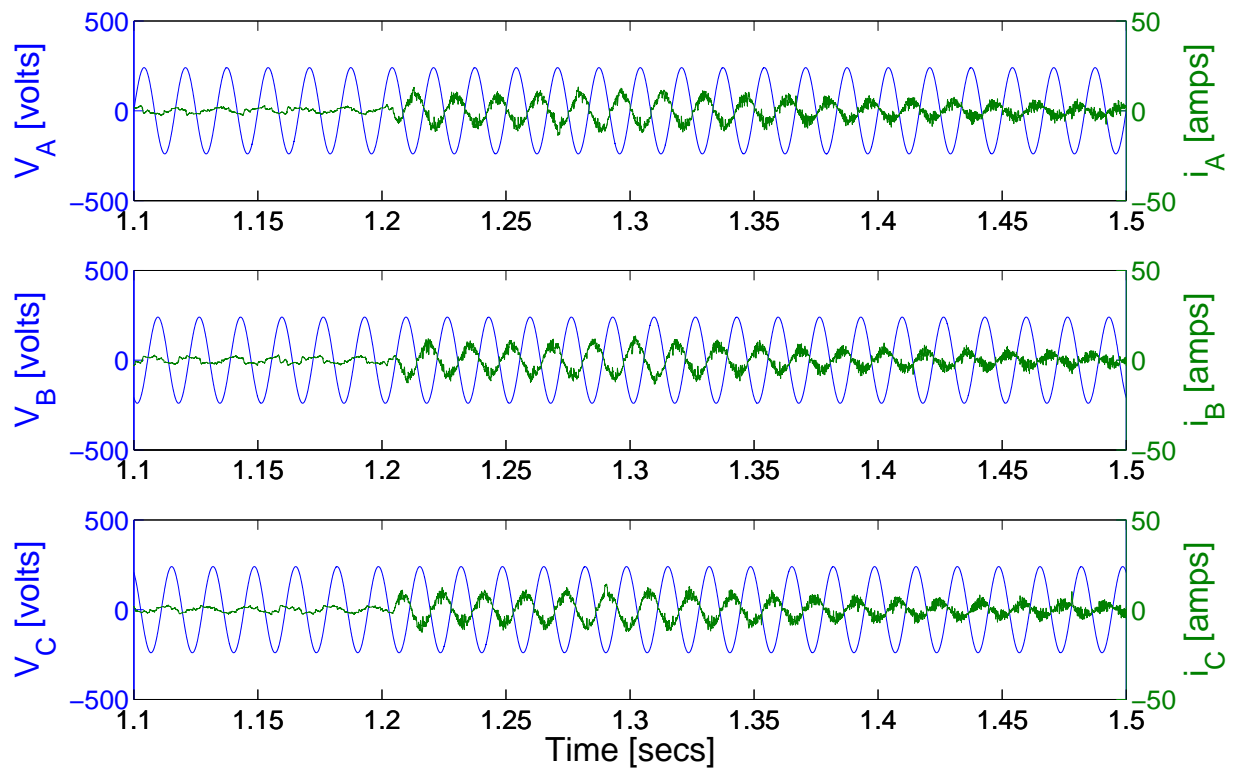

Figure 5.19: Phase Opposition between Input Phase Voltages and Input Phase Currents of the Matrix Converter during the Regeneration. $V_{\text {in }}=240 \mathrm{~V}$ at $60 \mathrm{~Hz}, \mathrm{q}=$ $0.75, f_{\text {out }}=60 \mathrm{~Hz}$ and $f_{s}=10 \mathrm{kHz}$ 


\subsection{Bi-Directional Switch (BDS) Method}

In this section, the simulation results for avoiding regeneration in the Matrix Converter using Bi-Directional Switch (BDS) method with both regeneration detection techniques (Power Comparison and Input Voltage Reference) are presented. Figure 5.20 shows the circuit diagram for the BDS method. In this method 6-pulses are required to trigger the three bi-directional switches in the Regeneration Control Circuit (RCC) of the Matrix Converter, as discussed in the section 4.4.

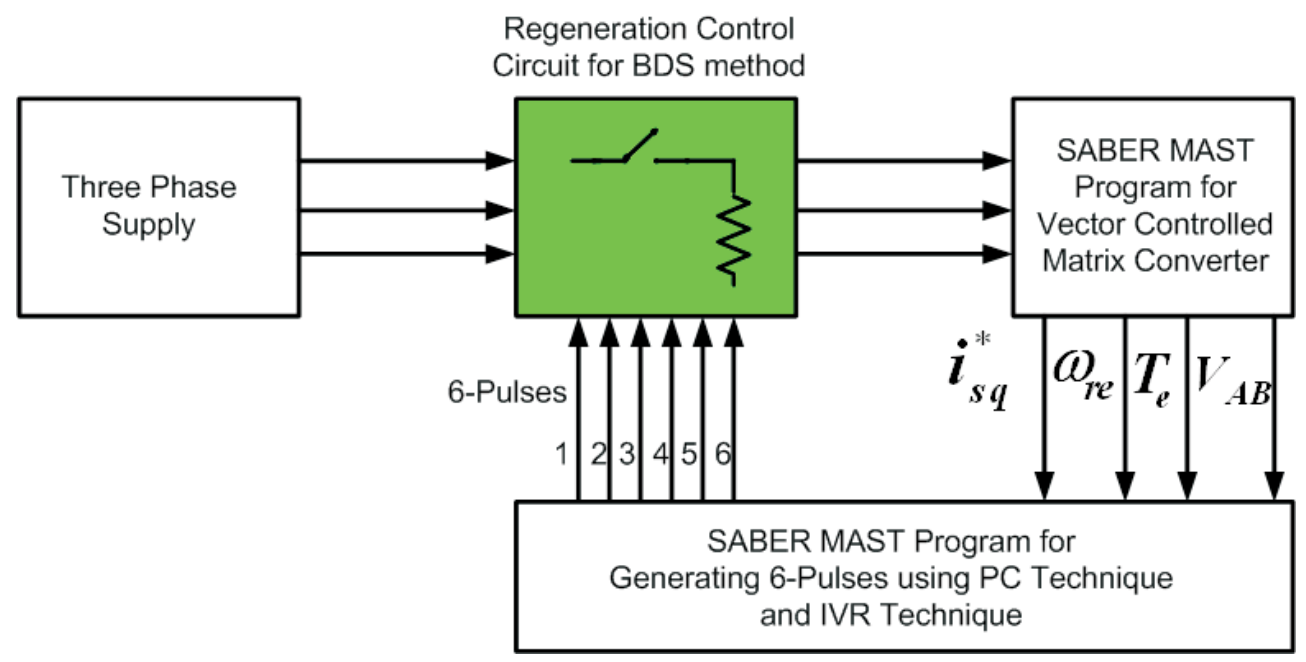

Figure 5.20: Circuit Diagram for a BDS Method with PC and IVR Technique

\subsubsection{Power Comparison (PC) Technique}

The generation of the required 6-pulses using PC technique for the Regeneration Control Circuit (RCC) is shown in the figure 5.21. These 6-pulses trigger the bidirectional switches in the Regeneration Control Circuit (RCC) to ensure balanced input phase currents $\left(i_{A}, i_{B}, i_{C}\right)$. The relationship between the duty cycle variation and the output power $\left(P_{o}\right)$ variation during the regeneration is shown in figure 5.21. As discussed in the section 4.3.1, the power dissipation is directly proportional to the duty cycle. The shape of duty cycle variation of the bi-directional switches is replica of the variation of negative output power of the induction motor, 

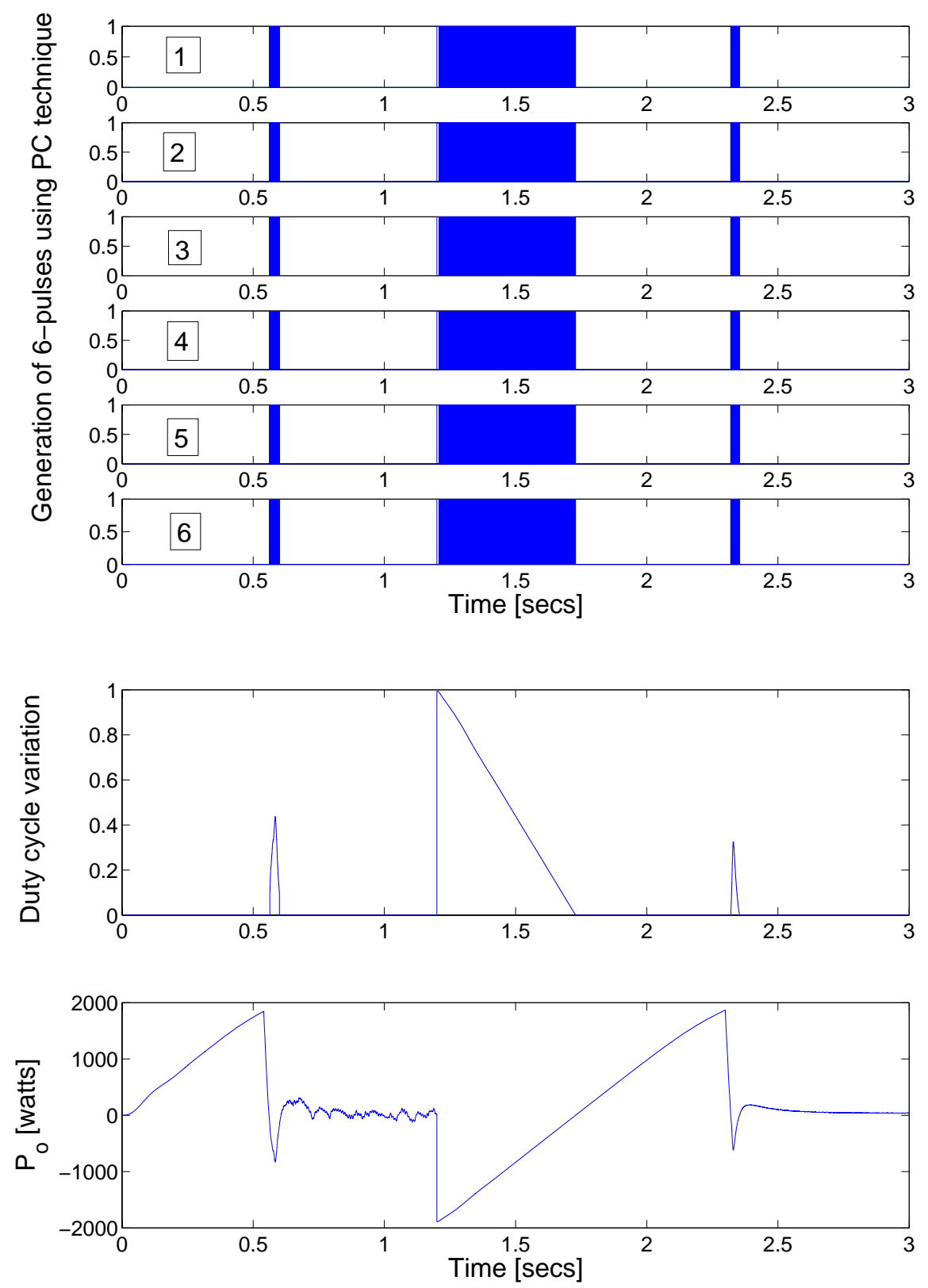

Figure 5.21: Generation of the 6-Pulses, Duty Cycle Variation and Output Power for Regeneration Control Circuit for the BDS Method with the PC Technique. $V_{i n}=240$ $\mathrm{V}$ at $60 \mathrm{~Hz}, \mathrm{q}=0.75, f_{\text {out }}=60 \mathrm{~Hz}$ and $f_{s}=10 \mathrm{kHz}$ 

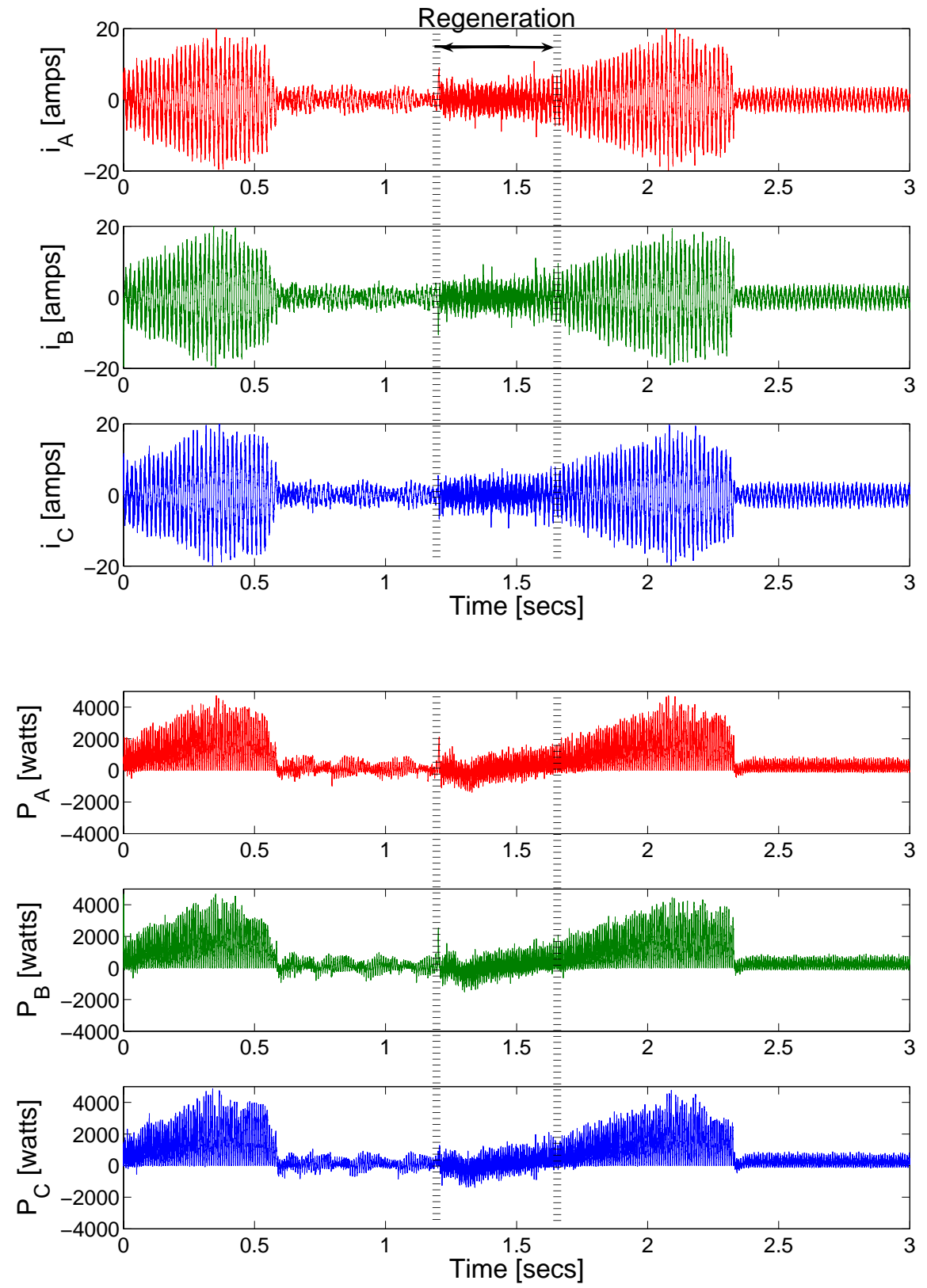

Figure 5.22: Input Phase Currents and Input Phase Powers for the BDS Method with the PC Technique. $V_{\text {in }}=240 \mathrm{~V}$ at $60 \mathrm{~Hz}, \mathrm{q}=0.75, f_{\text {out }}=60 \mathrm{~Hz}$ and $f_{s}=10 \mathrm{kHz}$ 


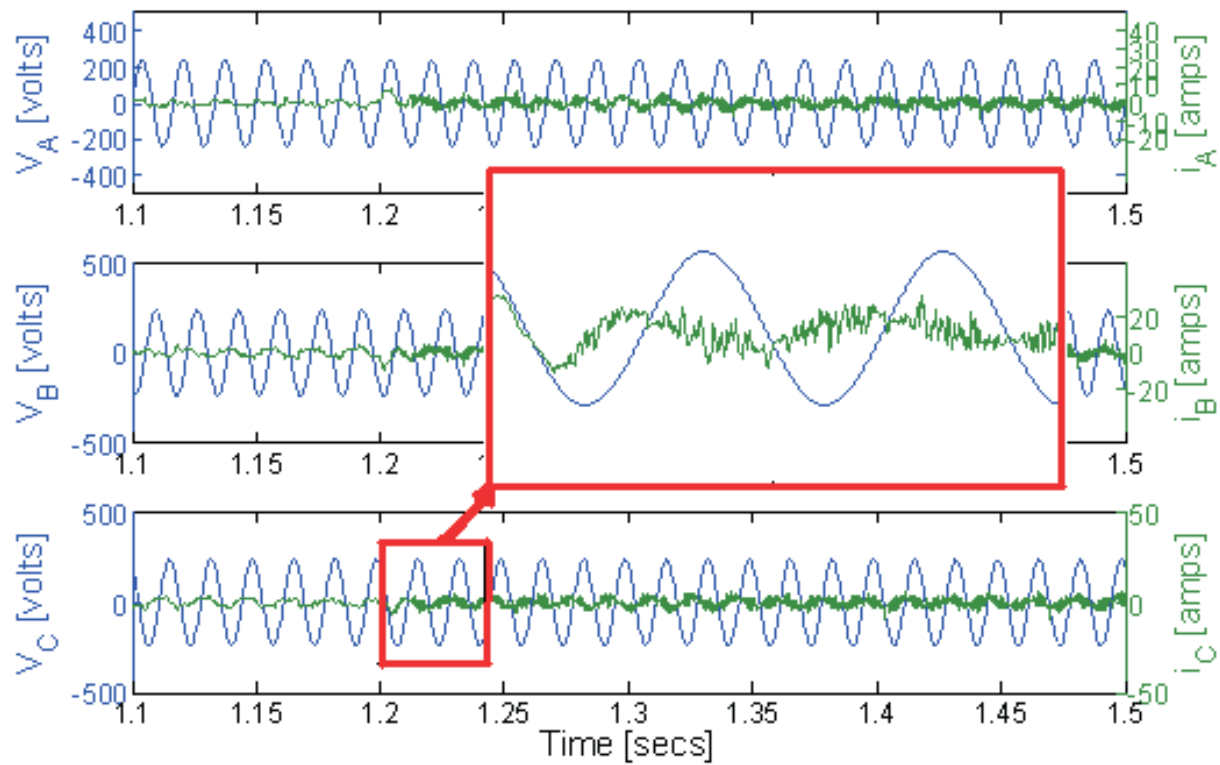

Figure 5.23: Phase Relationship between Input Phase Voltage and Input Phase Current in the BDS Method with the PC Technique. $V_{\text {in }}=240 \mathrm{~V}$ at $60 \mathrm{~Hz}, \mathrm{q}=0.75$, $f_{\text {out }}=60 \mathrm{~Hz}$ and $f_{s}=10 \mathrm{kHz}$

as shown in figure 5.21. In addition, the linear variation of the duty cycle with respect to the output power also shown in figure 5.21. In order to verify the regenerative energy dissipation, the input phase powers are calculated using input phase voltages and the input phase currents. The resulting input phase powers are shown in the figure 5.22. When compared to the figure 5.17 showing the input currents before avoiding regeneration, the figure 5.22 demonstrates that it is possible to avoid regeneration using proposed methods. However, there is some input power left in the waveforms because of constant losses (such as friction, windage losses and inertial losses) in the induction motor. In addition some switching noise is left in the input power waveforms. The phase relationship between the input phase voltages $\left(V_{A}, V_{B}, V_{C}\right)$ and input phase currents $\left(i_{A}, i_{B}, i_{C}\right)$ whilst avoiding regeneration is shown in the figure 5.23. These results can be compared to those in figure 5.19. 


\subsubsection{Input Voltage Reference (IVR) Technique}

The generation of modulation waveforms for the three bi-directional switches in the Regeneration Control Circuit (RCC) using Input Voltage Reference (IVR) technique is shown in the figure 5.24. The duty cycle variation and output power $\left(P_{o}\right)$ of the induction motor during the regeneration are also shown in the figure 5.24. From this graph, it can be seen that duty cycle is varying linearly, as discussed in the section 4.3.3. The duty cycle varies proportional to voltage across the input filter capacitor with respect to the output power $\left(P_{o}\right)$.

The resulting input phase currents and input phase powers are depicted in the figure 5.25. Figure 5.25 illustrates that the input power dissipation is similar to the input power dissipation in the $\mathrm{PC}$ technique. The reason is that duty cycle of the bidirectional switches is linearly varying. It is clearly proved that IVR technique is capable of dissipating the regenerative power in the Matrix Converter. 

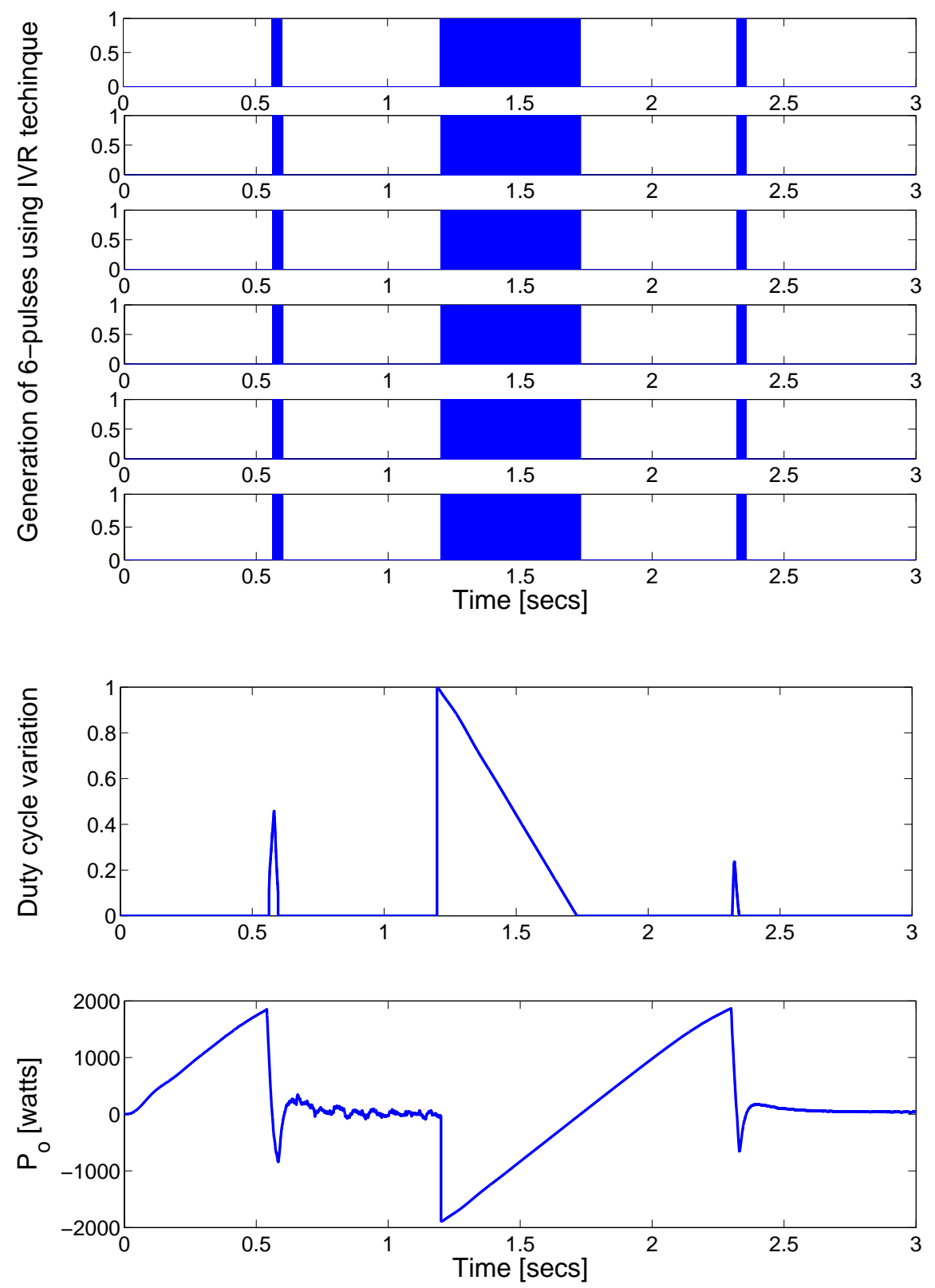

Figure 5.24: Generation of 6-Pulses for RCC, Duty Cycle Variation and Output Power for the BDS Method with IVR Technique. $V_{\text {in }}=240 \mathrm{~V}$ at $60 \mathrm{~Hz}, \mathrm{q}=0.75, f_{\text {out }}=60$ $\mathrm{Hz}$ and $f_{s}=10 \mathrm{kHz}$ 

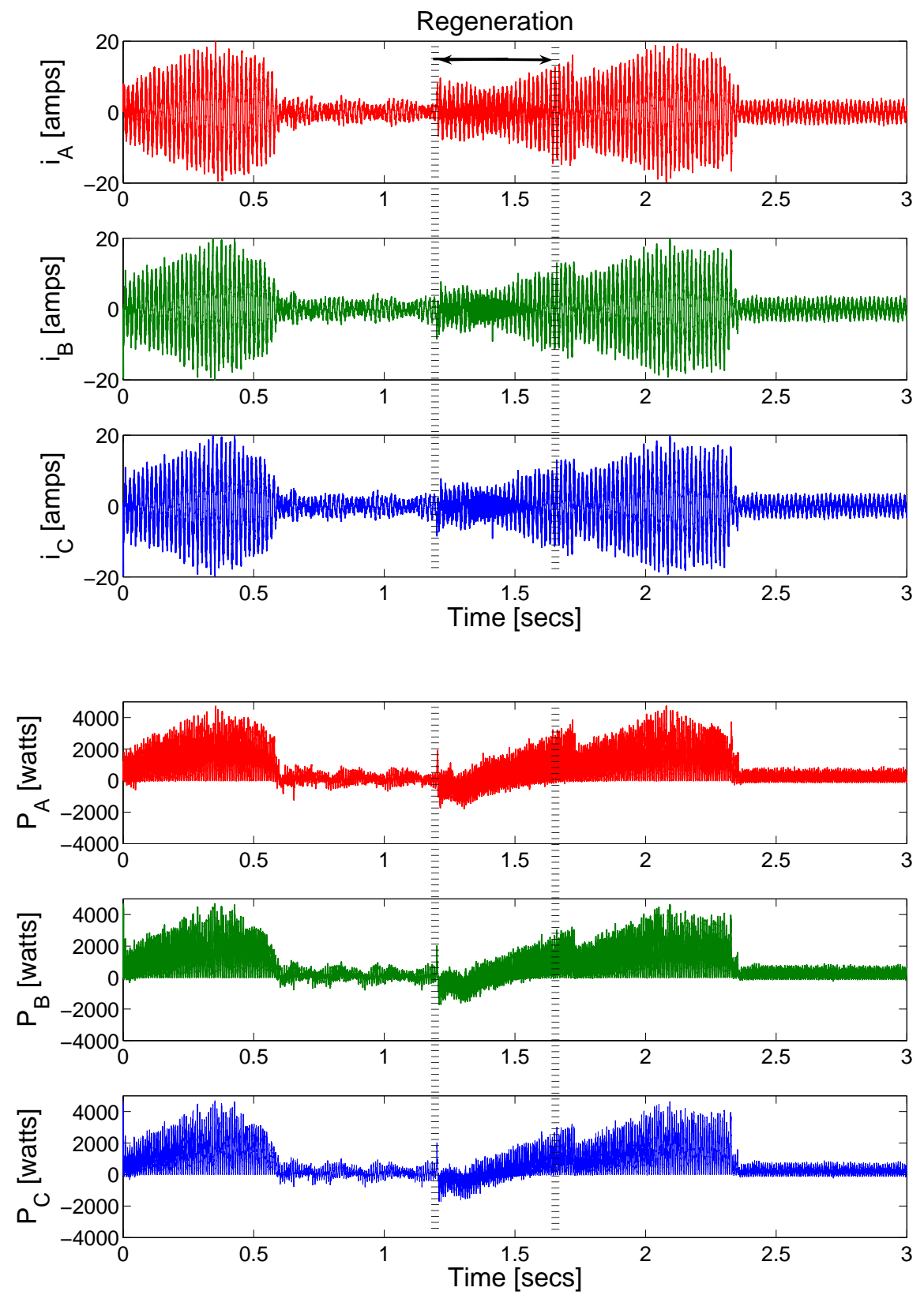

Figure 5.25: Input Phase Currents and Input Phase Powers for the BDS Method with IVR Technique. $V_{\text {in }}=240 \mathrm{~V}$ at $60 \mathrm{~Hz}, \mathrm{q}=0.75, f_{\text {out }}=60 \mathrm{~Hz}$ and $f_{s}=10 \mathrm{kHz}$ 


\subsection{Input Power Clamp (IPC) Method}

The Input Power Clamp (IPC) method requires a pulse to activate the switch in the Regeneration Control Circuit (RCC). This section deals with the simulation results obtained from the IPC method with two different regeneration detection techniques (PC and IVR). The system diagram for the IPC method is shown in figure 5.26.

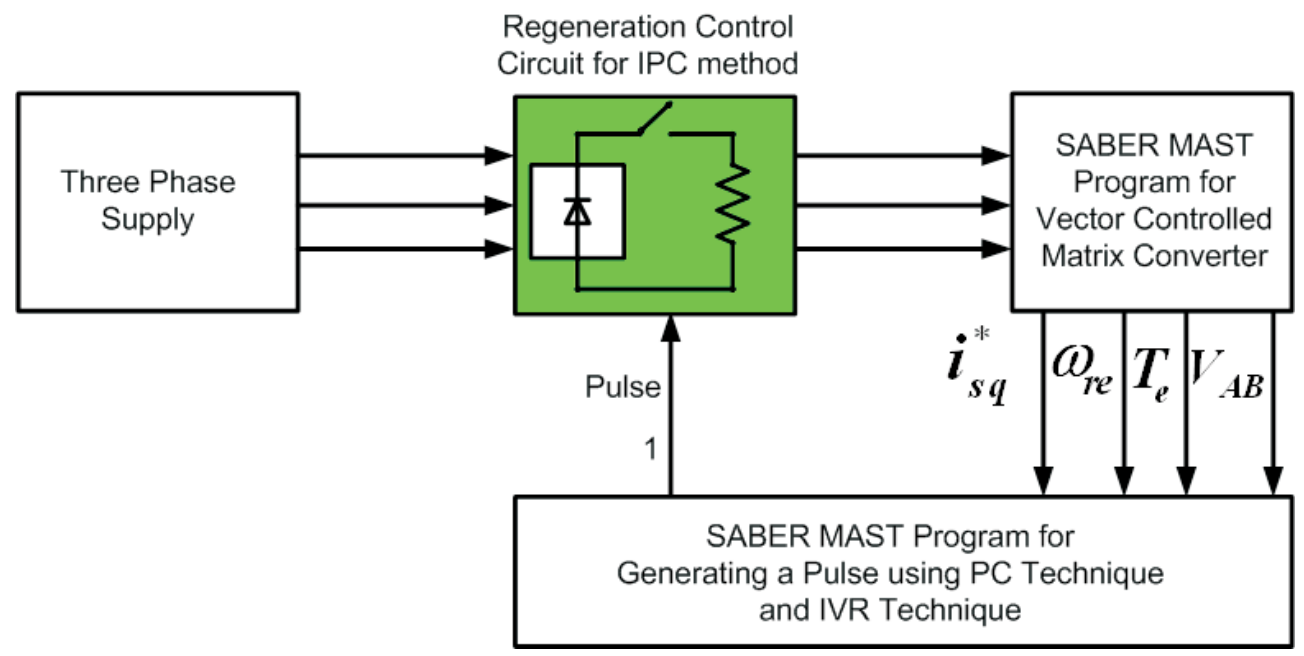

Figure 5.26: Simulation Diagram for a IPC Method with PC and IVR Technique

\subsubsection{Power Comparison (PC) Technique}

In the IPC method with the PC technique, the duty cycle variation is linear and similar to the BDS method with the PC technique. Figure 5.27 shows the pulse for RCC, duty cycle variation and the output power $\left(P_{o}\right)$ of the induction motor. The rectified DC voltage after the input clamp diode bridge (full wave diode bridge) is shown in figure 5.28. The current $\left(i_{r}\right)$ through and voltage $\left(V_{r}\right)$ across the Regeneration Control Circuit (RCC) resistor is also shown in the figure 5.28. In addition to figure 5.28 demonstrates the in-phase relationship between the input voltage and the current. The input phase currents and input phase power during electrical braking are shown in the figure 5.29. From these simulation results, it is concluded that the PC technique with both methods (BDS and IPC) are produce good results. 

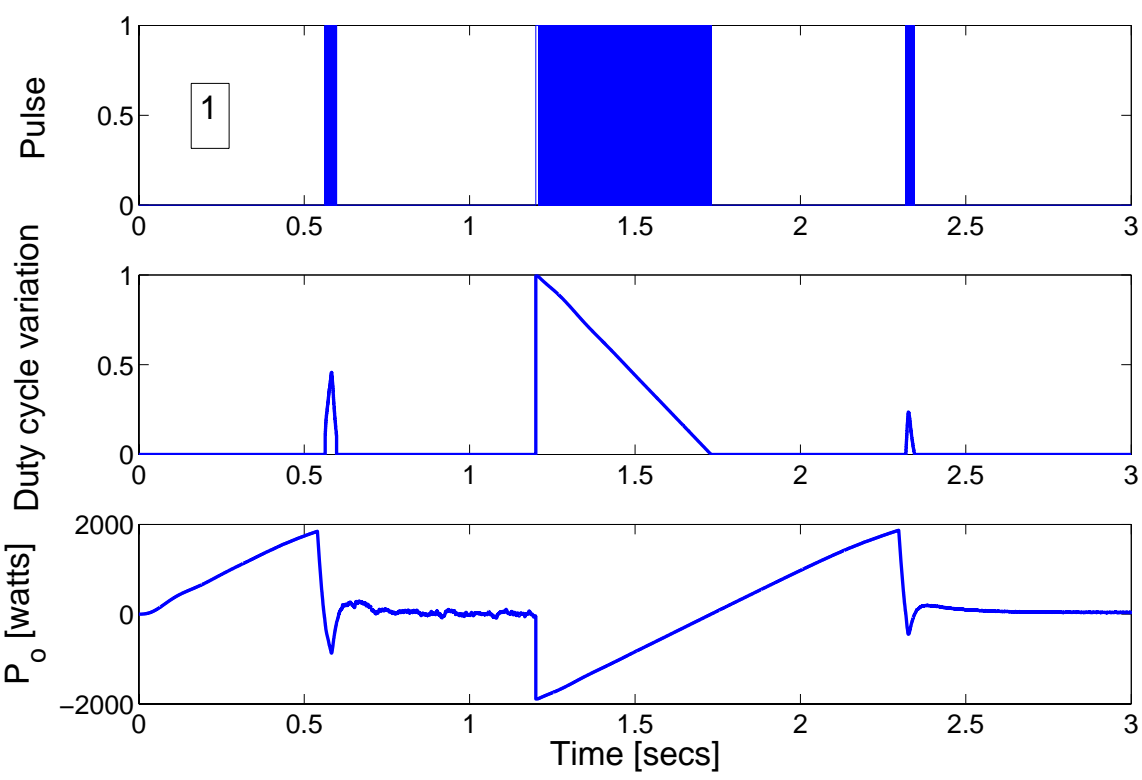

Figure 5.27: Pulse for RCC, Duty Cycle Variation and Output Power for the IPC Method with the PC Technique. $V_{\text {in }}=240 \mathrm{~V}$ at $60 \mathrm{~Hz}, \mathrm{q}=0.75, f_{\text {out }}=60 \mathrm{~Hz}$ and $f_{s}=10 \mathrm{kHz}$
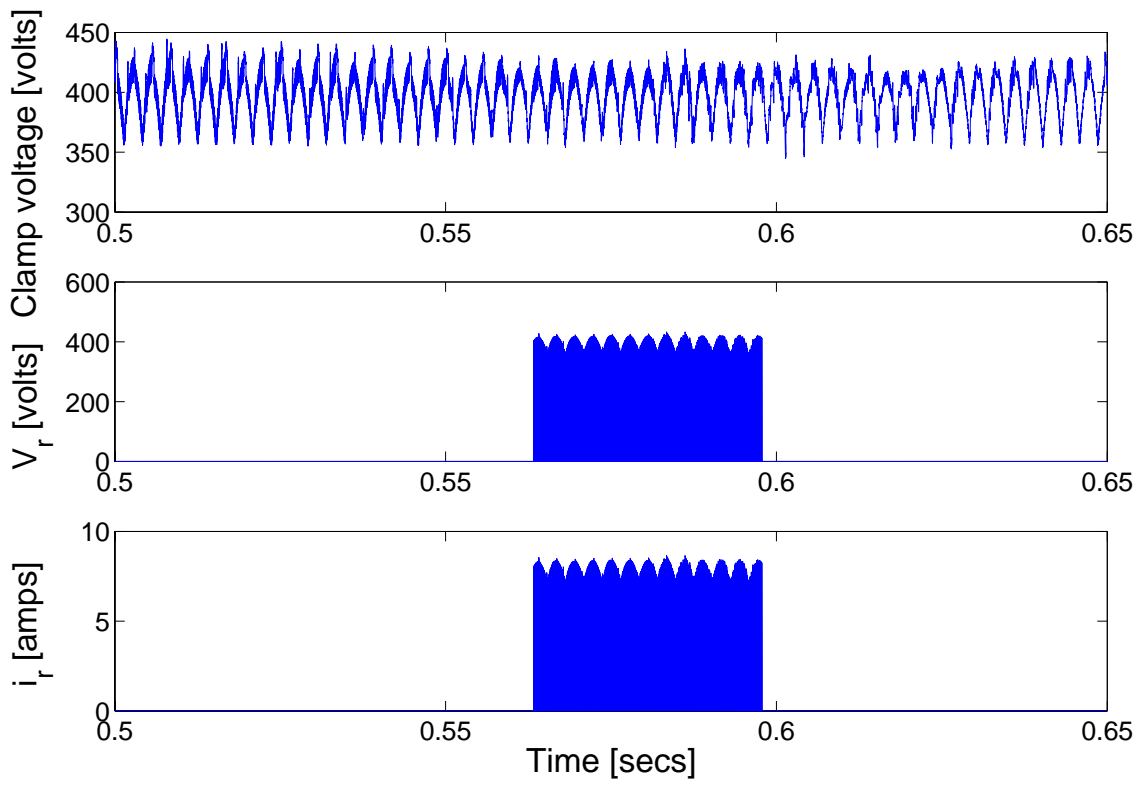

Figure 5.28: Input Clamp Voltage, Voltage and Current of the RCC Resistor for the IPC Method with the PC Technique. $V_{\text {in }}=240 \mathrm{~V}$ at $60 \mathrm{~Hz}, \mathrm{q}=0.75, f_{\text {out }}=60 \mathrm{~Hz}$ and $f_{s}=10 \mathrm{kHz}$ 

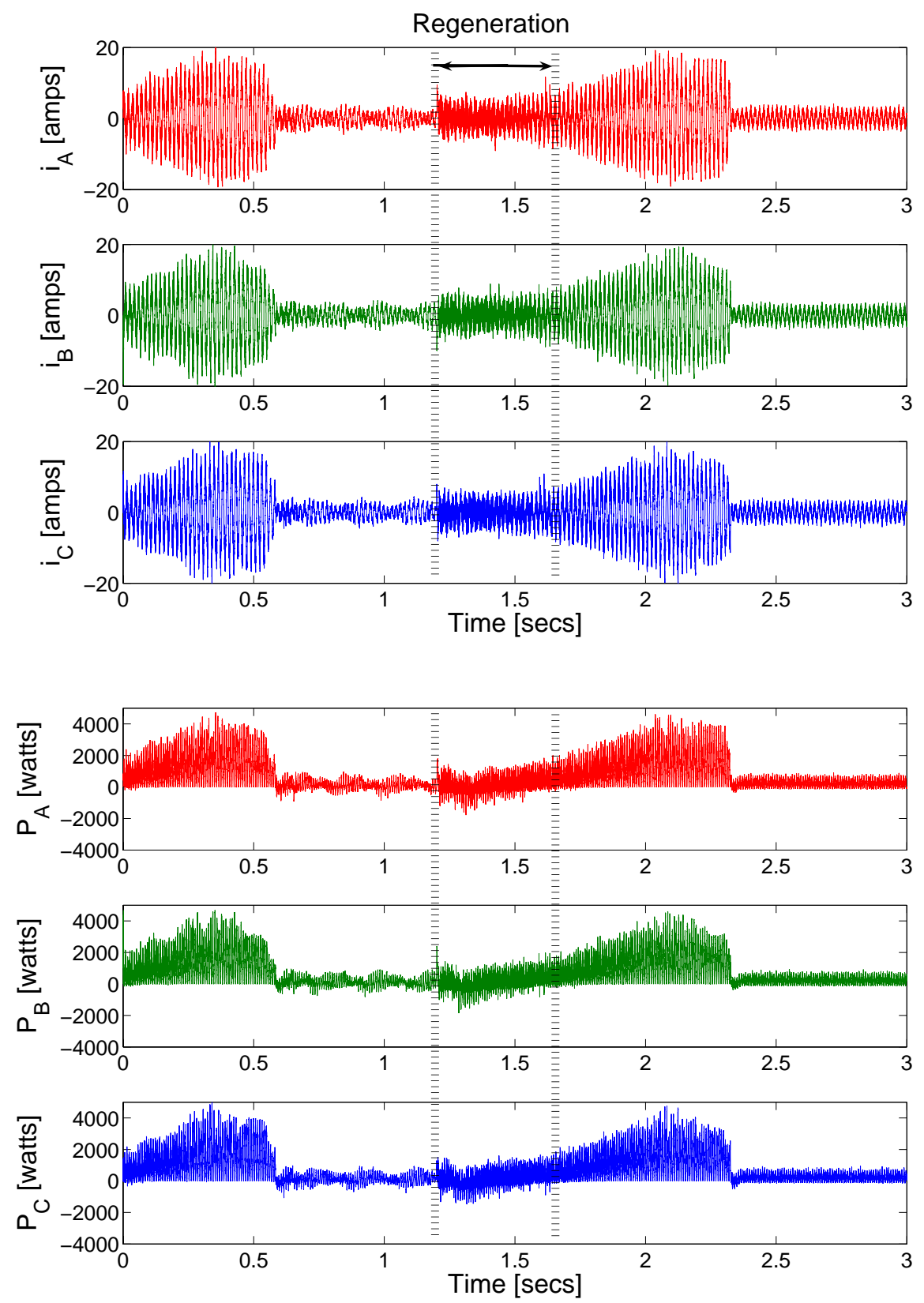

Figure 5.29: Input Phase Currents and Input Phase Powers for the IPC Method with the PC Technique. $V_{\text {in }}=240 \mathrm{~V}$ at $60 \mathrm{~Hz}, \mathrm{q}=0.75, f_{\text {out }}=60 \mathrm{~Hz}$ and $f_{s}=10 \mathrm{kHz}$ 


\subsubsection{Input Voltage Reference (IVR) Technique}

The generation of a pulse to trigger the RCC , duty cycle variation and the output power $\left(P_{o}\right)$ variation during regeneration is shown in figure 5.30.

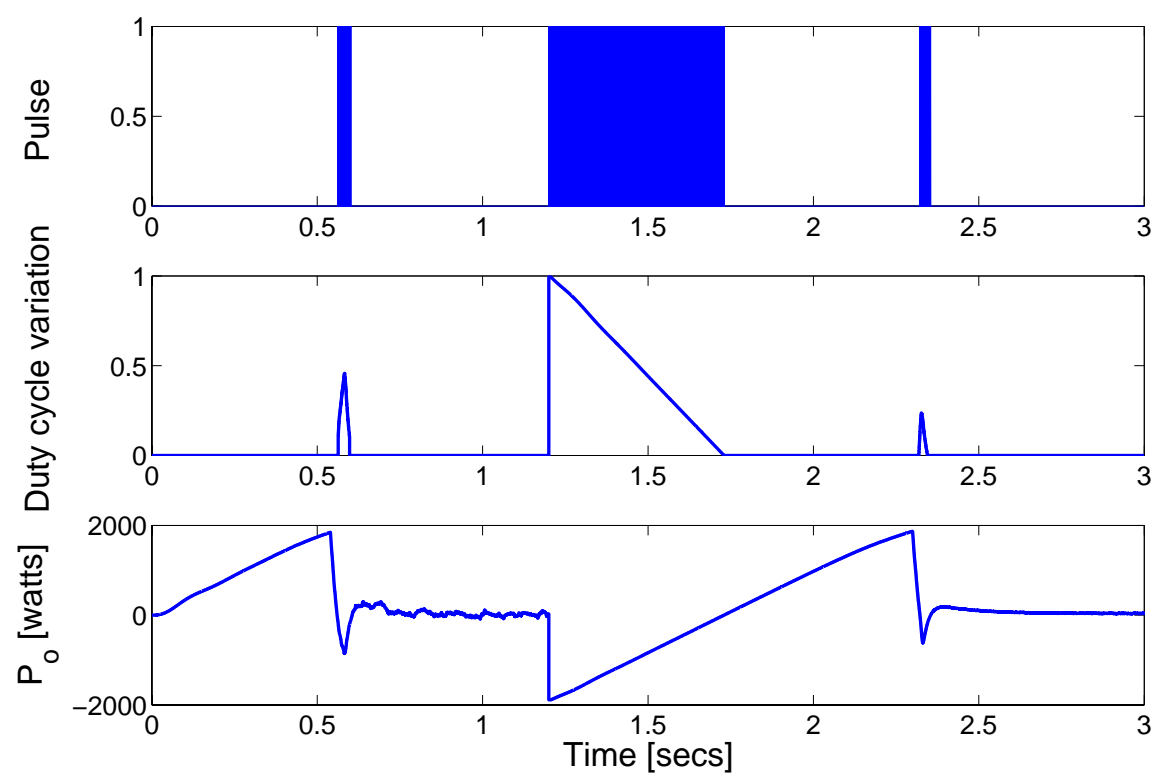

Figure 5.30: Pulse for RCC, Duty Cycle Variation and Output Power for the IPC Method with the IVR Technique. $V_{\text {in }}=240 \mathrm{~V}$ at $60 \mathrm{~Hz}, \mathrm{q}=0.75, f_{\text {out }}=60 \mathrm{~Hz}$ and $f_{s}=10 \mathrm{kHz}$

The input phase currents and input phase powers during the avoiding regeneration are shown in figure 5.31. The simulation results of IVR technique for both methods (IPC and BDS) are producing acceptable results similar to PC technique because of linear duty cycle variation. From figure 5.31, the input regenerative power dissipation is completely dissipated through the Regeneration Control Circuit (RCC) and some switching noise is left in the waveforms so that it is concluded that the IVR technique is acceptable technique as the $\mathrm{PC}$ technique. 

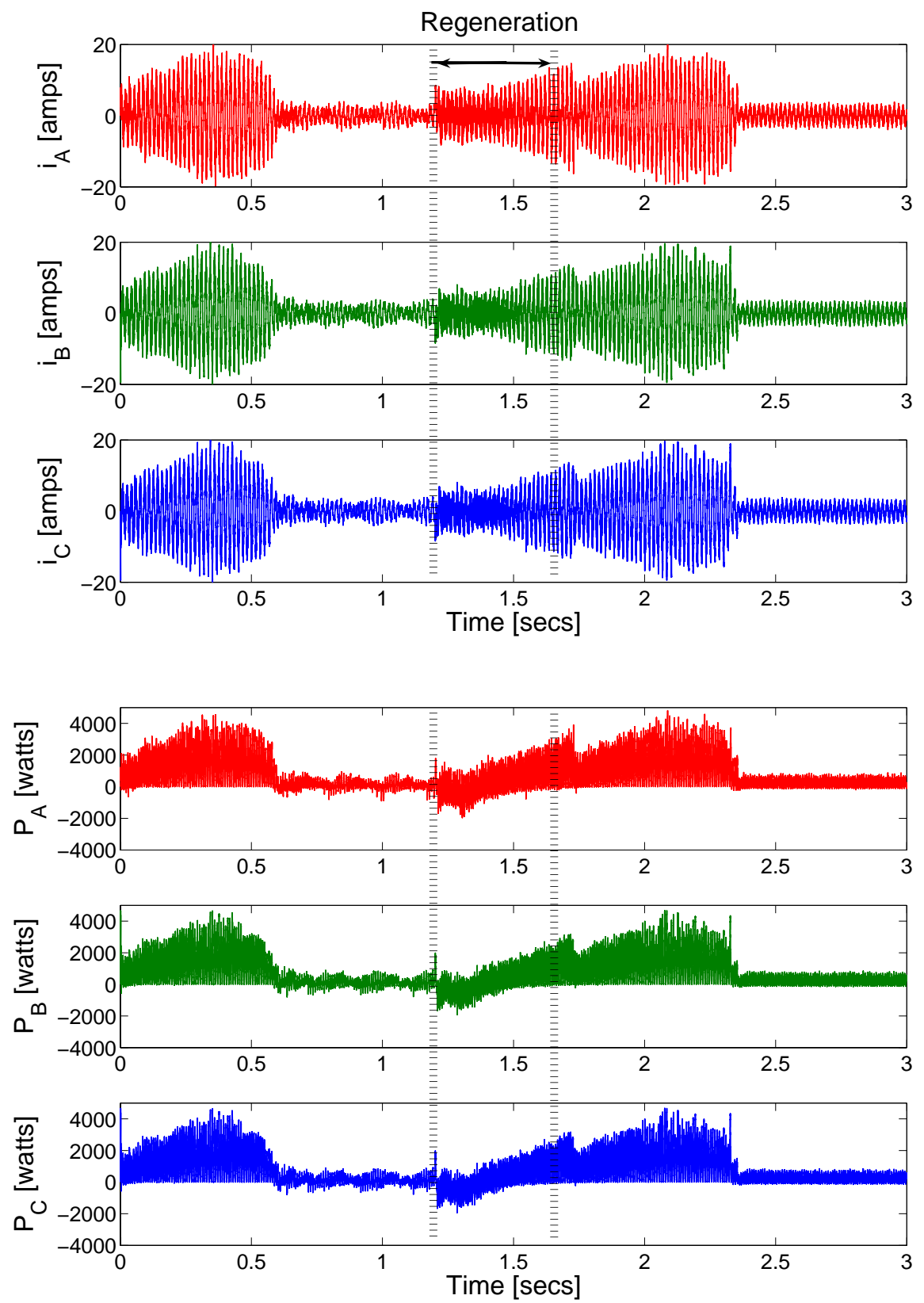

Figure 5.31: Input Phase Currents and Input Phase Powers for the IPC Method with the IVR Technique. $V_{\text {in }}=240 \mathrm{~V}$ at $60 \mathrm{~Hz}, \mathrm{q}=0.75, f_{\text {out }}=60 \mathrm{~Hz}$ and $f_{s}=10 \mathrm{kHz}$ 


\subsection{Conclusions}

In this simulation study, results for the three phase to three phase Matrix Converter with an R-L load and an induction motor load have been presented [64]. In addition, the simulation results for regeneration in the Matrix Converter and the novel methods for avoiding regeneration in the Matrix Converter are also presented.

For an R-L load, the spectrum input and output waveforms for the Matrix Converter at different output frequencies have been shown. The simulation results for a Matrix Converter fed induction motor drive confirms that the Matrix Converter is suitable for adjustable speed drives without any restrictions in the output frequency.

Simulation results for indirect field oriented vector control of an induction motor have been presented. The simulation results, such as those in figure 5.12 and figure 5.13, demonstrate that the Matrix Converter motor drive with the vector control is capable of good torque and speed response.

Finally, the simulation results for the novel regeneration avoidance methods, such as the BDS method and the IPC method have been investigated. Based on the validated simulation results, avoiding regeneration in a Matrix Converter drive is feasible [65]. Therefore, it is concluded that Matrix Converters are suitable for the aerospace applications, such as aircraft surface actuation systems and in-flight refuelling systems, where regeneration into the supply is not allowed. Even though both proposed techniques produce good results, the PC technique is more preferred to the IVR technique because it is more robust and less susceptible to input voltage disturbances. 


\section{Chapter 6}

\section{Experimental Implementation of the Matrix Converter}

\subsection{Introduction}

This chapter describes the experimental implementation of a three phase to three phase Matrix Converter with a novel Regeneration Control Circuit (RCC). Figure 6.1 shows the complete block diagram of the laboratory prototype which has been used to validate the novel concept for avoiding regeneration in the Matrix Converter. The design and construction of the laboratory prototype can be split into three sections:

1. Matrix Converter power circuit

2. Control and Interface Circuits

3. Regeneration Control Circuit

The first section of this chapter outlines the design and construction of the Matrix Converter. This section describes the implementation of the main circuits such as 
gate drives, power assembly, input filter, output current polarity detection and the protection clamp.

The second section of this chapter describes the implementation of control and interface circuits for the Matrix Converter, such as the DSP (TMS320C6713), FPGA card (ProASIC A500K050), interface card and encoder interface board.

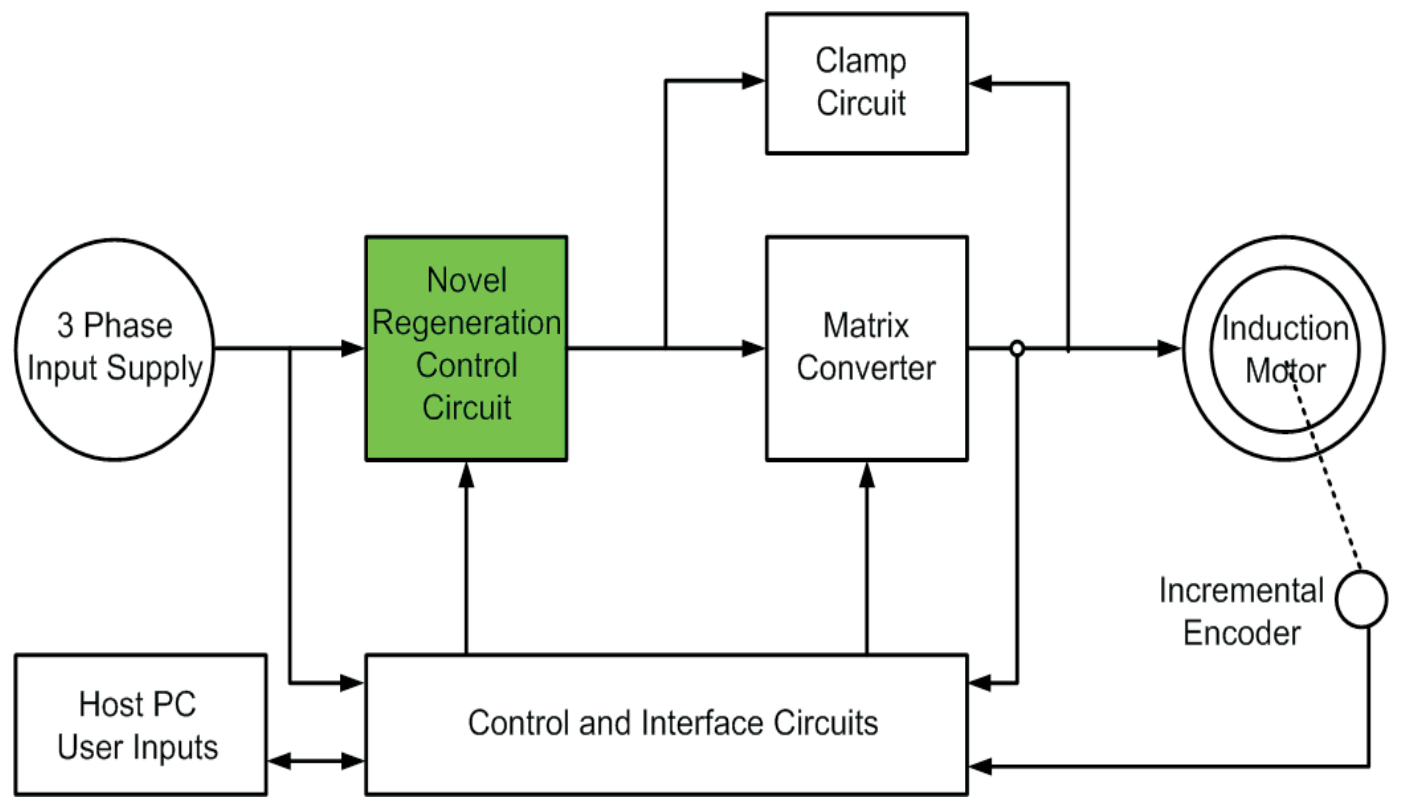

Figure 6.1: Overview of the Experimental Implementation of the Novel Concept for Avoiding Regeneration in a Matrix Converter Motor Drive

The final section describes the construction of the Regeneration Control Circuit (RCC). The programming of the DSP and FPGA is discussed. The final section also includes a description of the code for the novel Regeneration Control Circuit (RCC). The experimental results will be presented and discussed in the chapter 7 . 


\subsection{Matrix Converter Design}

This section describes the design of the prototype Matrix Converter which includes the gate drive circuit, power assembly, input filter, output current polarity detection circuit and protection clamp circuit. A Matrix Converter rated at $7.5 \mathrm{~kW}$ was originally designed by James Campbell from the Power Electronics Machines and Control (PEMC) group at the University of Nottingham. This design has been modified to include the Regeneration Control Circuit (RCC).

\subsubsection{Gate Drive Circuit}

The required gate signals for the power devices in the Matrix Converter are generated by the FPGA card. These gate signals are connected to the IGBT (SK60GM123) modules through gate driver circuits, as shown in the figure 6.2.

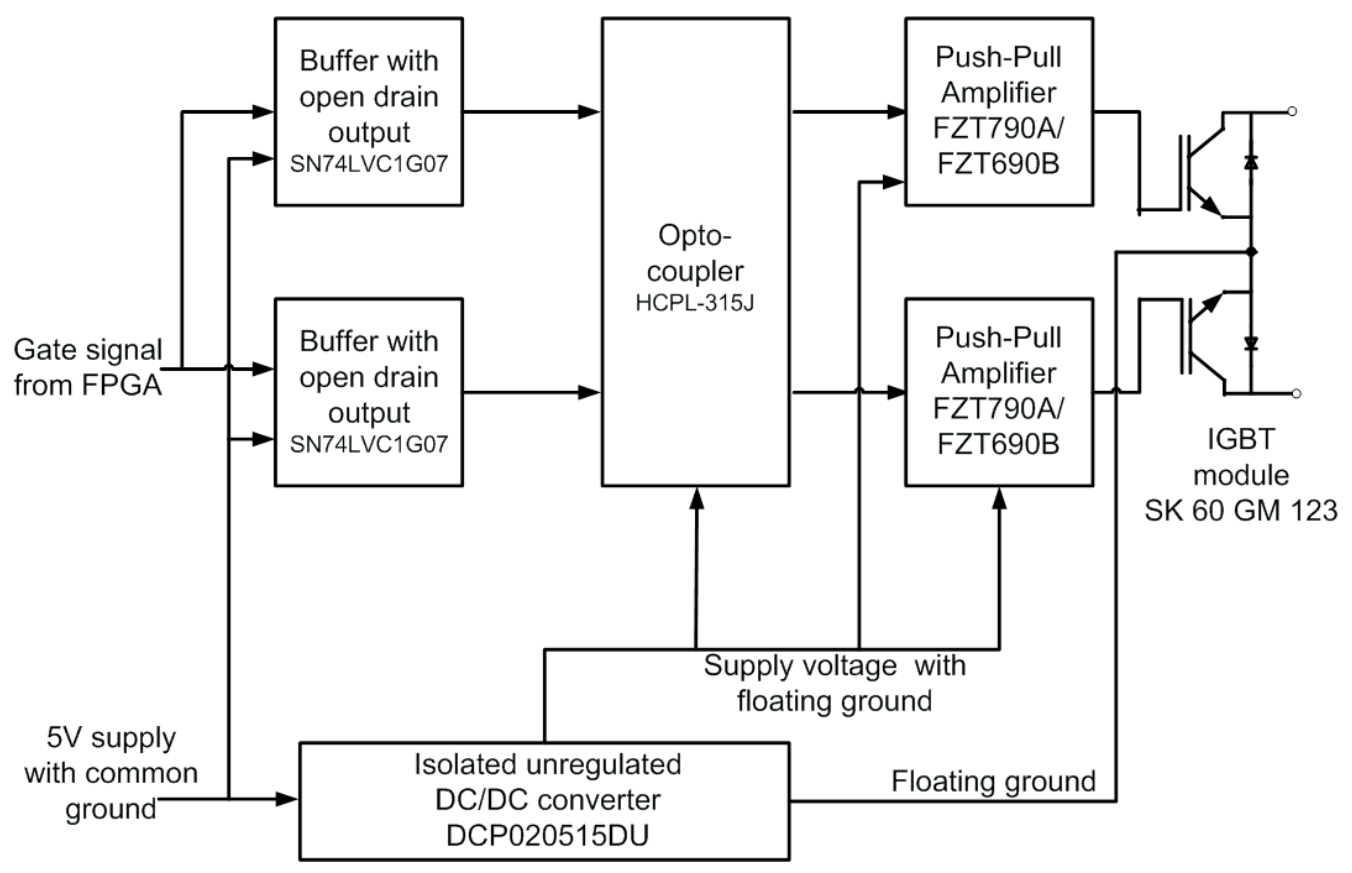

Figure 6.2: Overview of the Matrix Converter Gate Drive Circuit 
The IGBT gate drive circuit consists of four main components: the dc/dc converter (DCP020515DU), the buffer (SN74LVC1G07), the opto-coupler (HCPL-315J) and the NPN/PNP transistors (FZT790A/FZT690B).

The isolation between the control signals and the power circuit is provided by the dc/dc converter (DCP020515DU) and the opto-coupler (HCPL-315J). The dc/dc converter offers a dual supply +15 Volts $/-15$ Volts derived from the conversion 5 Volts supply. The +5 Volts supply is shared with the dual opto-couplers (HCPL-315J).

The gate signals from the FPGA card go through the open drain output buffer (SN74LVC1G07), as shown in the figure 6.2. This buffer is used to protect the FPGA and provide the current required by the opto-coupler. The output of the buffer is input to the opto-coupler which provides galvanic isolation between the control signal and the IGBT switch module.

The selection of the gate drive resistor plays a role in terms of the turn-on and turn-off characteristics as well as the switching losses. A high value of gate drive resistance increases the switching losses but it helps to reduce the rate of the switching transients. A low value of the gate drive resistance decreases the switching losses, however this can cause transient problems if reduced too far.

The output of the opto-coupler is input to the push-pull amplifier, formed using two discrete NPN and PNP transistors (FZT790A and FZT690B). The output of this push-pull amplifier is fed to the IGBT module through the gate drive resistor. In this gate drive design a $10 \Omega$ gate drive resistor is used. To achieve a compact design the IGBT modules are mounted immediately below the gate drive circuits. This arrangement minimizes the effects of stray inductance. 


\subsubsection{Power Circuit}

The power circuit of the Matrix Converter consists of nine IGBT modules (SK60GM123) arranged in a 3x3 matrix [19]. A photograph of the IGBT module is shown in the figure 6.3. These modules are manufactured by SEMIKRON company in the Germany.

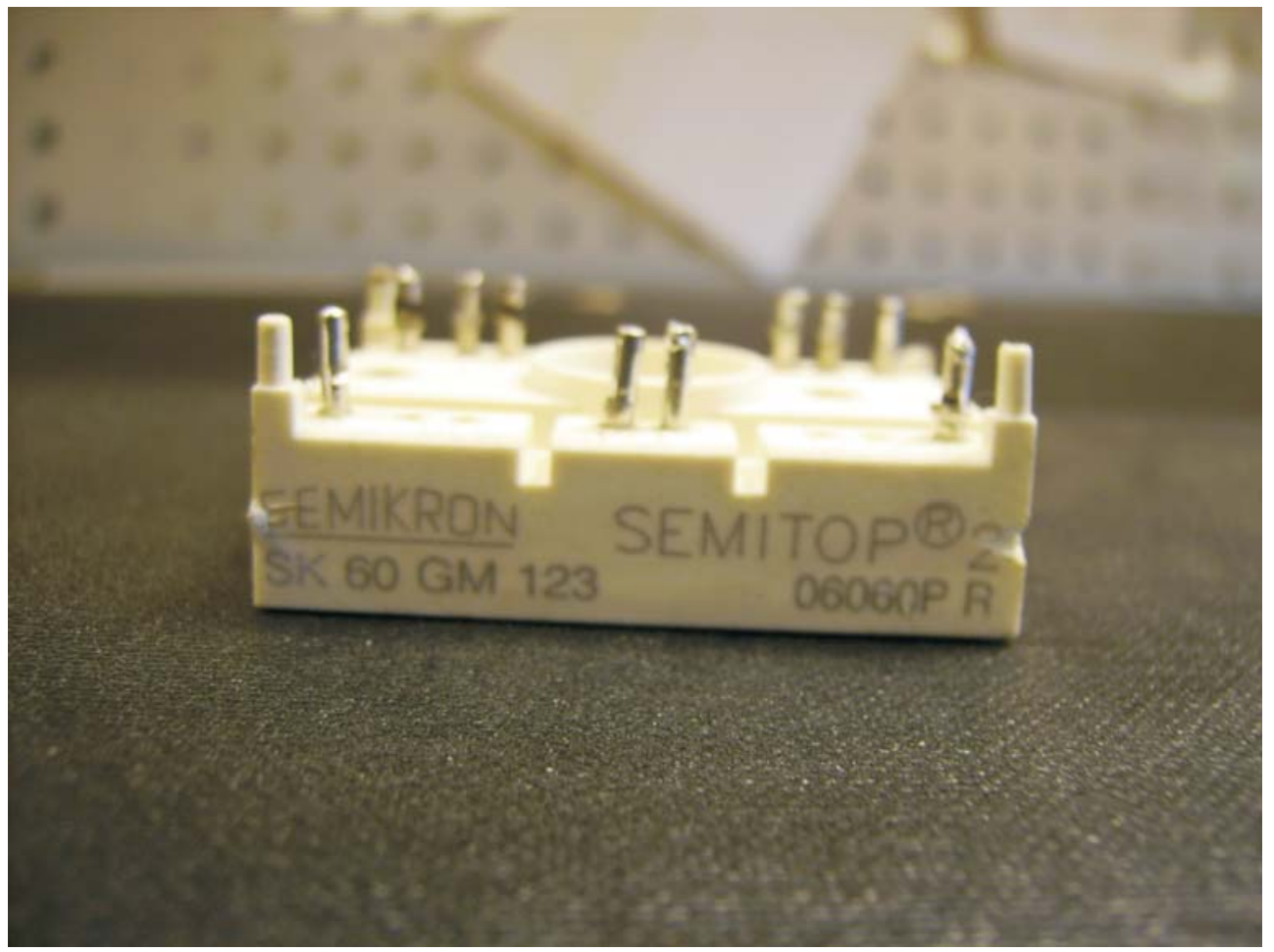

Figure 6.3: IGBT Switch Module SK60GM123 used in the Power Circuit

The IGBT module is rated at 1200 (volts) and 60 (amps) and uses the common emitter configuration. This common emitter bi-directional switch arrangement consists of two diodes and two IGBTs connected in anti-parallel. The advantages and disadvantages of this configuration were discussed in the section 2.5.1.2. The internal circuit layout of the IGBT module (SK60GM123) is shown in the figure 6.4. 


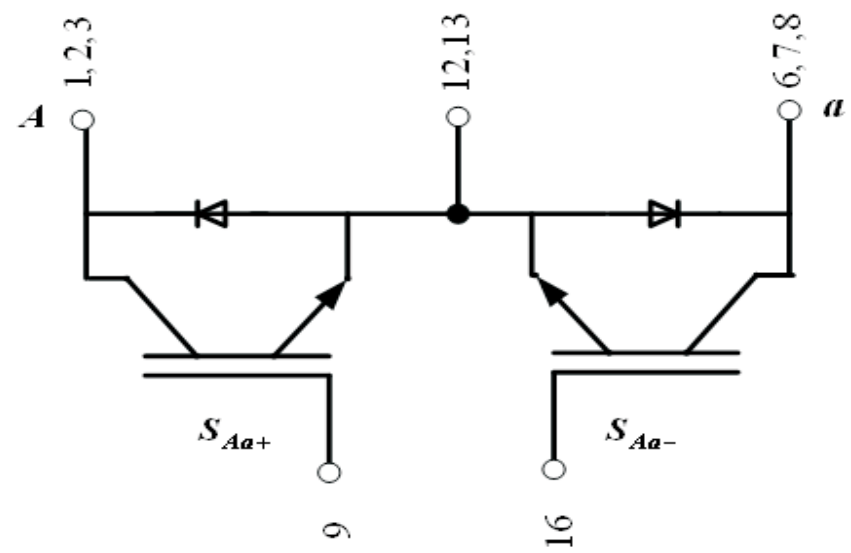

Figure 6.4: Internal Circuit Layout of IGBT Module SK60GM123

\subsubsection{Input Filter Circuit}

A Matrix Converter needs an input filter to circulate the high switching frequency harmonics in the input current. The cut-off frequency of the input filter must be lower than the switching frequency of the Matrix Converter. In this design, the input filter consists of a three-phase source inductance $\left(L_{A}, L_{B}, L_{C}\right)$ and three capacitors $\left(C_{A B}\right.$, $C_{B C}, C_{A C}$ ), which are connected across the input phases as shown in the figure 6.5. In this project variac is used as input source for the Matrix Converter, so the inductances of the variac is used rather than additional line inductors. $2 \mu \mathrm{F}$ of capacitance is used for the input filter capacitors. The cut-off frequency of the input filter is $2.5 \mathrm{kHz}$. In order to reduce the stray inductance between the input filter capacitors and the power modules of the Matrix Converter, the input filter capacitors are mounted on a power plane PCB (Printed Circuit Board) [66]. This arrangement is essential so that the input filter capacitors are as close as possible to the power modules.

\subsubsection{Output Current Polarity Detection Circuit}

To achieve the proper four-step current commutation, as explained in the section 2.5.2.2, information regarding the output current direction of the Matrix Converter is needed. 


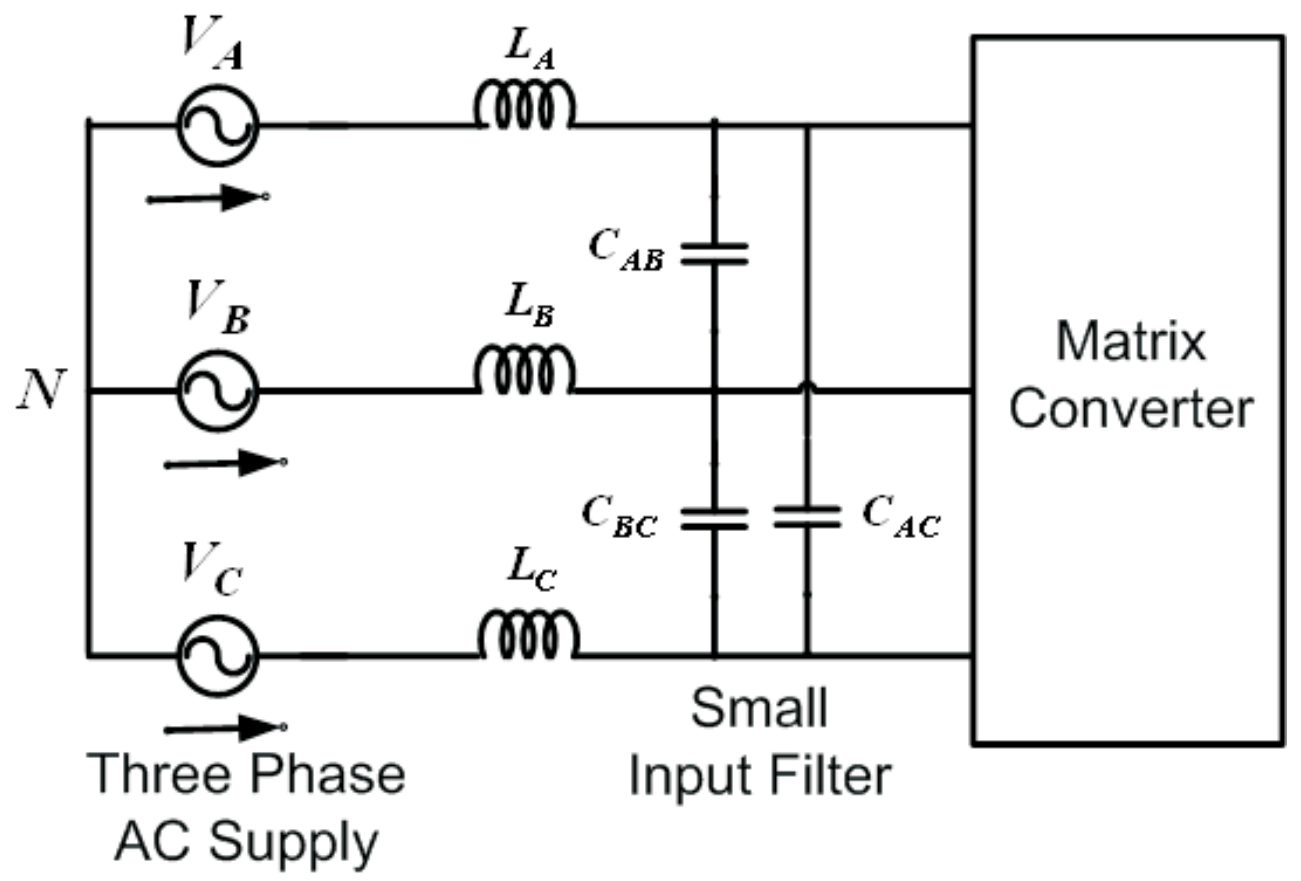

Figure 6.5: A Small Input Filter for the Matrix Converter

To obtain the output current direction information, two ultra fast SCHOTTKY diodes (30CTQ045S), with the same rating as IGBT modules, are connected in antiparallel in each output phase of the Matrix Converter, as shown in figure 6.6. In addition a comparator (LM311) and opto-coupler (.61N 627) are required.

The voltage drop across the antiparallel diodes is measured. This voltage drop may be positive or negative depending on the direction of the output current. The diode voltage drop is input to the voltage comparator. The comparator provides a logic voltage signal which is sent through the opto-coupler to the FPGA card. This current direction information is then used by the FPGA to perform four-step current based commutation, as described in section 2.5.2.2. 


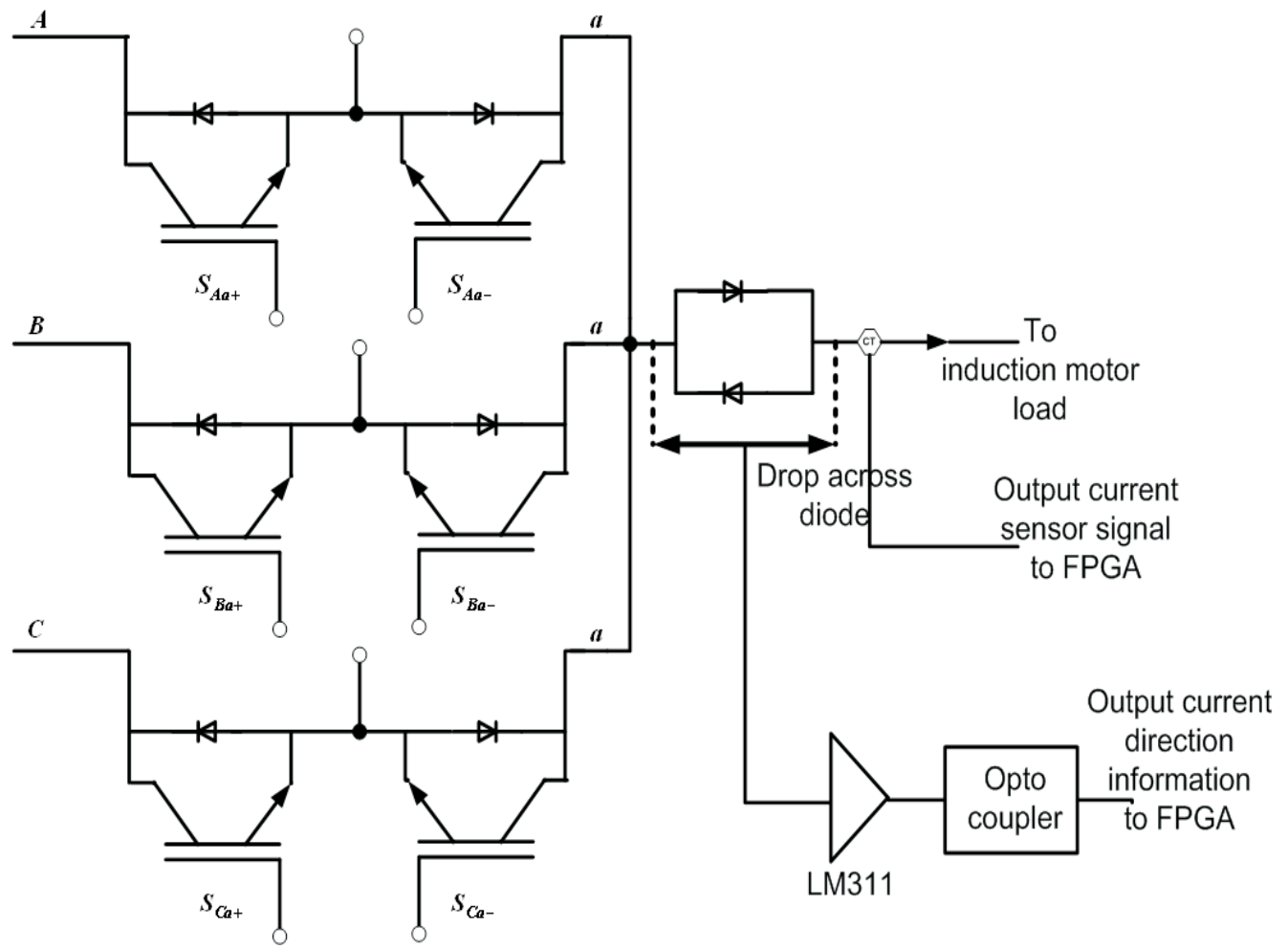

Figure 6.6: The Matrix Converter Output Current Direction Detection Circuit for One Output Phase

\subsubsection{Clamp Circuit}

To protect the Matrix Converter from the over voltages caused by the abnormal conditions, such as input voltage disturbances and from sudden open circuits on the output side, a clamp circuit is introduced, as shown in the figure 6.7.

During the abnormal condition or fault conditions, all the inductive load energy can be transferred to the clamp capacitors. This must be done within the voltage rating of the IGBT modules.

The clamp circuit consists of three main components:

1. The fast soft recovery diodes $(8 \mathrm{EWF} 12 \mathrm{~S})$

2. The clamp capacitors (TS-UP 450 Volts, $150 \mathrm{uF}$ ) 


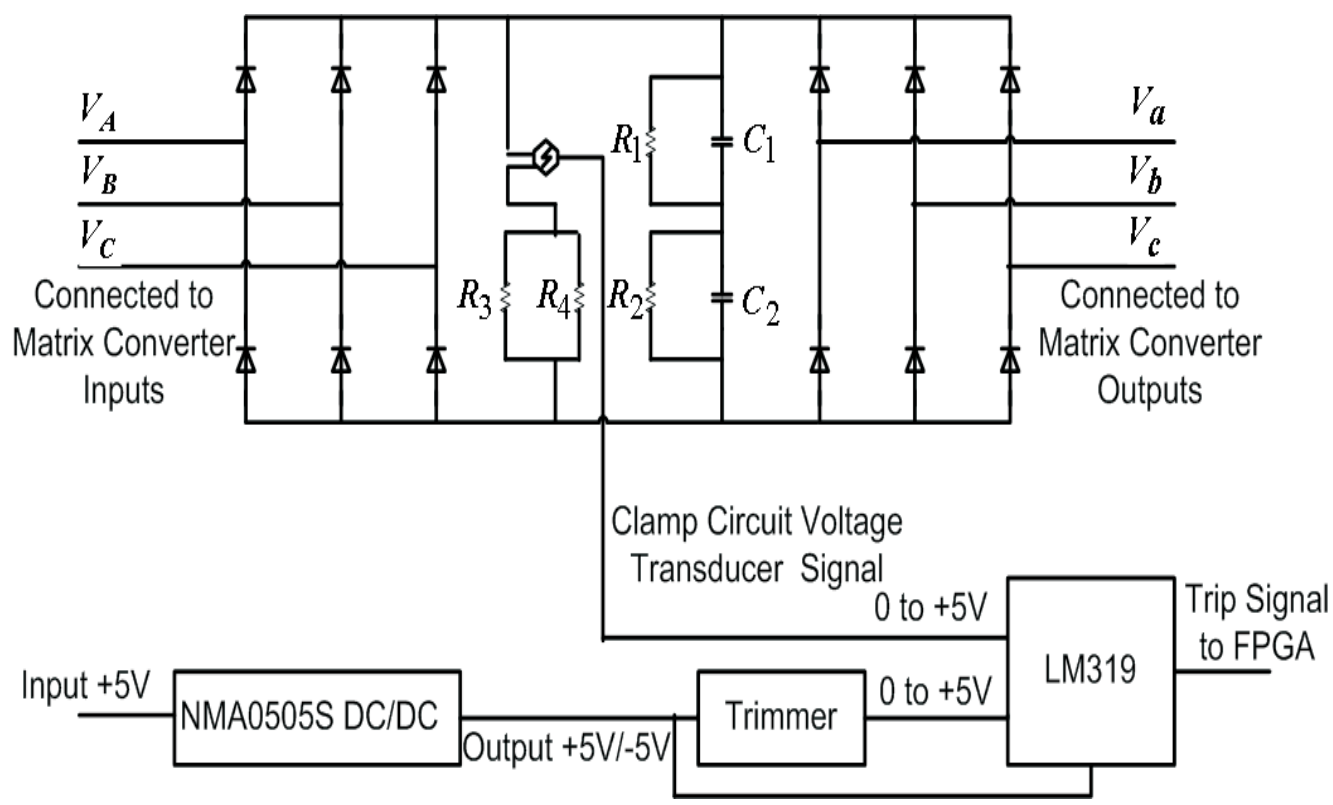

Figure 6.7: Matrix Converter Clamp Circuit

3. The discharge shunt resistors $(47 \mathrm{k} \Omega, 7$ Watts)

Twelve fast soft recovery diodes are used to form the clamp circuit. These diodes are rated at 1200 Volts. The series clamp capacitors $\left(C_{1}, C_{2}\right)$ are connected between the input side and the output side of the diode bridges as shown in the figure 6.7. The design (size) of the clamp capacitors is based on two factors:

1. The amount of the maximum inductive load energy which may be transferred to the clamp capacitors.

2. The maximum peak to peak input supply voltage.

The maximum inductive load energy stored $\left(E_{\text {motor }}\right)$ in the induction motor phases is based on two factors:

1. The leakage line inductance $\left(L_{l s}\right)$ of the attached motor. In this application, 4 $\mathrm{kW}$ induction motor is used and its leakage line inductance is $19.45 \mathrm{mH}$. 
2. The line currents $\left(i_{a}, i_{b}\right.$ and $\left.i_{c}\right)$ of the three phase induction motor. $150 \%$ of the nominal rating of the induction motor is considered for sizing the clamp capacitors. $i_{a}=13.2$ Amps, $i_{b}=13.2$ Amps and $i_{c}=13.2$ Amps is used in this application.

The calculation for maximum inductive load energy stored in the induction motor is given in equation 6.1 ,

$$
E_{\text {motor }}=\frac{1}{2} L_{l s}\left(i_{a}^{2}+i_{b}^{2}+i_{c}^{2}\right)=\frac{3}{4} L \hat{I}^{2}
$$

Where $L_{l s}=19.45 \mathrm{mH}$ and $i_{a}, i_{b}$ and $i_{c}$ are the instantaneous values of phase currents. $\hat{I}$ is the peak value of the equivalent sum of the three phase currents. This value of the current is the rated current of the induction motor, 8.8 Amps. Using equation 6.1, the maximum inductive load energy is $E_{\text {motor }}=2.54$ Joules. This is the maximum amount of inductive load energy that may be transferred to the clamp capacitor $\left(E_{c a p}\right)$ when the converter is disabled. The calculation for $E_{c a p}$ is shown in equation 6.2.

$$
E_{\text {motor }}=E_{\text {cap }}=\frac{1}{2} C\left(V_{\text {max }}^{2}-V_{\text {initial }}^{2}\right)
$$

where, $C$ is the clamp capacitor, $V_{\max }$ is the maximum clamp voltage, $V_{\text {initial }}$ is the initial clamp voltage. In the experimental converter 200 Volts is used as a line to neutral input voltage, so the expected initial clamp voltage is 490 Volts. Using equation 6.2 the size of the capacitor $(\mathrm{C}=72.76 \mu \mathrm{F})$ is calculated. Maximum voltage $\left(V_{\max }\right)$ across the clamp is limited to 700 Volts. The reason for choosing 700 Volts is the rating of the capacitors (400 Volts, 400 Volts). In this application two series capacitors $\left(C_{1}, C_{2}\right)$ rated as $150 \mu \mathrm{F}$ are used as the clamp capacitor $(C)$. The information used to size the clamp capacitors is given in Table 6.1.

The energy stored in the clamp capacitors can be discharged by the resistors $\left(R_{1}\right.$, $\left.R_{2}\right)$, which are connected in parallel with the clamp capacitors $\left(C_{1}, C_{2}\right)$. The value 


\begin{tabular}{||c||c||}
\hline \hline Parameters Required & Datas Used \\
\hline \hline Motor Leakage Line Inductance & $19.45 \mathrm{mH}$ \\
$150 \%$ Rating of Phase Current of 4 kW Induction Motor & $13.2 \mathrm{Amps}$ \\
Maximum Clamp Voltage & 700 Volts \\
Initial Clamp Voltage & 490 Volts \\
Limited Clamp Signal Voltage & 600 Volts \\
Expected Inductive Energy & 2.54 Joules \\
\hline \hline
\end{tabular}

Table 6.1: Required data Information for Sizing the Clamp Capacitors

of these resistors is $47 \mathrm{k} \Omega$. The maximum power dissipation $\left(P_{\text {loss }}\right)$ in these resistors is calculated using equation 6.3

$$
P_{l o s s}=\frac{V^{2}}{R}
$$

so the calculated maximum power dissipation is 2.55 Watts.

The purpose of the voltage transducer is to monitor the voltage across the clamp capacitors. The signal voltage from the voltage transducer is compared to the safe (reference) clamp circuit signal voltage using the comparator. The comparator produces a logic trip signal whenever the signal voltage from the voltage transducer is too high. Then the trip signal from the comparator is sent to the FPGA card which disables the state machines (and hence the Matrix Converter). The trip occurs whenever the signal voltage from the voltage transducer is higher than the reference clamp circuit voltage. Using a trimmer, the safe (reference) clamp circuit voltage is set. In this application, 3.0 Volts is the reference voltage, which is equivalent to 600 Volts across the DC capacitors. 


\subsection{Control and Interface Circuit Design}

This section describes the Matrix Converter control platform. The control platform includes both the control circuits and the interface circuits. The control circuit consists of a DSP card and an FPGA card. The general purpose FPGA card was originally developed by Lee Empringham from the Power Electronics Machines and Control (PEMC) group at the University of Nottingham [67, 68].

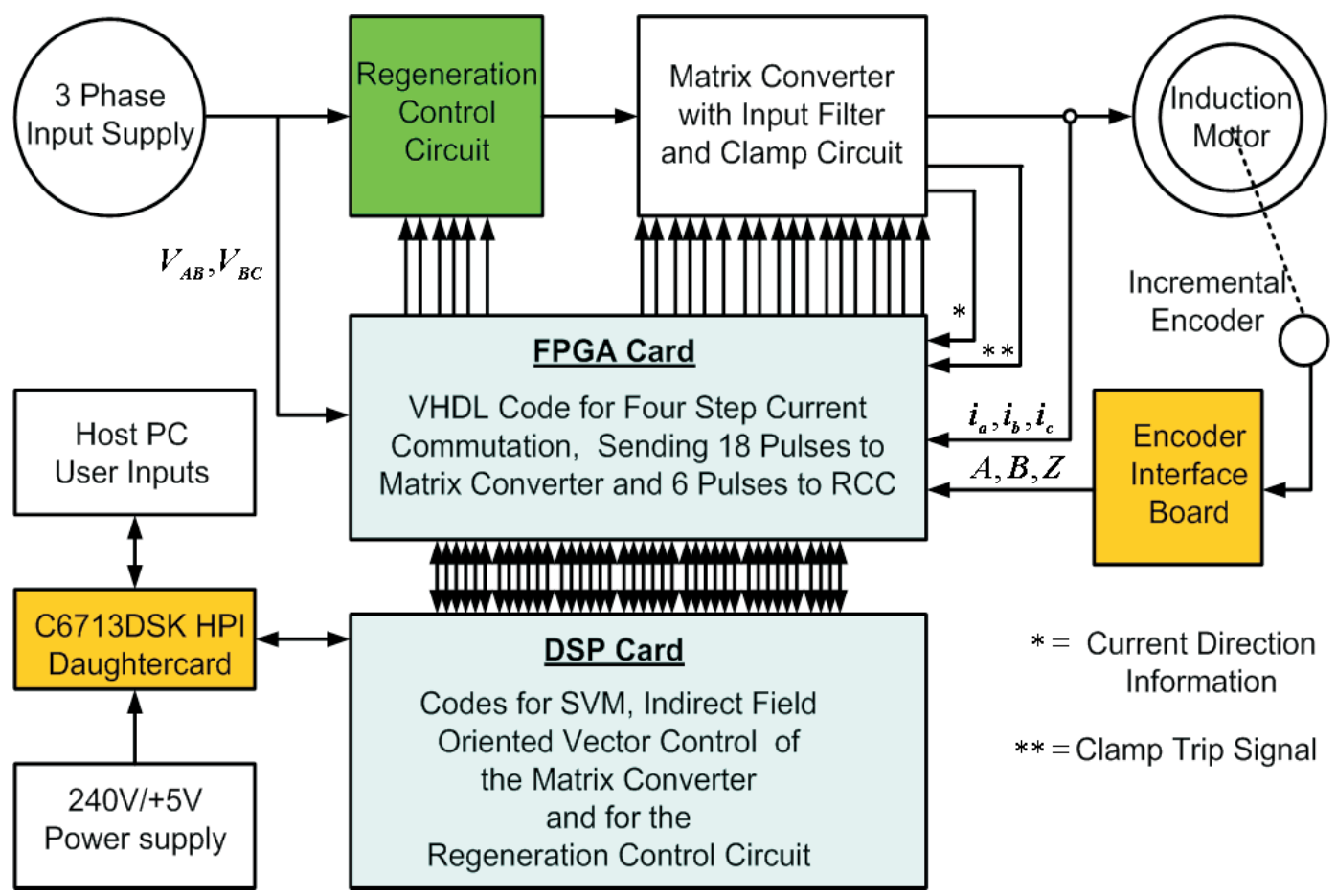

Figure 6.8: Layout of Control and Interface Circuit

Some additional VHDL blocks have been added to the standard FPGA code to make the design suitable for avoiding regeneration in the Matrix Converter. The interface circuit includes the daughter card (C6713DSK HPI) interface with DSP and interface board for encoder signals. By using interface circuits all the required feedback signals and user inputs from the host PC are transferred to the DSP/FPGA control boards, as shown in the figure 6.8 . 


\subsubsection{Control Circuits: DSP and FPGA}

The control of the Matrix Converter has implemented using a Texas Instruments, 32-bit, Floating-Point Digital Signal Processor (TMS320C6713). The DSP has some special features such as a 32-bit External Memory Interface (EMIF), a 16-bit HostPort Interface (HPI), two 32-bit general purpose timers and a flexible Phase Locked Loop (PLL). The above features allow the DSP to connect to the external peripherals such as FPGA and daughter cards. In addition, the External Memory Interface (EMIF) supports $512 \mathrm{MB}$ of addressable external memory space which is accessed through the FPGA card (using memory map address) and daughter card.

Only one of the two memory space enables has used in this application because only one daughter card has been implemented. The PLL clock is synchronised with the FPGA clock so that the waveform sampling occurs at the PWM frequency, $12.5 \mathrm{kHz}$. The parallel port interface of the C6713DSK HPI incorporates a connection to the Host Port Interface (HPI). The HPI port is a high speed data port which allows a host PC to access the internal memory of the DSP without interrupting the Central Processing Unit. This allows a bi-directional data transfer between the host PC and the DSP which is used to control the Matrix Converter and download sampled data. The parallel port interface also provides access to an embedded JTAG emulator for source code debugging.

A 5Volt external power supply is used to power the DSP board, as shown in the figure 6.8. On-board switching voltage regulators provide the 1.26Volt DSP core supply and the 3.3Volt input/output supply. Code composer is used to communicate with the DSP through an embedded JTAG emulator with a host interface.

The FPGA card provides the DSP with interface circuitry and allows connection to the analogue to digital (A/D) converters which all the measure analogue signals. A photograph of the FPGA card is shown in the figure 6.9. The FPGA card is interfaced to the DSP using two 80 pin connectors (6). The input port (1) of the FPGA card is used to connect to the analogue signals from the power circuit of the Matrix Converter 
that are connected to the FPGA card. Digital signals are connected to the FPGA using the 8-pin port (3). The PWM outputs from the FPGA card to gate drives of IGBT power modules of the Matrix Converter and the Regeneration Control Circuit (RCC) use connectors (4) and (5) respectively. The board includes ten 14-bit A/D channels (2). Only five channels are used in this application as follows:

- three A/D channels for the output currents $\left(i_{a}, i_{b}, i_{c}\right)$

- two A/D channels for the line to line input voltages $\left(V_{A B}, V_{B C}\right)$

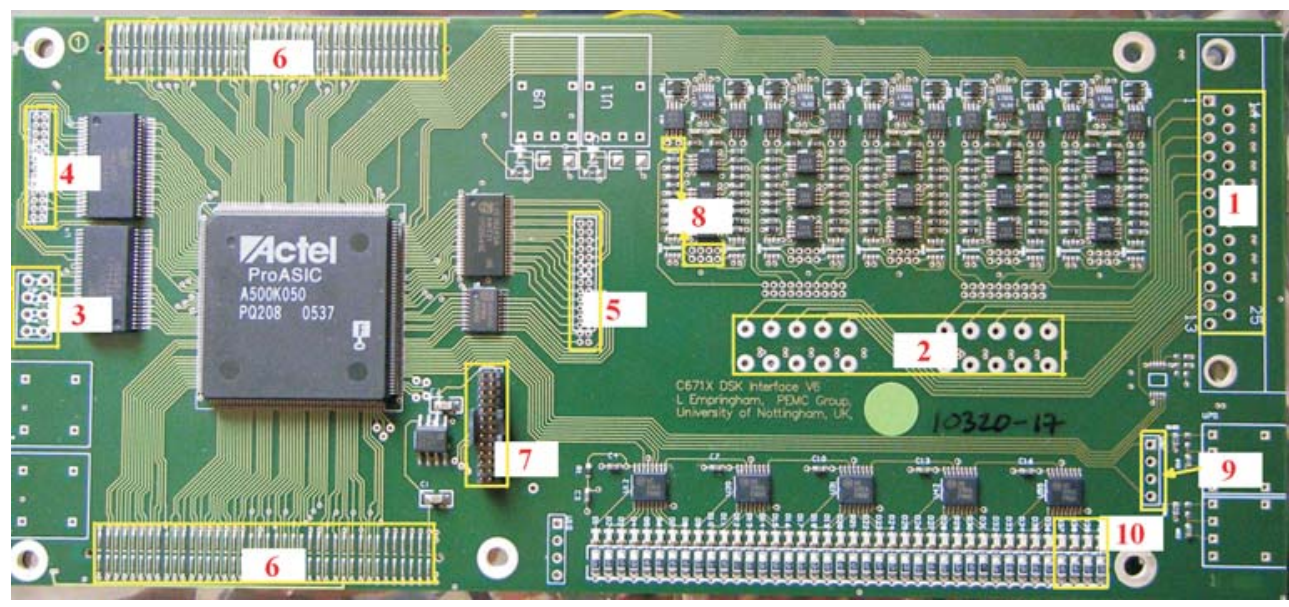

Figure 6.9: Photograph of the FPGA card

The FPGA card also provides the over current protection using trips (8) which can be set from voltage references. The FPGA card startup and reset is manually activated using toggle and reset switches (9). LED indicators (10) show the state machine outputs for each output leg of the Matrix Converter. A header (7) is used for FPGA card programming.

One function of the FPGA is to provide the PWM generator unit and the three state machines (one for each output leg of the matrix converter) to commutate the current between the bi-directional switches depending on the direction of the load current and the demanded switch state. A schematic diagram of the FPGA is shown in the figure 6.10. The FPGA also provides a watchdog timer, trip monitor and temperature sensor interface, although not all these interfaces are used in this application. 


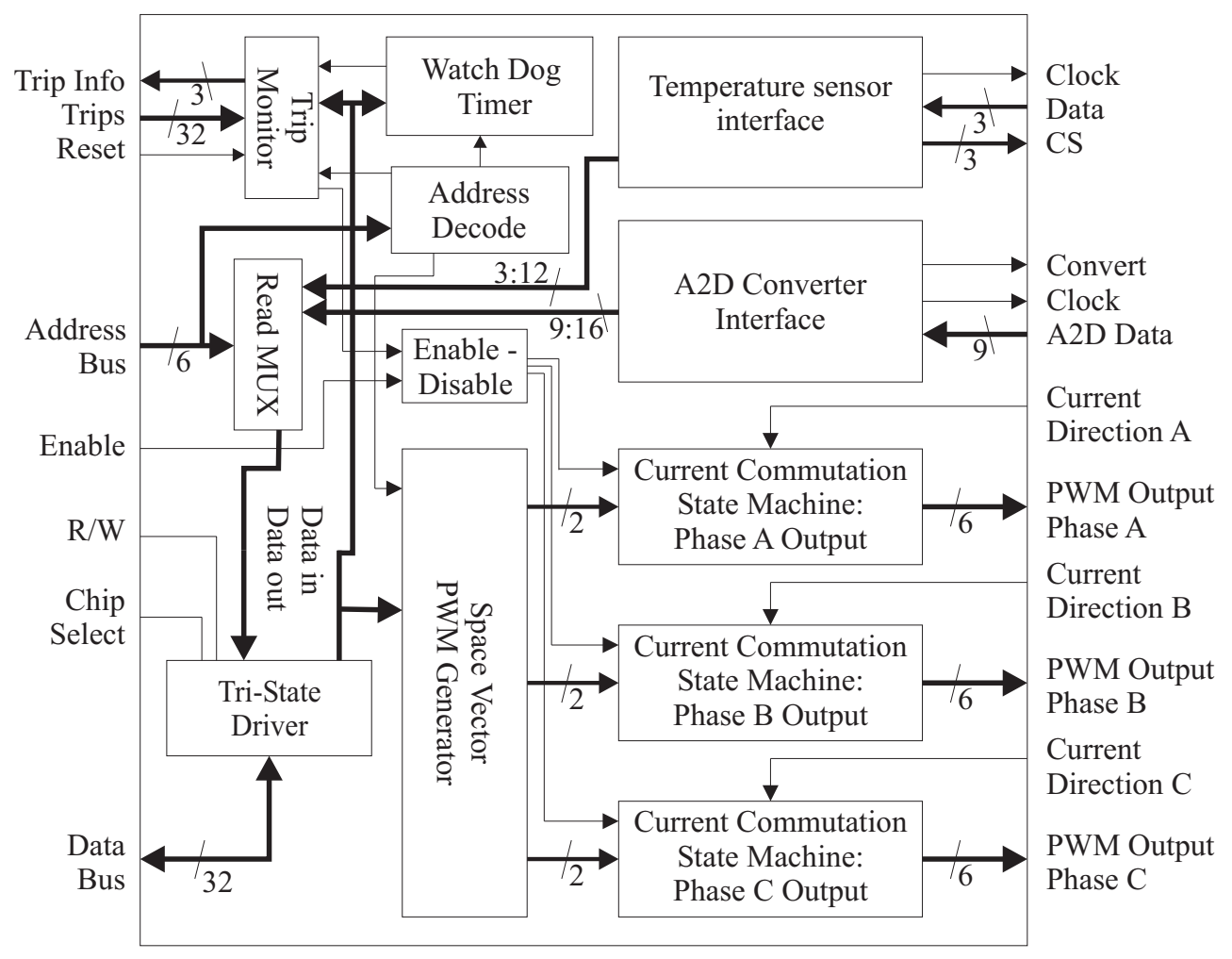

Figure 6.10: Block diagram of the FPGA card

Table 6.2 shows the trip sources used in this application. The output of the watchdog timer feeds directly into the trip monitor. The watchdog timer is serviced at the beginning of each control interrupt. If it is not serviced, for example if the DSP has crashed or is not functioning correctly, a trip will be generated and the converter disabled.

This code has been modified for this application. During the interrupt routine which generates the Matrix Converter gate signals, information from the A/D channels is extracted from the FPGA registers and manipulated so that the scaled output currents and input line to line voltages can be calculated. This information, together with the desired input current angle and the output voltage angle and magnitude are used to calculate the duty cycles for the Space Vector Modulation (SVM) strategy. Finally, using the DATA BUS in the FPGA card, the space vectors calculated by the DSP are loaded into the appropriate FPGA register to allow the FPGA to perform the PWM generation. The current commutation state machines require the output of 


\begin{tabular}{|c|c|}
\hline Hardware & Software \\
\hline Over Current & Instantaneous Over Current \\
PWM Fifo Empty & Averaged Over Current \\
Watchdog Timer & Loss of Supply \\
Encoder Fail & \\
Clamp Over Voltage & \\
\hline
\end{tabular}

Table 6.2: Hardware and Software Trips Used in this Application

the PWM generator and information about the current direction to perform a 4-step current direction based current commutation routine.

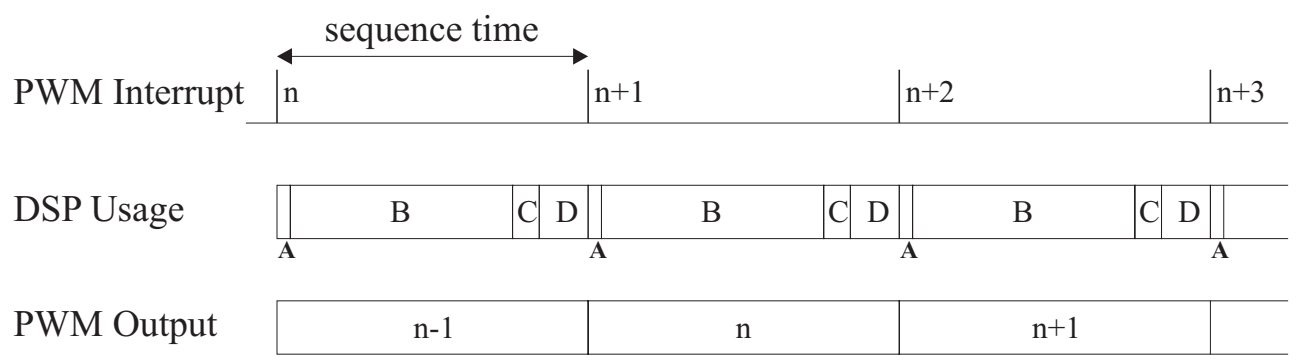

Figure 6.11: Diagram to show PWM interrupt DSP usage

Figure 6.11 shows a diagram that represents the DSP functions during the interrupt routine. At point $\mathbf{A}$ the $\mathrm{A} / \mathrm{D}$ channels are sampled and the data is moved from the FPGA card to the DSP. The time period labelled $\mathbf{B}$ is used to calculate the output PWM vectors and vector times according to the space vector control strategy. The vectors and vector times are transferred into the PWM generator within the FPGA during period $\mathbf{C}$. The time remaining (D) before the next interrupt occurs is free to be used for the communication with the host PC. The combination of the characteristics of the high speed DSP and the versatility of the FPGA allows all of the necessary controller functionality to be implemented and the control calculations can be performed at the necessary speed. 


\subsubsection{DSP/Host PC Interface}

In order to analyse the system performance during the development stages of the project, a DSK6713 HPI daughter card with a MATLAB interface was used. The daughter card helps to capture data (such as measured analogue signals and feed back signals). The captured data can be plotted using MATLAB. The daughter card transfers DSP data to host PC through a USB with using debugging software developed by Educational DSP [69].

The stand-alone application allows the Host PC to communicate with the DSP. A photograph of the DSK6713 HPI daughter card used in this application is shown in the figure 6.12 .

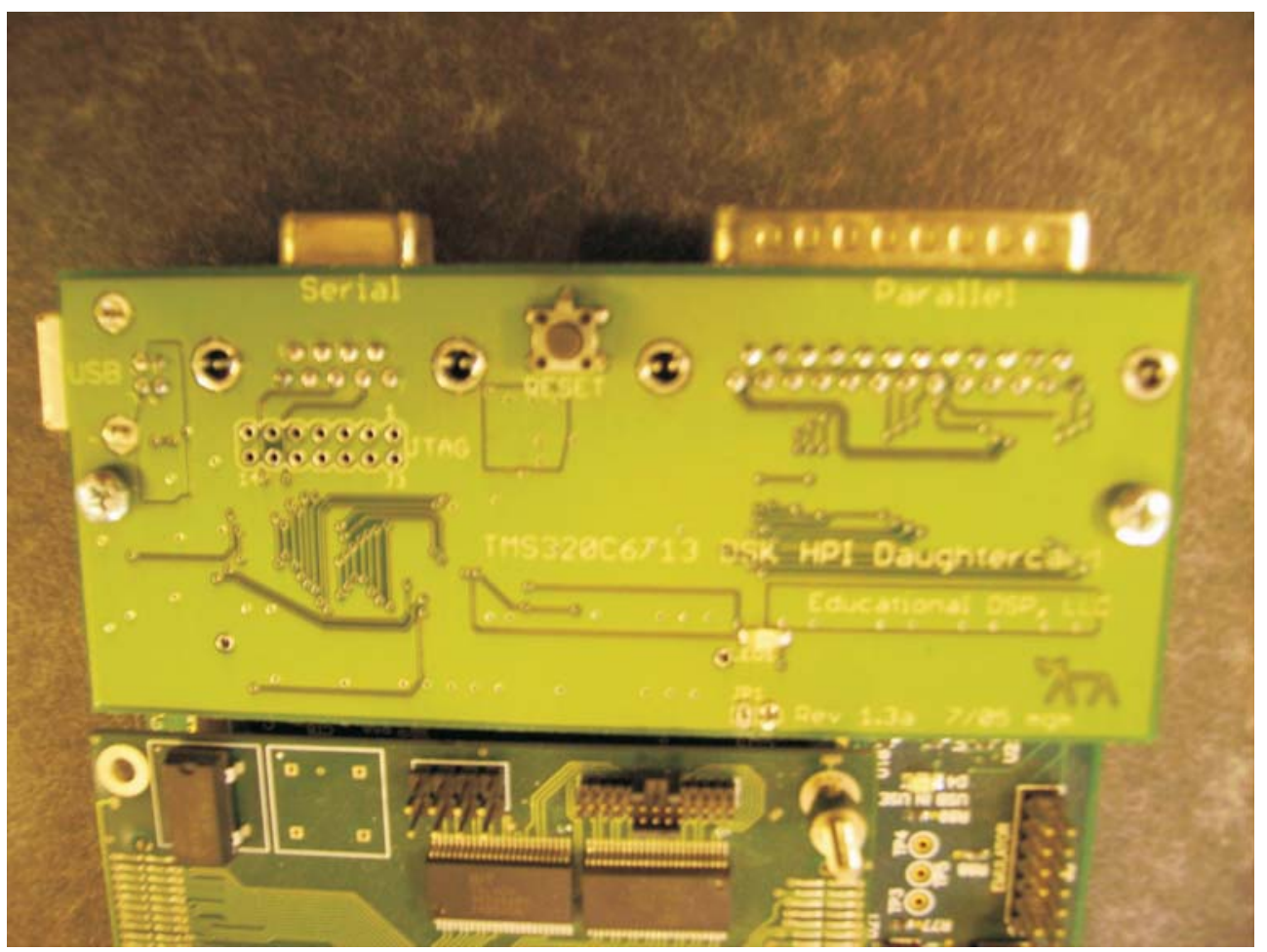

Figure 6.12: Photograph of the DSK6713 HPI Daughtercard 


\subsubsection{Encoder Interface Board}

This section explains how the rotor position of the motor is obtained using an incremental encoder [70]. The encoder is mounted on the shaft of the motor. The specifications of the encoder are given in the Table 6.3. The encoder output signals $\left(A, A^{\prime}, B, B^{\prime}, Z, Z^{\prime}\right)$ are fed to the FPGA card in order to find the rotor position, as shown in the figure 6.13.

\begin{tabular}{|c|c|}
\hline Datas & Specifications \\
\hline Manufacturer & British Encoder \\
Product type & $755 / 2 / \mathrm{HV}$ \\
DC Supply & $+5 \mathrm{~V}$ \\
Pulses Per Revolution & 2500 \\
Encoder Architecture & Rotary \\
Encoder type & Incremental \\
\hline
\end{tabular}

Table 6.3: Specifications of the Encoder

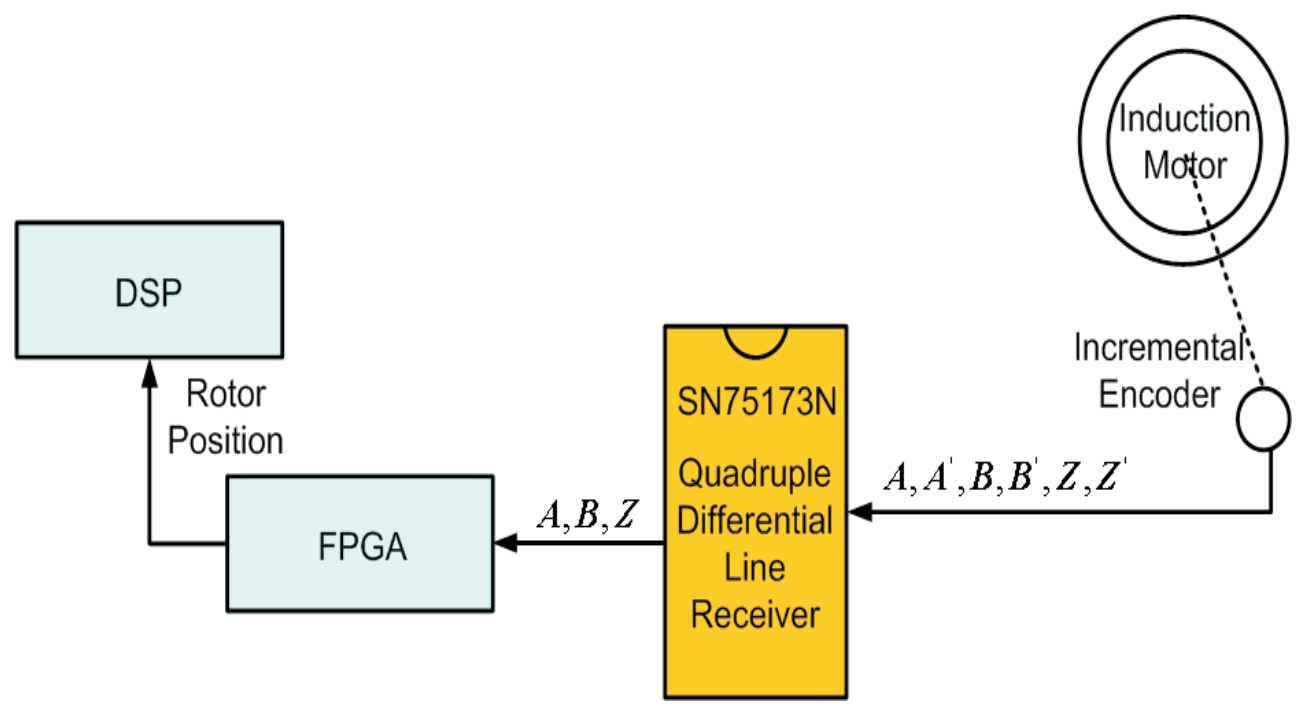

Figure 6.13: The Layout of Encoder Interface Circuit

The encoder interface circuit contains a Quadruple Differential Line Receiver using the encoder output signals as its input signals $\left(A, A^{\prime}, B, B^{\prime}, Z, Z^{\prime}\right)$ and producing three output signals $(A, B$ and $Z$ ) for the FPGA card. The DC supply for the SN75173 is obtained from the FPGA card to avoid the noise problems. A photograph of the encoder interface board is shown in the figure 6.14. 


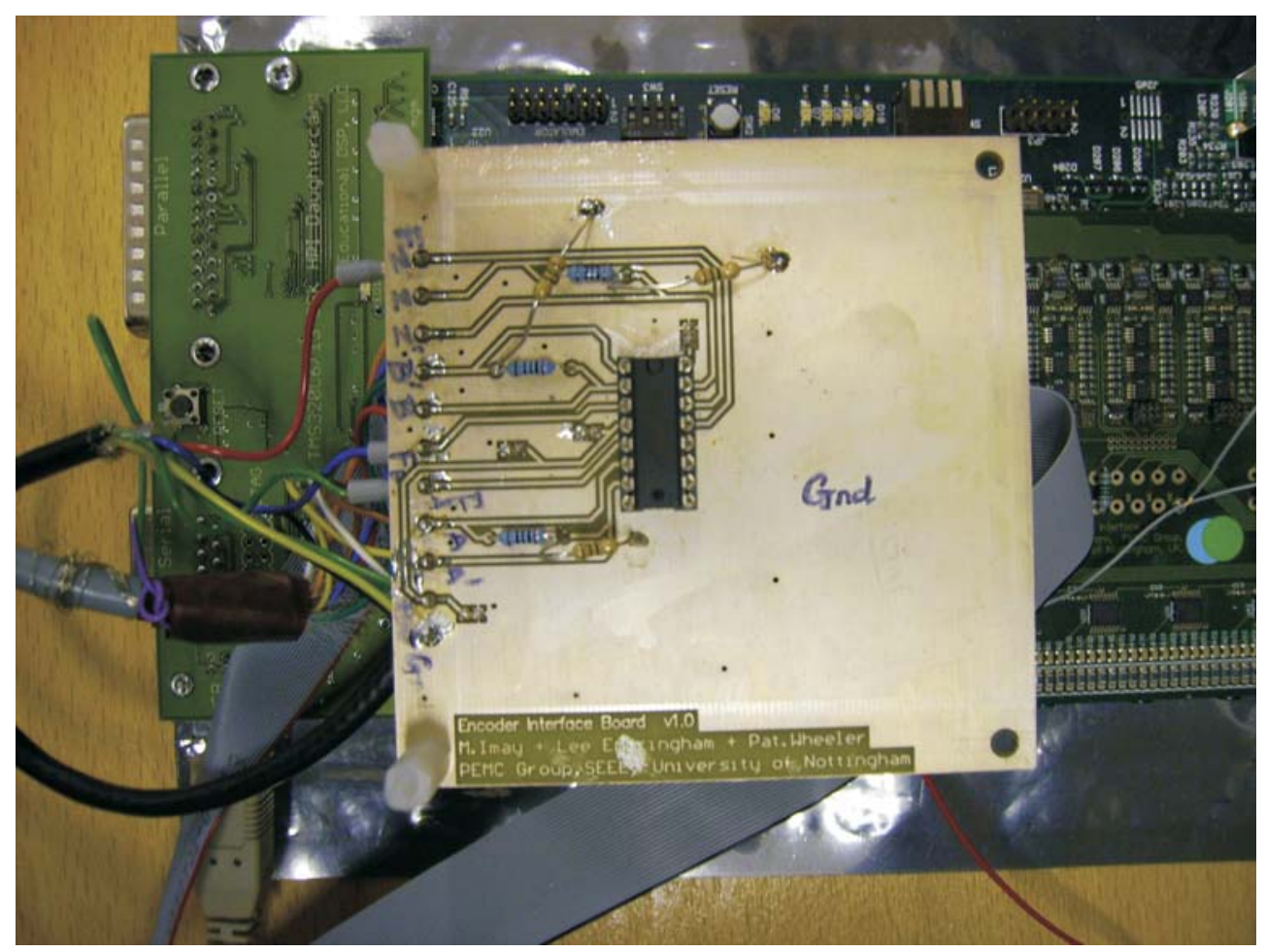

Figure 6.14: Photograph of the Encoder Interface Board

\subsection{Regeneration Control Circuit (RCC) Design}

This section describes the practical implementation of the power and control, for the Regeneration Control Circuit (RCC). The power circuit for the RCC consists of gate drives and IGBT modules and is similar in construction to the power circuit of the Matrix Converter. With regard to this control circuit, the C-code and the VHDL program for Bi-Directional Switch (BDS) method with Power Comparison (PC) technique are programmed in the DSP and the FPGA card respectively.

\subsubsection{Power Circuit for RCC}

As explained in the chapter 4, the novel Regeneration Control Circuit (RCC) is used to dissipate the regenerative power from the Matrix Converter. A block diagram of the experimental set-up of the RCC using the Bi-Directional Switch (BDS) method 


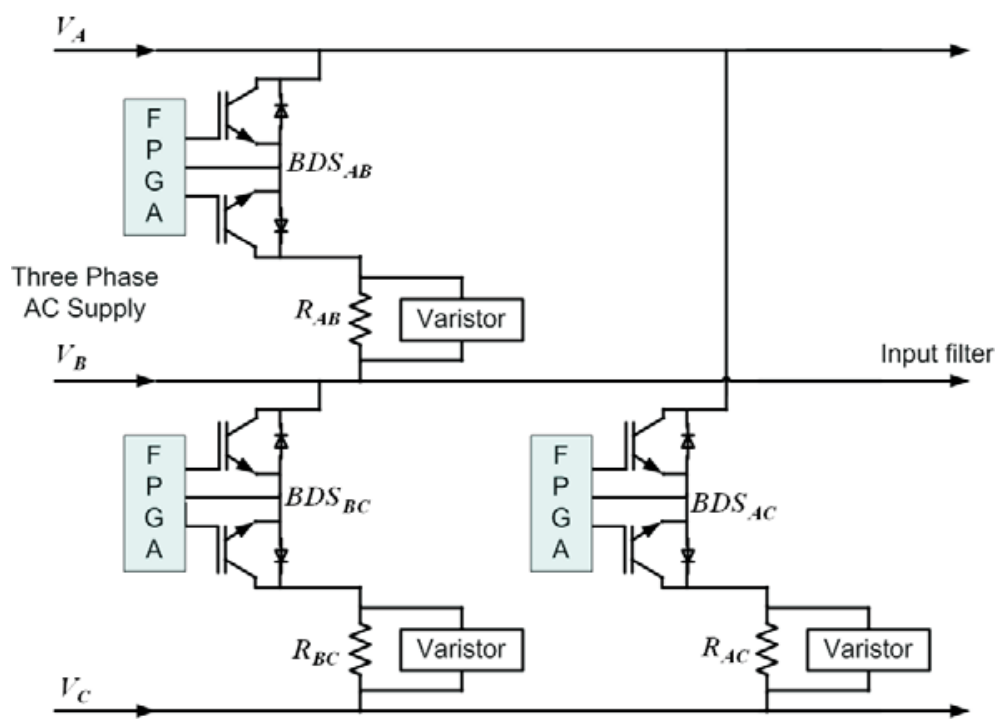

Figure 6.15: Overview of the Regeneration Control Circuit used to avoid Regeneration in the Matrix Converter

is shown in the figure 6.15. The power circuit for the Regeneration Control Circuit (RCC) consists of three main components:

- three IGBT modules (SK60GM123) with gate drive circuits

- three resistors (TAP1000 Series)

- three varistors (EPCOS, 320VAC)

The RCC is connected between the input supply and the input filter capacitors (2), as shown in the Figure 6.16. Three bi-directional switches $\left(B D S_{A B}, B D S_{B C}, B D S_{A C}\right)$ are connected between in the input lines $\left(V_{A B}, V_{B C}, V_{A C}\right)$. The RCC resistors $\left(R_{A B}\right.$, $\left.R_{B C}, R_{A C}\right)$ are connected in series (1) with the bi-directional switches. The triggering pulses (3) for bi-directional switches are obtained from FPGA card. In order to dissipate the power, the selection of the RCC resistors is based on the power dissipation requirement. This RCC is more suitable to use with Back to Back VSI. However, the size of the power dissipation circuit is bigger than the power dissipation circuit in the conventional dynamic braking method. 
The specifications of the Regeneration Control Circuit (RCC) resistors (TAP1000 Series) used in this application is given in the Table 6.4.

\begin{tabular}{|c|c|}
\hline Datas & Specifications \\
\hline Manufacturer & Ohmite \\
Product type & TAP1000 Series \\
Resistance value & $30 \Omega$ \\
Power rating & 1000 Watts \\
Maximum voltage & $\sqrt{\text { Power } * \text { Resistance }}$ \\
Maximum current & 10 Amps \\
Temperature range & $-55^{\circ} \mathrm{C}$ to $150^{\circ} \mathrm{C}$ \\
\hline
\end{tabular}

Table 6.4: Specification of the RCC resistors

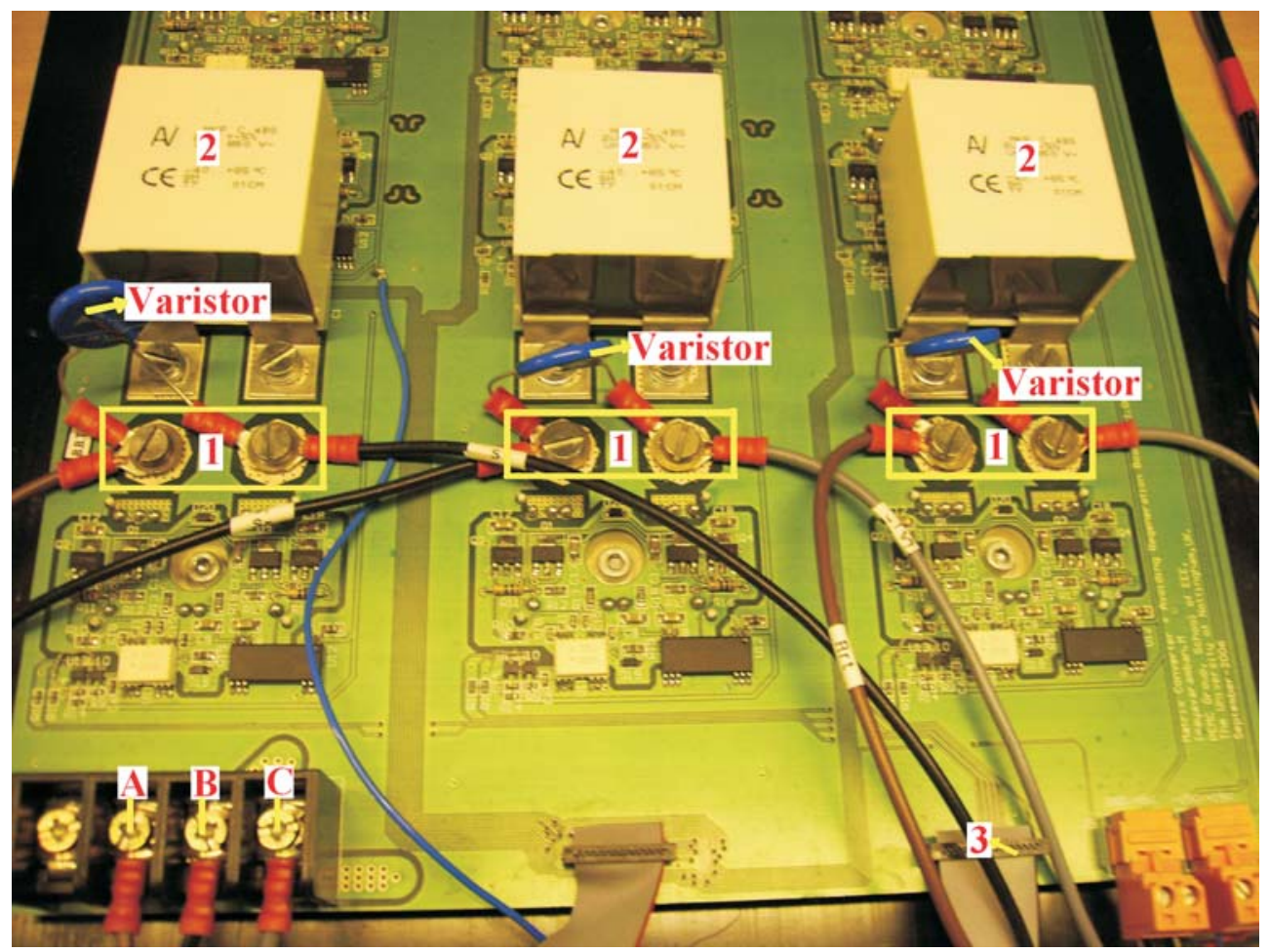

Figure 6.16: Photograph of the RCC for Bi-Directional Switch (BDS) Method

The RCC resistors are not mounted on the PCB because the heat dissipation during the regeneration may affect other power electronic components on the PCB. The RCC resistors (1) are mounted on the heat sinks (2) with cooling fans, as shown in Figure 6.17. The distance between the PCB board and the RCC resistors is short to minimise the inductance of the connection wires. In addition, varistors are connected in parallel 


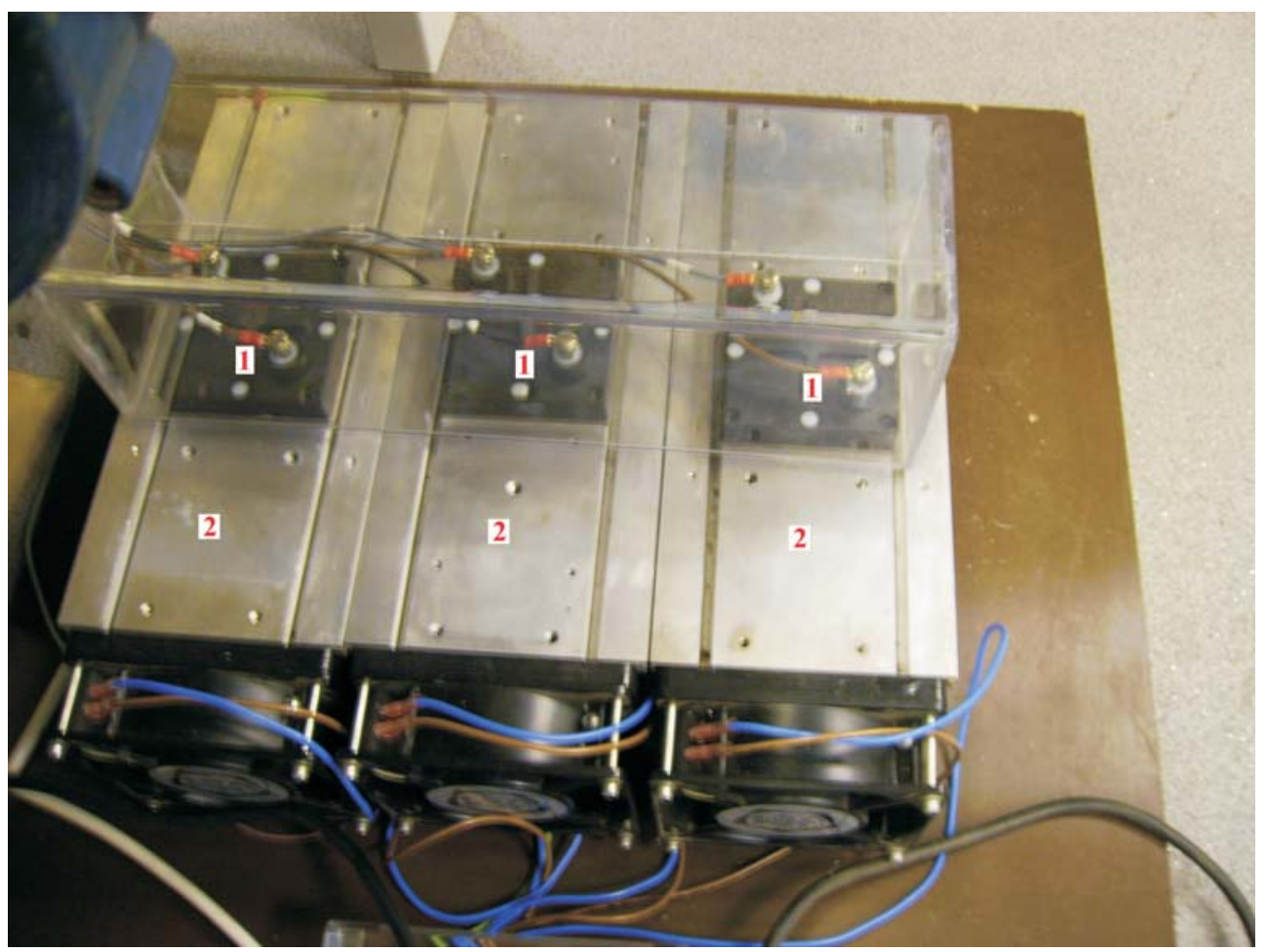

Figure 6.17: Photograph of the Regeneration Control Circuit (RCC) for BiDirectional Switch (BDS) Method

with the Regeneration Control Circuit (RCC) resistors, as shown in Figures 6.15 and 6.16. The specifications of the varistor (EPCOS, 320VAC) used in this application

\begin{tabular}{|c|c|}
\hline Datas & Specifications \\
\hline Manufacturer & EPCOS \\
Voltage rating & $320 \mathrm{VAC}$ \\
Maximum clamping voltage & $840 \mathrm{~V}$ \\
Energy & $184 \mathrm{~J}$ \\
Temperature range & $40^{\circ} \mathrm{C}$ to $85^{\circ} \mathrm{C}$ \\
\hline
\end{tabular}

Table 6.5: Specification of the varistors

is given in the Table 6.5. The varistors remove any voltage spikes caused by the switching of the current in the resistors. 


\subsubsection{DSP/FPGA Control for RCC}

This section discusses the modulation of the Regeneration Control Circuit (RCC) using the DSP/FPGA control platform. As discussed in the section 4.3.1, six unique pulses are generated for the three bi-directional switches in the RCC. This modulation can be achieved in two steps:

1. Detecting regeneration by calculation in the DSP.

2. Generating six PWM signals in the FPGA.

\section{Detecting the regeneration :}

The sign of feedback signals for the induction motor, the torque producing current $\left(i_{q}\right)$ and rotor speed $\left(\omega_{r e}\right)$, are used to detect the regeneration. During the regeneration the output power $\left(P_{o}\right)$ is negative. The output power $\left(P_{o}\right)$ is calculated as the product of the torque producing current $\left(i_{q}\right)$ and rotor speed $\left(\omega_{r e}\right)$. Whenever the negative output power is detected the RCC is activated.

$$
P_{o}=k i_{q} \omega_{r e}
$$

\section{PWM Generation :}

The FPGA control for generating the PWM signals for the Regeneration Control Circuit (RCC) is shown in the figure 6.18. This process consists of three steps:

1. Design flow

2. Simulation

3. Programming 
The Actel's Libero software is used to perform the above three functions. The Actel's Libero has two main components: Smartgen and Viewdraw. Smartgen is used to create VHDL logic blocks in design flow, as shown in figure 6.18. Viewdraw generates the equivalent VHDL code for the logic blocks in the design flow.

If regeneration is detected, the DSP sends the duty cycle information to FPGA using a memory map address register. This is a 5-bit address used to identify the specific FPGA memory map register used for Regeneration Control Circuit (RCC).

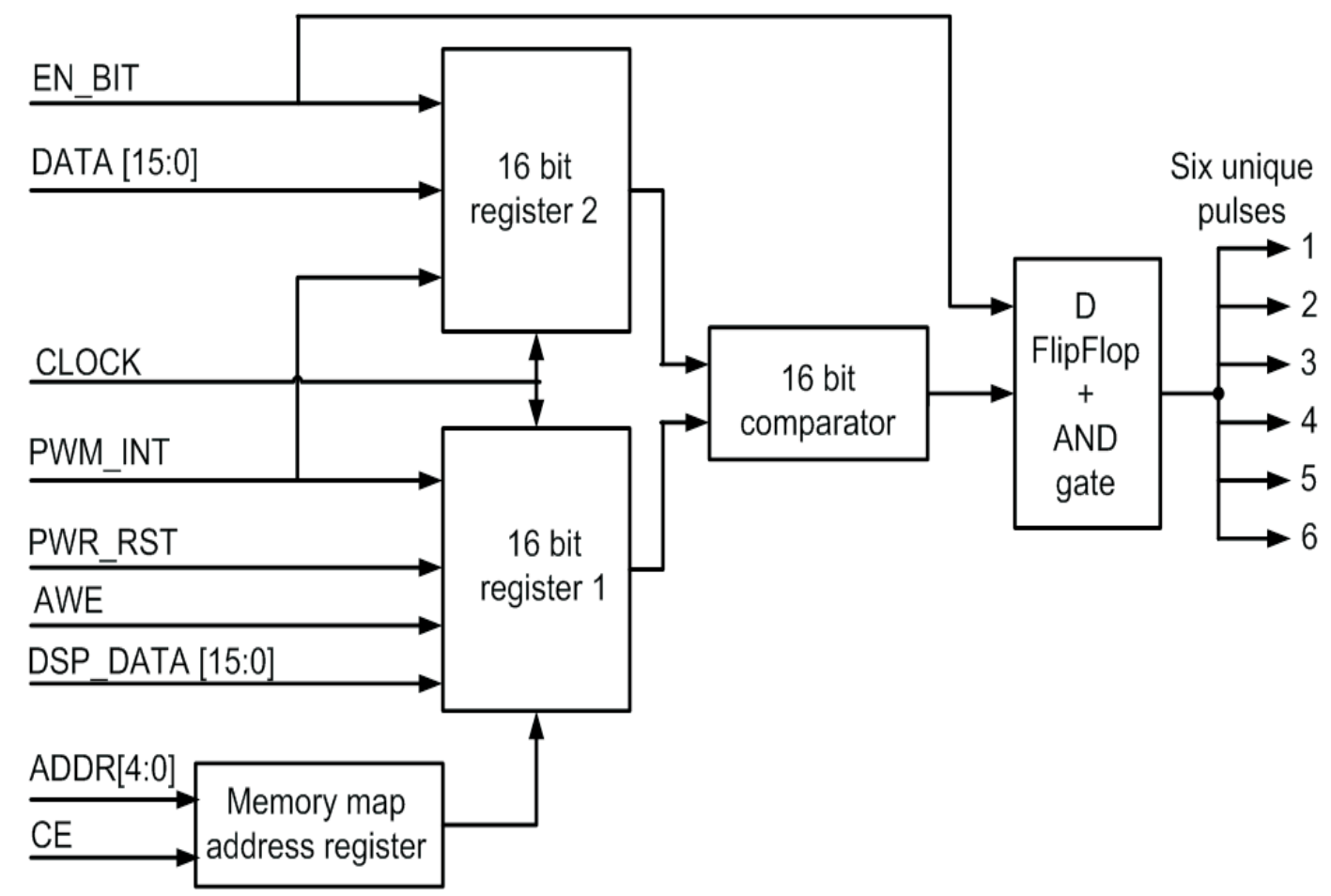

Figure 6.18: Overview of VHDL Blocks used in the FPGA Control Design for Regeneration Control Circuit

A comparator compares the duty cycle information from the DSP to the reference. Start-up and reset of the 16-bit registers are controlled using PWM interrupt and PWM reset signals. The output of the comparator, logic signal, is sent to the D-Flip Flop with AND gate. Finally, the FPGA card sends this logic output to the gate drives of IGBT modules in the RCC when the enable bit is set high. This concept is verified using FPGA simulations before programming, as described in Appendix A. 


\subsection{Conclusions}

The experimental set-up for the vector controlled Matrix Converter motor drive using a DSP/FPGA control platform has been described. The FPGA design and DSP code for the novel Regeneration Control Circuit (RCC) have been discussed. Figure 6.19 shows the complete experimental set-up. In this figure (A) represents the host PC which is used to monitor system variables using the daughter card interface. The power circuit (C) and control circuit (B) of the laboratory prototype Matrix Converter are highlighted. (D) indicates the $4 \mathrm{~kW}$ induction motor used as a load. Finally, (E) highlights the Regeneration Control Circuit (RCC) resistors with their heat sink arrangement.

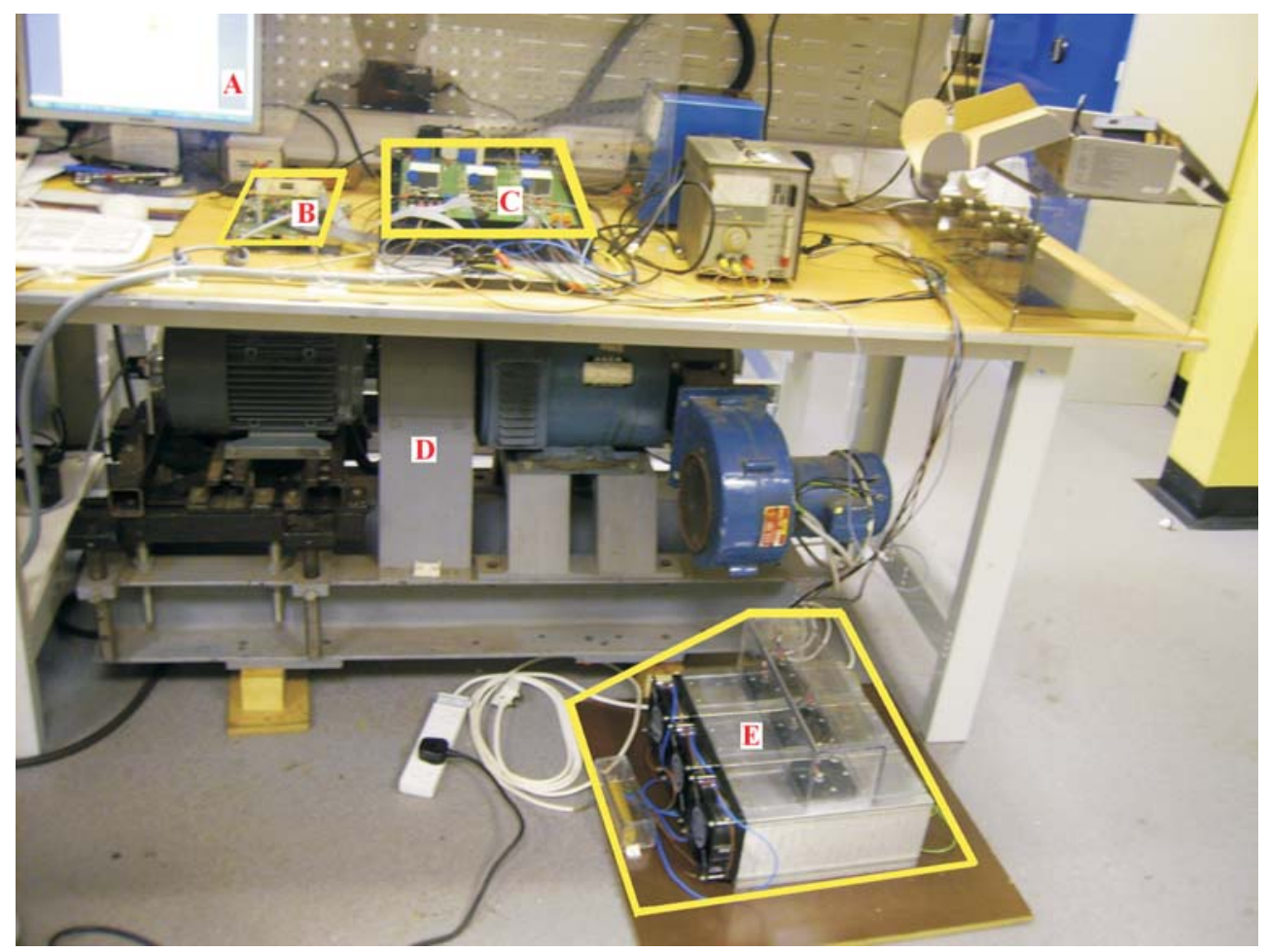

Figure 6.19: The Photograph of the Complete Experimental Converter 


\section{Chapter 7}

\section{Testing and Experimental Results}

\subsection{Introduction}

This chapter confirms the validity of the proposed concept for avoiding regeneration in the Matrix Converter by experiments carried out in the PEMC Group's GE Aviation laboratory using a prototype rated at $7.5 \mathrm{~kW}$ feeding a $4 \mathrm{~kW}$ induction motor. Table 7.1 shows the test data for these experiments.

\begin{tabular}{|c|c|}
\hline Specifications & Datas \\
\hline Voltage transfer ratio & 0.75 \\
Input filter Capacitor & $2 \mu \mathrm{F}$ \\
Sampling frequency & $12.5 \mathrm{kHz}$ \\
Rated power of motor & $4 \mathrm{~kW}$ \\
Limit of $i_{s q}^{*}$ & $5.0 \mathrm{Amps}$ \\
Constant value of $i_{s d}^{*}$ & $3.0 \mathrm{Amps}$ \\
Control damping factor & 0.707 \\
\hline
\end{tabular}

Table 7.1: Test Data's used in this Application

First section of this chapter describes the preliminary tests and protection trips setting during the development of the converter. In the next section of this chapter, experimental results are presented to prove the effectiveness and feasibility of the novel regeneration control in a Matrix Converter motor drive. 


\subsection{Test Procedures}

The test procedure for finding the DC offset and gain of the voltage and current transducers used in this application are discussed in this section. To protect the system from abnormal conditions during testing, some trips are implemented in the FPGA card, such as clamp trip, over voltage trip and over current trip. The setting procedure for the above trips are explained below.

\subsubsection{Finding the DC offset and the Gain for the Transducers}

Two voltage transducers are used to measure the input line to line voltages $\left(V_{A B}, V_{B C}\right)$ of the Matrix Converter. As explained in section 6.3.1, the measurement signals from the voltage transducers are sent to two dedicated A/D channels on the FPGA card using burden resistors $120 \Omega$. Figure 7.1 shows the block diagram of the $\mathrm{A} / \mathrm{D}$ test for voltage transducer. The A/D test is used to find the gain and DC offset of the particular measurement signal of the voltage transducer.

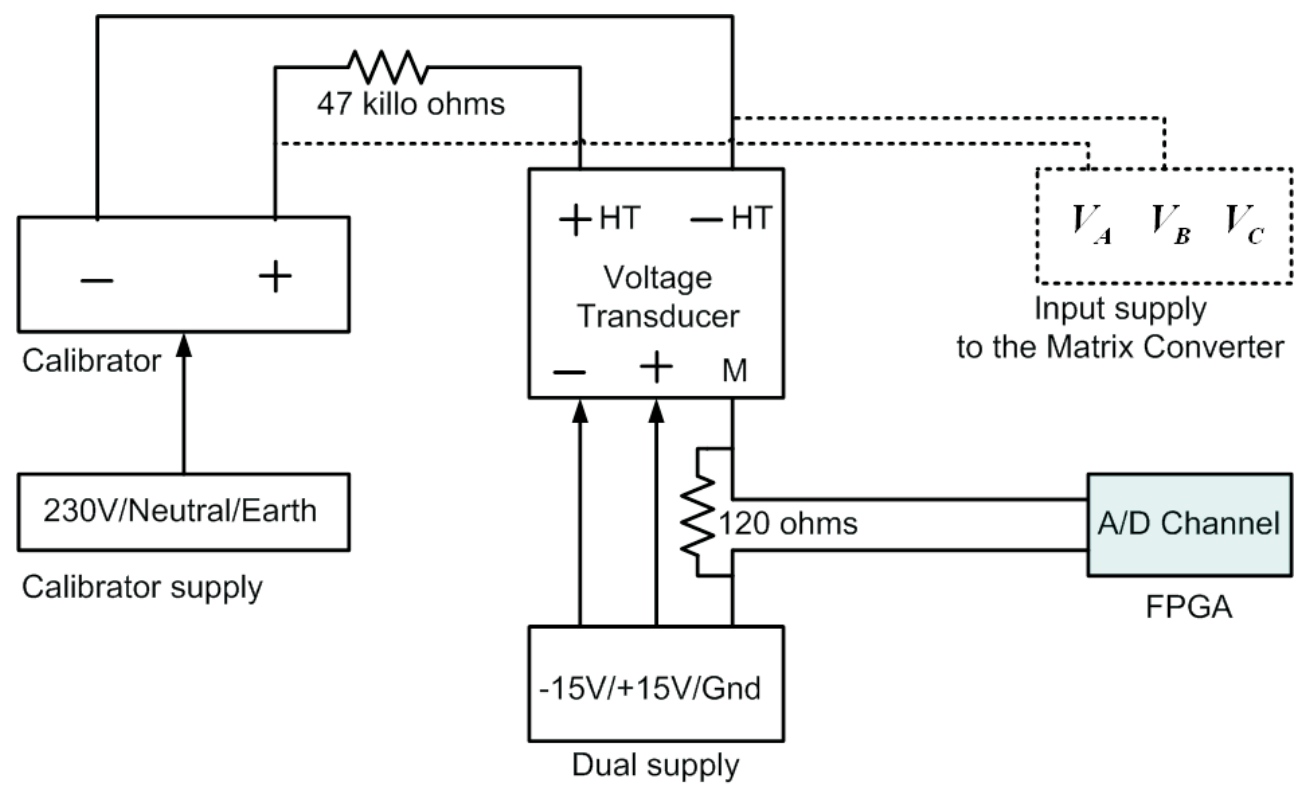

Figure 7.1: The Block Diagram of A/D Test for the Voltage Transducers 
The DSP code for A/D test and the STAPL file for FPGA chip (Actel A500K050) is uploaded in the DSP and FPGA card respectively. The calibrator is used to find the DC offset and gain. During the A/D test, the calibrator supplies variable voltages to the voltage transducer through a $47 \mathrm{k} \Omega$ resistor. Meanwhile, the electrical connection between the transducer and the Matrix Converter input supply is temporarily disconnected as shown by the dotted lines in figure 7.1. The testing procedure is common to both voltage transducers $\left(V_{A B}, V_{B C}\right)$ with the exceptions of the electrical connection. However, the DC offset and gain will be slightly different for each A/D channel. The A/D test for voltage transducer is performed by following below steps:

1. The single phase supply to the calibrator and the dual supply (+15 Volts /-15 Volts) to the transducers are switched on.

2. The DSP code for A/D test is complied, loaded and run.

3. The desired testing voltage from the calibrator is set and corresponding readings from the A/D channel are recorded.

4. Step 3 is repeated for various input voltages from the calibrator.

5. Microsoft Excel, the graph is drawn between the A/D channel readings and applied voltages to the transducer through the calibrator.

6. Finally, the slope of the resulting linear graph is found. The slope is considered as the gain of the transducer and the constant value is the DC offset

In this application, 0.0976 and 0.0970 are the calculated gain of voltage transducers for $V_{A B}$ and $V_{B C}$ respectively. 
The A/D test procedure for the current transducers is similar to the voltage transducers. Three current transducers are used to measure the three output phase currents $\left(i_{a}, i_{b}, i_{c}\right)$ of the Matrix Converter. The block diagram in figure 7.2 shows the A/D test circuit for output phase current $\left(i_{a}\right)$ transducer of the Matrix Converter.

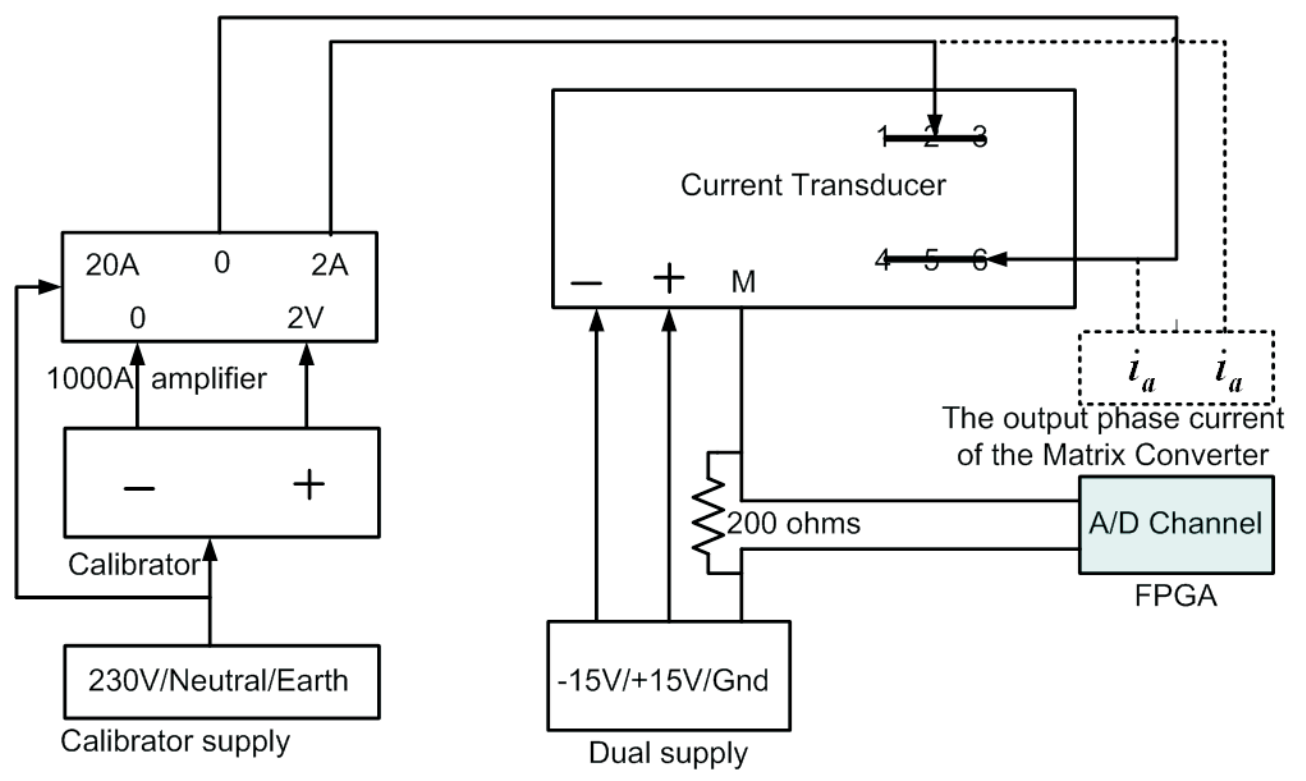

Figure 7.2: The Block diagram of A/D Test Circuit for the Current Transducers

As shown in Figure 7.2, the calibrator with a 1000 Amp transcouductance amplifier is used to set the desired current for A/D test in terms of calibrator voltage. Setting different test voltages in the calibrator is input to the amplifier in the ratio of 0 to 2 Volts. The amplifier then delivers the equivalent current to the current transducers. For this application the range from 0 to 2 Amps is selected in the amplifier. By following the testing procedure, the gain of the three current transducers, $i_{a}=0.003115$, $i_{b}=0.003126$, and $i_{c}=0.003088$, are found. 


\subsubsection{Protection Trips Setting}

The FPGA card includes the protection system for the prototype converter. The protection system on the FPGA card consists of trips which helps to trip the converter disabling the state machines (state machines are used to set the PWM pulses to the Matrix Converter and Regeneration Control Circuit) whenever the abnormal conditions (over voltage or over current) are detected.

This section explains how the power circuit of the Matrix Converter is protected using the clamp circuit trip. The set-up made to set the trip for clamp circuit is shown in Figure 7.3. In order to set the clamp trip, finding the clamp trip voltage level is obviously important.

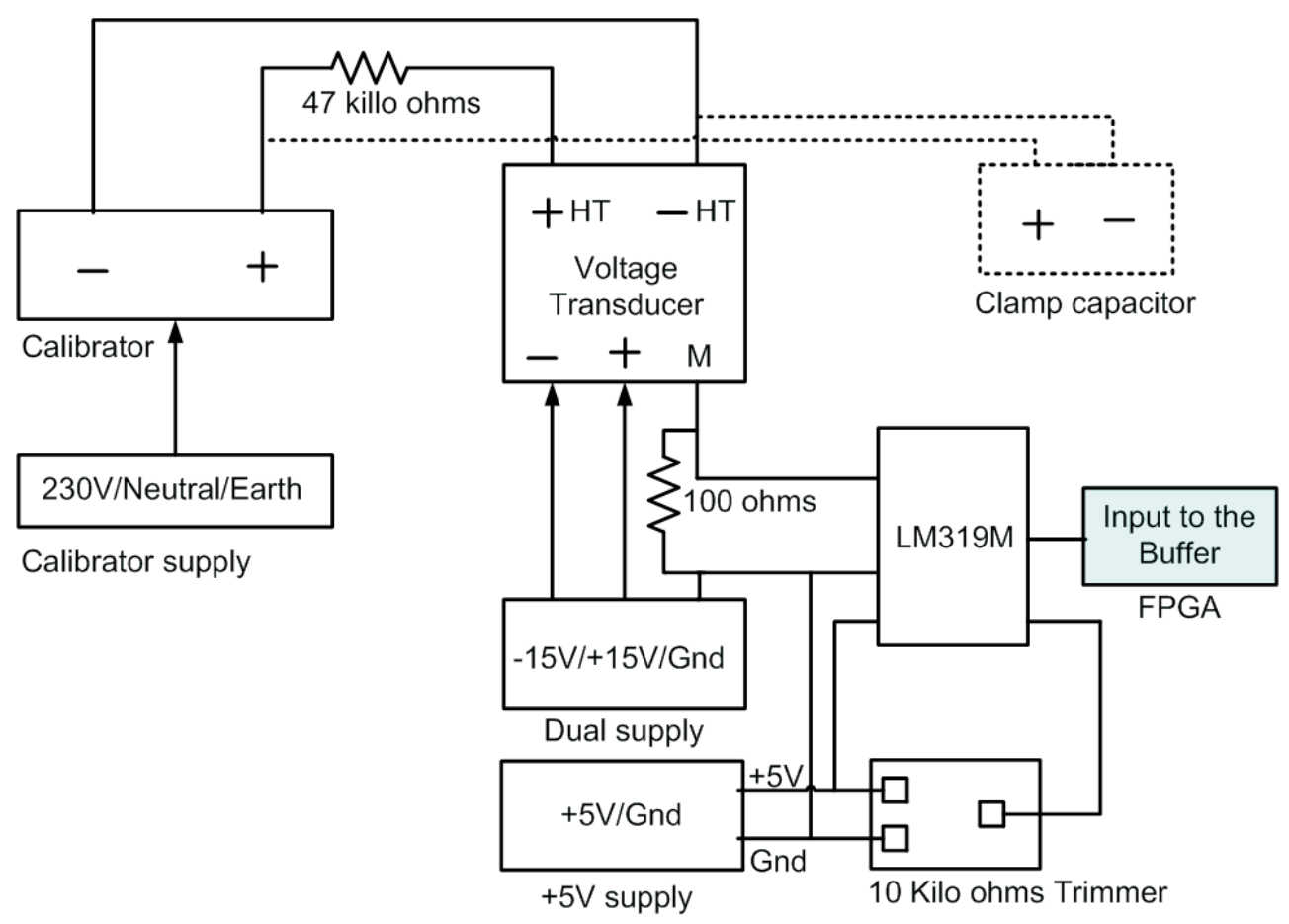

Figure 7.3: The Block diagram for Clamp Trip Setting

The clamp trip is set to activated at $10 \%$ above the line to line input voltages. The resulting voltage is considered as a trip level for the clamp circuit. As shown in Figure 7.3, the calibrator is used to apply the various voltages across the clamp capacitor. The measured signal from the voltage transducer (clamp) is monitored. 
The reference for the trip signal voltage is obtained using the $10 \mathrm{k} \Omega$ trimmer and the +5 Volts supply. The same +5 Volts supply is used as a supply to the LM319M comparator. The grounds of both the +5 Volts supply and dual supply (+15 Volts/15 Volts) are tied together. During the test, the terminals of the voltage transducer are disconnected from the clamp capacitor as shown (dotted lines) in Figure 7.3.

The measured signal from the voltage transducer and the reference trip signal voltage from the trimmer are compared. The resulting logic signal is considered as a trip signal input to the FPGA card. Whenever the measured signal goes above to the reference trip signal voltage, the output of the comparator goes high and the clamp trip is enabled. The state machines are instantly disabled so that the Matrix Converter power circuit is protected. In this application, +3.0 Volts is used as reference trip signal voltage, which is approximately equal to 600 Volts. Table 7.2 shows test datas for the different reference trip signal voltage and equivalent voltage across the clamp capacitor.

\begin{tabular}{|c|c|}
\hline Reference trip signal voltage & Voltage across the clamp capacitor \\
\hline 0.5 Volts & +100 Volts \\
0.75 Volts & +160 Volts \\
1.1 Volts & +205 Volts \\
1.5 Volts & +300 Volts \\
2.1 Volts & +405 Volts \\
3.14 Volts & +620 Volts \\
\hline
\end{tabular}

Table 7.2: Test Data for the Clamp Circuit Trip Voltage Transducer

In this application, other than the clamp trip there are 5 more trips (such as the three output current trips $\left(i_{a}, i_{b}, i_{c}\right)$ and the two input line to line voltage trips $\left(V_{A B}\right.$, $\left.V_{B C}\right)$ ) are implemented to protect the experimental converter. 


\subsubsection{Test for the Four Step Commutation}

Achieving four step commutation is essential to avoid the failure of the power circuit of the Matrix Converter. In order to test the four step commutation information about the output current direction is needed. The test set-up for the four step commutation is shown in Figure 7.4. Two input phases (A and B) connecting the output phase (a) through the two bi-directional switches $\left(S_{A a+}, S_{A a-}, S_{B a+}\right.$ and $\left.S_{B a-}\right)$ are considered for this test. The switches are not connected to the load, but instead the calibrator with the transconductance amplifier is connected. The output current information is provided by the calibrator. The output of the amplifier is connected in series with the anti-parallel diodes of the output phase (a) of the Matrix Converter.

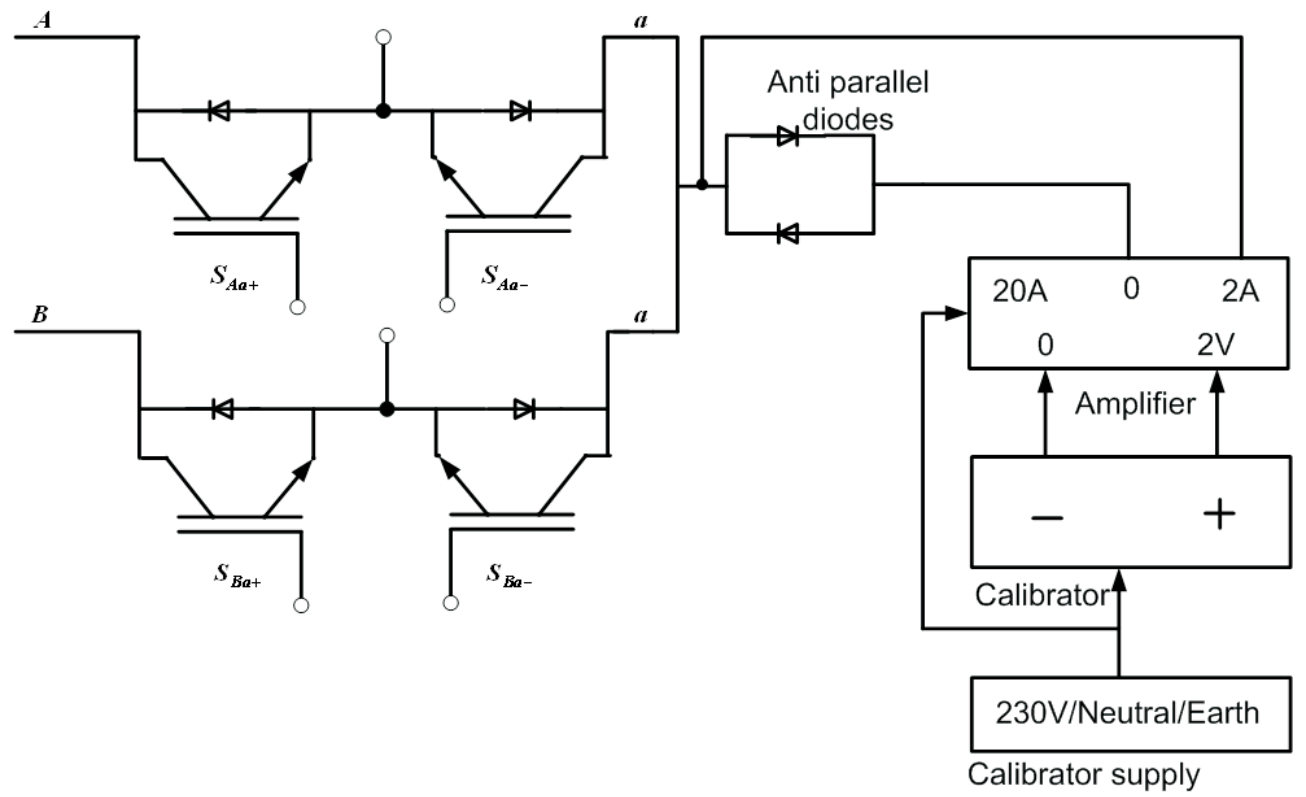

Figure 7.4: Test Setup for the Four Step Commutation

During this test, the input supply is not applied to the Matrix Converter. However, the supply $(+5$ Volts, +15 Volts/-15 Volts) to the gate drives of bi-directional switches $\left(S_{A a+}, S_{A a-}, S_{B a+}\right.$ and $\left.S_{B a-}\right)$ are applied.

To verify the four step current commutation, the current is applied in such a way that the current direction is positive. The magnitude of the applied current is 0.5 Amps. The output terminals of the gate drives are connected to the scope to see the four 
step commutation sequence. The resulting experimental result for this test is shown in Figure 7.5. The four steps can be seen: $S_{A a-}$ is off, $S_{B a+}$ is on, $S_{A a+}$ is off and $S_{B a-}$ is on. The commutation intervals T1, T2 and T3 between these switches are all set to $0.5 \mu$ secs.

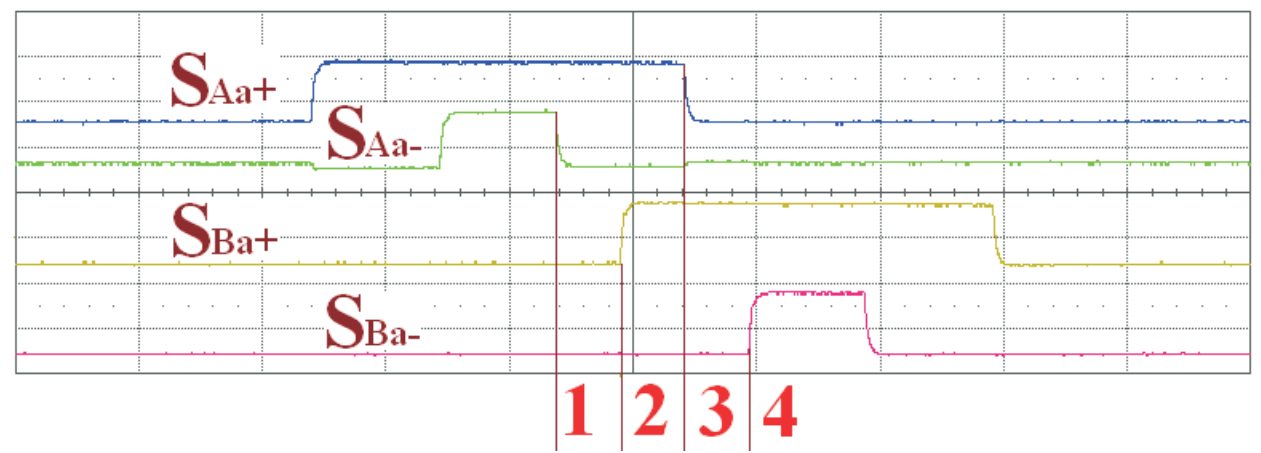

Figure 7.5: Four Step Commutation: Positive Output Current Direction

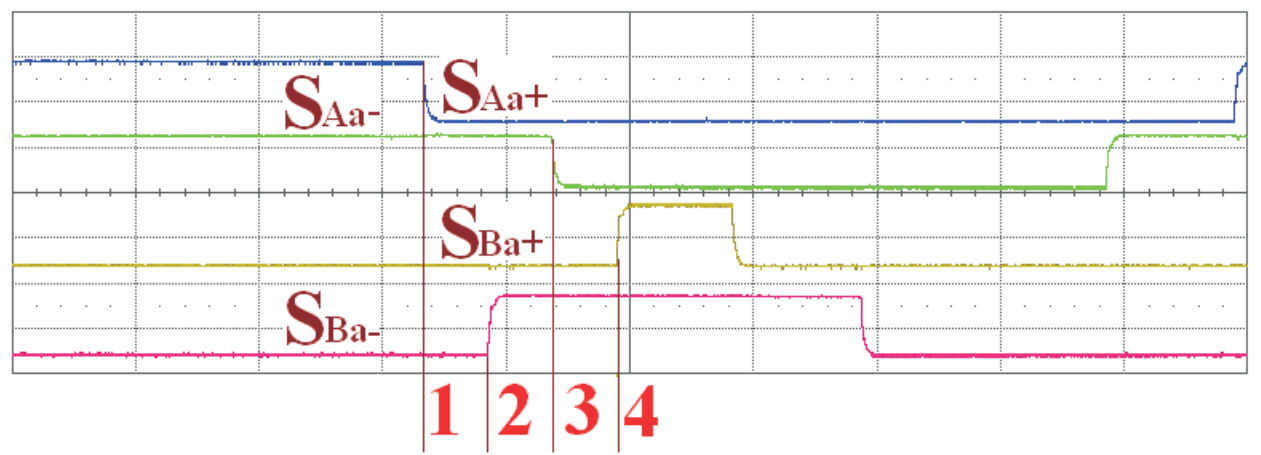

Figure 7.6: Four Step Commutation: Negative Output Current Direction

\begin{tabular}{|c|c|c|}
\hline step & +ve direction & -ve direction \\
\hline 1 & $S_{A a-}$ is off & $S_{A a+}$ is off \\
2 & $S_{B a+}$ is on & $S_{B a-}$ is on \\
3 & $S_{A a+}$ is off & $S_{A a-}$ is off \\
4 & $S_{B a-}$ is on & $S_{B a+}$ is on \\
\hline
\end{tabular}

Table 7.3: Four Steps for Current Commutation

The negative current direction is set using the calibrator. The resulting waveforms are shown in figure 7.6. Table 7.3 shows the position of the switches during the four step commutation for both + ve and -ve directions. 


\subsubsection{Fixed Duty Cycle PWM Test}

In order to check the working status of the Matrix Converter, a fixed duty cycle PWM test is conducted. The concept of this test is that, each of the output phases ( $a, b$, c) are sequentially connected to the input phases (A, B, C) with fixed duty cycles, as shown in Figure 7.7. For example, in one PWM interrupt $(80 \mu \mathrm{S})$ the output phase 'a' (highlighted in colour) sequentially connected to the input phase voltages A (Duty cycle $=0.5)$, B (Duty cycle $=0.25)$ and C (Duty cycle $=0.25)$. Similarly for 'b' and 'c' output phase voltages. Four fixed vectors (AAA, ABB, BCC, CCC) with fixed times are repetitively applied to connect the output phase voltages sequentially.

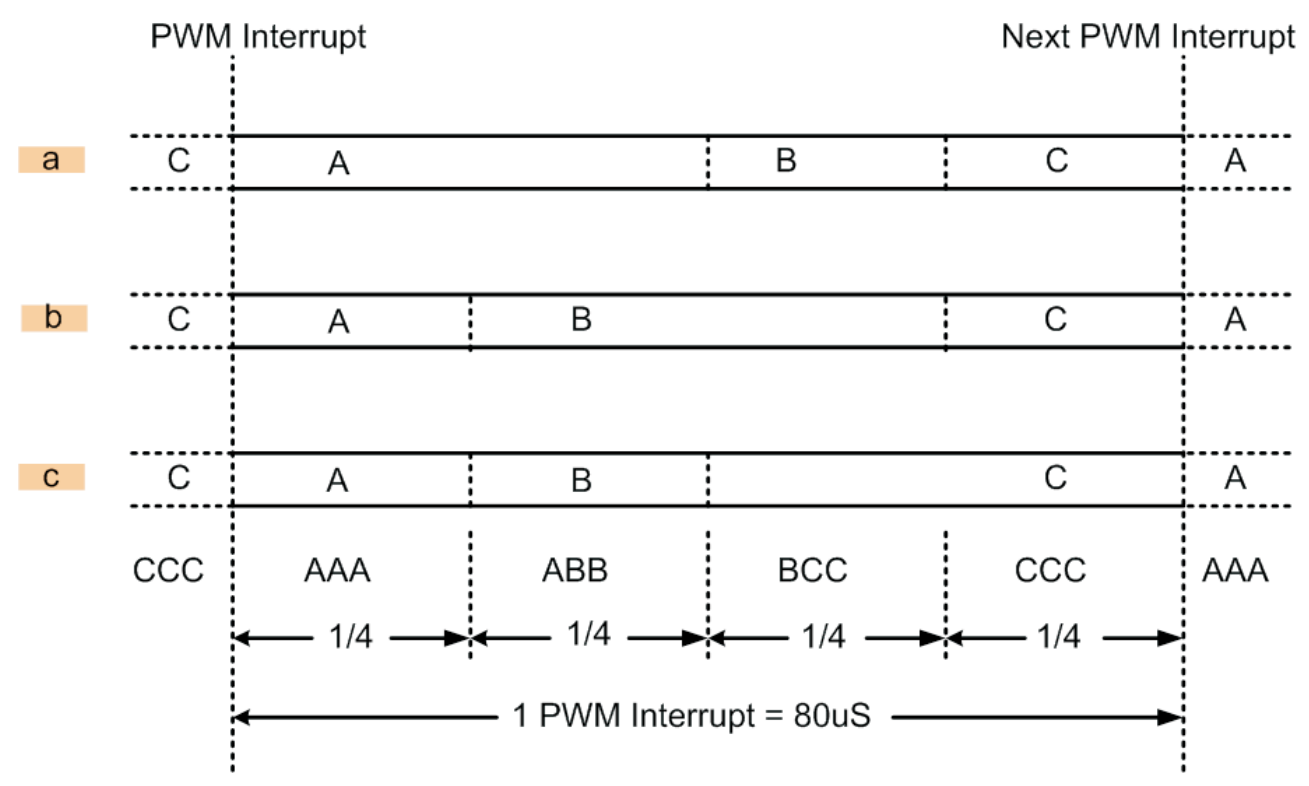

Figure 7.7: The Switching Pattern of the Fixed Duty Cycle PWM Test

To prove this concept, the Matrix Converter is connected to the $\mathrm{R}-\mathrm{L}$ load ( $\mathrm{R}=30$ $\Omega, \mathrm{L}=4.14 \mathrm{mH})$ with a small input voltage $\left(25 V_{r m s}\right)$ applied. From this test, it was concluded that the power circuit and control circuit of the Matrix Converter was working properly. 


\subsection{Experimental Results}

To prove the effectiveness and reliability of the proposed concept experimental results are discussed in this section. The experimental results includes both steady-state and transient performance with the passive R-L load and induction motor load. In addition to the experimental results for Voltz/Hertz motor control, vector control, regeneration and the proposed control system for avoiding regeneration using BiDirectional Switch (BDS) method are explained.

\subsubsection{R-L load}

The Matrix Converter is tested with the R-L load. Preliminary tests with R-L load has been carried out to confirm the proper operation of the well designed $7.5 \mathrm{~kW}$ Matrix Converter. For R-L load test, the output phases (a, b, c) of the Matrix Converter are connected to the three phase star connected rheostats (variable resistors) in series with the three phase inductors. The load parameters are $\mathrm{R}=30 \Omega$ and $\mathrm{L}=4.14 \mathrm{mH}$. To test the steady state behaviour of the Matrix Converter, a small input voltage
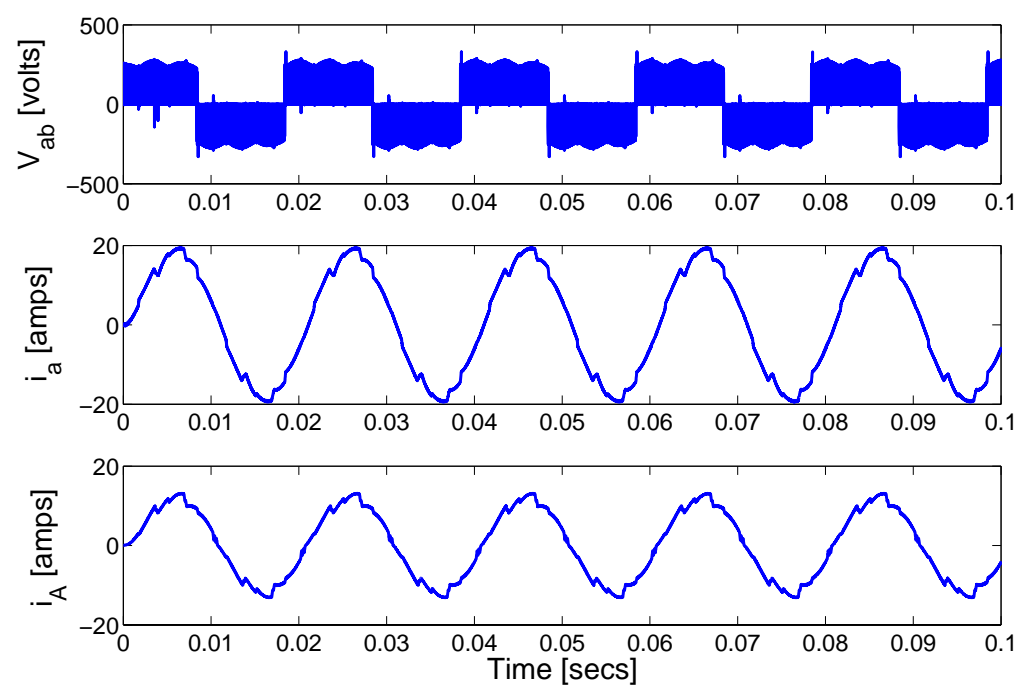

Figure 7.8: Output Line Voltage, Output Current and Input Current for a Matrix Converter with an R-L Load. $V_{\text {in }}=100 \mathrm{~V}$ at $50 \mathrm{~Hz}, \mathrm{q}=0.75, f_{\text {out }}=50 \mathrm{~Hz}$ 
supply of 100 Volts/phase at $50 \mathrm{~Hz}$ is applied. The obtained experimental results from the R-L load test has shown in figure 7.8.

\subsubsection{Voltz/Hertz Motor Control}

After testing the Matrix Converter with an R-L load, an induction motor is connected. The open loop Voltz/Hertz motor control test can be used to adequate check the Matrix Converter motor drive operation at any speed within the motor's limits. Using the DSP code, a slope variable is calculated for Voltz/Hertz motor control. During the run time, the proportional relationship between the applied voltage magnitude and the supply frequency at any operating point is maintained, as shown in Figure 7.9 .

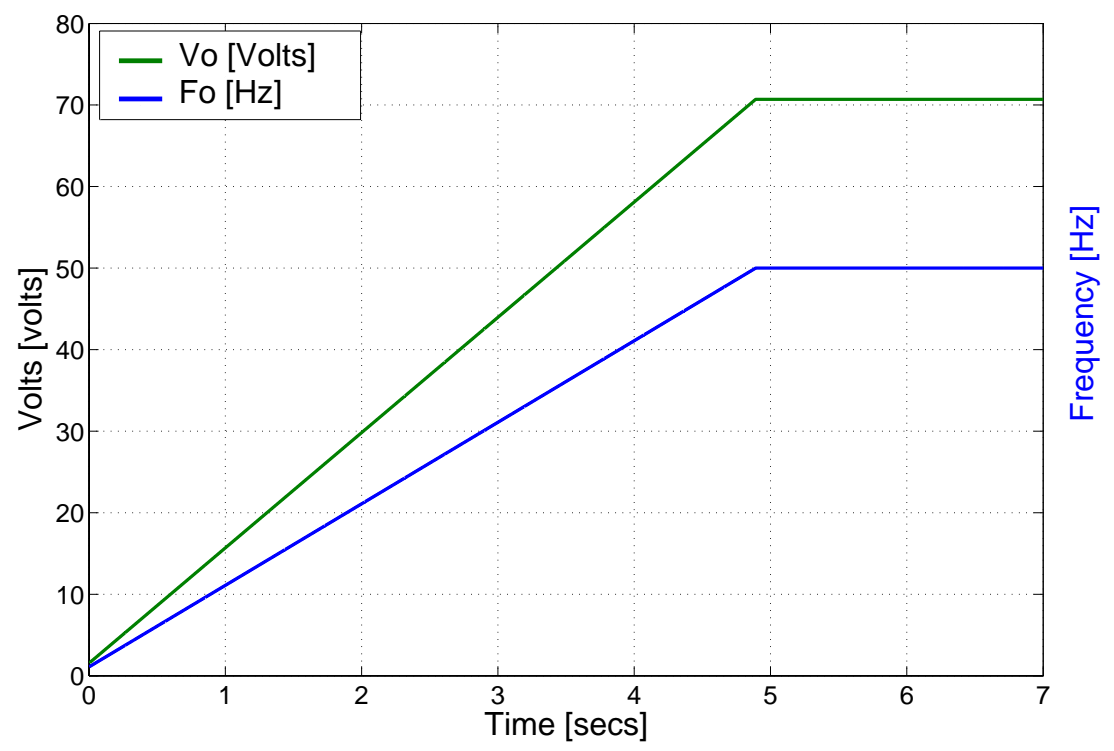

Figure 7.9: Voltz/Hertz Motor Control for MC. $V_{i n}=100$ Volts, $f_{o}=50 \mathrm{~Hz}$

Figure 7.10 shows the experimental results of the Voltz/Hertz motor control. After getting the satisfactory experimental results from the Voltz/Hertz motor control, it is concluded to proceed the research with vector control. 


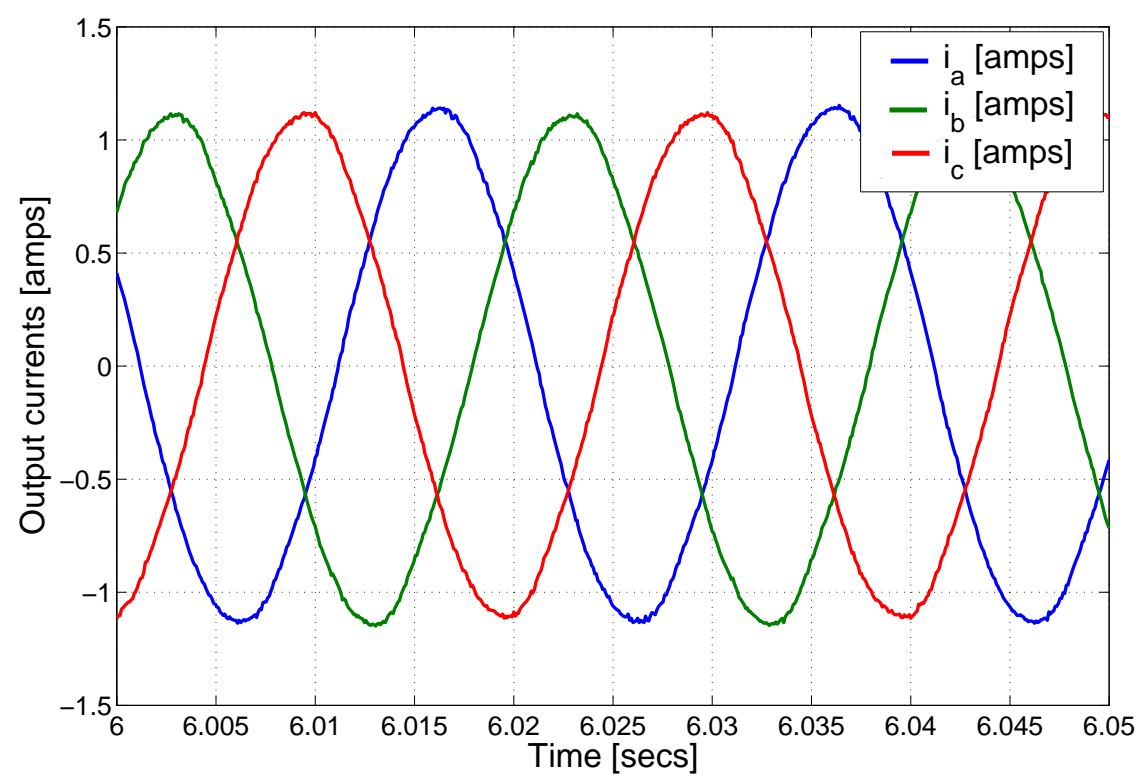

Figure 7.10: Output Currents for Voltz/Hertz Motor Control $V_{i n}=100$ Volts, $f_{o}=$ $50 \mathrm{~Hz}$

\subsubsection{Vector Control and Regeneration}

This section describes the experimental results of the closed loop vector control of the induction motor. In order to confirm the dynamic performance of the vector control, some preliminary tests are performed. The experimental results for normal operation of the vector controlled Matrix Converter motor drive are shown in the figures 7.11 and 7.12 .

The figure 7.11 shows the dig- angle, motor speed (speed) and reference of dq-voltages ( $\mathrm{vd}_{-}$ref and vq_ ref) for operation of the motor at $210 \mathrm{rad} / \mathrm{s}$ with a voltage transfer ratio of about 0.75 . The rotor angle counts up to 10000 pulses because in this application 2500 PPR (Pulses Per Revolution) incremental encoder is used with the 4 -pole induction motor. By using the rotor angle, the desired rotor flux angle $(\lambda)$ is calculated to find the actual dq-currents $\left(i_{s d}\right.$ and $\left.i_{s q}\right)$. Figure 7.12 shows the three phase stator currents of the motor and dq-currents $\left(i_{s d}\right.$ and $\left.i_{s q}\right)$ with their references $\left(i_{s d}^{*}\right.$ and $\left.i_{s q}^{*}\right)$. The actual dq-currents and motor speed follows their respective ref- 


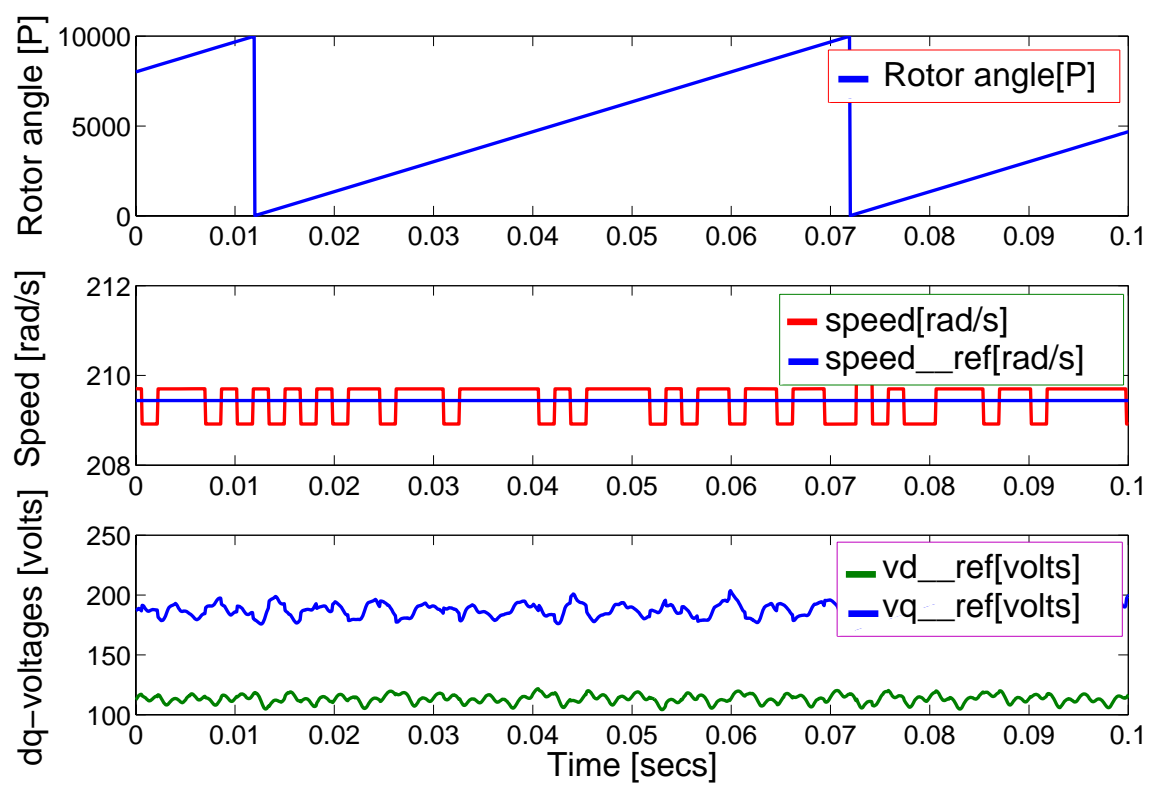

Figure 7.11: Digital angle, Motor speed and dq-voltages for the Vector Controlled Matrix Converter $\left[V_{\text {in }}=200\right.$ Volts, $f_{\text {in }}=50 \mathrm{~Hz}, f_{s}=12.5 \mathrm{kHz}$ and $\left.\mathrm{q}=0.75\right]$
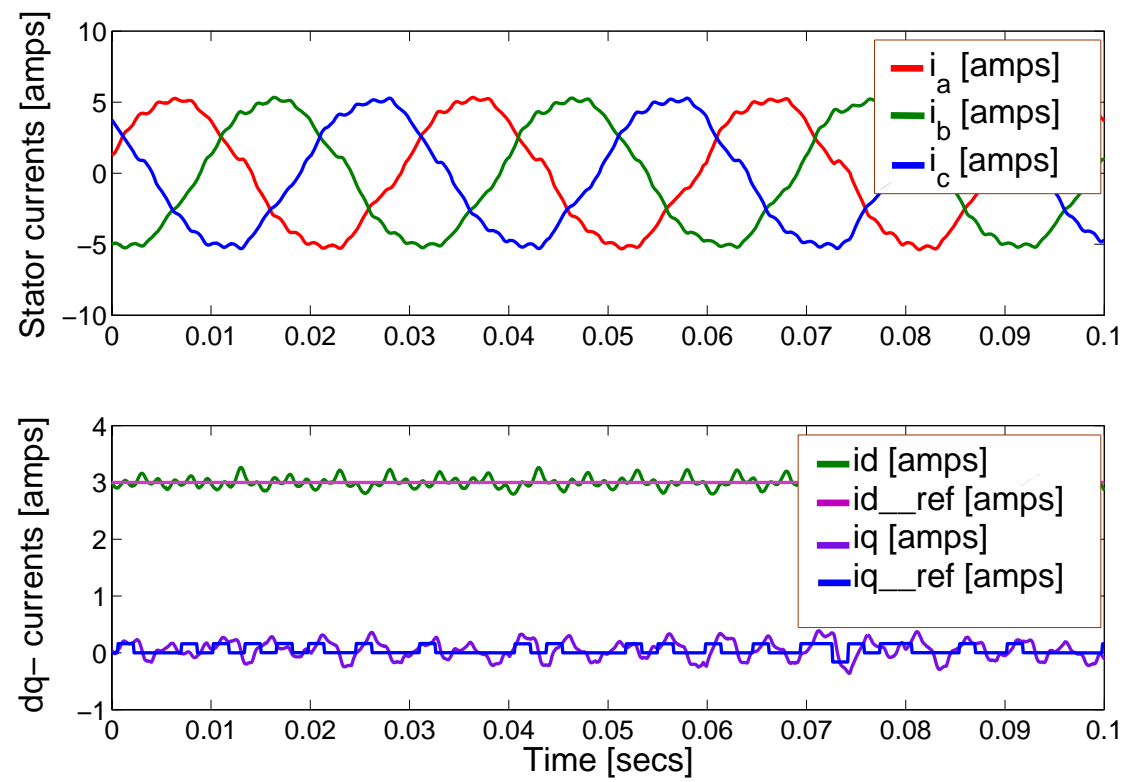

Figure 7.12: Output Currents and dq-Currents for Vector Controlled Matrix Converter $\left[V_{\text {in }}=200\right.$ Volts, $f_{\text {in }}=50 \mathrm{~Hz}, f_{s}=12.5 \mathrm{kHz}$ and $\left.\mathrm{q}=0.75\right]$ 
erences without any problems. These basic experimental results (Figures 7.11 and 7.12) confirm that the vector controlled Matrix Converter motor drive was successfully implemented.

Regeneration is created by reversing the speed of the induction motor by sending the negative speed command to DSP through the Host PC using keyboard. In this application, all the experimental results are produced under no load conditions but the inertial load of the motor is increased by coupling a DC motor to the shaft of the induction motor. With regard to coupling of the DC motor with an induction motor, DC motor has the same moment of inertia $\left(\mathrm{j}=0.015 \mathrm{~kg} \cdot \mathrm{m}^{2}\right)$ as the induction motor, so the total inertial load $\left(\mathrm{j}=0.03 \mathrm{~kg} \cdot \mathrm{m}^{2}\right)$ of the system is doubled.
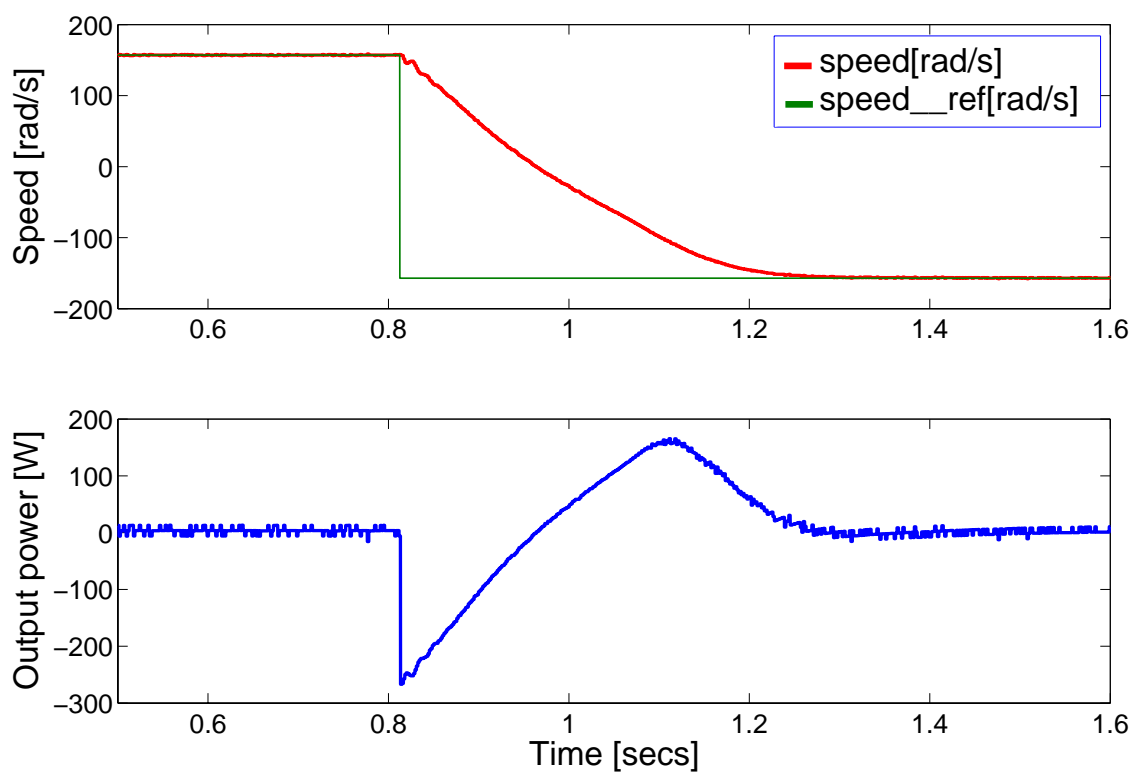

Figure 7.13: Speed and Output Power of the Motor in Regeneration at speed reversal from $+157 \mathrm{rad} / \mathrm{s}$ to $-157 \mathrm{rad} / \mathrm{s}\left[V_{i n}=200\right.$ Volts, $f_{s}=12.5 \mathrm{kHz}$ and $\left.\mathrm{q}=0.75\right]$

Figure 7.13 shows the motor speed and calculated output power for a speed reversal from $+157 \mathrm{rad} / \mathrm{s}$ to $-157 \mathrm{rad} / \mathrm{s}$ while the field current $\left(i_{s d}^{*}\right)$ is maintained constant at 3.0 (amps) and the torque current $\left(i_{s q}^{*}\right)$ is limited up to 5.0 (amps). The inherent four quadrant operation (forward motoring, forward regeneration, reverse motoring and reverse regeneration) of the Matrix Converter is clearly pictured in the Figure 7.13. 

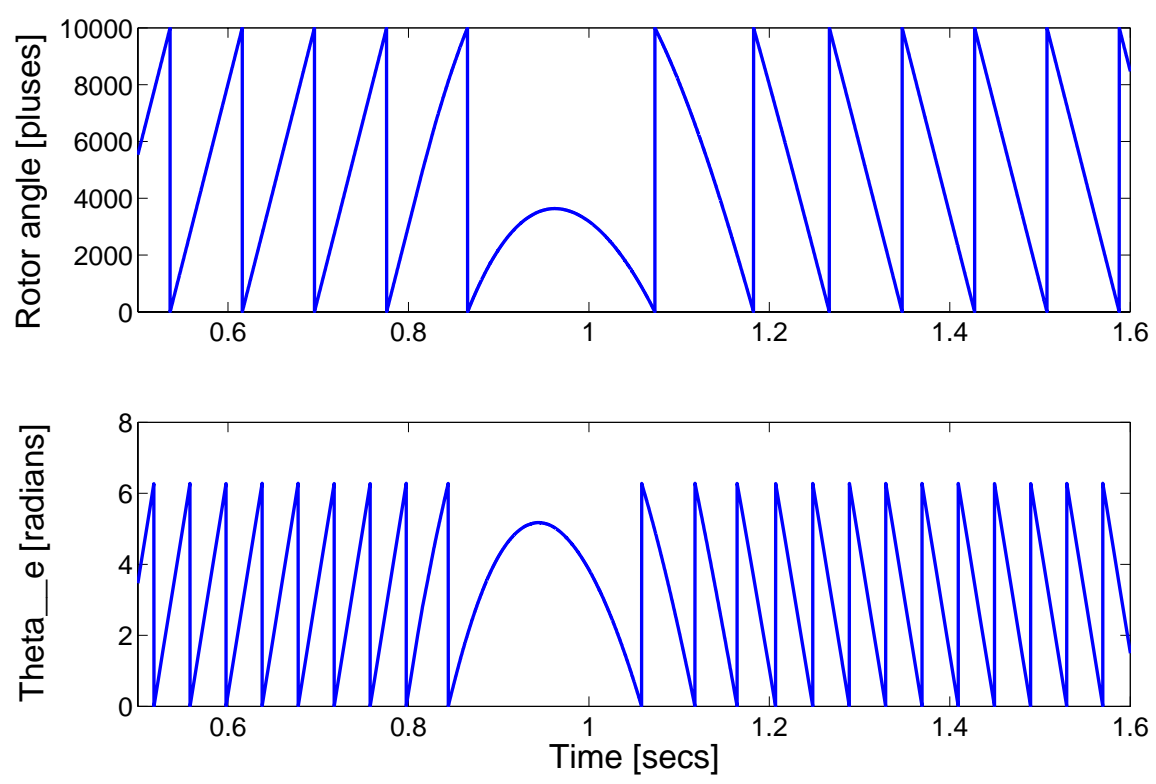

Figure 7.14: Rotor position (rotor angle) and Rotor flux angle $(\lambda)$ in Regeneration during a speed reversal from $+157 \mathrm{rad} / \mathrm{s}$ to $-157 \mathrm{rad} / \mathrm{s}\left[V_{i n}=200\right.$ Volts, $f_{s}=12.5$ $\mathrm{kHz}$ and $\mathrm{q}=0.75]$

In order to get the smooth and stable four quadrant operation for a wide range of speeds, the closed loop controllers gains are adjusted for the calculated field current and the maximum limit of torque current. During the forward regeneration the output power is negative this means that input power is also negative. The proposal of this research is to dissipate the excessive regenerative power using the novel Regeneration Control Circuit (RCC) instead of feeding it back to the supply. Figure 7.14 illustrates the rotor position and the rotor flux angle $(\lambda)$ for the same speed reversal conditions. During the speed reversal the change in the rotor flux angle's direction is shown in the Figure 7.14 .

The field current (d-currents), torque current (q-currents) and torque of the motor are shown in the Figure 7.15. During the regeneration period the reference for the torque producing current reaches the limit and stays until the motor speed reaches the desired speed. Meanwhile, the field current follows its reference. The developed torque in the motor is directly proportional to the torque producing current is shown in the Figure 7.15. 


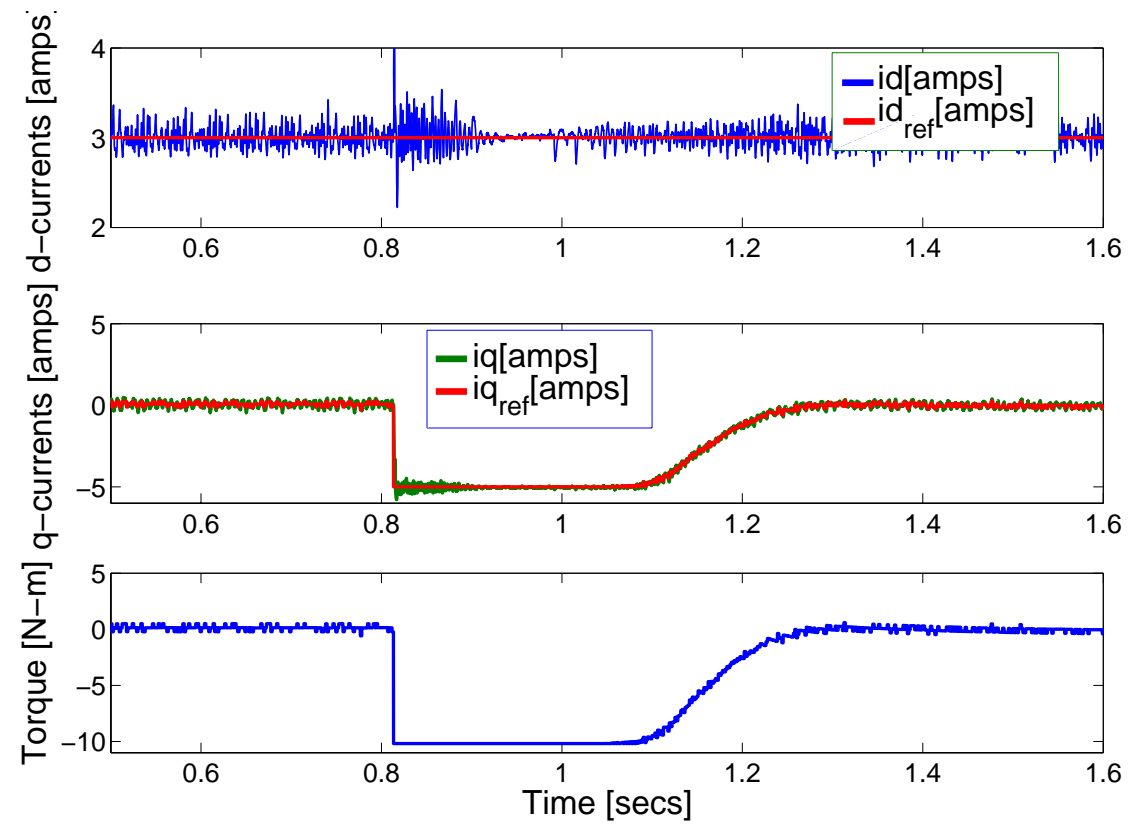

Figure 7.15: Torque and dq-Currents of the Motor during Regeneration during a speed reversal from $+157 \mathrm{rad} / \mathrm{s}$ to $-157 \mathrm{rad} / \mathrm{s}\left[V_{i n}=200\right.$ Volts, $f_{s}=12.5 \mathrm{kHz}$ and q $=0.75]$
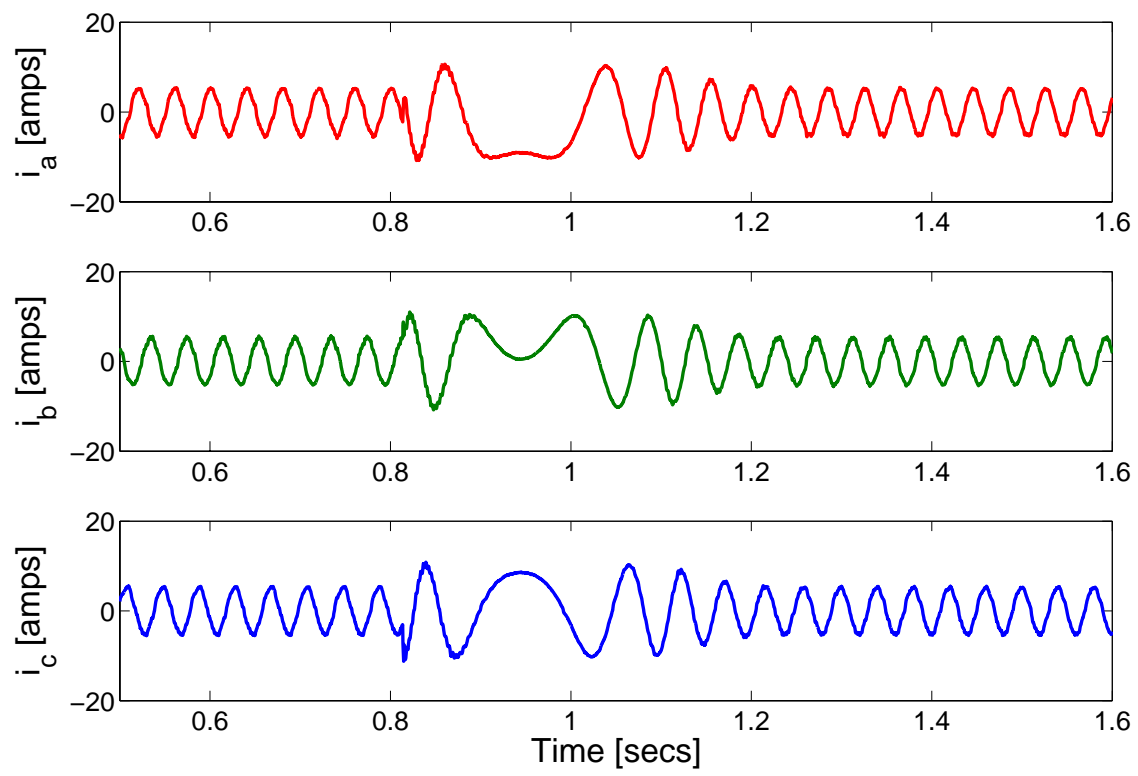

Figure 7.16: Stator Currents of the Motor during Regeneration during a speed reversal from $+157 \mathrm{rad} / \mathrm{s}$ to $-157 \mathrm{rad} / \mathrm{s}\left[V_{i n}=200\right.$ Volts, $f_{i n}=50 \mathrm{~Hz}, f_{s}=12.5 \mathrm{kHz}$ and $\mathrm{q}=$ $0.75]$ 

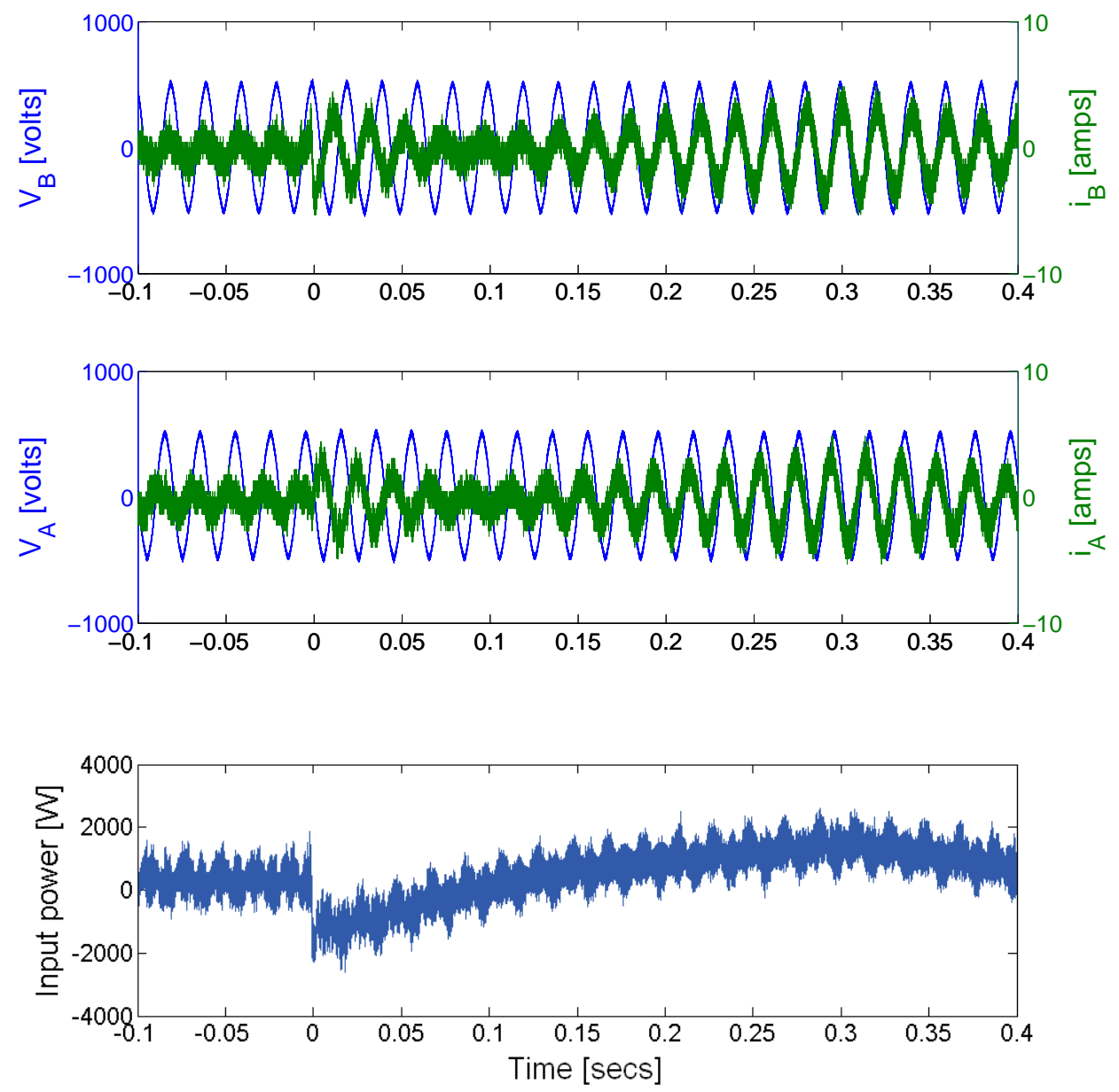

Figure 7.17: Input Phase Voltages $\left(V_{A}, V_{B}\right)$, Input Phase Currents $\left(i_{A}, i_{B}\right)$ and Three Phase Input Power (using two-wattmeter method) during Regeneration during a speed reversal from $+157 \mathrm{rad} / \mathrm{s}$ to $-157 \mathrm{rad} / \mathrm{s}\left[V_{i n}=200\right.$ Volts, $f_{i n}=50 \mathrm{~Hz} f_{s}=$ $12.5 \mathrm{kHz}$ and $\mathrm{q}=0.75]$ 
The output power is calculated using the developed torque in the motor and the motor speed as shown in the Figure 7.13. Figure 7.16 illustrates the stator currents of the motor during the speed reversal.

The input phase voltages $\left(V_{A}, V_{B}\right)$ and input phase currents $\left(i_{A}, i_{B}\right)$ during the regeneration are shown in the Figure 7.17. The $180^{\circ}$ phase opposition between the input phase voltage and input phase current is clearly shown in the Figure 7.17. This means that the direction of the input phase current is reversed and flowing towards to the source. The calculated three phase input power using the two watt meter method is shown in the Figure 7.17. The negative power means that the inductive load is feeding the power to the input supply. According to the aircraft power quality specifications, the excessive regenerative power is not allowed in the aircraft's power supply so the negative power to be dissipated in the motor itself. The dissipation of the negative power using the RCC is explained in the next section. 


\subsubsection{Avoiding Regeneration using BDS Method}

This section explains the experimental results for avoiding regeneration using the Bi-Directional Switch (BDS) method with the Power Comparison (PC) technique as discussed in the Chapter 4. Figure 7.18 illustrates the duty cycle variation of the bi-directional switches used in the Regeneration Control Circuit (RCC) with respect to the output power variation during the forward regeneration period. The input power dissipation is proportional to the output power variation. The above condition must be satisfied to avoid input power dissipation in the circuit.
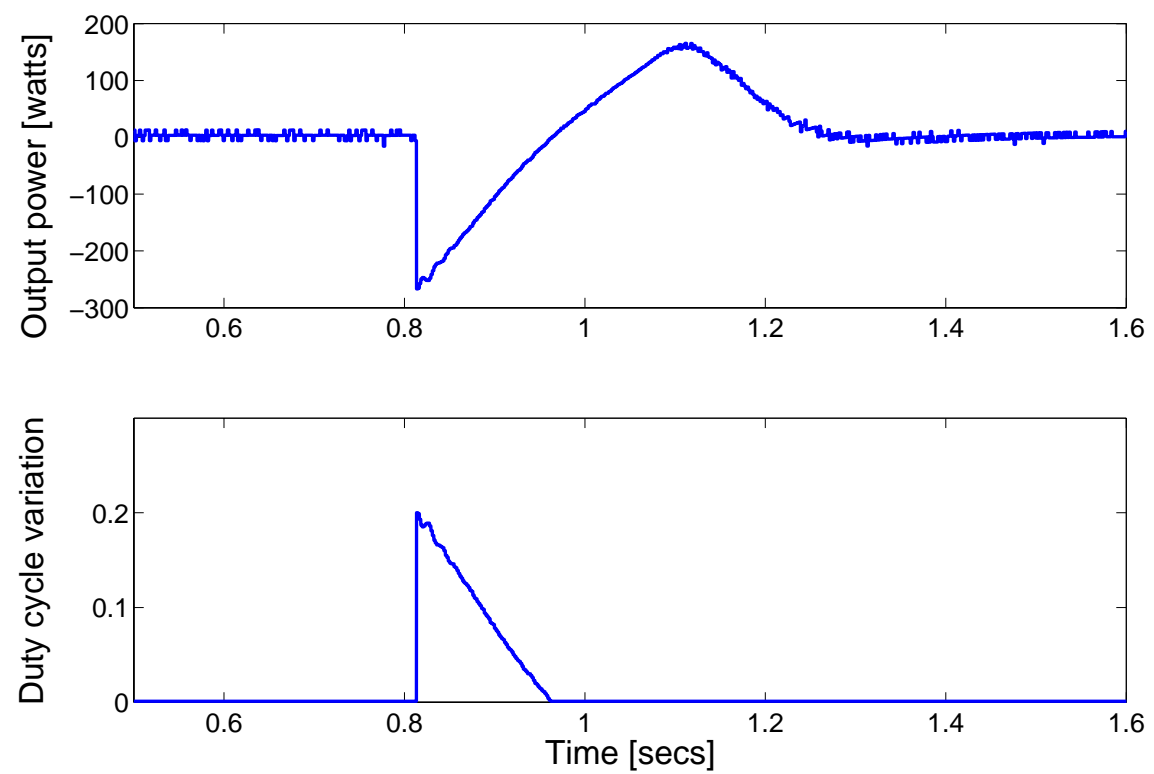

Figure 7.18: The Output Power of the Motor and Duty Cycle Variation of the BiDirectional Switches in the RCC during a speed reversal from $+157 \mathrm{rad} / \mathrm{s}$ to -157 $\mathrm{rad} / \mathrm{s}\left[V_{\text {in }}=200\right.$ Volts, $f_{\text {in }}=50 \mathrm{~Hz} f_{s}=12.5 \mathrm{kHz}$ and $\left.\mathrm{q}=0.75\right]$

Figure 7.19 shows the duty cycle variation, the voltage $\left(V_{A B}\right)$ across the $R_{A B}$ in RCC and the current $\left(i_{A B}\right)$ through $R_{A B}$ in RCC during the regeneration period for about 0.14 seconds. The input power dissipation through the RCC is also shown in the Figure 7.19. This figure proves that the linear input power dissipation during the avoiding regeneration process. 

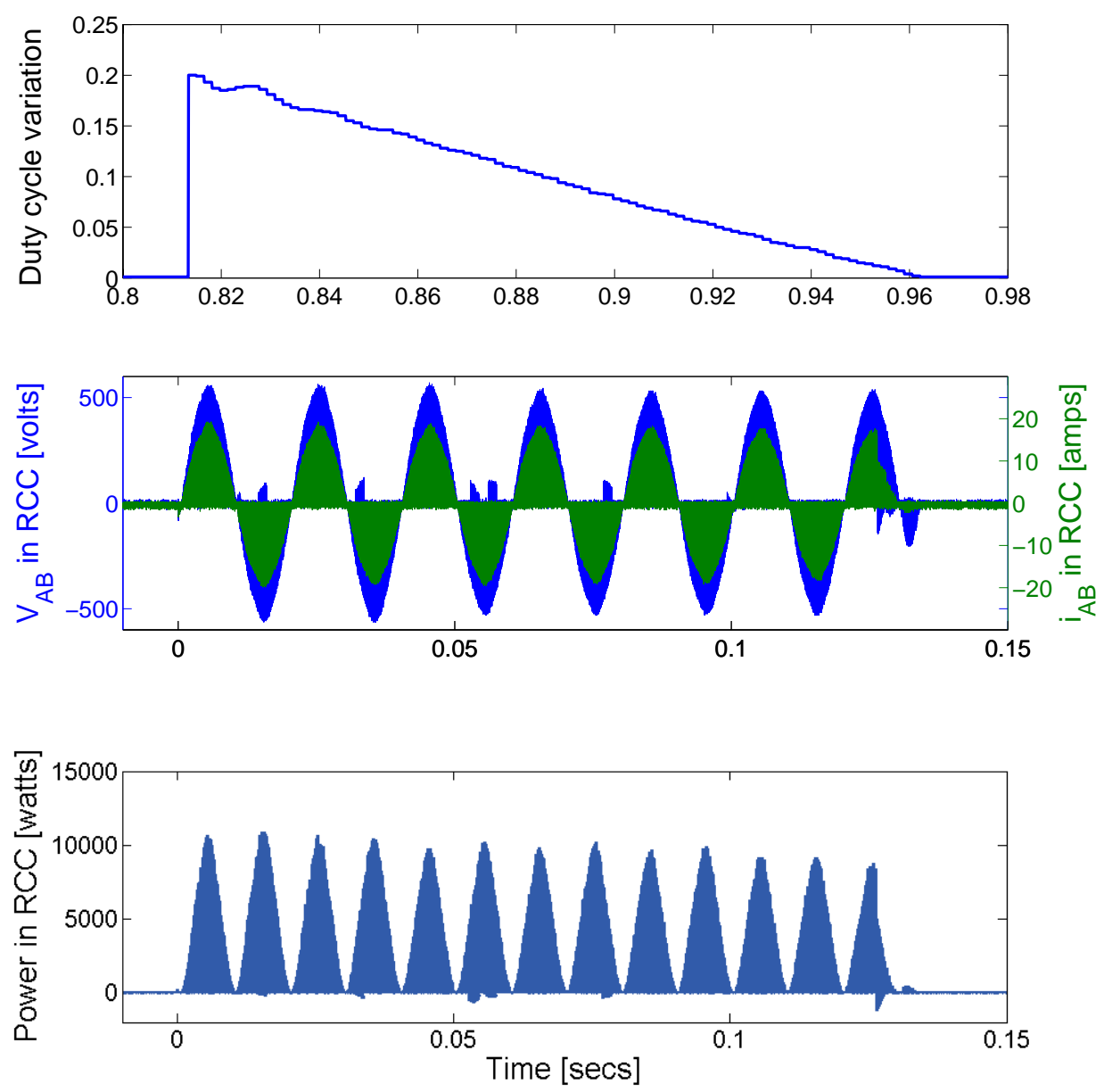

Figure 7.19: Duty Cycle Variation, Voltage $\left(V_{A B}\right)$ across the $R_{A B}$ in RCC, Current $\left(i_{A B}\right)$ through $R_{A B}$ and Input Power Dissipation for One Phase through the RCC during a speed reversal from $+157 \mathrm{rad} / \mathrm{s}$ to $-157 \mathrm{rad} / \mathrm{s}\left[V_{\text {in }}=200\right.$ Volts, $f_{\text {in }}=50 \mathrm{~Hz}$ $f_{s}=12.5 \mathrm{kHz}$ and $\left.\mathrm{q}=0.75\right]$ 

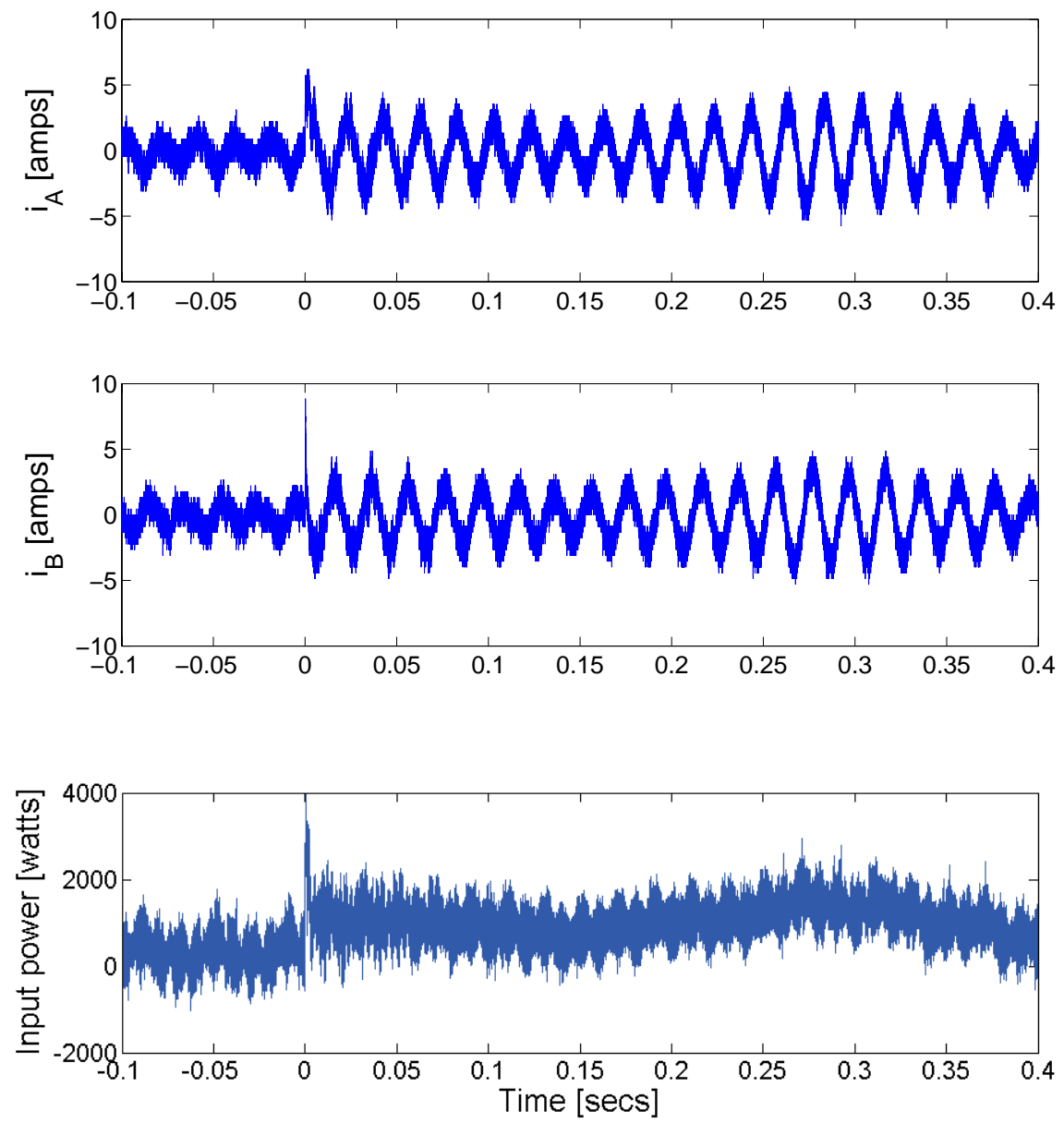

Figure 7.20: Input Phase Currents $\left(i_{A}, i_{B}\right)$ and Three Phase Input Power during a speed reversal from $+157 \mathrm{rad} / \mathrm{s}$ to $-157 \mathrm{rad} / \mathrm{s}\left[V_{i n}=200\right.$ Volts, $f_{i n}=50 \mathrm{~Hz} f_{s}=12.5$ $\mathrm{kHz}$ and $\mathrm{q}=0.75]$ 
The input phase currents $\left(i_{A}, i_{B}\right)$ are shown in the figure 7.20. The calculated three phase input power whilst avoiding regeneration is also shown in the Figure 7.20. This figure shows that some input power is left in the regeneration period (0.14 seconds) because of other losses such as device losses in the Matrix Converter and losses in the induction motor. The above experimental results (from figure 7.18 to figure 7.20) clearly show that the regenerative (negative) power is dissipated through the Regeneration Control Circuit. 


\subsection{Conclusions}

In first half of this chapter, the required precautionary test procedures for the experimental analysis has been discussed. For example, setting the protection trips and the clamp trip have been discussed. In order to avoid the failure in the power circuit of the Matrix Converter, four step commutation test and fixed PWM test has been demonstrated with experimental results.

In second half of this chapter, the preliminary tests for a lab prototype with the induction motor have been demonstrated. For example, the Volts/Hertz motor control confirms a constant stator flux level in the induction motor. The dynamic response of the vector controlled Matrix Converter motor drive has demonstrated with the experimental results. Finally, the novel Regeneration Control Circuit (RCC) using Bi-Directional Switch (BDS) method for avoiding regeneration with a Matrix Converter motor drive has been demonstrated. The obtained experimental results are similar to the simulation results as explained in the Chapter 5. From these experimental results, it is concluded that avoiding regeneration with a Matrix Converter drive is feasible. 


\section{Chapter 8}

\section{Conclusions}

Matrix Converter technology is well known for direct power (AC/AC) conversion applications for almost more than 29 years. Most of the research work published on the Matrix Converter focuses on the following concepts:

- Matrix Converters for industrial applications

- Stability of Matrix Converters

- Commutation techniques to avoid the failure of the power circuit

- Optimizing the modulation strategies for the Matrix Converter.

Until this work, there is no single publication on avoiding regeneration in the Matrix Converter. No attention has paid on this research area which will make the Matrix Converter feasible for aerospace applications and some specific industrial applications.

At the beginning of the $21^{s t}$ century, the Matrix Converter has made as a commercial product for industrial applications, manufactured by Yaskawa (Japan). The Power Electronics Machines and Control (PEMC) Group at the University of Nottingham has been developing $150 \mathrm{kVA}$ Matrix Converter for higher power applications. 
Especially, the conventional Matrix Converter is considered for many aerospace applications because of the following reasons given in the Table 8.1.

\begin{tabular}{|c|c|}
\hline Aero space requirements & Suitability of Matrix Converter \\
\hline Wide range of input frequencies & Yes \\
Sinusoidal input current & Yes \\
Compact design, single stage power conversion & Yes \\
Adjustable input displacement power factor & Yes \\
\hline
\end{tabular}

Table 8.1: Suitability of the Matrix Converter for aerospace applications

Table 8.1 shows the suitability of the Matrix Converter for aerospace applications. According to aerospace power specifications, the inherent regeneration capability of the Matrix Converter should not be allowed.

In this $\mathrm{PhD}$ research work the novel concept for avoiding regeneration (the inherent property of the Matrix Converter) with a Matrix Converter motor drive has been proposed and proved. A detailed simulation study of the proposed concept has been completed. The experimental results that have been produced validate the simulation results.

The work described in this thesis is the :

- Simulation of avoiding regeneration with a Matrix Converter motor drive.

- Validation of the simulation results using a laboratory prototype.

As a result of this work the Matrix Converter can now be considered in aerospace applications where regeneration is not permitted. 


\subsection{Further Work}

Even though good experimental results are obtained at reasonable power level for the proposed concept, remaining a lot of research work still has to be done. The following research works are expected to do in future to make the proposed concept as a matured concept integrated with the commercial applications.

- Making the experimental system with more reliable as a commercial product by increasing the operating drive at rated power level with full load torque level.

- Implementing the Regeneration Control Circuit (RCC) using the diode embedded bi-directional switch instead of using the common emitter bi-directional switch.

- Implementing the proposed concepts on the aircraft.

The published international papers for avoiding regeneration in a Matrix Converter are listed at the end of this thesis in appendix C. 


\section{Appendix A}

\section{Parameters used}

For Simulation Analysis :

\section{Matrix Converter :}

Switching Frequency $=10.0 \mathrm{kHz}$

Voltage transfer ratio $=0.75$

Input Filter :

Inductance $=4.14 \mathrm{mH}$

Capacitance $=5.9741 \mu \mathrm{F}$

Damping resistor $=2.0 \Omega$

RL Load :

Resistance $=5.0 \Omega$

Inductance $=5.0 \mathrm{mH}$ 


\section{Output Filter :}

Resistance $=1000.0 \Omega$

Capacitance $=100.0 \mathrm{nF}$

Induction Motor (ind-3psc) :

$$
\begin{aligned}
& \mathrm{P}=4 \\
& \mathrm{j}=0.089 \mathrm{~kg} \cdot \mathrm{m}^{2} \\
& \mathrm{~B}=0.001(\mathrm{~N} \cdot \mathrm{m}) /(\mathrm{rad} / \mathrm{s}) \\
& L_{m}=69.30 \mathrm{mH} \\
& L_{s}=2.0 \mathrm{mH} \\
& L_{r}=2.0 \mathrm{mH} \\
& R_{s}=0.435 \Omega \\
& R_{r}=0.816 \Omega
\end{aligned}
$$

\section{Vector Control :}

$$
\begin{aligned}
& i_{s d}^{*}=10.0 \text { Amps } \\
& i_{s q}^{*} \text { limit }=35.0 \text { Amps } \\
& v_{s d}^{*} \text { limit }=400.0 \text { Volts } \\
& v_{s q}^{*} \text { limit }=400.0 \text { Volts } \\
& \tau_{r}=0.0874
\end{aligned}
$$


$\sigma_{L s}=0.0041$

$L_{o}^{2} / L_{r}=0.06735$

PI Values for Speed Controller :

$k_{p}=4.8$

$k_{i}=0.09$

PI Values for Current Controllers :

$k_{p}=2.352$

$k_{i}=990.831$

Regeneration Control Circuit :

Resistors $\left(R_{A B}, R_{B C}, R_{C A}\right)=50 \Omega$ 


\section{For Experimental Analysis :}

\section{Matrix Converter :}

Sampling Frequency $=12.5 \mathrm{kHz}$

Voltage Transfer Ratio $=0.75$

\section{Input Filter :}

Capacitance $=2.0 \mu \mathrm{F}$

\section{Induction Motor :}

Name Plate Details :

Rated Power $=4.0 \mathrm{~kW}$

Voltage $=415 \mathrm{~V}$

Phase $=3$

Frequency $=50 \mathrm{~Hz}$

Current $=8.4 \mathrm{~A}$

Speed $=1420 \mathrm{rpm}$

Connection $=$ Delta

\section{RL Load :}

Resistance $=30.0 \Omega$

Inductance $=4.14 \mathrm{mH}$ 


\section{Vector Control :}

$i_{s d}^{*}=3.0$ Amps

$i_{s q}^{*} \operatorname{limit}=5.0 \mathrm{Amps}$

$v_{s d}^{*}$ limit $=200.0$ Volts

$v_{s q}^{*}$ limit $=200.0$ Volts

PI Values for Speed Controller :

$k_{p}=0.926$

$k_{a}=10.0$

PI Values for Current Controllers :

$k_{p}=25.0$

$k_{a}=500.0$

Regeneration Control Circuit :

Resistors $\left(R_{A B}, R_{B C}, R_{C A}\right)=30 \Omega$ 


\section{DSP/FPGA Control for RCC :}

If enable bit is low, no PWM signals are sent to the gate drives of the Regeneration Control Circuit (RCC) The Enable bit control arrangement is made for safety purpose to avoid the improper triggering of the gate drives of the RCC.

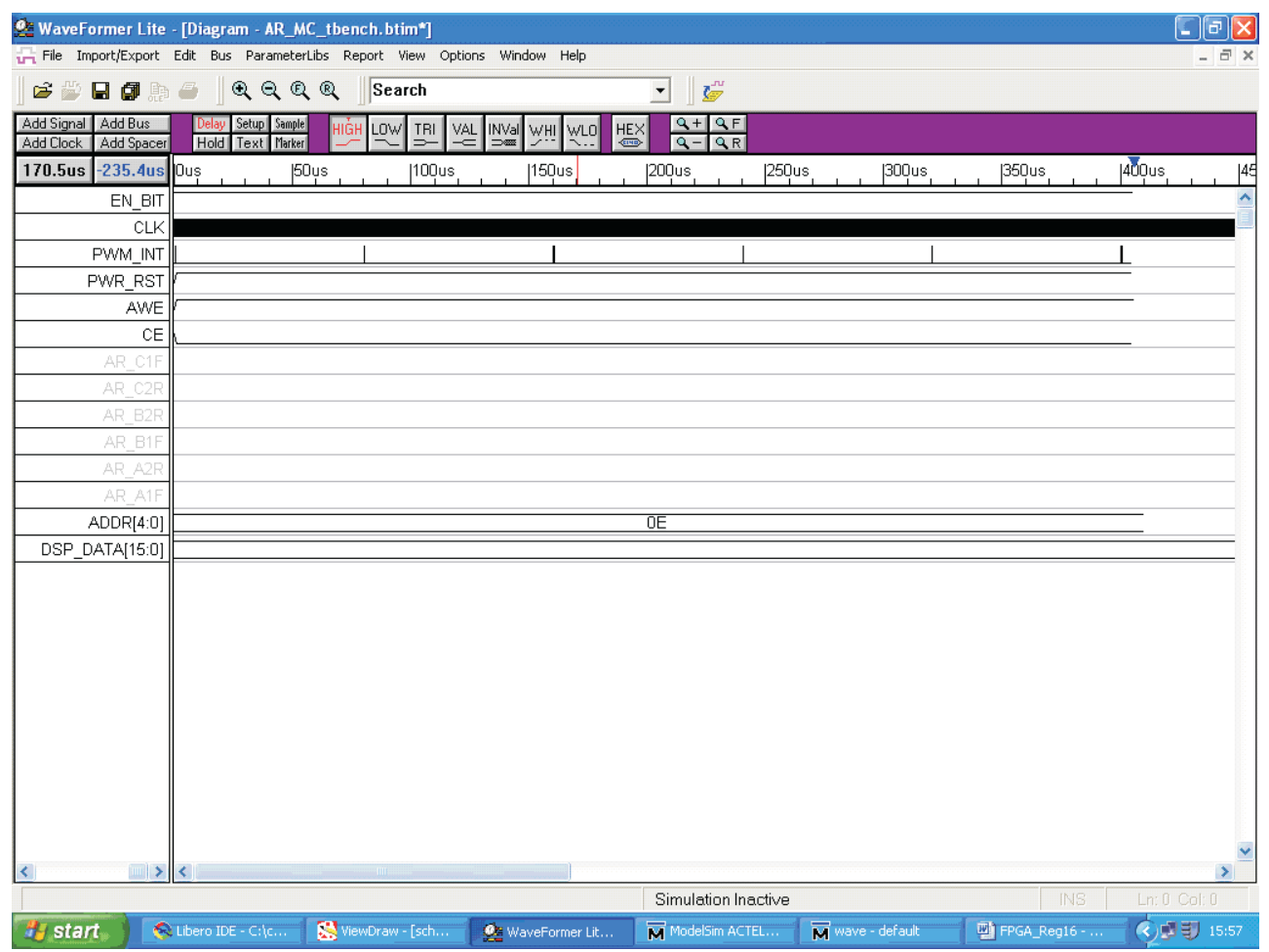

Figure A.1: FPGA Test Bench to generate the PWM Signals for the Gate Drives of the Regeneration Control Circuit (RCC)

\begin{tabular}{|c|c|}
\hline Input Signals & User Defined Datas \\
\hline$E N \_B I T$ & High \\
CLK & $10 \mathrm{MHz}$ \\
PWM_INT & $80 \mu \mathrm{S}$ \\
PWR_RST, AWE & High \\
CE & Low \\
ADDR [4:0] & $0 E:$ means address of FPGA Register14 \\
DSP_DATA & 16-bit data (50\% duty cycle) \\
\hline
\end{tabular}

Table A.1: Input Signals with Datas of the Test Bench to generate PWM signals

Before programming, FPGA simulation has done to verify the concept by creating the virtual test bench. Figure A.1 shows a test bench created for generating the PWM 
signals for the gate drives of the RCC. The input signals (EN_BIT, CLK, PWM_ INT, PWR_ RST, CE, ADDR [4:0] and DSP_ DATA) of the test bench is defined by a user in order to generate PWM signals with $50 \%$ duty cycle. The user defined datas of the input signals used in the test bench is given in the Table A.1. For example, the 16 -bit address, $0 E$, for the FPGA register is specified to identify the logic blocks used in the (RCC). When the Acknowledge Write Enable is high, as shown in figure A.1, the fixed duty cycle information FE6F (50\% duty cycle) is sent by the DSP to the FPGA. The resulting test bench simulation results have shown in figure A.2. This figure have divided into two parts: $\mathbf{A}$ and $\mathbf{B}$.

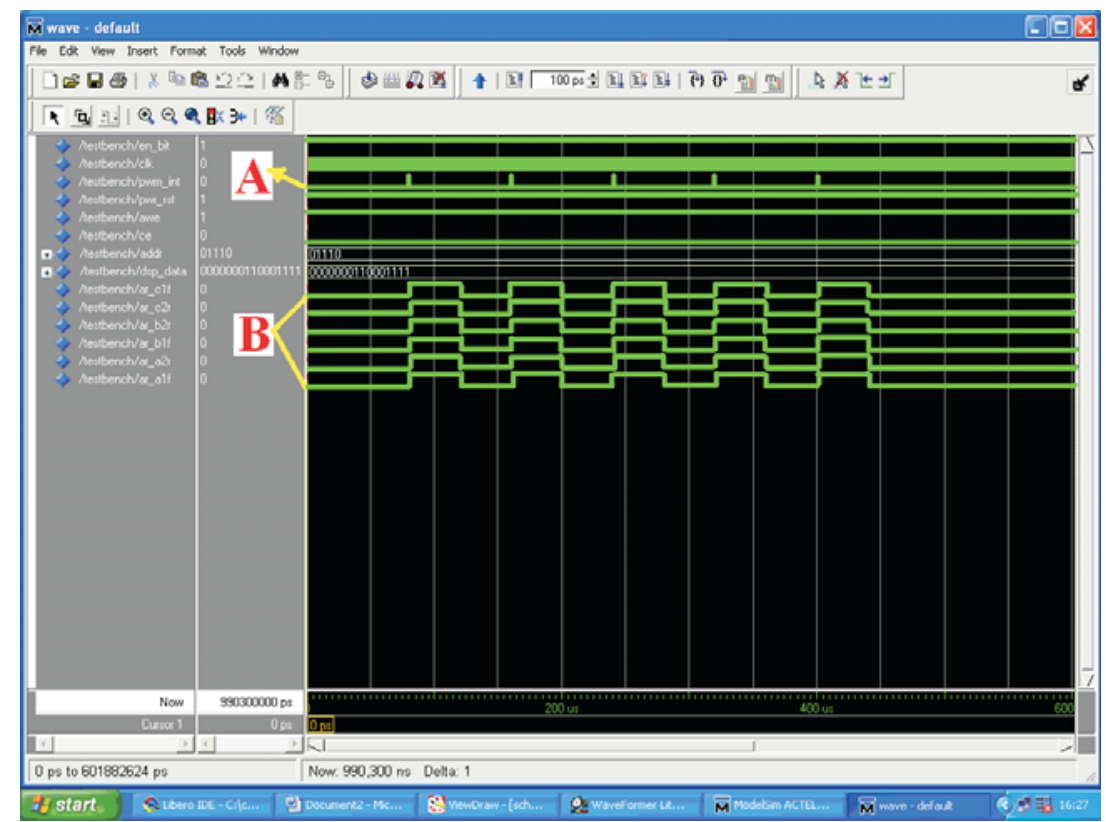

Figure A.2: FPGA Simulation Results for PWM generation for RCC

A : Indicates the all input signals $\left(E N \_B I T\right.$, CLK, PWM_ INT, PWR_ RST, CE, ADDR [4:0] and DSP_ DATA) defined in the test bench. For example, generating the PWM interrupt at every $80 \mu \mathrm{S}$ is indicated. It can be believed that the PWM interrupt for the Matrix Converter and the RCC is common in order to obtain the synchornised input signals for the RCC from the DSP.

B : Indicates the PWM signals $\left(A R_{-} A 1 F, A R \_A 2 R, A R \_B 1 F, A R \_B 2 R, A R \_C 1 F\right.$, $\left.A R \_C 2 R\right)$ for gate drives of the RCC with $50 \%$ duty cycle. 
Once the Regeneration Control Circuit (RCC) concept is verified using the FPGA simulation, the STAPL file is created and this file is programmed into the FPGA Chip (ACTEL ProASIC A500K050) using Flash Pro device. 


\section{Appendix B}

\section{Circuit Diagrams}

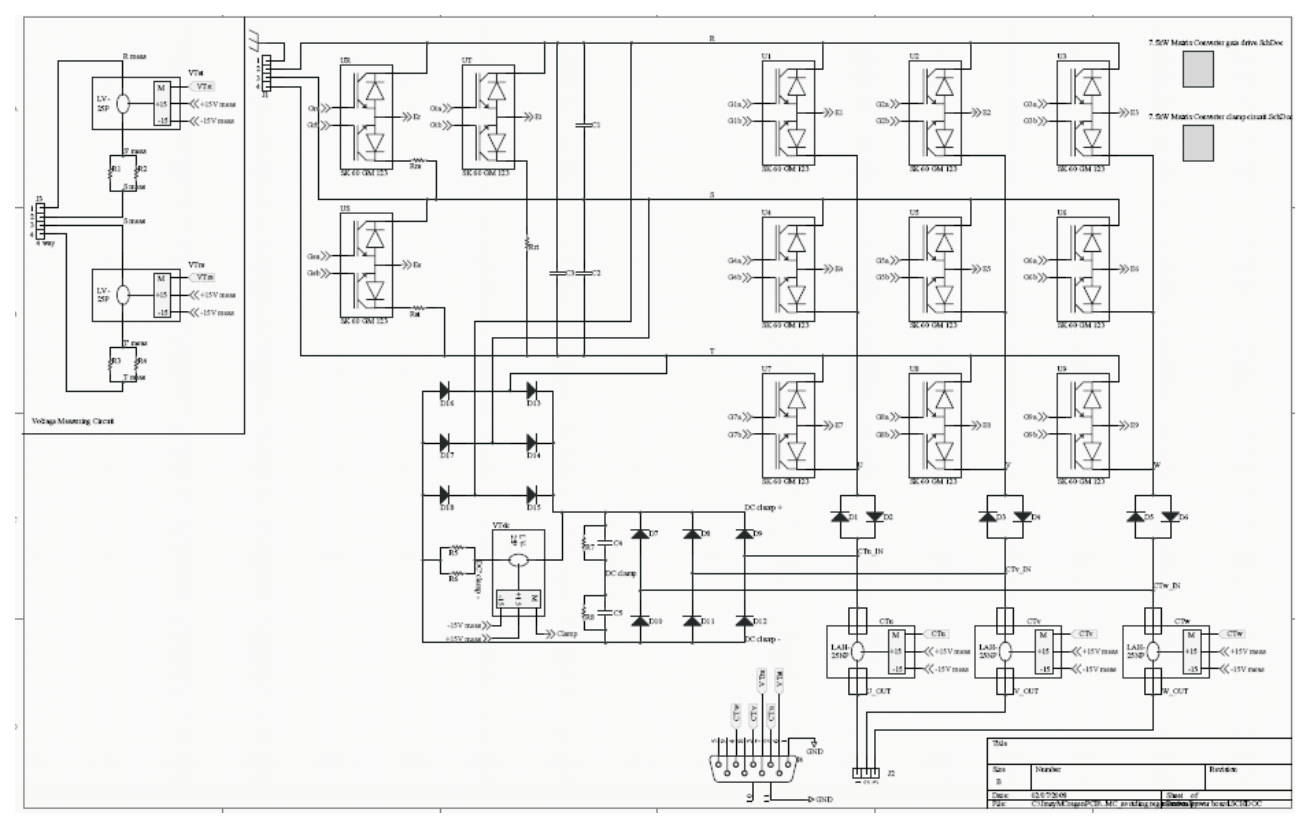

Figure B.1: Schematic of Power Circuit PCB for Avoiding Regeneration 


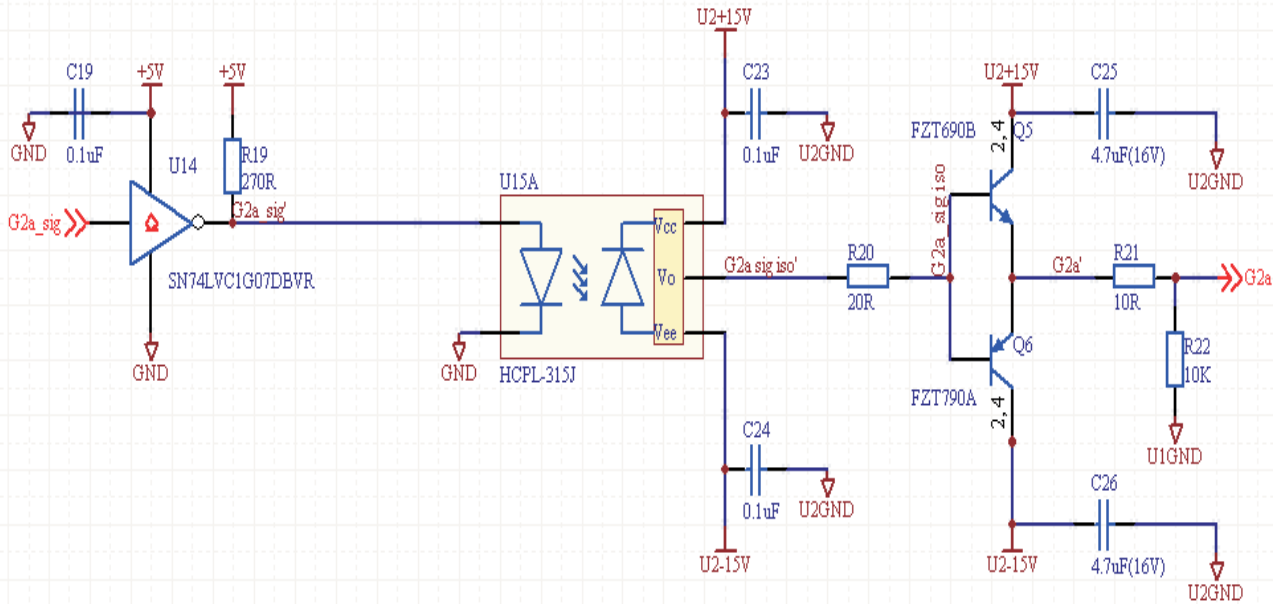

Figure B.2: Schematic of Gate Drive PCB for Avoiding Regeneration 


\section{Appendix C}

\section{Published Papers}

The work has resulted in the following papers having been published:

- M. Imayavaramban and P.W. Wheeler, "Avoiding Regeneration with a Matrix Converter Drive," in Proc. IEEE PESC 2007, Florida, USA, page(s):2529-2534, June 17-21, 2007.

- M. Imayavaramban, P.W. Wheeler and J.C. Clare, "Regeneration Control for Matrix Converter Drive," in Proc. IEEE IECON 2007, Taiwan, China, page(s):1805-1810, Nov 5-8, 2007.

- M. Imayavaramban, P.W. Wheeler, L. Empringham and J.C. Clare, "Input Power Clamp for Controlling Regeneration in Matrix Converter Drive," in Proc. IET PEMD 2008, York, UK, page(s):515-519, April 2-4, 2008. 


\section{Appendix D}

\section{List of Symbols}

\begin{tabular}{||l||l||}
\hline \hline Symbols used & Meaning \\
\hline \hline$\omega_{i}$ & Frequency of input voltage of Matrix Converter \\
$\omega_{o}$ & Frequency of output voltage of Matrix Converter \\
$\omega_{m}$ & Frequency of of Modulation \\
$M_{X x}$ & Duty cycle of the switch $S_{X x}$ \\
$I_{i n}$ & Input current \\
$I_{o}$ & Output current \\
$q$ & Voltage transfer ratio \\
$T_{s}$ & Sampling period \\
$T_{\beta \alpha}$ & Switching times for bi-directional switches \\
$T_{e}$ & Electromagnetic torque \\
$\phi$ & Air gap flux \\
$\psi_{r}$ & Rotor flux vector \\
$i_{a}$ & Armature current \\
$i_{f}$ & Field current \\
$V_{A}, V_{B}, V_{C}$ & Three phase input voltages to Matrix Converter \\
$V_{A B}, V_{B C}, V_{A C}$ & Three line to line input voltages \\
$V_{a}, V_{b}, V_{c}$ & Three phase output voltages to Matrix Converter \\
\hline \hline
\end{tabular}




\begin{tabular}{|c|c|}
\hline Symbols used & Meaning \\
\hline$i_{A}, i_{B}, i_{C}$ & Three phase input currents to Matrix Converter \\
\hline$i_{a}, i_{b}, i_{c}$ & Three phase output currents to Matrix Converter \\
\hline$\omega_{e}$ & Angular velocity \\
\hline$i_{s \alpha}, i_{s \beta}$ & $\alpha \beta$ stationary co-ordinates \\
\hline$i_{s d}, i_{s q}$ & dq rotating co-ordinates \\
\hline$\psi_{r \alpha}, \psi_{r \beta}$ & Rotor flux linkages \\
\hline$\psi_{o \alpha}, \psi_{o \beta}$ & Air gap flux linkages \\
\hline$\lambda$ & Rotor flux angle \\
\hline$\sigma_{r}$ & Leakage co-efficient \\
\hline$\omega_{r m}$ & Mechanical speed \\
\hline$\omega_{r e}$ & Measured shaft speed in electrical \\
\hline$\omega_{s l}$ & Slip frequency \\
\hline$\tau_{r}$ & Rotor time constant \\
\hline$\tau_{m}$ & Motor time constant \\
\hline$\tau_{s}$ & Armature time constant \\
\hline$R_{s}$ & Stator resistance \\
\hline$L_{r}$ & Rotor inductance \\
\hline$R_{r}$ & Rotor resistance \\
\hline$L_{o}$ & Mutual inductance \\
\hline$L_{s}$ & Stator inductance \\
\hline$\sigma L_{s}$ & Motor Leakage co-efficient or stator transient \\
\hline$\zeta$ & Damping ratio \\
\hline$v_{s d c}^{*}, v_{s q c}^{*}$ & Compensation voltage terms \\
\hline$v_{s d}^{*}, v_{s q}^{*}$ & dq reference voltages \\
\hline$v_{s \alpha}, v_{s \beta}$ & Stationary reference voltages \\
\hline$V_{a}^{*}, V_{b}^{*}, V_{c}^{*}$ & Stator reference voltages \\
\hline$P_{m b}$ & Braking power \\
\hline$R_{b}$ & Braking resistor \\
\hline$I_{b}$ & Braking current \\
\hline
\end{tabular}




\begin{tabular}{||l||l||}
\hline \hline Symbols used & Meaning \\
\hline \hline$V_{c}$ & Voltage across the input filter capacitor \\
$B D S_{A B}, B D S_{B C}, B D S_{A C}$ & Bi-directional switches in the RCC \\
$R_{A B}, R_{B C}, R_{A C}$ & Resistors in the RCC \\
$L_{A}, L_{B}, L_{C}$ & Three input phase source inductances \\
$C_{A B}, C_{B C}, C_{A C}$ & Three input line capacitors \\
$C_{1}, C_{2}$ & Clamp capacitors \\
$R_{1}, R_{2}$ & Shunt metal film resistors \\
$R_{3}, R_{4}$ & Burden resistors \\
$d i g-$ angle & Rotor position in terms of pulses \\
$i_{m}$ & Magnetising current \\
$P$ & Number of poles \\
$j$ & Motor moment of Inertia \\
$B$ & Friction co-efficient \\
\hline \hline
\end{tabular}




\section{Bibliography}

[1] B.K. Bose, "Energy, environment and advances in power electronics," IEEE Transactions on Power Electronics, vol. 15, No. 4, pp. 688 - 701, 2000.

[2] E.I. Carroll, "Power electronics for very high power applications," IET Power Electronics and Varaibale Speed Drives, vol. No. 456, pp. 218 - 223, 1998.

[3] S. Bhowmik and R. Spee, "A guide to the application-oriented selection of ac/ac converter topologies," IEEE Applied Power Electronics Conference and Exposition, pp. 571 - 578, 1992.

[4] T.A. Lipo, "Recent progress in the development in solid-state ac motor drives," IEEE Trans. on Power Electronics, vol. 3, No. 2, pp. 105 - 117, 1988.

[5] L. Gyugyi and B. Pelly, Static Power Frequency Changers: Theory,Performance and Applications, John Wiley and Sons, New York, 1976.

[6] A. Alesina and M. Venturini, "Solid-state power conversion: A fourier analysis approach to generalized transformer synthesis," IEEE Trans on Circuit and System, vol. 4, pp. 319 - 330, 1981.

[7] A. Alesina and M.G.B Venturini, "Analysis and design of optimum amplitude nine-switch direct ac-ac converters," IEEE Trans on Power Electronics, vol. 2, pp. $1284-1291,1989$.

[8] A. Maamoun, "Development of cycloconverters," IEEE Canadian Conference on Electrical and Computer Engineering, vol. 1, pp. 521 - 524, 2003. 
[9] R. Krishnan and A.S Bharadwaj, "A review of parmeter sensitivity and adaptation in indirect vector controlled induction motor drive systems," IEEE Power Electronics Specialists Conference, pp. 560 - 566, 1990.

[10] F. Blaschke, "The principle of field orientation as applied to the new transvector closed loop control for rotating machines," Seimens Rev., vol. 39, No 5, pp. 217 $-220,1972$.

[11] W. Leonhard, Control of electrical drives, Springer-Verlag, Berlin, 1985.

[12] N.R. Zargari and G. Joos, "A near unity power factor input stage with minimum control requirements for ac drive applications," IEEE Trans on Industry Applications, vol. 31, No. 5, pp. 1129 - 1135, 1995.

[13] N.R. Raju, "An scr based regenerative converter for vsi drives," IEEE Power Electronics Specialists Conference, pp. 1770 - 1774, 2003.

[14] L. Helle and S. Munk-Nielsen, "Comparison fo converter efficiency in large variable speed wind turbines," Applied Power Electronics Conference and Exposition, pp. $628-634,2001$.

[15] Ju-Won Baek, Myung-Hyo Ryoo , Jong Hyun Kim, and Jih-Sheng Lai, "50kva regenerative load for power test system," Power Electronics and Applications, pp. $1-8,2007$.

[16] Ajit. K. Chattopadhyay, "Analog computer simulation of an adjustable-speed induction motor drive with a cycloconverter-type thyristor-commutator in the rotor," IEEE Trans on Industrial Electronics and Control Instrumentaion, vol. 22, No. 3, pp. $433-440,1975$.

[17] Wesis. W. Herbert, "Adjustable speed ac drive systems for pump and compressor applications," IEEE Trans on Industry Applications, vol. 10, No. 1, pp. 162 $167,1974$.

[18] P. Wheeler, J. Clare, L. Empringham, M. Apap, and M. Bland, "Matrix conveters," IEEE Power Engineering Journal, vol. 16, No. 6, pp. 273 - 282, 2002. 
[19] P.W. Wheeler, J. Rodriquez, J.C Clare, L. Empringham, and A. Weinstein, "Matrix conveters- a technology review," IEEE Trans on Industrial Electronics, vol. 49, No. 2, pp. $276-288,2002$.

[20] L. Helle, K.B. Larsen, A.H. Jorgensen, S. Munk-Nielsen, and F. Blaabjerg, "Evaluation of modulation schemes for three-phase to three-phase matrix conveters," IEEE Trans on Industrial Electronics, vol. 51, No. 1, pp. 158 - 171, 2004.

[21] P.W. Wheeler and D.A Grant, "A low loss matrix conveter for variable speed drives," IEE EPE Conference Record, pp. 27 - 32, 1993.

[22] N. Burany, "Safe control of four quadrant switches," IEEE IAS Conference record, vol. 1, pp. $1190-1194,1989$.

[23] Yaskawa Electric Corporation, "Matrix converter drive varispeed ac," Inverter Drive on Yaskawa Technical Review, vol. 69, 2007.

[24] C. Klumpner, P. Nielsen, I. Boldea, and F. Blaabjerg, "A matrix conveter motor(mcm) for industry applications," IEEE Trans on Industrial Electronics, vol. 49, No. 2, pp. 325 - 335, 2002.

[25] C. Klumpner and F. Blaabjerg, "Experimetnal evauluation of ride-through capabilities for a matrix converter under short power interruptions," IEEE Trans on Industrial Electronics, vol. 49, No. 2, pp. 315 - 324, 2002.

[26] W.A Tabisz and F.C. Lee, "Zero-voltage-switching multi-resonant technique-a novel approach to improve performance of high frequency quasi-resonant converters," IEEE Power Electronics Specialists Conference, vol. 1, pp. 9 - 17, 1988.

[27] K.H Liu and F.C. Lee, "Resonant swithces- a unified approach to improve performance of swithcing converters," IEEE INTELEC Conference, pp. $344-$ 351, 1994.

[28] V. Vorperian, "Approximate small-signal analysis of the series and the parallel resonant converters," IEEE Trans on Power Electronics, vol. 4, No. 1, pp. 15 24, 1989. 
[29] N.H Malik, "Analysis and performance characteristics of three-thase, thyrode ac voltage controllers," IEEE Trans on Power Electronics, vol. 4, No. 3, pp. 355 361,1989 .

[30] K.E. Addoweesh and M.S. Al-Khalidi, "Ac chopping technique with phase and voltage control," IEEE International Symposium on Industrial Electronics Conference Record, pp. 684 - 688, 1993.

[31] N.A Ahmed and E.H El-Zohri, "Power factor improvement of single-phase ac voltage controller employing extinction angle control technique," IEEE International Midwest Symposium on Circuits and Sytems, vol. 3, pp. 1075 - 1080, 2003

[32] J. Zhang, G.P Hunter, and V.S Ramsden, "A single phase input cycloconverter driving a three phase motor," IEE European Power Electronics Conference Record, vol. 5, pp. 128 - 132, 1993.

[33] H. Nomura, K. Fujiwara, and H. Kawakami, "A power factor compensator using a force-commutated cycloconverter," IEEE Trans on Industry Applications, vol. 26, No. 4, pp. $769-776,1990$.

[34] Fa-Hai Li, Yao-Hua Li, Xiang-Heng Wang, and Jing-De Gao, "Modelling and simulation of synchronous motor fed by cycloconverter," IEEE Power Electronics Specialists Conference, vol. 2, pp. 830 - 834, 1994.

[35] G.M. Hashem and M.K. Darwish, "Generalized symmetrical angle pwm technique for ac voltage controller," IEEE Universities Power Engineering Conference Record, vol. 2, pp. 898 - 901, 2004.

[36] M.H Rashid, Power Electronics: Circuits, Devices and Applications, PrenticeHall, New Jersey, 2 edition, 1993.

[37] M. Venturini, "A sine wave in, sine wave out, conversion technique eliminates reactive elements," IEEE POWERCON Conference Record, pp. E3-1-E3-15, 1980. 
[38] G. Roy, L. Duaguay, S. Manias, and G.E April, "Aysynchronous operation of cycloconverter with improved voltage gain by employing a scalar control algorithm," IEEE IAS Conference Record, pp. 889 - 898, 1987.

[39] G. Roy and G.E April, "Cycloconverter operation under a new scalar control algorithm," IEEE Power Electronics Specialists Conference, vol. 1, pp. 368 $375,1989$.

[40] L. Huber and D. Borojevic, "Space vector modulator for forced commutated cycloconverters," IEEE IAS Conference Record, vol. 1, pp. 871 - 876, 1989.

[41] D. Casadei, G. Serra, G. Tani, and L. Zarri, "A new general approach based on space-vector representation of the switch state," IEEE Trans on Industry Applications, vol. 49, No. 2, pp. 370 - 381, 2002.

[42] Dynex Semiconductor, "Igbt bi-directional switch module dim200mbs12a000," Device Date Sheet, vol. 1, www.dynexsemi.com, 2007.

[43] M. Munzer, M. Loddenkotter, O. Simon, and M. Bruckman, "Economac the first all-in-one igbt module for matrix converters," Drives and Control and Power Electronics Conference Record, 2001.

[44] S. Sunter and J.C Clare, "A true four quadrant matrix converter induction motor drive with servo performance," IEEE Power Electronics Specialists Conference, vol. 1, pp. $146-151,1996$.

[45] C.L. Neft and C.D. Schauder, "Theory and design of a 30-hp matrix converter," IEEE IAS Conference Record, vol. 1, pp. 934 - 939, 1988.

[46] L Empringham, P.W. Wheeler, and J.C Clare, "Intelligent commutaion of matrix converter bi-directional switch cells using novel gate drive techniques," IEEE Power Electronics Specialists Conference, vol. 1, pp. 707 - 713, 1998.

[47] Vedam. Subrahmanyam, Electrical Drives: Concpets and Applications, McGrawHill Professional, New Delhi, 1996. 
[48] Galco Industrial Electronics, "Five soultions to braking control," Tech Tips: Notes on Braking control, vol. 1, www.galco.com/circuit/brakecontrol, 2002.

[49] M. Grotzbach and R. Redmann, "Line current harmonics of vsi-fed adjustablespeed drives," IEEE Trans on Industry Applications, vol. 36, No. 2, pp. 683 690,2000 .

[50] L Empringham, P.W. Wheeler, and J.C Clare, "A matrix converter induction motor drive using intelligent gate drive level current commutation techniques," IEEE IAS Conference Record, vol. 3, pp. 1936 - 1941, 2000.

[51] A. Munoz-Garcia, T.A. Lipo, and D.W. Novotny, "A new induction motor v/f control method capable of high-performance regulation at low speeds," IEEE Trans. on Industry Applications, vol. 34, No. 4, pp. 813 - 821, 1998.

[52] T. Kataoka, Y. Sato, and A. Bendiabdellah, "A novel volts/hertz control method for an induction motor to improve the torque characteristics the low speed range," in Proc. EPE Conf, vol. 5, pp. 455 - 458, Sept. 1993.

[53] J. Pongpant, Po-ngam, Sakorn, Kongirun, and Mongkol, "The performance improvement constant $\mathrm{v} / \mathrm{f}$ control of induction motor method for an induction motor drive in low speed range," in Proc. IEEE TENCON'06, pp. 1- 4, 2006.

[54] L. Zhao, C.H.Ham, Q.Han, T.X.Wu, L.Zhengand K.B.Sundaram, J.Kapat, and L.Chow, "Design of an optimal v/f control for a super high speed permanent manet sychoronous motor," in Proc. IEEE IECON'04, pp. 2260 - 2263, 2004.

[55] Edited by B.K. Bose, Power Electronics and Motor Drives : Advances and Trends, Academic Press, USA, 2006.

[56] Edited by B.K. Bose, Power Electronics and Variable Frequency Drives, IEEE Press, Piscataway, NJ, USA, 1997.

[57] J.M.D. Murphy and F.G. Turnbull, Power Electronic Control of AC Motors, Pergamon Press, United Kingdom, 1989. 
[58] R. Krishnan and A.S Bharadwaj, "A review of parameter sensitivity and adaptation in indirect vector controlled induction motor drive systems," IEEE Trans on Power Electronics, vol. 6, No. 4, pp. 560 - 566, 1991.

[59] Peter. Vas, Vector Control of AC Machines, Clarenden Press Oxford Science Publications, London, UK, 2 edition, 1990.

[60] S. Doki, Y. Kinpara, S. Okuma, and S. Sangwongwanich, "Unified interpretation of indirect and direct vector control [of electric machines]," in Proc. Power Conversion Conference, pp. 297 - 302, 1993.

[61] R. Mathew, D. Houghton, and W. Oghanna, "Vector control techniques for induction motors," in Proc. Power Electronics and Drive Systems Conference, vol. 2, pp. $813-818,1995$.

[62] M. Sumner, G.M Asher, and R. Pena, "The experimental investigation of rotor time constant identification for vector controlled induction motor drives during transient operating conditions," in Proc. Power Electronics and Applications Conference, vol. 5, pp. $51-56,1995$.

[63] P.J Randewijk and J.H.R Enslin, "Inverting dc traction substation with active power filtering incorporated," IEEE Power Electronics Specialists Conference, vol. 1, pp. $360-366,1995$.

[64] Synopsys Inc., "Mast user guide: Mast template library(feb 2001)," SABER Sketch: Copyright(c)1985-200\%, vol. Version: 4.0, http://solvnet.synopsys.com, 1985.

[65] M. Imayavaramban and P.W. Wheeler, "Avoiding regeneration with a matrix converter drive," IEEE Power Electronics Specialists Conference, pp. 2529 $2534,2007$.

[66] P.W. Wheeler, J.C Clare, M. Apap, L. Empringham, K.J. Bradley, S. Pickering, and D. Lampard, "A fully integrated $30 \mathrm{kw}$ motor drive using matrix conveter technology," IEE European Power Electronics Conference Record, vol. 2, pp. P.1 - P.9, 2005. 
[67] P.W. Wheeler, L. Empringham, M. Apap, L. De Lillo, J.C Clare, K.J. Bradley, C. Whitley, and G. Towers, "A matrix converter drive for an aircraft actuation system," IEE European Power Electronics Conference Record, 2003.

[68] L. De Lillo Liliana, "A matrix converter drive system for an aircraft rudder electro- mechanical actuator," Tech. Rep., PhD thesis, Department of Electrical and Electronics Engineering, University of Nottingham, 2006.

[69] Educational DSP, "Dsk6xxxhpi daughtercard," www.educationaldsp.com, 2007.

[70] British Encoder Products Co, "755/2/hv, serial number: 08189249," www.britencoder.com, 2007. 